\title{
Tissue distribution and function of arginase I : an experimental study
}

Citation for published version (APA):

Sankaranarayanan, S. (2015). Tissue distribution and function of arginase I : an experimental study. [Doctoral Thesis, Maastricht University]. Maastricht University. https://doi.org/10.26481/dis.20150416ss

Document status and date:

Published: 01/01/2015

DOI:

10.26481/dis.20150416ss

Document Version:

Publisher's PDF, also known as Version of record

\section{Please check the document version of this publication:}

- A submitted manuscript is the version of the article upon submission and before peer-review. There can be important differences between the submitted version and the official published version of record.

People interested in the research are advised to contact the author for the final version of the publication, or visit the DOI to the publisher's website.

- The final author version and the galley proof are versions of the publication after peer review.

- The final published version features the final layout of the paper including the volume, issue and page numbers.

Link to publication

\footnotetext{
General rights rights.

- You may freely distribute the URL identifying the publication in the public portal. please follow below link for the End User Agreement:

www.umlib.nl/taverne-license

Take down policy

If you believe that this document breaches copyright please contact us at:

repository@maastrichtuniversity.nl

providing details and we will investigate your claim.
}

Copyright and moral rights for the publications made accessible in the public portal are retained by the authors and/or other copyright owners and it is a condition of accessing publications that users recognise and abide by the legal requirements associated with these

- Users may download and print one copy of any publication from the public portal for the purpose of private study or research.

- You may not further distribute the material or use it for any profit-making activity or commercial gain

If the publication is distributed under the terms of Article $25 \mathrm{fa}$ of the Dutch Copyright Act, indicated by the "Taverne" license above, 


\section{Tissue Distribution and}

\section{Function of Arginase I: an experimental study}


Tissue Distribution and Function of Arginase I: an experimental study (C) Selvakumari Sankaranarayanan

ISBN: 978-94-6259-610-8

Printed by: Ipskamp Drukkers 


\title{
Tissue Distribution and \\ Function of Arginase I: an experimental study
}

\begin{abstract}
Proefschrift
ter verkrijging van de graad van doctor

aan de Universiteit Maastricht, op gezag van de Rector Magnificus Prof.

Dr. L.L.G. Soete, volgens het College van Decanen in het openbaar te verdedigen op donderdag 16 april 2015 om 14:00 uur
\end{abstract}

door

Selvakumari Sankaranarayanan

Geboren November 20, 1976

te Tirunelveli, Tamil Nadu, India 


\section{Promotor}

Prof. Dr. W.H. Lamers

Co-Promotor

Dr. S.E. Köhler

Beoordelingscommissie

Prof. Dr. W.A. Buurman (voorzitter)

Prof. Dr. E. Wouters

Prof. Dr. M.P.J. de Winther (UvA, Amsterdam)

Prof. Dr. L.J.I. Zimmerman 


\section{TABLE OF CONTENTS}

Chapter I Role of arginine in macrophage function

Synopsis and Scope of the Thesis

Chapter II Experiences with the construction of conditional knock-out mice

Chapter III Ablation of Argl in hematopoeitic cells im-proves respiratory function of lung paren-chyma, but not that of larger airways or inflammation in asthmatic mice

Chapter IV The human neonatal small intestine has the potential for arginine synthesis; developmental changes in the expression of arginine-synthesizing and -catabolizing enzymes

Chapter V Hepatic adaptation compensates inactivation of intestinal arginine biosynthesis in suckling mice

Chapter VI Arginine deficiency causes runting in the suckling period by selectively activating the stress kinase GCN2

Chapter VII General Discussion

Nederlandstalige samenvatting

Acknowledgements

Curriculum vitae 



\section{CHAPTER I}

\section{ROLE OF ARGININE IN MACROPHAGE FUNCTION}

Selvakumari Sankaranarayanan, Wouter H. Lamers, S. Eleonore Köhler

Department of Anatomy \& Embryology and NUTRIM School for Nutrition, Toxicology and Metabolism, Maastricht University, The Netherlands 


\section{CHAPTER I}

\section{ROLE OF ARGININE IN MACROPHAGE FUNCTION .....................7}

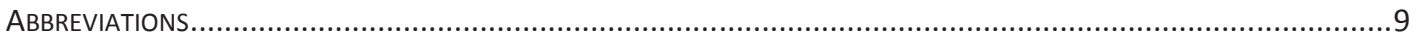

KEYWORDS ...

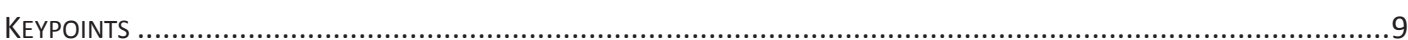

\section{ROLE OF ARGININE IN MACROPHAGE FUNCTION ...................10}

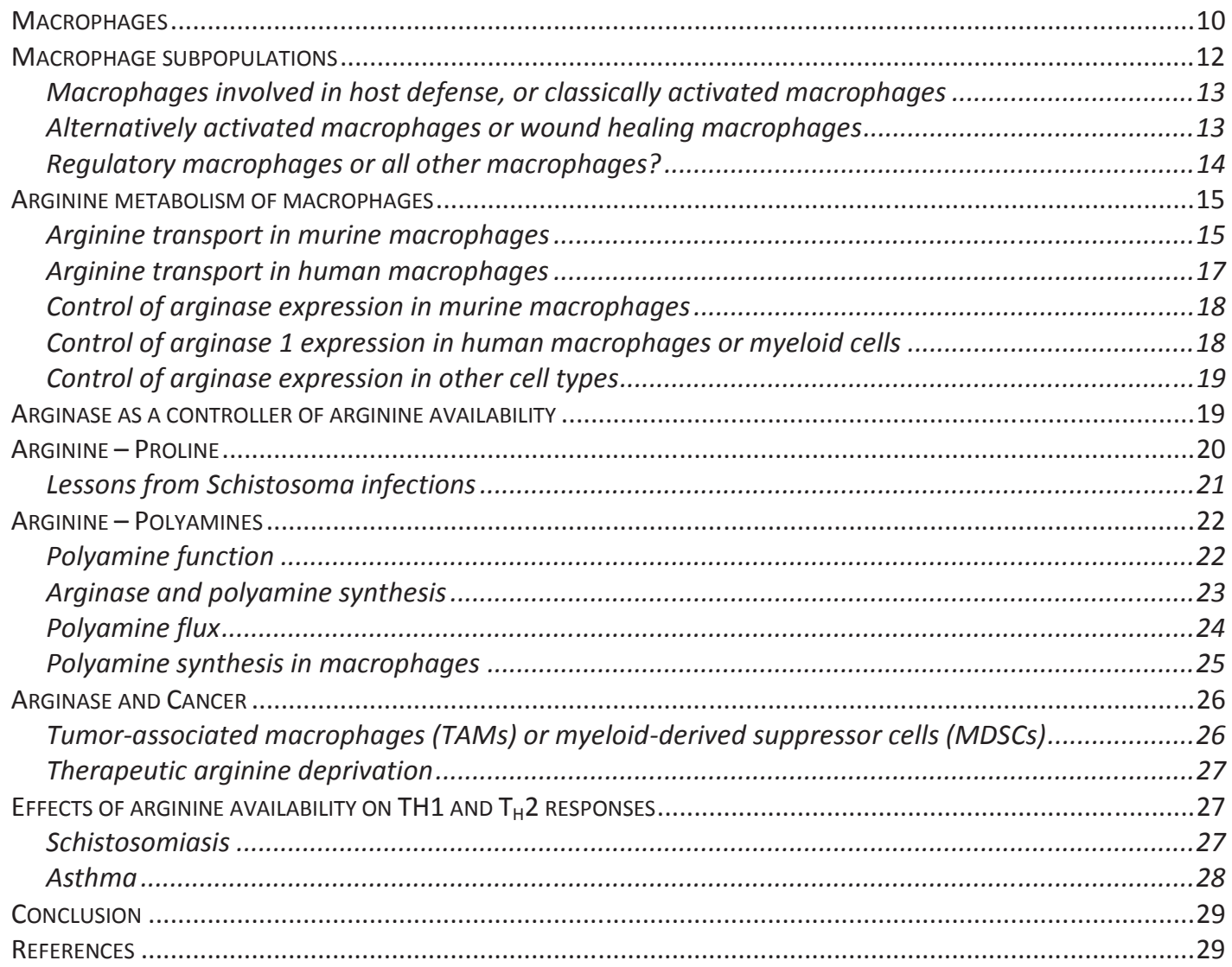




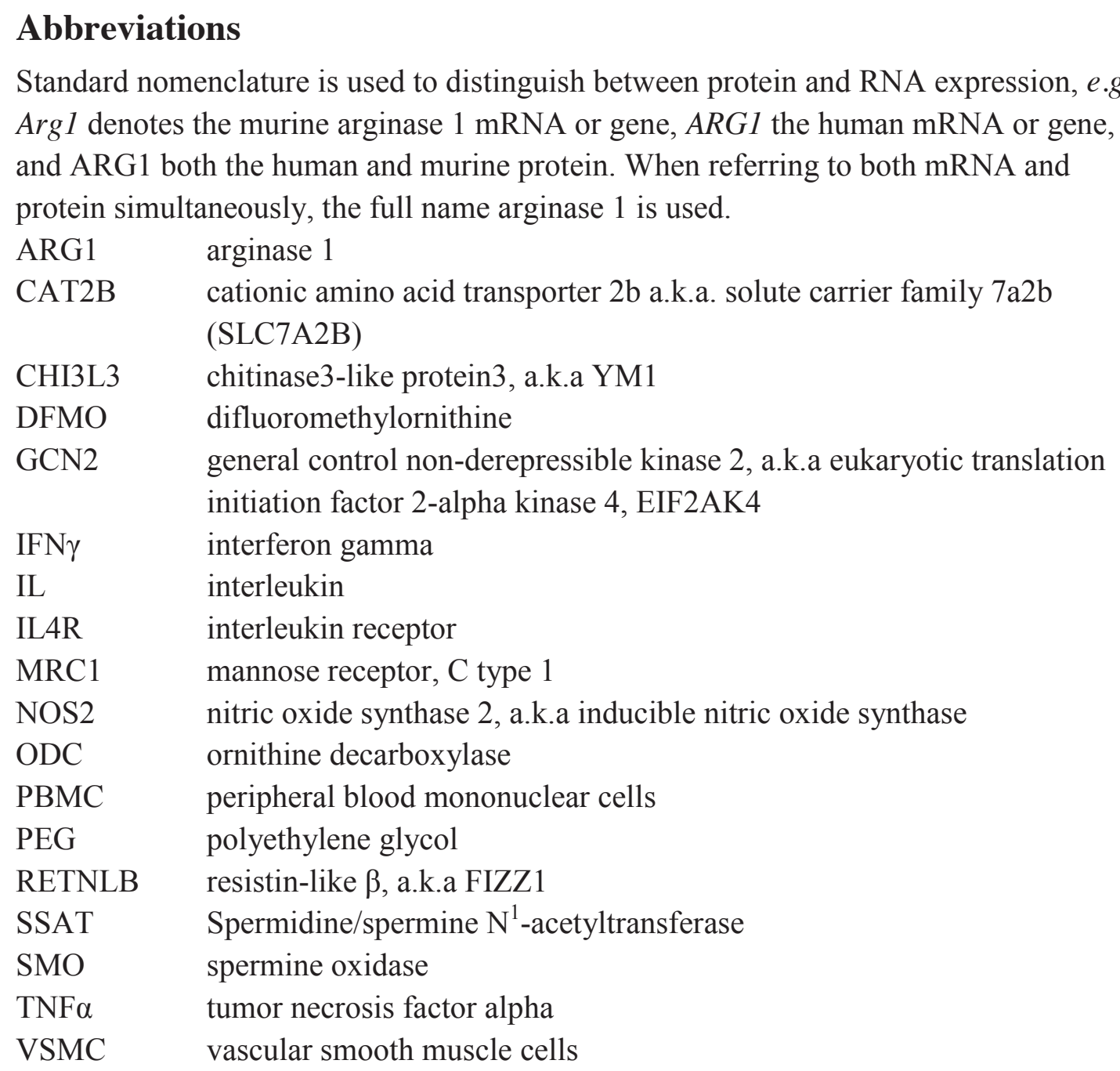

\section{Keywords}

arginine metabolism, alternative activation, polyamines, arginine transport, inflammatory disease

\section{Keypoints}

- Macrophage classification in vivo should be based on function

- Arginine metabolism and transport in macrophages serves to control ambient arginine

- Control of local arginine availability is a mechanism to limit inflammation and fibrosis

- Macrophage arginase 1 does not play a role in polyamine synthesis

- Macrophage arginase 1 does not play a significant role for proline synthesis to support collagen deposition 


\section{Role of arginine in macrophage function}

\section{Macrophages}

Macrophages are gluttons with daily garbage clearance and recycling among their major functions in the body. They phagocytose up to $2 \times 10^{11}$ erythrocytes per day in the spleen, preserving the iron from hemoglobin for reuse, and they remove cellular debris and apoptotic cells everywhere else. The enormous importance of this task is reflected by the huge numbers of macrophages (10-15\% of all cells) that are found in almost every tissue (1). If one assumes the recently published estimate of $3,72 \times 10^{13}$ cells in a human body (2), this amounts to $\sim 5 \times 10^{12}$ macrophages. Although the phagocytic function clearly was the inspiration for their name, macrophages are usually associated with their role in innate and adaptive immune defense. Accordingly, a Pubmed inquiry with the search terms "macrophages" and "immunity" results in $\sim 37,800$ hits, whereas "macrophages AND phagocytosis NOT immunity" delivers only 3460 references (August 2014).

Macrophages are a heterogeneous cell population and are classified according to their tissue distribution, their activation status and their expressed surface markers, depending on the interests of the researcher or the methods applied. None of these criteria is permanent, since tissue distribution, activation status and surface markers can change rapidly in response to environmental triggers, such as cytokines, infectious agents, and foreign substances. Nevertheless, the activation status is the most relevant characteristic for the function of macrophages in innate and acquired immunity. In accordance with the $\mathrm{T}_{\mathrm{H}} 1 / \mathrm{T}_{\mathrm{H}} 2$ nomenclature, macrophages have been classified as $\mathrm{M} 1$ and $\mathrm{M} 2$, or classically and alternatively activated macrophages, respectively (3). M1 macrophages show enhanced microbiocidal and tumoricidal capacity, and are induced by IFN $\gamma$ and LPS or TNF $\alpha$, whereas M2 macrophages are often activated by IL4 and IL13 and support $\mathrm{T}_{\mathrm{H}} 2$-associated effector functions, play a role in wound healing, and in parasite killing. The M2 label has been further subdivided into M2a, M2b and M2c subpopulations $(4,5)$ based on the stimuli that are required for their activation:

- M2a: IL4/IL13-elicited alternatively activated macrophages;

- M2b: induced by immune complexes, Toll-like receptor (TLR) agonists or IL1R agonists; and

- M2c: activated by IL10 and glucocorticoid hormones.

Macrophage subsets 2a-2c share some common functional properties, such as low IL12 expression and involvement in $\mathrm{T}_{\mathrm{H}} 2$ responses and are, therefore, often collectively named M2 macrophages. According to some references, all M2 subpopulations show increased IL10 expression $(5,6)$, but others assign high IL10 expression only to subpopulations $2 \mathrm{~b}$ and $2 \mathrm{c}(7,8)$. The evolving view is that M1 and M2 polarization are the extremes of a continuum, that macrophages can switch activation states, and intermediate forms exist $(3,8,9)$. Pure M1- or M2-polarized macrophages probably only exist in culture where well-defined triggers are used but not in vivo where the cells are exposed to a multitude of triggers in combinations and concentrations which differ in 
every tissue and with every type of infection. In addition, the often described plasticity of macrophages allows them to change from one activation status to another provided the appropriate triggers are delivered by the environment as has been demonstrated in vitro $(10,11)$ and in vivo (12-14), and reviewed extensively $(15,16)$.

In addition to their highly desirable protective immunological and repair functions, all macrophage populations named above also aggravate pathological situations by supporting excessive inflammation (M1), or tumor growth, tissue fibrosis and allergy (M2).

Since macrophages grouped under M2 include cells with remarkable differences with respect to gene expression and physiologic function on the one hand, and since macrophages with similar expression profiles of marker genes can be elicited by quite diverse stimuli on the other hand (see below), a classification based on fundamental functions has also been suggested (8). This classification distinguishes:

- macrophages involved in host defense, which are identical to the classically activated or M1 macrophages,

- wound-healing macrophages that are important in repair processes and, finally,

- regulatory macrophages that suppress or down-regulate immune responses.

The regulatory macrophages include tumor-associated macrophages (TAM) and a subgroup of the related myeloid-derived suppressor cells (MDSC). Both play an important role in tumor progression and will be discussed later.

As for the classification by activation triggers, the authors of the classification by fundamental function also stress that hybrid and transition states exist between all populations. The classification by function, however, matches better with recent observations discussed below.

A case in point is the metabolism of the amino acid arginine by macrophages. It is often stated that the macrophage populations named above differ in their usage of the amino acid arginine, which is a substrate for both nitric oxide synthases (NOS) and arginases (ARG) (Figure 1). Expression of Nos2 is characteristic for classically activated macrophages (or M1), whereas STAT6-dependent expression of Arg1 (17) has always been associated with alternatively activated and regulatory macrophages (subpopulations 2a \& 2c), but not macrophages activated via immune complexes and TLRs (subpopulation 2b). However, STAT6-independent induction of host Argl gene expression by TLR stimulation has been demonstrated in classically activated macrophages infected with intracellular pathogens (18), such as Mycobacterium bovis or bacillus Calmette-Guérin (BCG). In addition, characterization of wound macrophages in a polyvinylalcohol (PVA) sponge wound model in mice has surprisingly revealed that wound macrophages express several markers of the alternative phenotype, including ARG1, but that neither IL4, IL13 nor STAT6 phosphorylation plays a role in the activation of those macrophages (19). We, therefore, strongly support the suggestion (8) that a classification of macrophages based on their function in vivo is more useful than a classification based on stimuli required for eliciting a specific macrophage subtype in vitro. 
Arginine metabolism is not a simple marker for macrophage activation status, but has a strong effect on the outcome of many diseases. This review will, therefore, investigate macrophage arginine metabolism and its role in chronic diseases.

\section{Fates of Arginine}

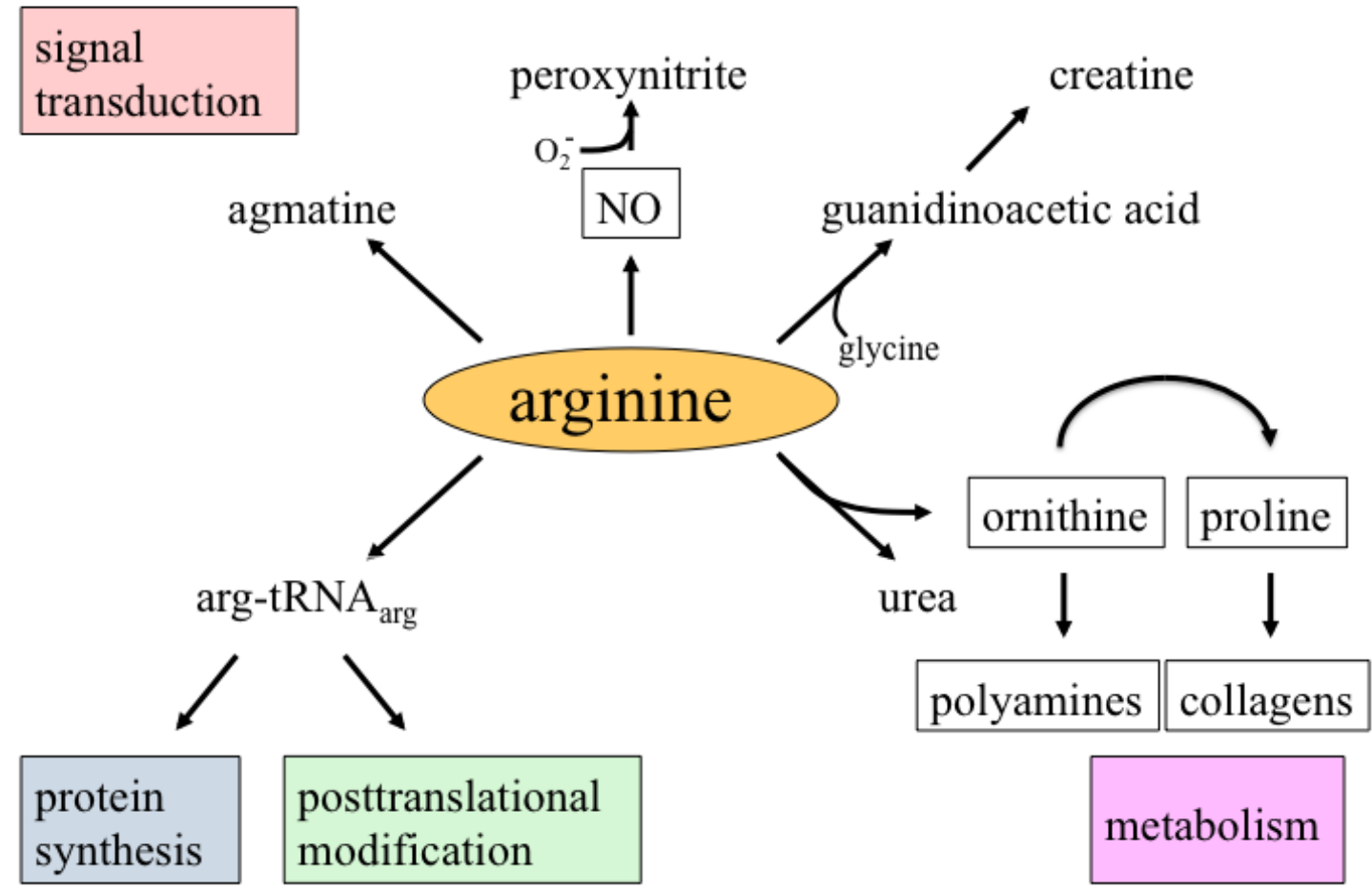

Figure 1. Fates of Arginine. Arginine is one of the 20 basic amino acids and as such a precursor for protein synthesis. Arg-tRNA also serves to arginylate proteins, an important pathway in protein degradation and protein modification during development (167). Arginine is the precursor for signaling molecules, namely agmatine, which seems to be an important neuromodulator (168) and, more importantly, the radical nitric oxide, which is generated by nitric oxide synthases and is amongst other things a relaxing agent for smooth muscle cells and a bactericidal agent in the immune defense. Arginine is also a precursor for creatine production. Arginases break down arginine to yield ornithine and urea. Ornithine is a precursor for polyamines and proline. This review focuses on two aspects of macrophage arginine metabolism that is NO formation and arginine degradation, and their consequences for health and disease.

\section{Macrophage subpopulations}

Macrophages can respond to external stimuli with dramatic changes in gene expression. Dependent on the kind of stimulus, different gene expression programs are induced resulting in macrophages with very different immunological properties. Understanding these properties and being able to modify them could lead to very promising new therapeutic approaches. A recent review suggests the use of epigenetic interventions such as targeting histone deacetylases to modulate macrophage polarization and to thereby treat inflammatory diseases (20). 


\section{Macrophages involved in host defense, or classically activated macrophages}

IFN $\gamma$, together with TNF $\alpha$ or stimuli that induce TNF $\alpha$, will result in macrophages that play a role in host defense, the so-called classically activated macrophages. These macrophages are characterized by a high capacity to present antigen, are immune effector cells that kill intracellular pathogens through $\mathrm{NO}$ and oxygen radical production, and secrete pro-inflammatory cytokines, such as IL1, IL6, IL12 and IL23 to induce and amplify $T_{H} 1$ and $T_{H} 17$-dependent immune responses (8). $T_{H} 17$-cells are a group of recently identified $\mathrm{T}$-helper cells associated with chronic inflammation in autoimmune diseases and host defense in bacterial and fungal infections (21) (22). In analogy with the $\mathrm{T}_{\mathrm{H}} 1$ nomenclature, these macrophages are often called M1. They are important in host defense, but are also potent mediators in inflammatory diseases, such as inflammatory bowel disease (IBD) (23) (24) and atherosclerosis (25). If not properly controlled, they may also play a role in cancer development through persistent inflammation (26). Classical activation in murine macrophages leads to the induction of NOS2 and cationic amino-acid transporter 2B (Cat2b or Slc7a2b) expression $(27,28)$, which results in increased arginine uptake and $\mathrm{NO}$ production.

\section{Alternatively activated macrophages or wound healing macrophages}

Alternatively activated macrophages, a subgroup of the M2 macrophages, are induced in vitro by IL4 and IL13 with enhancing roles suggested for IL21 (29), IL33 (30,31) and galectin-3 (32). The cytokines IL4 and IL13 signal via STAT 6 and this results in the expression of typical marker genes, such as Argl, the macrophage mannose receptor (mannose receptor, C type $1(\mathrm{Mrcl})$ ), resistin-like $\beta$ (Retnlb, also known as Fizz1), and chitinase3-like protein3 (Chi3l3, also known as $Y m 1$ ), and, at least in culture, Cat $2 b$ $(S l c 7 a 2 b)(28)$. Note that $C a t 2 b$ is also a marker for classically activated macrophages. These macrophages are thought to promote wound healing through extracellular matrix reorganization and stimulation of fibroblasts to increase collagen production. This is reflected in their expression of growth factors that promote fibroblast proliferation and proteins that interact with, or support extracellular matrix deposition. It is often suggested that the role of arginase 1 in this scenario is the production of ornithine, which can serve as a precursor for either proline or polyamines, relevant molecules in collagen production and cell proliferation, respectively (8).

A more detailed in vivo characterization of wound macrophages in a murine PVA sponge model now challenges, however, the concept that the alternatively activated macrophages of the Petri dish are the wound-healing macrophages encountered in vivo (19). Wound macrophages isolated on days 1, 3 and 7 from sponges implanted subcutaneously in mice indeed express arginase 1, CHI3L3, mannose receptor and TGF $\beta$ proteins, but they also produce TNF $\alpha$, a marker for classically activated macrophages. More importantly, neither IL4/IL13 nor STAT6 phosphorylation seem to be involved in eliciting the expression of these marker genes. IL4 or IL13 were not found in wound fluid, wound macrophages showed no STAT6 phosphorylation and, 
most compellingly, Il4ra ${ }^{-/-}$macrophages, which lack functional IL4 and IL13 receptors, are indistinguishable from wild type wound macrophages in this model. The lack of IL4 in wound fluids was previously demonstrated in rodents in a burn wound model (33) and in foreign body-response models $(34,35)$, lending extra credibility to the findings of Daley et al. (19,36). The absence of IL4/STAT6 signaling has recently also been confirmed in wound-healing macrophages in a laser-injury wound model of choroidal neovascularization in the eye (37).

From these data, we conclude that wound-healing macrophages express the markers described for alternatively activated markers, but can obviously be induced by stimuli other than IL4 and IL13. Depending on the type of wound, the same macrophage function can be elicited by different triggers. In helminth infections, IL4 and IL13 are abundant and expression of wound healing markers is STAT6 dependent (38). Other types of wounds, such as sterile foreign body-induced wounds or burn wounds, may depend on other triggers to activate the desired macrophage phenotype. Again, this argues for a classification of macrophages by function rather than by external stimuli. The question that remains, however, is - what is the trigger for the wound healing phenotype in sterile wounds? One good candidate for such an alternative trigger is TGF $\beta$ that is found in abundance in certain wound fluids and capable of inducing arginase 1 protein expression (39) in fibroblasts (40) and microglia (41), and increasing arginase activity in macrophages (42).

\section{Regulatory macrophages or all other macrophages?}

The term regulatory macrophages was introduced by David Mosser and Justin Edwards (8) to distinguish macrophages with strong anti-inflammatory activity from woundhealing macrophages. These regulatory macrophages are characterized by high IL10/low IL12 expression and are elicited by various stimuli including immune complexes that bind to TLRs, prostaglandins, G-protein coupled receptor (GPCR) ligands, glucocorticoids, apoptotic cells or by IL10 stimulation. They also express arginase 1 mRNA (43), although ARGINASE 1 protein expression has been described as limited (44) or is not mentioned at all (45). In addition, they produce the chemokines CCL17, -18 and -22 , and also TGF $\beta(4,5)$. IL10 production is high in TLR-stimulated macrophages, whereas stimulation by IL4 and/or IL13 alone (definition of alternatively activated macrophages) does not seem to result in significant IL10 expression (8), although conflicting reports exist $(5,46)$. Unfortunately, high IL10/low IL12 expression is also named as a characteristic of tumor-associated macrophages and myeloid-derived suppressor cells (discussed below in "Arginase as a controller of arginine availability" and "Arginase and Cancer"), but often also simply for M2 macrophages (47) to distinguish them from M1 macrophages $(5,48)$, which renders this characteristic useless for a meaningful distinction of macrophage populations. In agreement, a recent article on the nomenclature of macrophages started with the encouraging sentence: "Description of macrophage activation is currently contentious and confusing" (22). The authors strongly advise a coherent nomenclature based on macrophage origin, activators 
used and a consensus set of markers for characterization. As stated above, however, a nomenclature based on these criteria is most useful for in vitro experiments, where the activators can be controlled.

It is very obvious that macrophages can be activated by a wide variety of triggers on the one hand and can respond with an equally wide range of activation profiles on the other hand: the more markers are measured, the more different populations are found. The usefulness of these distinctions is mostly descriptive and depends on the experimental circumstances. The distinction of regulatory and wound-healing macrophages is based on the assumption that wound-healing macrophages participate, in addition to exerting their immunosuppressive activities, also in matrix deposition and possibly tissue healing/proliferation through ornithine production by arginase 1. Ornithine can serve as a precursor for both proline and polyamines (Figure 1). Recent research, however, seems to indicate that there are only two main functions of macrophages, namely immune activation and immune suppression and that the arginase activity of wound-healing macrophages is more important in immune suppression than in matrix deposition or proliferation. This will be discussed below.

\section{Arginine metabolism of macrophages}

\section{Arginine transport in murine macrophages}

Murine macrophages take up arginine via the $\mathrm{y}^{+} \mathrm{L}$ or $\mathrm{y}^{+}$system of transporters. The $\mathrm{y}^{+} \mathrm{L}$ system is well characterized (49) and consists of a light chain (SLC7A6, a.k.a y ${ }^{+}$LAT2, or SLC7A7, a.k.a ${ }^{+}$LAT1; SLC stands for solute carrier family) that associates with a heavy chain (SLC3A2, a.k.a 4F2hc or CD98) for surface expression. These heterodimeric transporters are exchangers, which are subject to "trans-stimulation". Trans-stimulation occurs when a compound on one side of a membrane stimulates transport on the other side of the membrane (50). $\mathrm{y}+\mathrm{L}$ transporters preferably import a large neutral amino acid (such as leucine) plus $\mathrm{Na}^{+}$in exchange for the export of a cationic amino acid. $y^{+}$LAT2 can mediate an efficient influx of large neutral and cationic amino acids, but the efflux is clearly biased towards cationic amino acids. The uptake of arginine into cells is, therefore, often inhibited with leucine plus sodium, which actually stimulates arginine efflux. In the absence of extracellular leucine, measurable arginine $\mathrm{y}^{+}$LAT2-mediated influx occurs, as was shown in erythroid cells (51).

The $\mathrm{y}^{+}$system is encoded by the cationic amino-acid transporter (Cat) genes Slc7AI (Cat1), Slc7A2 (splice variants Cat2a and Cat2b) and Slc7A3 (Cat3). These transporters all mediate $\mathrm{Na}^{+}$-independent transport of the cationic amino acids arginine, lysine and ornithine $(52,53)$, but CAT1 shows a strong trans-stimulation, which is lacking in CAT2. The three transporters differ in spatial and temporal expression patterns. CAT3 is important in embryogenesis and is found in central neurons in the adult. Cat1 mRNA is often constitutively expressed, but its translation (54) and activity (55) are strictly regulated by nutrient status, cytokines and hormones. CAT2 exists in 2 splice-variants. 
The constitutively expressed, low-affinity CAT2A variant is expressed in liver, pancreas, skeletal muscle, cardiomyocytes and vascular smooth muscle, while the high-affinity CAT2B is inducible by inflammatory cytokines.

Under basal, i.e. non-stimulated conditions, macrophages take up most of the arginine via the $\mathrm{y}^{+} \mathrm{L}$ system. Once they are stimulated with M-CSF to proliferate, increased arginine import via CAT1 is observed (28). Stimulation of macrophages with either the $\mathrm{T}_{\mathrm{H}} 1$ cytokine IFN $\gamma$ plus LPS or the $\mathrm{T}_{\mathrm{H}} 2$ cytokines IL4 and IL10 leads to upregulation of Slc7a2b (Cat2b) (28). Cat $2 b$ expression stimulated by $\mathrm{T}_{\mathrm{H}} 1$ cytokines is often induced together Nos2 expression. Accordingly, sustained NO production by peritoneal macrophages from $\mathrm{Cat}^{-/-}$mice is virtually abolished (56). Intracellular arginine concentration and Nos 2 expression, however, are unchanged in these macrophages. This has been interpreted as a strong indication for the presence of different arginine pools in macrophages that are not freely exchangeable (49). Another study in experimental asthma showed upregulation of Cat2 together with Arg1, but not Nos2; unfortunately, the Cat2 isoform that was expressed (A or B) was not identified (57).

Based on a study on murine bone marrow-derived macrophages with ${ }^{14} \mathrm{C}$-labeled arginine (28), the following model was suggested: quiescent macrophages import arginine via the $\mathrm{y}^{+} \mathrm{L}$ system, incorporate a small amount thereof into proteins and return the rest to the medium. Proliferating macrophages, stimulated by M-CSF, probably take up arginine through CAT1. 50\% of this arginine goes into protein synthesis, $5 \%$ into polyamine synthesis and the rest is returned to the medium. Classically or alternatively activated macrophages both import arginine via CAT2B and use it for NO production via NOS2 or for ornithine/urea production via arginase 1, respectively (28). However, data from $\mathrm{Cat}^{-/-}$mice support those findings only partially. Infection of such mice with Toxoplasma gondii, which elicits a $\mathrm{T}_{\mathrm{H}} 1$-type response, indeed results in a much higher susceptibility to the infection due to decreased NO production. Infection of the same mice with Schistosoma mansoni, which results in a pronounced $\mathrm{T}_{\mathrm{H}} 2$ response, also led to the development of more severe disease-related pathologies. However, bone marrowderived macrophages from these mice show higher urea production, a measure of arginase activity, in culture, when stimulated with $\mathrm{T}_{\mathrm{H}} 2$ cytokines. In the same study, higher arginase 1 mRNA expression was found in lung tissue of infected mice (58). These observations strongly suggest that arginase 1 also has access to a CAT2independent arginine pool, but the experiments performed do not allow the distinction between an extracellular or intracellular source of arginine. Again, it is obvious that the association of specific stimuli with specific transporters found in vitro cannot be directly translated into the in vivo situation.

A recent study (24) demonstrated that the different susceptibility of C57BL/6 and $\mathrm{Balb} / \mathrm{C}$ mice to Leishmania infections is due to a mutation in the Cat 2 promoter of C57BL/6 mice, which results in diminished arginine uptake into macrophages when stimulated with IL4 (but not IFN $\gamma$ ). Increased CAT2 activity provides arginine for polyamine synthesis for the intracellular pathogen in Balb/C, but not in $\mathrm{C} 57 \mathrm{BL} / 6$ mice. 
Neither Catl $\left(\mathrm{y}^{+}\right)$mRNA expression nor basal $\mathrm{y}^{+}$L-mediated arginine transport are affected by macrophage activation (28). Since CAT1 protein expression is regulated at the translational rather than the transcriptional level in mice (54) and men (59), protein expression may still be increased and serve as a source of arginine in $\mathrm{T}_{\mathrm{H}} 2$-cytokinestimulated macrophages. The lack of a specific antibody has been hampering a detailed investigation of the regulation of Cat1 under these circumstances. Unfortunately, Cat $1^{\text {flfl }} /$ Tie2Cre mice on a $129 \mathrm{~Sv} / \mathrm{OlaHs}$ background do not survive after birth due to severe anemia, similar to the phenotype of constitutive $\mathrm{Cat1}^{-/-}$mice [our own unpublished observations: CC de Theije, SE Köhler, WH Lamers]. Hopefully, Cat $^{\text {fllfl}} /$ LysMCre mice will enable us to address the role of CAT1 in substrate delivery to macrophages under type II inflammatory conditions. Intriguingly, backcrossing the Cat $^{\text {fllfl }} /$ Tie2Cre from a129Sv/Ola background to C57BL/6J increases the life expectancy of these mice to adult age and even allows the breeding of homozygous mice. They remain, however, fragile with a higher than normal mortality and smaller than their wild-type littermates as adults, which hampered vessel cannulation for blood-pressure measurements [our own unpublished observations: CC de Theije, SE Köhler, WH Lamers, R. Chennupati].

\section{Arginine transport in human macrophages}

Arginine transport in human monocytes and macrophages is less well characterized than in mice. System $\mathrm{y}^{+} \mathrm{L}$ is reportedly mainly responsible for basal transport in human alveolar macrophages. These cells do not respond with increased arginine import or NO production to LPS stimulation, although they upregulate $C A T 2 B$ mRNA expression (60). In contrast, an increased $\mathrm{y}^{+}$-dependent transport activity and $\mathrm{NO}$ production was reported in PBMCs from septic patients (61). The authors assigned the increased transport to CAT2 expression, since they found CAT2 mRNA in 5 of 7 PBMC samples from septic patients, but not in controls, and no change in CAT1 mRNA levels in the two groups. It is possible, however, that translation of CAT1 mRNA was also upregulated in these patients. This hypothesis is supported by an increased NO production without concomitant CAT2 mRNA expression in 2 of the 7 septic patients. Increased CAT2 expression and $\mathrm{y}^{+}$-dependent arginine transport have also been reported in PBMCs of pregnant women, but no clear correlations between arginine transport, CAT2 expression and NO production were found (62). Stimulation of freshly isolated human monocytes with IFN $\gamma$ resulted in increased arginine import attributable to system $\mathrm{y}+\mathrm{L}$ and was accompanied by an increased expression of SLC7A7 (y+LAT1) (63), whereas mRNA expression of other cationic amino-acid transporters such as CAT1 (SLC7A1) and $C A T 2 B$ (SLC7A2) was unaffected. A more rigorous analysis of arginine transport in human macrophages is highly desirable.

In summary, data from murine macrophage cultures suggest that activation of macrophages leads to stimulation of arginine transport through gene and protein expression and that the same transporter, CAT2B, is used in both the classical and alternative activation state $(28,58)$. In vivo data with macrophage-specific gene deletion 
confirmed the role of CAT2 under $\mathrm{T}_{\mathrm{H}} 1$ conditions, but were less convincing for $\mathrm{T}_{\mathrm{H}} 2$ conditions. The question whether the same intracellular arginine pool is accessible for NOS2 and arginase 1 is, therefore, still not fully answered. The fact that $\mathrm{Cat} 2^{-/-}$mice are viable and fertile suggests that there is redundancy in arginine transporters in C57BL/6J, but probably not in 129Sv/Ola mice. Moreover, the metabolic activity and intracellular arginine content of $\mathrm{Cat}^{-/-}$macrophages is not affected in the basal, unchallenged state (56), a finding that fits with the observation that the system $\mathrm{y}^{+} \mathrm{L}$ is the major arginine transporter under those conditions (28).

It is tempting to speculate that the different degrees of trans-stimulation observed for CAT1, CAT2A and CAT2B add an extra level of control. In such a scenario, CAT1 would serve as the ideal transporter in an arginase 1-expressing cell to deplete the environment of arginine, CAT2B would be best for arginine uptake in a cell that rapidly metabolizes arginine, and CAT2A would allow arginine uptake and accumulation without (excessive) export of another cationic amino acid in exchange. The expression of CAT2A in liver cells and CAT2B in activated macrophages fits with this suggestion, but the role of CAT1 as the transporter of choice in proliferating macrophages is difficult to combine with its pronounced exchanger profile.

\section{Control of arginase expression in murine macrophages}

Arginase 1 expression is constitutive in periportal hepatocytes, but inducible by cytokines in other cell types, such as macrophages and fibroblasts. The majority of extra-hepatic arginase 1-expressing cells are macrophages and dendritic cells as shown by a reporter mouse that carries an IRES-YFP knock-in allele into the 3'-end of the arginase 1 gene (64). In macrophages and dendritic cells, arginase 1 expression is associated with $\mathrm{T}_{\mathrm{H}}$ 2-type cytokines, such as IL4, IL10, IL13 and TGF $\beta$, which are all strong inducers of arginase 1 expression in vitro. This induction is STAT6- and C/EBP $\beta$ dependent (65). Remarkably, in classically activated macrophages, STAT6-independent, MyD88- and C/EBP $\beta$-dependent expression of arginase 1 has been demonstrated after infection with intracellular pathogens (18).

Mouse models, deficient for IL4, IL10, IL13 or combinations thereof indicate that IL4 and IL13 are the major inducers of arginase 1 expression in vivo. IL10 (66) shows significant synergistic effects with IL4 on arginase 1 induction, probably due to the upregulation of Il4ra expression (67). On its own, IL10 is only able to induce a low level arginase 1 expression.

\section{Control of arginase 1 expression in human macrophages or myeloid cells}

The expression of arginase 1 in human macrophages is still controversial. Several studies have shown that in human monocytes/macrophages in vitro alternative activation by either IL4, IL10 or IL13 does not lead to induction of arginase 1 (and other murine markers of alternative activation) (68-72). Other studies, however, have shown that 
human macrophages can and do express arginase 1 during filarial infection in vivo (73) and after infection with Coxiella burnetti in vitro (74). The same authors demonstrated that uptake of apoptotic cells induced an alternative phenotype in human macrophages characterized by high expression of mannose receptor and secretion of TGF $\beta$ and IL10. Neutralization of IL10 or TGF $\beta$ prevented persistent Coxiella infection (75). Interestingly, both types of infection also result in alternative macrophage activation in susceptible mouse strains $(76,77)$. In addition, weak arginase 1 gene expression has been shown in human adipose-tissue macrophages (78). Again, this provides an argument for classification of macrophages by function (i.e. the protein expression profiles) rather than activation trigger in vivo. For in vitro studies, the recently proposed, more complex nomenclature framework for macrophages, which is based on the source of the macrophages, the activators and a consensus selection of markers, will be useful for comparison of different cell populations and cell populations of different research groups (22).

Immune functions that are covered by macrophages in mice may be performed by other immune cells in humans. Constitutive $A R G 1$ expression is found in human circulating PMNs or granulocytes, which sequester arginase 1 in intracellular granules. Upon certain triggers, these granules are released into plasma and decrease arginine concentration there $(69,79,80)$.

\section{Control of arginase expression in other cell types}

TGF $\beta$-dependent induction of arginase 1 has also been shown in vascular smooth muscle cells and resulted in measurable increases of putrescine and proline production in vitro (81). TGF $\beta$ also seems to be an important inducer of arginase 1 in fibroblasts $(82,83)$. In addition, arginase 1 expression was shown in endothelial and vascular smooth-muscle cells of aged rats $(84,85)$ and in human intestinal microvascular-endothelial cells after stimulation of with the inflammatory triggers LPS and TNF $\alpha$ (86). Wound fibroblasts express high levels of arginase. Interestingly, deletion of CAT2 leads to increased arginase activity in both cultured macrophages and fibroblasts as determined by urea production (58). The authors suggest that CAT2 suppresses arginase activity, but the mechanism is unclear. The role of CAT2B upregulation by type II cytokines would then be limitation of arginase activity rather than provision of substrate, thereby limiting the extent of type II response-associated inflammation.

\section{Arginase as a controller of arginine availability}

Intracellular arginase 1 expression can control local extracellular arginine levels and, thus, reduce arginine availability for neighboring cells that do not express arginase. The suggested mechanism involves rapid uptake of arginine by a cationic amino-acid transporter (CAT) and degradation by cytosolic arginase 1 . The formed ornithine, in turn, stimulates arginine import via CAT-mediated ornithine-arginine exchange. This mechanism seems highly relevant in immunosuppression, where alternatively activated 
macrophages or related cells, such as dendritic cells or granulocytes, can suppress T-cell activation by local arginine depletion. T-cells are very sensitive to arginine deficiency, as has been demonstrated both in vitro in murine $(87,88)$ and human cells $(89,90)$, and in vivo in mouse tumor models $(91,92)$.

The so-called myeloid-derived suppressor cells (MDSC), a collective name for cells that support tumor growth in murine models and in human cancers, and includes precursors of granulocytes, macrophages, dendritic cells, or early myeloid progenitors. MDSCs express arginase 1 intracellularly (93) and use CAT1-mediated ornithine-arginine exchange to locally deplete the extracellular fluid of arginine through uptake and subsequent degradation to ornithine and urea $(88,94)$. Ornithine may be further metabolized to polyamines or exported. As a consequence of arginine deficiency, T-cells become anergic through the activation of GCN2 kinase (95), which results in suppression of general protein translation. In vitro, this process of T-cell inhibition can be reversed through the addition of arginine.

It has been suggested, that cells expressing the cationic amino-acid transporter CAT1 may even be depleted of their intracellular arginine, when the cells are in contact with extracellular arginase or an arginase-expressing cell (96). This depletion results from trans-stimulation of CAT1-mediated arginine export from the cell by another extracellular cationic amino acid, because CAT1 functions much more efficiently as an amino-acid exchanger than as a unidirectional transporter (see section on "Arginine transport"). High extracellular concentrations of ornithine provided by arginase activity in another cell, i.e. a MDSC, or by extracellular arginase activity could thus induce increased ornithine import in exchange for arginine export from neighboring cells, such as T-cells, thereby rapidly depleting those cells of arginine and making them anergic $(95,97)$. Once depleted, CAT1-expressing cells take up arginine only very slowly. Although this sounds like a very elegant and plausible mechanism, CAT1 expression in lymphocytes has, as far as we know, not yet been demonstrated.

\section{Arginine - Proline}

Arginine can also serve as a precursor for proline or glutamate, provided ornithine aminotransferase (OAT) is co-expressed with arginase. In this case, ornithine produced by arginase is converted by OAT to glutamic $\gamma$-semialdehyde, which cyclizes nonenzymatically to pyrroline-5-carboxylate, which is then reduced by NADPH-dependent pyrroline-5-carboxylate reductase to proline. It has been repeatedly suggested that arginase expression acerbates fibrosis due to excessive collagen production from proline (98-100) or supports wound healing through the same mechanism (101). M2 macrophages of the "wound-healing" type have in particular been associated with increased production of proline in fibrotic disease (102). Arginase 1-overexpressing mice, however, show no fibrosis in any tissue and certainly not in the gut where the enzyme is overexpressed $(103,104)$. Few papers show actual experimental data linking arginase expression to proline formation or collagen deposition. Dependence of collagen 
deposition on arginase activity was shown in murine fibroblasts in vitro and in the same paper increased arginase 1 expression was demonstrated in myofibroblasts in bleomycin-induced pulmonary lesions in mouse lung (40). Arginase-dependent proline production has also been shown in VSMC stimulated by either cyclic stretch or TGF $\beta 1$ $(81,105)$. Proline production from arginine was demonstrated in vivo, but the amount of arginine-derived proline incorporated into protein-bound proline was only 5\% of total that of direct proline incorporation (106), indicating that this metabolic route is hardly relevant. The in vivo finding that proline is abundant in wound fluid and arginine scarce (in rodents) further supports the notion that arginine is not an important precursor for collagen synthesis, even though both arginine and ornithine have positive effects on hydroxyproline production and scar strength in mice (107). Interestingly, the stimulatory effect of arginine (108), but not that of ornithine (109) on hydroxyproline production and scar strength are abolished in NOS $2^{-/-}$mice, suggesting that the NOS2 pathway plays a role in mediating the effects of arginine on wound healing. In cell culture, inhibition of arginase reduces collagen synthesis in rat, but not in human fibroblasts (82). Since inhibitor studies may be hampered by undesired inhibition of enzymes other than the intended target, results from arginase knockout mice can hopefully further clarify the issue. A recent study by Campbell et al. (37) indeed showed that arginase 1 is required to accelerate wound healing, since absence of arginase 1 from macrophages resulted in delayed wound closure and a more inflammatory wound environment. The absence of arginase 1 in this model resulted in increased numbers of NO-producing cells, but did not diminish collagen expression. This however did not result in increased matrix deposition, since the expression of gelatinases (matrix metalloproteinases) was also increased in this pro-inflammatory environment. Again, the main effect of arginase seems not to lie in the provision of precursors for proline and hence collagen synthesis, but rather in the control and suppression of excess inflammatory cells.

\section{Lessons from Schistosoma infections}

Mice deficient in M2 macrophages due to a macrophage-specific disruption of the IL4R $\alpha$ gene (Interleukin-4 receptor alpha chain) show no change of fibrotic lesion size after Schistosoma mansoni infection. These mice do, however, succumb to the disease much faster than their wild-type littermates due to excessive $\mathrm{T}_{\mathrm{H}} 1$ cytokine responses and increased NOS2 activity (110). In a less drastic mouse model with macrophage-specific deletion of arginase 1 (ArgI $I^{f l f l} /$ Tie2-Cre and Arg $1^{f l f l} /$ LysM-Cre mice with arginase 1 deletion in all hematopoietic and endothelial cells, or in granulocytes and macrophages, respectively), infection with Schistosoma mansoni resulted in even larger fibrotic lesions in the knockout animals than their arginase 1-expressing litter mates (92). These findings suggest that macrophage arginase 1 protects against rather than sensitizes to fibrosis. Furthermore, the local depletion of arginine by alternatively activated macrophages suppressed proliferation of T-cells in this model. A consequence of this suppression was a reduction of excessive macrophage accumulation in granulomatous lesions. This suggests that the major role of macrophage arginase 1 is suppression of Tcell proliferation by local arginine depletion. The observed increased fibrosis in the 
arginase-deficient model is probably a consequence of increased stimulation of collagen deposition by myofibroblasts through inflammatory cells. A very recent review by Wynn \& Barron (111) also emphasizes the role of macrophages as regulators of fibrosis controlling the collagen-depositing activity of myofibroblasts. These authors also interpret the role of macrophage arginase as a controller of arginine availability, depriving both $\mathrm{CD}^{+}{ }^{+} \mathrm{T}$-cells and myofibroblasts of a metabolite that is essential for their survival. Supportive evidence for this claim comes from Schistosoma-infected Cat $2^{-/}$ mice that show increased arginase 1 expression in myofibroblasts in granulomatous lesions with concomitant collagen deposition and increased lesion size (58). The ornithine produced by alternatively activated macrophages obviously played no significant role in stimulating collagen deposition, whereas the depletion of arginine by macrophages reduced arginine availability to myofibroblasts. There are two possible explanations for these seemingly contradictory findings. Firstly, extracellularly produced ornithine is not a precursor for collagen, whereas intracellularly produced ornithine is, or secondly, ornithine in general is not a relevant precursor for collagen-incorporated proline. Two studies that investigated the role of arginine in wound healing come to a similar conclusion, namely, that it remains to be proven that ornithine is an important precursor of collagen-incorporated proline $(106,107)$.

\section{Arginine - Polyamines}

\section{Polyamine function}

Polyamines, such as putrescine, spermine and spermidine, are aliphatic cationic molecules that consist of, respectively, 1, 2, and 3 putrescine moieties. Due to their highly positive charge, polyamines bind and stabilize RNA and DNA. Moreover, they seem to be able to regulate local histone acetylation via upregulation of histone acetylases (HATs) and histone deacetylases (HDACs) (112). They can increase the accessibility of promoters and facilitate transcription and translation of specific genes (for a review see (113)). Polyamines are also thought to play an important role in cell cycle regulation and proliferation (114). Liver regeneration after partial hepatectomy is, for example, absolutely dependent on the presence of spermidine $(115,116)$. Furthermore, polyamine metabolism is frequently deregulated in cancer (117). Accordingly, polyamine levels are tightly controlled by feedback mechanisms that regulate synthesis, breakdown and transport. These feedback mechanisms result in adaption of the expression of polyamine-synthesizing or -degrading enzymes $(118,119)$ to keep free polyamine concentrations stable (Figure 2).

Polyamines are either taken up from the diet or synthesized by decarboxylation of ornithine by ornithine decarboxylase (ODC), which catalyzes the first, rate-determining step. Decarboxylation of arginine to agmatine can also, via agmatinase, yield putrescine. Agmatinase is structurally related to arginase. Both arginine decarboxylase and agmatinase are expressed in RAW 264.7 macrophages and this expression is regulated by LPS, TGF $\beta$, IL4 and IL10 (120). However, there is some doubt about the 
functionality of murine agmatinase (121) Most of the evidence for the requirement of polyamines for cell function comes from experiments using the inhibitor $\alpha$ difluoromethylornithine (DMFO or eflornithine), and knockout or overexpression studies of ODC (117).

\section{Polyamine synthesis and degradation}

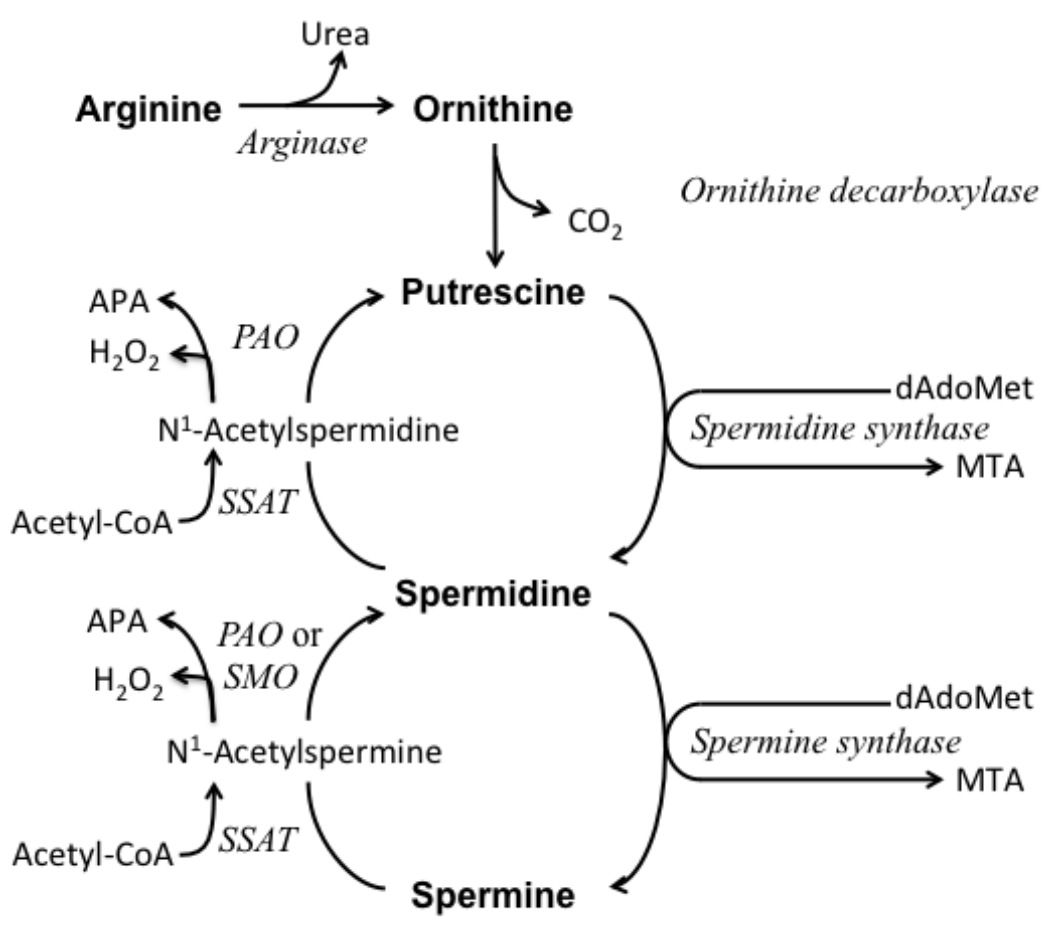

Figure 2. Polyamine Synthesis and Degradation. Synthesis and degradation of the three polyamines putrescine, spermidine and spermine and the most important enzymes and precursors or degradation products in shown. APA: acetamidoproprionaldehyde, dAdoMet: decarboxylated S-adenosylmethionine, MTA: methylthioadenosine, PAO: polyamine oxidase, SMO: inducible spermine oxidase, SSAT:

Spermidine/spermine- $\mathrm{N}^{1}$-acetyltransferase

\section{Arginase and polyamine synthesis}

Since arginine is a precursor for ornithine, arginase activity can exert control over polyamine synthesis when ornithine is limiting, as has been shown in experiments where arginase 1 was either overexpressed (122) or induced by TGF $\beta$ in vascular smooth muscle cells (VSMC) (81); see also (123) for references). Since polyamine production and ODC expression are elevated in many tumors (118) and in wound healing (124), and since arginase 1 expression has also been associated with tumor growth and metastasis (125), and wound healing (126), the logical conclusion seems that arginase 1-expressing macrophages may increase polyamine production to support tissue regeneration in wounds (127) and vascularization of tumors (128). Experimental evidence for this particular hypothesis is, however, scarce. Thus far, few papers have investigated changes 
in expression and /or activity of both ODC and arginase simultaneously. A study on arginine- and ornithine-metabolizing enzymes in the kidney after testosterone treatment (129) showed a 1.5-fold increase in arginase activity and a 450-fold increase in ODC activity. Since incorporation of the carbon backbone of arginine into polyamines was not determined, it is precarious to deduce a functional relation. A similar critique can be raised against a recent study (130), in which the stimulatory effects of smoking in asthmatics on arginase and ODC expression were reported. In this study, enzyme activities did, for instance, not correlate with polyamine concentrations or levels of polyamine-degrading enzymes. Similarly, a recently claimed positive correlation of polyamine concentrations and arginase activity in sputum was not convincing, see below (16).

Another compelling example arguing against a direct relation between arginase levels and polyamine synthesis is that arginase 1 and arginase 2 single- and double-knockout mice show hardly any changes in polyamine levels in liver, kidney, small intestine or brain, even though the animals were only 2 weeks old (131). Similarly, polyamine levels (putrescine, spermine and spermidine) in the small intestines of mice overexpressing arginase 1 in their enterocytes were not increased, despite a 30\% increase in ornithine in the same tissue (103). Finally, IL4 induced polyamine production is not impaired in arginase 1-deficient macrophages (15). On the contrary, Argl-deficient macrophages even showed increased polyamine production upon IL4 stimulation when compared to their wild-type counterparts. A possible explanation for this surprising finding is that, instead of providing ornithine as a substrate, arginase 1 activity, together with a cationic amino-acid exchanger, depletes the cell of ornithine (for each molecule of arginine imported, one molecule of ornithine is exported), thereby efficiently preventing polyamine synthesis. In the absence of arginase, ornithine is no longer exported and available for ODC. Together, these findings suggest that arginase 1 suppresses polyamine synthesis in the expressing cell, i.e. the macrophage. In support, a recent study in mice on the effects of polyamines on asthma showed virtually no correlation between increased concentrations of polyamines and arginase activity in sputum (16). Polyamine concentration was 1.5 -fold increased (with very little variation) in this model. Arginase 1 activity was, as expected, not detectable in non-asthmatic sputum and elevated in asthmatic sputum, but the variation in arginase 1 activity was no less than 6fold.

\section{Polyamine flux}

It was recently shown that even though tissue polyamine concentrations do not change when ODC or SSAT are overexpressed or inhibited/knocked-out, polyamine turnover and thus metabolic flux may change considerably. Increased polyamine flux can lead to the depletion of important metabolites, such as cytosolic acetyl-CoA and malonyl-CoA (132) (see Figure 2), and to an increase in toxic by-products such as $\mathrm{H}_{2} \mathrm{O}_{2}$. It is, therefore, possible that unchanged polyamine levels mask an increased polyamine flux, in particular when substrate levels are high. Some of the phenotypic abnormalities observed in arginine-deficient mice, such as hair loss in arginase1-overexpressing F/A2 
mice and ornithine transcarbamoylase-deficient Spf/Ash mice (133) are comparable to those of spermidine/spermine N1-acetyltransferase (SSAT)-overexpressing mice. Overexpression of SSAT results in an increased polyamine flux, but is also characterized by an accumulation of putrescine, which was not found in F\A2 mice. Circumstantial evidence in the SSAT mice points to putrescine accumulation as the culprit of the hair loss (see Minireview (115)), whereas in F/A2 mice, tissue polyamine levels were not changed. Instead, the arginine deficiency had activated the integrated stress response kinase GCN2 in many tissues (134). A recent review (135) presents evidence that polyamines can induce stress responses resulting amongst other things in inhibition of general protein synthesis, similar to the effects of GCN2-mediated eIF2 $\alpha$ phosphorylation in mammals. Whether hair loss in transgenic SSAT, Spf/Ash, and F\A2 mice is the consequence of activation of the integrated stress response is intriguing and warrants further investigation.

\section{Polyamine synthesis in macrophages}

The increased polyamine synthesis in VSMC cells that overexpress arginase 1 (see section on "Arginase and polyamine synthesis") could not be reproduced in the murine macrophage cell line RAW 264.7, suggesting that arginase-derived ornithine is only rate-limiting for polyamine production when no other ornithine source such as proline or glutamate (and the necessary enzymes) is available (136). An arginase-dependent increase in polyamine synthesis in RAW 264.7 cells could, nevertheless, be demonstrated after LPS- or 8-Bromo-cAMP-stimulated ODC expression. After 6 hours of treatment with LPS or 8-Bromo-cAMP stimulation, arginase 1-overexpressing macrophages showed marked increases in the levels of putrescine (3-fold) and spermidine (1.5-fold) compared to lacZ-transfected or untransfected control cells. The higher increase in putrescine than in spermidine is in line with increased polyamine flux (115) in these cells to maintain stable polyamine levels and is not accompanied by increased cell growth (136).

The experiment described above mimics the situation in pathogen-infected macrophages. Indeed, increased polyamine production in macrophages is observed in vivo after infection with different pathogens, and this increased production has disastrous effects on the macrophages themselves. The opportunistic pathogen Pneumocystis induces upregulation of AZI, the antizyme inhibitor of ODC antizyme, which results in increased cellular ODC protein and polyamine levels. This, in turn, results in increased polyamine oxidase expression and activity. A by-product of polyamine oxidation is $\mathrm{H}_{2} \mathrm{O}_{2}$, which leads to macrophage apoptosis (137). Helicobacter pylori infection has a similar effect via a different mechanism. Helicobacter activates c-Myc in gastric macrophages, which upregulates ODC expression and spermine production. Spermine suppresses NOS2 transcription, which prevents an effective immune response against the pathogen. In addition, Helicobacter infection results in increased SMO expression (a sperminespecific polyamine oxidase; see Figure Polyamine Metabolism) and $\mathrm{H}_{2} \mathrm{O}_{2}$ production in the macrophages and concomitant macrophage apoptosis. 
Susceptible ("non-healer") strains of mice, such as BALB/c, respond to Leishmania major infection with a polarized $\mathrm{T}_{\mathrm{H}} 2$ response with increased arginase 1 expression and a concomitant increase in polyamines (138). Inhibition of arginase reduces polyamine production and parasite growth. The authors conclude that the pathogens exploit ornithine and polyamine production by the host for their own multiplication. Accordingly, non-susceptible ("healer") strains, such as the $\mathrm{T}_{\mathrm{H}} 1$-biased $\mathrm{C} 57 \mathrm{Bl} / 6$ mice, do not express arginase in their macrophages at the onset of infection and are therefore able to resolve it (139). Interestingly, when a healer strain is treated with a daily dose of ornithine or putrescine during Leishmania infection, the lesion size increased, lending further support to the conclusion that the pathogen uses host ornithine for growth $(140,141)$. In the first two cases, this leads to macrophage apoptosis thereby supporting the infection, whereas in the latter case, the accelerated growth of the pathogen is supported through host polyamines. ODC inhibitors such as DMFO are already successfully used against Trypanosoma infections and other ODC inhibitors seem promising in treating Leishmaniasis (142).

In conclusion, macrophage arginase 1 can support increased polyamine synthesis in disease or infection if ODC levels are also upregulated, but this results in either host-cell apoptosis or increased pathogen growth rather than host tissue proliferation. There is evidence that fibroblast or smooth-muscle arginase 1, on the other hand, does support host cell proliferation $(122,143)$ and tissue remodeling and that this may become excessive when not controlled by macrophage arginase 1 .

\section{Arginase and Cancer}

Tumor-associated macrophages (TAMs) or myeloid-derived suppressor cells (MDSCs)

Increased expression of arginase 1 in MDSCs (93) (for a recent review see (144)) has been demonstrated in mouse models (145-147) and human MDSCs isolated from melanoma, small cell lung cancer and renal carcinoma patients $(97,148,149)$. The effect of arginase expression, however, can either be immunosuppressive and thus tumorpromoting, or tumor-inhibiting, depending on tumor properties and arginase concentration.

Arginase 1 expression can result in local arginine depletion, which negatively affects Tcell proliferation and activation (see Arginase as a controller of arginine availability), and thereby promotes tumor growth through immunosuppression, or cancer cells themselves and thereby inhibits tumor growth. Cancer cell lines that are sensitive to arginine deprivation lack argininosuccinate synthetase (ASS), the enzyme that catalyzes the rate-limiting step in arginine synthesis from citrulline (150). Immunohistological characterization of tumors is, therefore, necessary to identify tumors that may be targeted by arginine deprivation $(151,152)$. Interestingly, reduced ASS expression in osteosarcoma is associated with a higher risk of pulmonary metastasis after surgery (153). 
Arginase expression in MDSC is, therefore, presumable only beneficial for the host when the tumor in question is susceptible to arginine deprivation, a hypothesis that can be tested in murine tumor models with arginase 1-deficient MDSC. On the other hand, increased tumorigenesis has been associated with disturbed polyamine metabolism due to elevated ODC levels and concomitantly increased polyamine concentrations $(112,117)$, but also with increased expression of the polyamine-degrading enzyme spermidine/spermine N1-acetyltransferase (SSAT) (154). Both observations together have led to the often cited hypothesis that arginase 1-derived ornithine serves as a precursor for polyamines, which, in turn, are essential for rapidly growing tumor cells. Inhibition of arginase by N-hydroxy-L-arginine (NOHA) in susceptible tumor cells reduced spermine content and subsequently caused apoptosis (155). The same authors demonstrated later, however, that apoptosis was not a consequence of polyamine depletion but an effect of NOHA that was independent of polyamine depletion (156).

Attempts to modulate polyamine concentrations often result in increased polyamine flux due to compensatory overexpression of polyamine-catabolizing enzymes $(157,158)$. Accelerated flux leads to the depletion of acetyl-CoA and ATP and the generation of harmful compounds such as $\mathrm{H}_{2} \mathrm{O}_{2}$ that may lead to tissue damage and inflammation, and subsequently to tumor formation. Whether arginase-dependent production of ornithine is relevant for the increased polyamine metabolism in tumors has not been demonstrated to our knowledge.

\section{Therapeutic arginine deprivation}

New therapeutic approaches make use of the sensitivity of certain tumors to arginine deprivation by treating patients with PEGylated arginine deiminase (L-arginine iminohydrolase), a stabilized form of the enzyme that rapidly reduces plasma arginine concentrations by hydrolyzing arginine to citrulline. The therapy was well tolerated in patients with unresectable hepatocellular carcinoma, even when plasma arginine levels were below the detection limit for 3 months (159). Another approach is the combination of arginine deprivation followed by canavanine treatment (160), an arginine analogue that is incorporated into proteins and causes misfolding. Cancer cells in vitro were more susceptible than healthy cells.

\section{Effects of arginine availability on TH1 and $T_{H} 2$ responses}

\section{Schistosomiasis}

Schistosomiasis is a chronic helminthic infection that causes a $\mathrm{T}_{\mathrm{H}} 2$-type inflammation in response to the eggs deposited in the intestines and liver, and results in hepatic fibrosis and portal hypertension. $\mathrm{T}_{\mathrm{H}} 2$-type cytokines, such as IL4 and IL13, induce alternative activation of macrophages, including arginase 1 expression. 
As mentioned above, arginase 1 ablation in hematopoietic cells aggravates schistosoma pathology (92) and comparable results were found for Mesocestoides corti infections in IL4-deficient mice, where arginase expression in macrophages is diminished (161). The decreased TGF $\beta$ and increased IL12/IL23p40 production of peritoneal exudate cells in mice with arginase 1-deficient macrophages appear to account for the observed excessive pathology, as blocking IL12/IL23p40 production ameliorated the diseaseassociated pathology considerably and improved survival (162). Collectively, the data therefore support the hypothesis that the immunoregulatory function, i.e. suppression of $\mathrm{T}_{\mathrm{H}} 17$ and $\mathrm{T}_{\mathrm{H}} 1$ responses, is the main function of arginase 1 in macrophages.

Interestingly, a greatly enhanced fibrosis in lung and liver, portal hypertension, increased granuloma size, a significant increase in mast cells and eosinophils, and an unchanged schistosoma burden were found in $\mathrm{Cat}^{-/-}$mice (58). Despite the increased pathological response, inflammatory cytokine production of both $\mathrm{T}_{\mathrm{H}} 1$ cytokines (IFN $\gamma$ ) and $\mathrm{T}_{\mathrm{H}} 2$ cytokines (IL4, IL13) was reduced in these mice. Since both macrophages and granuloma-derived fibroblasts of $\mathrm{Cat}^{-/-}$mice show elevated arginase activity, the authors attribute the reduced T-cell proliferation to local arginine deprivation and suggest that CAT2 both supports NO production and suppresses arginase activity. One possible mechanism that might explain this observation is the reduced production of $N^{\omega}$ hydroxy-nor-L-arginine (nor-NOHA) in $\mathrm{Cat}^{-/-}$deficient mice. Macrophages that can no longer sustain high NO production by NOS-2 also produce less nor-NOHA, an efficient suppressor of arginase activity. In any case, the data on arginase 1- and CAT2Bdeficient mice strongly support the notion that arginase 1 overexpression inhibits T-cell proliferation and does not provide substrates for proline and polyamines production.

\section{Asthma}

A pronounced increase of arginase 1 expression in asthma has been demonstrated in both mice (163) and men (57), and a link with disease severity has been suggested. The precise location of the expressed arginase has however not yet been demonstrated convincingly. Weak arginase 1 protein expression was shown in bronchiolar-epithelium of healthy rats (164) and mock-immunized BALB/c mice. In OVA-sensitized and challenged mice a modest increase of this expression was observed (163). In our murine model and in another study with experimental asthma in mice (57), however, arginase 1staining by immunohistochemical techniques was only detected in macrophages of asthmatic animals and never in their bronchial epithelium. Animals, which were not sensitized to OVA, did not show any arginase 1-positive macrophages in their lungs as tested by immunohistochemistry on lung tissue or Western blotting of lung protein extracts (165). Ablation of Argl in macrophages (Argl flffl $/ \mathrm{Tie} 2 \mathrm{Cr} e^{\mathrm{tg} /-}$ ) led to an improvement of peripheral lung function in OVA -treated mice, without altering air hyperreactivity and lung inflammation (165).

In another series of experiments with arginine- rather than Arg1-deficient mice (manuscript in preparation: (166)), we found that circulating arginine concentrations primarily affected airway resistance in the larger airways. We, therefore, hypothesized 
that ablation of Arg1 in lung macrophages increases the parenchymal arginine concentration, which, in turn, facilitates NO production and smooth-muscle relaxation in the peripheral airways, but not the larger conducting airways.

\section{Conclusion}

Macrophage arginase 1 can in cooperation with cationic amino acid transporters control ambient arginine availability by efficiently depleting arginine locally. In infectious diseases, this suppresses not only proliferation of inflammatory T-cells, but also decreases collagen deposition by fibroblasts. The often cited causal link between arginase activity and increased collagen production does not seem to play a role in wound healing or infectious diseases characterized by excess fibrosis. The same holds true for the claim that increased arginase activity is sufficient for increased polyamine production in disease. Alternatively activated macrophages rather limit both processes by controlling local arginine concentrations.

\section{References}

1. Henson PM, Hume DA. Apoptotic cell removal in development and tissue homeostasis. Trends Immunol 2006;27:244-250.

2. Bianconi E, Piovesan A, Facchin F, Beraudi A, Casadei R, Frabetti F, Vitale L, Pelleri MC, Tassani S, Piva F, Perez-Amodio S, Strippoli P, Canaider S. An estimation of the number of cells in the human body. Annals of human biology 2013;40:463-471.

3. Gordon S. Alternative activation of macrophages. Nat Rev Immunol 2003;3:23-35.

4. Mantovani A, Sica A, Locati M. New vistas on macrophage differentiation and activation. Eur J Immunol 2007;37:14-16.

5. Mantovani A, Sica A, Sozzani S, Allavena P, Vecchi A, Locati M. The chemokine system in diverse forms of macrophage activation and polarization. Trends Immunol 2004;25:677-686.

6. Kambayashi T, Jacob CO, Strassmann G. IL-4 and IL-13 modulate IL-10 release in endotoxinstimulated murine peritoneal mononuclear phagocytes. Cell Immunol 1996;171:153-158.

7. Edwards JP, Zhang X, Frauwirth KA, Mosser DM. Biochemical and functional characterization of three activated macrophage populations. J Leukoc Biol 2006;80:1298-1307.

8. Mosser DM, Edwards JP. Exploring the full spectrum of macrophage activation. Nat Rev Immunol 2008;8:958-969.

9. Gordon S, Taylor PR. Monocyte and macrophage heterogeneity. Nat Rev Immunol 2005;5:953964.

10. Porcheray F, Viaud S, Rimaniol AC, Leone C, Samah B, Dereuddre-Bosquet N, Dormont D, Gras G. Macrophage activation switching: an asset for the resolution of inflammation. Clin Exp Immunol 2005;142:481-489.

11. Stout RD, Jiang C, Matta B, Tietzel I, Watkins SK, Suttles J. Macrophages sequentially change their functional phenotype in response to changes in microenvironmental influences. J Immunol 2005; 175:342-349.

12. Khallou-Laschet J, Varthaman A, Fornasa G, Compain C, Gaston AT, Clement M, Dussiot M, Levillain O, Graff-Dubois S, Nicoletti A, Caligiuri G. Macrophage plasticity in experimental atherosclerosis. PLoS One 2010;5:e8852.

13. Sica A, Larghi P, Mancino A, Rubino L, Porta C, Totaro MG, Rimoldi M, et al. Macrophage polarization in tumour progression. Semin Cancer Biol 2008;18:349-355. 


\section{Chapter I}

14. Biswas SK, Sica A, Lewis CE. Plasticity of macrophage function during tumor progression: regulation by distinct molecular mechanisms. J Immunol 2008;180:2011-2017.

15. Van den Bossche J, Lamers WH, Koehler ES, Geuns JM, Alhonen L, Uimari A, Pirnes-Karhu S, Van Overmeire E, Morias Y. Brys L, Vereecke L, De Baetselier P, Van Ginderachter JA. Pivotal Advance: Arginase-1-independent polyamine production stimulates the expression of IL-4induced alternatively activated macrophage markers while inhibiting LPS-induced expression of inflammatory genes. Journal of leukocyte biology 2012;91:685-699.

16. North ML, Grasemann H, Khanna N, Inman MD, Gauvreau GM, Scott JA. Increased ornithinederived polyamines cause airway hyperresponsiveness in a mouse model of asthma. American journal of respiratory cell and molecular biology 2013;48:694-702.

17. Pauleau AL, Rutschman R, Lang R, Pernis A, Watowich SS, Murray PJ. Enhancer-mediated control of macrophage-specific arginase I expression. J Immunol 2004;172:7565-7573.

18. El Kasmi KC, Qualls JE, Pesce JT, Smith AM, Thompson RW, Henao-Tamayo M, Basaraba RJ, Konig T, Schleicher U, Koo MS, Kaplan G, Fitzgerald KA, Tuomanen EI, Orme IM, Kanneganti TD, Bogdan C, Wynn TA, Murray PJ. Toll-like receptor-induced arginase 1 in macrophages thwarts effective immunity against intracellular pathogens. Nat Immunol 2008;9:1399-1406.

19. Daley JM, Brancato SK, Thomay AA, Reichner JS, Albina JE. The phenotype of murine wound macrophages. J Leukoc Biol 2010;87:59-67.

20. Van den Bossche J, Neele AE, Hoeksema MA, de Winther MP. Macrophage polarization: the epigenetic point of view. Current opinion in lipidology 2014;25:367-373.

21. Iwakura Y, Ishigame H, Saijo S, Nakae S. Functional specialization of interleukin-17 family members. Immunity 2011;34:149-162.

22. Murray PJ, Allen JE, Biswas SK, Fisher EA, Gilroy DW, Goerdt S, Gordon S, et al. Macrophage activation and polarization: nomenclature and experimental guidelines. Immunity 2014;41:14-20.

23. Sanchez-Munoz F, Dominguez-Lopez A, Yamamoto-Furusho JK. Role of cytokines in inflammatory bowel disease. World J Gastroenterol 2008;14:4280-4288.

24. Bain CC, Mowat AM. Macrophages in intestinal homeostasis and inflammation. Immunol Rev 2014;260:102-117.

25. Swirski FK, Libby P, Aikawa E, Alcaide P, Luscinskas FW, Weissleder R, Pittet MJ. Ly-6Chi monocytes dominate hypercholesterolemia-associated monocytosis and give rise to macrophages in atheromata. J Clin Invest 2007;117:195-205.

26. de Visser KE, Eichten A, Coussens LM. Paradoxical roles of the immune system during cancer development. Nat Rev Cancer 2006;6:24-37.

27. Kakuda DK, Finley KD, Maruyama M, MacLeod CL. Stress differentially induces cationic amino acid transporter gene expression. Biochim Biophys Acta 1998;1414:75-84.

28. Yeramian A, Martin L, Arpa L, Bertran J, Soler C, McLeod C, Modolell M, Palacin M, Lloberas J, Celada A. Macrophages require distinct arginine catabolism and transport systems for proliferation and for activation. Eur J Immunol 2006;36:1516-1526.

29. Pesce J, Kaviratne M, Ramalingam TR, Thompson RW, Urban JF, Jr., Cheever AW, Young DA, Collins M, Grusby MJ, Wynn TA. The IL-21 receptor augments Th2 effector function and alternative macrophage activation. J Clin Invest 2006;116:2044-2055.

30. Hazlett LD, McClellan SA, Barrett RP, Huang X, Zhang Y, Wu M, van Rooijen N, Szliter E. IL33 shifts macrophage polarization, promoting resistance against Pseudomonas aeruginosa keratitis. Invest Ophthalmol Vis Sci 2009.

31. Kurowska-Stolarska M, Stolarski B, Kewin P, Murphy G, Corrigan CJ, Ying S, Pitman N, et al. IL-33 amplifies the polarization of alternatively activated macrophages that contribute to airway inflammation. J Immunol 2009;183:6469-6477.

32. MacKinnon AC, Farnworth SL, Hodkinson PS, Henderson NC, Atkinson KM, Leffler H, Nilsson UJ, Haslett C, Forbes SJ, Sethi T. Regulation of alternative macrophage activation by galectin-3. J Immunol 2008;180:2650-2658.

33. Varedi M, Jeschke MG, Englander EW, Herndon DN, Barrow RE. Serum TGF-beta in thermally injured rats. Shock 2001;16:380-382. 
34. Ford HR, Hoffman RA, Wing EJ, Magee DM, McIntyre L, Simmons RL. Characterization of wound cytokines in the sponge matrix model. Arch Surg 1989;124:1422-1428.

35. Pulichino AM, Wang IM, Caron A, Mortimer J, Auger A, Boie Y, Elias JA, et al. Identification of transforming growth factor beta1-driven genetic programs of acute lung fibrosis. Am J Respir Cell Mol Biol 2008;39:324-336.

36. Daley JM, Reichner JS, Mahoney EJ, Manfield L, Henry WL, Jr., Mastrofrancesco B, Albina JE. Modulation of macrophage phenotype by soluble product(s) released from neutrophils. J Immunol 2005;174:2265-2272.

37. Campbell L, Saville CR, Murray PJ, Cruickshank SM, Hardman MJ. Local arginase 1 activity is required for cutaneous wound healing. The Journal of investigative dermatology 2013;133:24612470 .

38. Kreider T, Anthony RM, Urban JF, Jr., Gause WC. Alternatively activated macrophages in helminth infections. Curr Opin Immunol 2007;19:448-453.

39. Mabalirajan U, Aich J, Agrawal A, Ghosh B. Mepacrine inhibits subepithelial fibrosis by reducing the expression of arginase and TGF-betal in an extended subacute mouse model of allergic asthma. Am J Physiol Lung Cell Mol Physiol 2009;297:L411-419.

40. Kitowska K, Zakrzewicz D, Konigshoff M, Chrobak I, Grimminger F, Seeger W, Bulau P, Eickelberg O. Functional role and species-specific contribution of arginases in pulmonary fibrosis. Am J Physiol Lung Cell Mol Physiol 2008;294:L34-45.

41. De Simone R, Niturad CE, De Nuccio C, Ajmone-Cat MA, Visentin S, Minghetti L. TGF-beta and LPS modulate ADP-induced migration of microglial cells through P2Y1 and P2Y12 receptor expression. J Neurochem 2010;115:450-459.

42. Shearer JD, Richards JR, Mills CD, Caldwell MD. Differential regulation of macrophage arginine metabolism: a proposed role in wound healing. Am J Physiol 1997;272:E181-190.

43. Modolell M, Corraliza IM, Link F, Soler G, Eichmann K. Reciprocal regulation of the nitric oxide synthase/arginase balance in mouse bone marrow-derived macrophages by TH1 and TH2 cytokines. Eur J Immunol 1995;25:1101-1104.

44. Kryczek I, Wei S, Zou L, Zhu G, Mottram P, Xu H, Chen L, Zou W. Cutting edge: induction of B7-H4 on APCs through IL-10: novel suppressive mode for regulatory T cells. J Immunol 2006; 177:40-44.

45. Biswas SK, Gangi L, Paul S, Schioppa T, Saccani A, Sironi M, Bottazzi B, et al. A distinct and unique transcriptional program expressed by tumor-associated macrophages (defective NFkappaB and enhanced IRF-3/STAT1 activation). Blood 2006;107:2112-2122.

46. Schebesch C, Kodelja V, Muller C, Hakij N, Bisson S, Orfanos CE, Goerdt S. Alternatively activated macrophages actively inhibit proliferation of peripheral blood lymphocytes and CD4+ T cells in vitro. Immunology 1997;92:478-486.

47. Duluc D, Corvaisier M, Blanchard S, Catala L, Descamps P, Gamelin E, Ponsoda S, Deineste Y, Hebbar M, Jeannin P. Interferon-gamma reverses the immunosuppressive and protumoral properties and prevents the generation of human tumor-associated macrophages. Int J Cancer 2009; 125:367-373.

48. Kim J, Hematti P. Mesenchymal stem cell-educated macrophages: a novel type of alternatively activated macrophages. Exp Hematol 2009;37:1445-1453.

49. Verrey F, Closs EI, Wagner CA, Palacin M, Endou H, Kanai Y. CATs and HATs: the SLC7 family of amino acid transporters. Pflugers Arch 2004;447:532-542.

50. White MF, Christensen HN. The two-way flux of cationic amino acids across the plasma membrane of mammalian cells is largely explained by a single transport system. J Biol Chem 1982;257:10069-10080.

51. Rotoli BM, Closs EI, Barilli A, Visigalli R, Simon A, Habermeier A, Bianchi N, et al. Arginine transport in human erythroid cells: discrimination of CAT1 and 4F2hc/y+LAT2 roles. Pflugers Arch 2009;458:1163-1173.

52. MacLeod CL, Finley KD, Kakuda DK. y(+)-type cationic amino acid transport: expression and regulation of the mCAT genes. J Exp Biol 1994;196:109-121. 


\section{Chapter I}

53. Ito K, Groudine M. A new member of the cationic amino acid transporter family is preferentially expressed in adult mouse brain. J Biol Chem 1997;272:26780-26786.

54. Hatzoglou M, Fernandez J, Yaman I, Closs E. Regulation of cationic amino acid transport: the story of the CAT-1 transporter. Annu Rev Nutr 2004;24:377-399.

55. Graf P, Forstermann U, Closs EI. The transport activity of the human cationic amino acid transporter hCAT-1 is downregulated by activation of protein kinase $\mathrm{C}$. Br J Pharmacol 2001;132:1193-1200.

56. Nicholson B, Manner CK, Kleeman J, MacLeod CL. Sustained nitric oxide production in macrophages requires the arginine transporter CAT2. J Biol Chem 2001;276:15881-15885.

57. Zimmermann N, King NE, Laporte J, Yang M, Mishra A, Pope SM, Muntel EE, et al. Dissection of experimental asthma with DNA microarray analysis identifies arginase in asthma pathogenesis. J Clin Invest 2003;111:1863-1874.

58. Thompson RW, Pesce JT, Ramalingam T, Wilson MS, White S, Cheever AW, Ricklefs SM, et al. Cationic amino acid transporter-2 regulates immunity by modulating arginase activity. PLoS Pathog 2008;4:e1000023.

59. Bhattacharyya SN, Habermacher R, Martine U, Closs EI, Filipowicz W. Relief of microRNAmediated translational repression in human cells subjected to stress. Cell 2006;125:1111-1124.

60. Rotoli BM, Dall'asta V, Barilli A, D'Ippolito R, Tipa A, Olivieri D, Gazzola GC, Bussolati O. Alveolar macrophages from normal subjects lack the NOS-related system $\mathrm{y}^{+}$for arginine transport. Am J Respir Cell Mol Biol 2007;37:105-112.

61. Reade MC, Clark MF, Young JD, Boyd CA. Increased cationic amino acid flux through a newly expressed transporter in cells overproducing nitric oxide from patients with septic shock. Clin Sci (Lond) 2002;102:645-650.

62. McCord N, Ayuk P, McMahon M, Boyd RC, Sargent I, Redman C. System y+ arginine transport and NO production in peripheral blood mononuclear cells in pregnancy and preeclampsia. Hypertension 2006;47:109-115.

63. Rotoli BM, Bussolati O, Sala R, Barilli A, Talarico E, Gazzola GC, Dall'Asta V. INFgamma stimulates arginine transport through system $\mathrm{y}+\mathrm{L}$ in human monocytes. FEBS Lett 2004;571:177-181.

64. Reese TA, Liang HE, Tager AM, Luster AD, Van Rooijen N, Voehringer D, Locksley RM. Chitin induces accumulation in tissue of innate immune cells associated with allergy. Nature 2007;447:92-96.

65. Rutschman R, Lang R, Hesse M, Ihle JN, Wynn TA, Murray PJ. Cutting edge: Stat6-dependent substrate depletion regulates nitric oxide production. J Immunol 2001;166:2173-2177.

66. Hesse M, Modolell M, La Flamme AC, Schito M, Fuentes JM, Cheever AW, Pearce EJ, Wynn TA. Differential regulation of nitric oxide synthase- 2 and arginase- 1 by type $1 /$ type 2 cytokines in vivo: granulomatous pathology is shaped by the pattern of L-arginine metabolism. J Immunol 2001;167:6533-6544.

67. Lang R, Patel D, Morris JJ, Rutschman RL, Murray PJ. Shaping gene expression in activated and resting primary macrophages by IL-10. J Immunol 2002;169:2253-2263.

68. Martinez FO, Gordon S, Locati M, Mantovani A. Transcriptional profiling of the human monocyte-to-macrophage differentiation and polarization: new molecules and patterns of gene expression. J Immunol 2006; 177:7303-7311.

69. Munder M, Mollinedo F, Calafat J, Canchado J, Gil-Lamaignere C, Fuentes JM, Luckner C, et al. Arginase I is constitutively expressed in human granulocytes and participates in fungicidal activity. Blood 2005;105:2549-2556.

70. Raes G, Brys L, Dahal BK, Brandt J, Grooten J, Brombacher F, Vanham G, et al. Macrophage galactose-type C-type lectins as novel markers for alternatively activated macrophages elicited by parasitic infections and allergic airway inflammation. J Leukoc Biol 2005;77:321-327.

71. Raes G, Van den Bergh R, De Baetselier P, Ghassabeh GH, Scotton C, Locati M, Mantovani A, Sozzani S. Arginase-1 and Ym1 are markers for murine, but not human, alternatively activated myeloid cells. J Immunol 2005;174:6561; author reply 6561-6562. 
72. Scotton CJ, Martinez FO, Smelt MJ, Sironi M, Locati M, Mantovani A, Sozzani S. Transcriptional profiling reveals complex regulation of the monocyte IL-1 beta system by IL-13. J Immunol 2005; 174:834-845.

73. Babu S, Kumaraswami V, Nutman TB. Alternatively activated and immunoregulatory monocytes in human filarial infections. J Infect Dis 2009;199:1827-1837.

74. Benoit M, Barbarat B, Bernard A, Olive D, Mege JL. Coxiella burnetii, the agent of Q fever, stimulates an atypical M2 activation program in human macrophages. Eur J Immunol 2008;38:1065-1070.

75. Benoit M, Ghigo E, Capo C, Raoult D, Mege JL. The uptake of apoptotic cells drives Coxiella burnetii replication and macrophage polarization: a model for Q fever endocarditis. PLoS Pathog 2008;4:e1000066.

76. Meghari S, Bechah Y, Capo C, Lepidi H, Raoult D, Murray PJ, Mege JL. Persistent Coxiella burnetii infection in mice overexpressing IL-10: an efficient model for chronic Q fever pathogenesis. PLoS Pathog 2008;4:e23.

77. Mylonas KJ, Nair MG, Prieto-Lafuente L, Paape D, Allen JE. Alternatively activated macrophages elicited by helminth infection can be reprogrammed to enable microbial killing. J Immunol 2009;182:3084-3094.

78. Bourlier V, Zakaroff-Girard A, Miranville A, De Barros S, Maumus M, Sengenes C, Galitzky J, et al. Remodeling phenotype of human subcutaneous adipose tissue macrophages. Circulation 2008;117:806-815.

79. Munder M, Schneider H, Luckner C, Giese T, Langhans CD, Fuentes JM, Kropf P, et al. Suppression of T-cell functions by human granulocyte arginase. Blood 2006;108:1627-1634.

80. Jacobsen LC, Theilgaard-Monch K, Christensen EI, Borregaard N. Arginase 1 is expressed in myelocytes/metamyelocytes and localized in gelatinase granules of human neutrophils. Blood 2007;109:3084-3087.

81. Durante W, Liao L, Reyna SV, Peyton KJ, Schafer AI. Transforming growth factor-beta(1) stimulates L-arginine transport and metabolism in vascular smooth muscle cells: role in polyamine and collagen synthesis. Circulation 2001;103:1121-1127.

82. Warnken M, Haag S, Matthiesen S, Juergens UR, Racke K. Species differences in expression pattern of arginase isoenzymes and differential effects of arginase inhibition on collagen synthesis in human and rat pulmonary fibroblasts. Naunyn Schmiedebergs Arch Pharmacol 2010;381:297-304.

83. Witte MB, Barbul A, Schick MA, Vogt N, Becker HD. Upregulation of arginase expression in wound-derived fibroblasts. J Surg Res 2002;105:35-42.

84. Berkowitz DE, White R, Li D, Minhas KM, Cernetich A, Kim S, Burke S, et al. Arginase reciprocally regulates nitric oxide synthase activity and contributes to endothelial dysfunction in aging blood vessels. Circulation 2003;108:2000-2006.

85. White AR, Ryoo S, Li D, Champion HC, Steppan J, Wang D, Nyhan D, Shoukas AA, Hare JM, Berkowitz DE. Knockdown of arginase I restores NO signaling in the vasculature of old rats. Hypertension 2006;47:245-251.

86. Horowitz S, Binion DG, Nelson VM, Kanaa Y, Javadi P, Lazarova Z, Andrekopoulos C, Kalyanaraman, B, Otterson MF, Rafiee P. Increased arginase activity and endothelial dysfunction in human inflammatory bowel disease. Am J Physiol Gastrointest Liver Physiol 2007;292:G1323-1336.

87. Choi BS, Martinez-Falero IC, Corset C, Munder M, Modolell M, Muller I, Kropf P. Differential impact of L-arginine deprivation on the activation and effector functions of $\mathrm{T}$ cells and macrophages. J Leukoc Biol 2009;85:268-277.

88. Rodriguez PC, Quiceno DG, Zabaleta J, Ortiz B, Zea AH, Piazuelo MB, Delgado A, et al. Arginase I production in the tumor microenvironment by mature myeloid cells inhibits T-cell receptor expression and antigen-specific T-cell responses. Cancer Res 2004;64:5839-5849. 


\section{Chapter I}

89. Kropf P, Baud D, Marshall SE, Munder M, Mosley A, Fuentes JM, Bangham CR, et al. Arginase activity mediates reversible $\mathrm{T}$ cell hyporesponsiveness in human pregnancy. Eur $\mathrm{J}$ Immunol 2007;37:935-945.

90. Zea AH, Rodriguez PC, Culotta KS, Hernandez CP, DeSalvo J, Ochoa JB, Park HJ, Zabaleta J, Ochoa AC. L-Arginine modulates CD3zeta expression and $\mathrm{T}$ cell function in activated human $\mathrm{T}$ lymphocytes. Cell Immunol 2004;232:21-31.

91. Bronte V, Serafini P, De Santo C, Marigo I, Tosello V, Mazzoni A, Segal DM, et al. IL-4induced arginase 1 suppresses alloreactive $\mathrm{T}$ cells in tumor-bearing mice. $\mathrm{J}$ Immunol 2003; 170:270-278.

92. Pesce JT, Ramalingam TR, Mentink-Kane MM, Wilson MS, El Kasmi KC, Smith AM, Thompson RW, Cheever AW, Murray PJ, Wynn TA. Arginase-1-expressing macrophages suppress Th2 cytokine-driven inflammation and fibrosis. PLoS Pathog 2009;5:e1000371.

93. Gabrilovich DI, Bronte V, Chen SH, Colombo MP, Ochoa A, Ostrand-Rosenberg S, Schreiber H. The terminology issue for myeloid-derived suppressor cells. Cancer Res 2007;67:425; author reply 426.

94. Rodriguez PC, Zea AH, DeSalvo J, Culotta KS, Zabaleta J, Quiceno DG, Ochoa JB, Ochoa AC. L-arginine consumption by macrophages modulates the expression of CD3 zeta chain in $\mathrm{T}$ lymphocytes. J Immunol 2003;171:1232-1239.

95. Rodriguez PC, Quiceno DG, Ochoa AC. L-arginine availability regulates T-lymphocyte cellcycle progression. Blood 2007;109:1568-1573.

96. Closs EI, Simon A, Vekony N, Rotmann A. Plasma membrane transporters for arginine. J Nutr 2004;134:2752S-2759S; discussion 2765S-2767S.

97. Rodriguez PC, Ernstoff MS, Hernandez C, Atkins M, Zabaleta J, Sierra R, Ochoa AC. Arginase I-producing myeloid-derived suppressor cells in renal cell carcinoma are a subpopulation of activated granulocytes. Cancer Res 2009;69:1553-1560.

98. Durante W, Johnson FK, Johnson RA. Arginase: a critical regulator of nitric oxide synthesis and vascular function. Clin Exp Pharmacol Physiol 2007;34:906-911.

99. Hardie WD, Glasser SW, Hagood JS. Emerging concepts in the pathogenesis of lung fibrosis. Am J Pathol 2009; 175:3-16.

100. Wu G, Bazer FW, Davis TA, Kim SW, Li P, Marc Rhoads J, Carey Satterfield M, Ssmith SB, Spencer TE, Yin Y. Arginine metabolism and nutrition in growth, health and disease. Amino Acids 2009;37:153-168.

101. Maarsingh H, Pera T, Meurs H. Arginase and pulmonary diseases. Naunyn Schmiedebergs Arch Pharmacol 2008;378:171-184.

102. Wynn TA. Fibrotic disease and the T(H)1/T(H)2 paradigm. Nat Rev Immunol 2004;4:583-594.

103. de Jonge WJ, Hallemeesch MM, Kwikkers KL, Ruijter JM, de Gier-de Vries C, van Roon MA, Meijer AJ, et al. Overexpression of arginase I in enterocytes of transgenic mice elicits a selective arginine deficiency and affects skin, muscle, and lymphoid development. Am J Clin Nutr 2002;76:128-140.

104. de Jonge WJ, Kwikkers KL, te Velde AA, van Deventer SJ, Nolte MA, Mebius RE, Ruijter JM, Lamers MC, Lamers WH. Arginine deficiency affects early B cell maturation and lymphoid organ development in transgenic mice. J Clin Invest 2002;110:1539-1548.

105. Durante W, Liao L, Reyna SV, Peyton KJ, Schafer AI. Physiological cyclic stretch directs Larginine transport and metabolism to collagen synthesis in vascular smooth muscle. Faseb J 2000; $14: 1775-1783$.

106. Albina JE, Abate JA, Mastrofrancesco B. Role of ornithine as a proline precursor in healing wounds. J Surg Res 1993;55:97-102.

107. Barbul A. Proline precursors to sustain Mammalian collagen synthesis. J Nutr 2008;138:2021S2024S.

108. Shi HP, Efron DT, Most D, Tantry US, Barbul A. Supplemental dietary arginine enhances wound healing in normal but not inducible nitric oxide synthase knockout mice. Surgery 2000;128:374378. 
109. Shi HP, Fishel RS, Efron DT, Williams JZ, Fishel MH, Barbul A. Effect of supplemental ornithine on wound healing. J Surg Res 2002;106:299-302.

110. Herbert DR, Holscher C, Mohrs M, Arendse B, Schwegmann A, Radwanska M, Leeto M, et al. Alternative macrophage activation is essential for survival during schistosomiasis and downmodulates T helper 1 responses and immunopathology. Immunity 2004;20:623-635.

111. Wynn TA, Barron L. Macrophages: master regulators of inflammation and fibrosis. Semin Liver Dis 2010;30:245-257.

112. Wei G, Hobbs CA, Defeo K, Hayes CS, Gilmour SK. Polyamine-mediated regulation of protein acetylation in murine skin and tumors. Mol Carcinog 2007;46:611-617.

113. Childs AC, Mehta DJ, Gerner EW. Polyamine-dependent gene expression. Cell Mol Life Sci 2003;60:1394-1406.

114. Casero RA, Jr., Marton LJ. Targeting polyamine metabolism and function in cancer and other hyperproliferative diseases. Nat Rev Drug Discov 2007;6:373-390.

115. Janne J, Alhonen L, Pietila M, Keinanen TA, Uimari A, Hyvonen MT, Pirinen E, Jarvinen A. Genetic manipulation of polyamine catabolism in rodents. J Biochem 2006;139:155-160.

116. Rasanen TL, Alhonen L, Sinervirta R, Keinanen T, Herzig KH, Suppola S, Khomutov AR, Vepsalainen J, Janne J. A polyamine analogue prevents acute pancreatitis and restores early liver regeneration in transgenic rats with activated polyamine catabolism. J Biol Chem 2002;277:39867-39872.

117. Shantz LM, Levin VA. Regulation of ornithine decarboxylase during oncogenic transformation: mechanisms and therapeutic potential. Amino Acids 2007;33:213-223.

118. Pegg AE. Regulation of ornithine decarboxylase. J Biol Chem 2006;281:14529-14532.

119. Pegg AE. Spermidine/spermine-N(1)-acetyltransferase: a key metabolic regulator. Am J Physiol Endocrinol Metab 2008;294:E995-1010.

120. Sastre M, Galea E, Feinstein D, Reis DJ, Regunathan S. Metabolism of agmatine in macrophages: modulation by lipopolysaccharide and inhibitory cytokines. The Biochemical journal 1998;330 ( Pt 3):1405-1409.

121. Morris SM, Jr. Vertebrate agmatinases: what role do they play in agmatine catabolism? Annals of the New York Academy of Sciences 2003;1009:30-33.

122. Wei LH, Wu G, Morris SM, Jr., Ignarro LJ. Elevated arginase I expression in rat aortic smooth muscle cells increases cell proliferation. Proc Natl Acad Sci U S A 2001;98:9260-9264.

123. Morris SM, Jr. Arginine metabolism: boundaries of our knowledge. J Nutr 2007;137:1602S1609S.

124. Gilmour SK. Polyamines and nonmelanoma skin cancer. Toxicol Appl Pharmacol 2007;224:249256.

125. Abe F, Dafferner AJ, Donkor M, Westphal SN, Scholar EM, Solheim JC, Singh RK, Hoke TA, Talmadge JE. Myeloid-derived suppressor cells in mammary tumor progression in FVB Neu transgenic mice. Cancer Immunol Immunother 2010;59:47-62.

126. Debats IB, Wolfs TG, Gotoh T, Cleutjens JP, Peutz-Kootstra CJ, van der Hulst RR. Role of arginine in superficial wound healing in man. Nitric Oxide 2009;21:175-183.

127. Albina JE, Mahoney EJ, Daley JM, Wesche DE, Morris SM, Jr., Reichner JS. Macrophage arginase regulation by CCAAT/enhancer-binding protein beta. Shock 2005;23:168-172.

128. Peranzoni E, Marigo I, Dolcetti L, Ugel S, Sonda N, Taschin E, Mantelli B, Bronte V, Zanovello P. Role of arginine metabolism in immunity and immunopathology. Immunobiology 2007;212:795-812.

129. Manteuffel-Cymborowska M, Chmurzynska W, Peska M, Grzelakowska-Sztabert B. Arginine and ornithine metabolizing enzymes in testosterone-induced hypertrophic mouse kidney. Int $\mathrm{J}$ Biochem Cell Biol 1995;27:287-295.

130. Bergeron C, Boulet LP, Page N, Laviolette M, Zimmermann N, Rothenberg ME, Hamid Q. Influence of cigarette smoke on the arginine pathway in asthmatic airways: increased expression of arginase I. J Allergy Clin Immunol 2007;119:391-397. 


\section{Chapter I}

131. Deignan JL, Livesay JC, Shantz LM, Pegg AE, O'Brien WE, Iyer RK, Cederbaum SD, Grody WW. Polyamine homeostasis in arginase knockout mice. Am J Physiol Cell Physiol 2007;293:C1296-1301.

132. Jell J, Merali S, Hensen ML, Mazurchuk R, Spernyak JA, Diegelman P, Kisiel ND, et al. Genetically altered expression of spermidine/spermine N1-acetyltransferase affects fat metabolism in mice via acetyl-CoA. J Biol Chem 2007;282:8404-8413.

133. Luiking YC, Hallemeesch MM, van de Poll MC, Dejong CH, de Jonge WJ, Lamers WH, Deutz NE. Reduced citrulline availability by OTC deficiency in mice is related to reduced nitric oxide production. Am J Physiol Endocrinol Metab. 2008;295: E1315-1322.

134. Marion V, Sankaranarayanan S, de Theije C, van Dijk P, Lindsey P, Lamers MC, Harding HP, et al. Arginine deficiency causes runting in the suckling period by selectively activating the stress kinase GCN2. J Biol Chem 2011;286:8866-8874.

135. Rhee HJ, Kim EJ, Lee JK. Physiological polyamines: simple primordial stress molecules. J Cell Mol Med 2007;11:685-703.

136. Kepka-Lenhart D, Mistry SK, Wu G, Morris SM, Jr. Arginase I: a limiting factor for nitric oxide and polyamine synthesis by activated macrophages? Am J Physiol Regul Integr Comp Physiol 2000;279:R2237-2242.

137. Liao CP, Lasbury ME, Wang SH, Zhang C, Durant PJ, Murakami Y, Matsufuji S, et al. Pneumocystis mediates overexpression of antizyme inhibitor resulting in increased polyamine levels and apoptosis in alveolar macrophages. J Biol Chem 2009;284:8174-8184.

138. Locksley RM, Heinzel FP, Sadick MD, Holaday BJ, Gardner KD, Jr. Murine cutaneous leishmaniasis: susceptibility correlates with differential expansion of helper T-cell subsets. Ann Inst Pasteur Immunol 1987;138:744-749.

139. Kropf P, Fuentes JM, Fahnrich E, Arpa L, Herath S, Weber V, Soler G, et al. Arginase and polyamine synthesis are key factors in the regulation of experimental leishmaniasis in vivo. Faseb J 2005;19:1000-1002.

140. Iniesta V, Carcelen J, Molano I, Peixoto PM, Redondo E, Parra P, Mangas M, et al. Arginase I induction during Leishmania major infection mediates the development of disease. Infect Immun 2005;73:6085-6090.

141. Iniesta V, Gomez-Nieto LC, Molano I, Mohedano A, Carcelen J, Miron C, Alonso C, et al. Arginase I induction in macrophages, triggered by Th2-type cytokines, supports the growth of intracellular Leishmania parasites. Parasite Immunol 2002;24:113-118.

142. Heby O, Persson L, Rentala M. Targeting the polyamine biosynthetic enzymes: a promising approach to therapy of African sleeping sickness, Chagas' disease, and leishmaniasis. Amino Acids 2007;33:359-366.

143. Peyton KJ, Ensenat D, Azam MA, Keswani AN, Kannan S, Liu XM, Wang H, et al. Arginase promotes neointima formation in rat injured carotid arteries. Arterioscler Thromb Vasc Biol 2009;29:488-494.

144. Ostrand-Rosenberg S, Sinha P. Myeloid-derived suppressor cells: linking inflammation and cancer. J Immunol 2009;182:4499-4506.

145. Corzo CA, Condamine T, Lu L, Cotter MJ, Youn JI, Cheng P, Cho HI, et al. HIF-1alpha regulates function and differentiation of myeloid-derived suppressor cells in the tumor microenvironment. J Exp Med 2010;207:2439-2453.

146. Lechner MG, Liebertz DJ, Epstein AL. Characterization of cytokine-induced myeloid-derived suppressor cells from normal human peripheral blood mononuclear cells. J Immunol 2010;185:2273-2284.

147. Zhao F, Obermann S, von Wasielewski R, Haile L, Manns MP, Korangy F, Greten TF. Increase in frequency of myeloid-derived suppressor cells in mice with spontaneous pancreatic carcinoma. Immunology 2009;128:141-149.

148. Liu CY, Wang YM, L. WC, Feng PH, Ko HW, Liu YH, Wu YC, et al. Population alterations of L-arginase- and inducible nitric oxide synthase-expressed CD11b+/CD14¡/CD15+/CD33+ 
myeloid-derived suppressor cells and CD8+ T lymphocytes in patients with advanced-stage nonsmall cell lung cancer. J Cancer Res Clin Oncol 2010:35-45.

149. Poschke I, Mougiakakos D, Hansson J, Masucci GV, Kiessling R. Immature immunosuppressive CD14+HLA-DR-/low cells in melanoma patients are Stat3hi and overexpress CD80, CD83, and DC-sign. Cancer Res 2010;70:4335-4345.

150. Shen LJ, Lin WC, Beloussow K, Shen WC. Resistance to the anti-proliferative activity of recombinant arginine deiminase in cell culture correlates with the endogenous enzyme, argininosuccinate synthetase. Cancer Lett 2003;191:165-170.

151. Dillon BJ, Prieto VG, Curley SA, Ensor CM, Holtsberg FW, Bomalaski JS, Clark MA. Incidence and distribution of argininosuccinate synthetase deficiency in human cancers: a method for identifying cancers sensitive to arginine deprivation. Cancer 2004;100:826-833.

152. Szlosarek PW, Klabatsa A, Pallaska A, Sheaff M, Smith P, Crook T, Grimshaw MJ, et al. In vivo loss of expression of argininosuccinate synthetase in malignant pleural mesothelioma is a biomarker for susceptibility to arginine depletion. Clin Cancer Res 2006;12:7126-7131.

153. Kobayashi E, Masuda M, Nakayama R, Ichikawa H, Satow R, Shitashige M, Honda K, et al. Reduced argininosuccinate synthetase is a predictive biomarker for the development of pulmonary metastasis in patients with osteosarcoma. Mol Cancer Ther 2010;9:535-544.

154. Tucker JM, Murphy JT, Kisiel N, Diegelman P, Barbour KW, Davis C, Medda M, et al. Potent modulation of intestinal tumorigenesis in Apcmin/+ mice by the polyamine catabolic enzyme spermidine/spermine N1-acetyltransferase. Cancer Res 2005;65:5390-5398.

155. Singh R, Pervin S, Karimi A, Cederbaum S, Chaudhuri G. Arginase activity in human breast cancer cell lines: N(omega)-hydroxy-L-arginine selectively inhibits cell proliferation and induces apoptosis in MDA-MB-468 cells. Cancer Res 2000;60:3305-3312.

156. Singh R, Pervin S, Wu G, Chaudhuri G. Activation of caspase-3 activity and apoptosis in MDAMB-468 cells by N(omega)-hydroxy-L-arginine, an inhibitor of arginase, is not solely dependent on reduction in intracellular polyamines. Carcinogenesis 2001;22:1863-1869.

157. Perez-Leal O, Barrero CA, Clarkson AB, Casero RA, Jr., Merali S. Polyamine-regulated translation of spermidine/spermine-N1-acetyltransferase. Molecular and cellular biology 2012;32:1453-1467.

158. Casero RA, Pegg AE. Polyamine catabolism and disease. Biochem J 2009;421:323-338.

159. Izzo F, Marra P, Beneduce G, Castello G, Vallone P, De Rosa V, Cremona F, et al. Pegylated arginine deiminase treatment of patients with unresectable hepatocellular carcinoma: results from phase I/II studies. J Clin Oncol 2004;22:1815-1822.

160. Vynnytska BO, Mayevska OM, Kurlishchuk YV, Bobak YP, Stasyk OV. Canavanine augments proapoptotic effects of arginine deprivation in cultured human cancer cells. Anticancer Drugs 2011;22:148-157.

161. O'Connell AE, Kerepesi LA, Vandergrift GL, Herbert DR, TJ VANW, Hooper DC, Pearce EJ, et al. IL-4(-/-) mice with lethal Mesocestoides corti infections--reduced Th2 cytokines and alternatively activated macrophages. Parasite Immunol 2009;31:741-749.

162. Herbert DR, Orekov T, Roloson A, Ilies M, Perkins C, O'Brien W, Cederbaum S, et al. Arginase I suppresses IL-12/IL-23p40-driven intestinal inflammation during acute schistosomiasis. J Immunol 2010;184:6438-6446.

163. Ckless K, Lampert A, Reiss J, Kasahara D, Poynter ME, Irvin CG, Lundblad LK, et al. Inhibition of arginase activity enhances inflammation in mice with allergic airway disease, in association with increases in protein S-nitrosylation and tyrosine nitration. J Immunol 2008;181:4255-4264.

164. Belik J, Shehnaz D, Pan J, Grasemann H. Developmental changes in arginase expression and activity in the lung. Am J Physiol Lung Cell Mol Physiol 2008;294:L498-504.

165. Cloots RH, Sankaranarayanan S, de Theije CC, Poynter ME, Terwindt E, van Dijk P, Hakvoort $\mathrm{TB}$, et al. Ablation of Arg1 in hematopoietic cells improves respiratory function of lung parenchyma, but not that of larger airways or inflammation in asthmatic mice. American journal of physiology. Lung cellular and molecular physiology 2013;305:L364-376. 


\section{Chapter I}

166. Cloots R, Poynter ME, Terwindt E, Lamers WH, Köhler SE. Hypo-argininemia exaggerates airway hyperresponsiveness in a mouse model of asthma. manuscript in preparation.

167. Saha S, Kashina A. Posttranslational arginylation as a global biological regulator. Developmental biology 2011;358:1-8.

168. Moretti M, Matheus FC, de Oliveira PA, Neis VB, Ben J, Walz R, Rodrigues AL, et al. Role of agmatine in neurodegenerative diseases and epilepsy. Frontiers in bioscience 2014;6:341-359. 
SYNOPSIS AND SCOPE OF THE THESIS 


\section{SYNOPSIS AND SCOPE OF THE THESIS}

L-arginine is a basic amino acid in physiological fluids. Arginine is a precursor for proteins, for creatine and for the signaling molecules agmatine and nitric oxide. Arginine is also a secretagogue for growth hormone, insulin, glucagon and prolactin. Its content is relatively high in seafood, watermelon juice; nuts, seeds, algae, meats, rice protein concentrate, and soy protein isolate $(1,2)$ but low in the milk of most mammals (including cows, humans, and pigs) $(3,4)$. In addition, preterm infants who represent $10-12 \%$ of newborns, exhibit arginine deficiency (5), resulting in hyperammonemia and multiorgan dysfunction (6). It has also been shown that arginine supplied in current diets is inadequate for maximal growth of milk-fed piglets (7) or maximal reproductive performance of swine (8). Thus, arginine nutrition remains a significant concern in both human and animal health. This thesis aims at characterizing the role of arginine in growth and chronic inflammatory diseases through manipulation of local or systemic arginine concentration using conditional knockout and other transgenic mouse models.

Macrophages are phagocytic cells involved in daily garbage clearance on the one hand and play an important role in innate and adaptive immunity on the other hand. Immunologically active macrophages are a heterogeneous cell population with two outer extremes, classified as M1 and M2 macrophages, or classically and alternatively activated macrophages (9), respectively. M1 macrophages (also described as inflammatory macrophages) use arginine for the generation of nitric oxide by inducible nitric oxide synthase (NOS2), whereas the immunosuppressive M2 macrophages deplete arginine through catabolism by arginases (ARG).

This raises the interesting question whether and to which extent arginine metabolism determines macrophage function. Arginine metabolism is not a simple marker for the activation status of macrophages, but also has a strong effect on the outcome of many diseases. The Chapter I of this thesis reviews the arginine metabolism of macrophage and its role in chronic diseases.

To further study the role of arginine - several knockout (KO) models were generated that allowed us to investigate arginine metabolism or to manipulate arginine availability. The models that were used affect arginine synthesis (conditional KO of arginine-synthetase, Ass), transport (conditional $\mathrm{KO}$ of cationic amino acid transporter 1, Cat1) or degradation (conditional $\mathrm{KO}$ of arginase 1, Arg1) or resulted in excessive arginine degradation (intestinal overexpression of rat arginase 1, F/A2). Chapter II of this thesis describes the chosen strategy for the generation of conditional knockout mice, and its advantages and limitations. The development of optimal screening and selection protocols for embryonic stem cells after transfection is described. We demonstrate that a PCR-based approach to amplify the homologous arms of a targeting construct is not very efficient due to the error rate of the heat-stable DNA polymerase. This chapter is a trouble-shooting guide for the generation of a conditional $\mathrm{KO}$ mouse.

To elucidate the role of arginase 1 in chronic diseases, a tissue-specific $\mathrm{KO}$ mouse of arginase 1 was created using Cre/loxP recombination. Argl $I^{\text {flfl }}$ mice were crossed with Tie2Cre or LysMCre 
mice to eliminate ARG1 expression from all hematopoietic and endothelial cells or from granulocytes and macrophages, respectively. Chapter III shows that ablation of Argl in hematopoietic and endothelial cells did not affect OVA sensitization and flow resistance but attenuated tissue elastance $(\mathrm{H})$ and tissue resistance $(\mathrm{G})$ in a murine model of asthma, indicating that Argl ablation mainly affected the lung parenchyma (10), but not the airways.

It is also possible that the main function of macrophages (and possibly other arginase-expressing cells) is the control of arginine availability. Interestingly, there is a limited period of perinatal intestinal arginine synthesis in rodents and pigs - which is later abolished by arginase expression. Mammalian milk contains too little arginine for normal growth, but its precursors proline and glutamine are abundant; but the small intestine of rodents and piglets produces arginine from proline during the suckling period. Parenterally fed, premature human neonates frequently suffer from hypoargininemia. These findings raised the question whether the human small intestine also expresses the enzymes that enable the synthesis of arginine from proline and/or glutamine. Chapter IV is a histological study which shows that the human intestine indeed has the capacity to synthesize arginine, and that this capacity is strongest in the first three years after birth. However, the function of the arginine thus produced is not clear (11).

It is believed that perinatal intestinal arginine synthesis compensates for insufficient arginine concentrations in maternal milk to ensure appropriate development. To test this hypothesis, we inactivated arginine synthesis in the gut by specifically inactivating ASS expression in the enterocytes of the small intestine. In contrast to mice overexpressing arginase 1 in the enterocytes (F/A2 mice), which showed severe retardation in general growth, reduced hair growth and impaired B cell maturation, mice deficient for ASS in their enterocytes showed no major phenotype. In Chapter $\mathbf{V}$ we characterized the mice with intestinal ASS deficiency. Absence of intestinal arginine biosynthesis in ASS deficient mice resulted in an increased production of citrulline by the gut and an increased hepatic absorption of arginine. Furthermore, arginine synthesis in the kidneys was increased (12). The question remained what might be the reason for the dramatic phenotype of F/A2 mice (clearly not the lack of intestinal arginine synthesis, but rather the excessive breakdown of not only intestinal arginine but also arginine from the diet) - in other words, what are the mechanisms underlying these dramatic effects of arginine deficiency?

The phenotype of F/A2 mice is reminiscent of the phenotype of IGF-1 deficient mice, which are also growth retarded. We hypothesized that the syndrome results from an interaction of the growth-hormone/IGF-1 axis and the amino acid-sensing GCN2 stress-kinase pathway. In Chapter VI we characterized this mouse model in vivo in combination with several in vitro cell culture models. We show that arginine deficiency inhibits the release of growth hormone from the pituitary gland and ubiquitously activates the stress kinase GCN2 leading to a general shutdown of protein synthesis. Our findings demonstrate the signaling properties of arginine on the growth hormone axis and on the protein synthesizing machinery (13). 
In the general discussion, we review known or claimed beneficial effects of arginine supplementation and analyze the available evidence from our own studies and those of others.

\section{References}

1. King DE, Mainous AG, 3rd, Geesey ME. Variation in L-arginine intake follow demographics and lifestyle factors that may impact cardiovascular disease risk. Nutr Res 2008;28:21-24.

2. Wu G, Collins JK, Perkins-Veazie P, Siddiq M, Dolan KD, Kelly KA, Heaps CL, Meininger CJda. Dietary supplementation with watermelon pomace juice enhances arginine availability and ameliorates the metabolic syndrome in Zucker diabetic fatty rats. J Nutr 2007;137:2680-2685.

3. Davis TA, Nguyen HV, Garcia-Bravo R, Fiorotto ML, Jackson EM, Lewis DS, Lee DR, Reeds PJ. Amino acid composition of human milk is not unique. J Nutr 1994;124:1126-1132.

4. Wu G, Knabe DA. Free and protein-bound amino acids in sow's colostrum and milk. J Nutr 1994;124:415424.

5. Becker RM, Wu G, Galanko JA, Chen W, Maynor AR, Bose CL, Rhoads JM. Reduced serum amino acid concentrations in infants with necrotizing enterocolitis. J Pediatr 2000;137:785-793.

6. Wu G, Jaeger LA, Bazer FW, Rhoads JM. Arginine deficiency in preterm infants: biochemical mechanisms and nutritional implications. J Nutr Biochem 2004;15:442-451.

7. Wu G, Knabe DA, Kim SW. Arginine nutrition in neonatal pigs. J Nutr 2004;134:2783S-2790S; discussion 2796S-2797S.

8. Mateo RD, Wu G, Bazer FW, Park JC, Shinzato I, Kim SW. Dietary L-arginine supplementation enhances the reproductive performance of gilts. J Nutr 2007;137:652-656.

9. Gordon S. Alternative activation of macrophages. Nat Rev Immunol 2003;3:23-35.

10. Cloots RH, Sankaranarayanan S, de Theije CC, Poynter ME, Terwindt E, van Dijk P, Hakvoort TB, Lamers WH, Köhler SE. Ablation of Arg1 in hematopoietic cells improves respiratory function of lung parenchyma, but not that of larger airways or inflammation in asthmatic mice. Am J Physiol Lung Cell Mol Physiol 2013;305:L364-376.

11. Köhler ES, Sankaranarayanan S, van Ginneken CJ, van Dijk P, Vermeulen JL, Ruijter JM, Lamers WH, Bruder E. The human neonatal small intestine has the potential for arginine synthesis; developmental changes in the expression of arginine-synthesizing and -catabolizing enzymes. BMC Dev Biol 2008;8:107.

12. Marion V, Sankaranarayanan S, de Theije C, van Dijk P, Hakvoort TB, Lamers WH, Köhler ES. Hepatic adaptation compensates inactivation of intestinal arginine biosynthesis in suckling mice. PLoS One 2013;8:e67021.

13. Marion V, Sankaranarayanan S, de Theije C, van Dijk P, Lindsey P, Lamers MC, Harding HP, Ron D, Lamers WH, Köhler SE. Arginine deficiency causes runting in the suckling period by selectively activating the stress kinase GCN2. J Biol Chem 2011;286:8866-8874. 


\section{CHAPTER II}

\section{EXPERIENCES WITH THE CONSTRUCTION OF CONDITIONAL KNOCKOUT MICE}

Selvakumari Sankaranarayanan*, Vincent Marion*, Chiel C. de Theije*, Wouter H. Lamers and S. Eleonore Köhler

Department of Anatomy \& Embryology and NUTRIM School for Nutrition, Toxicology and Metabolism, Maastricht University, The Netherlands

*: These autors contributed equally 
Chapter II

\section{CHAPTER II}

Introduction .............................................................................................................................45

The Targeting Plasmid .................................................................................................................45

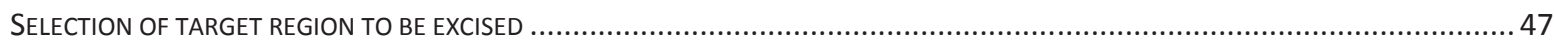

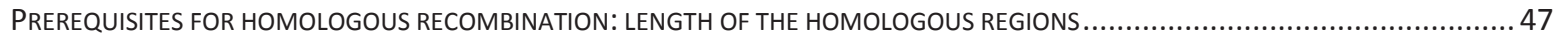

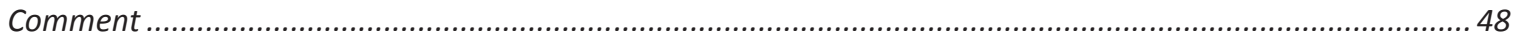

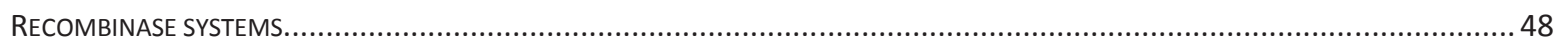

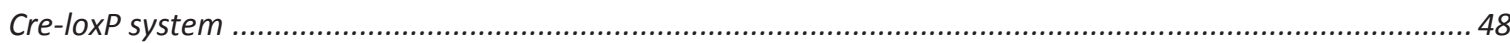

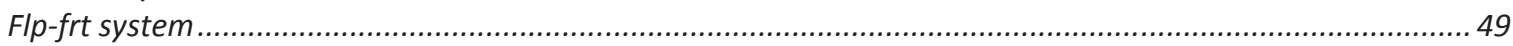

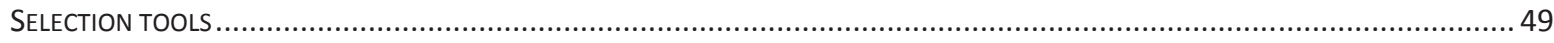

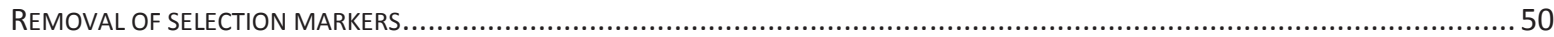

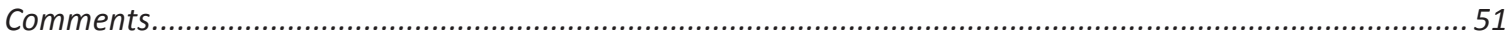

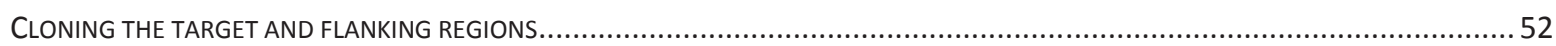

$P C R$

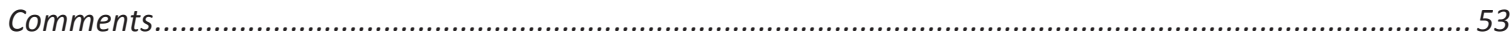

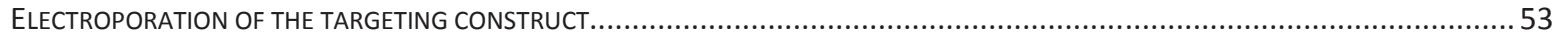

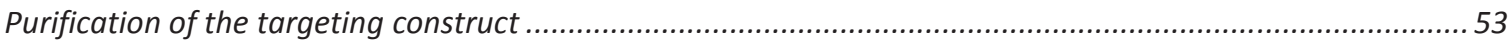

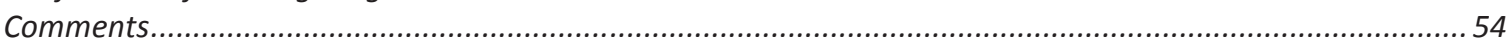

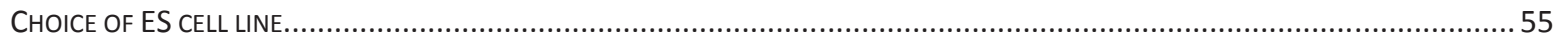

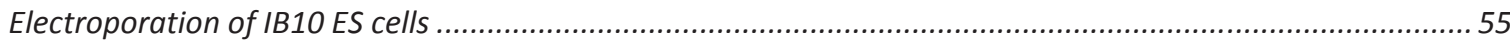

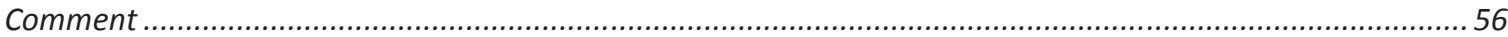

Screening for Homologously Recombined Clones ..................................................56

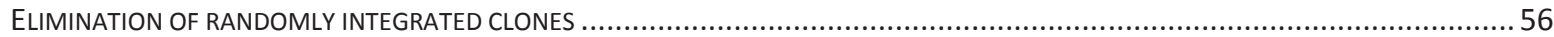

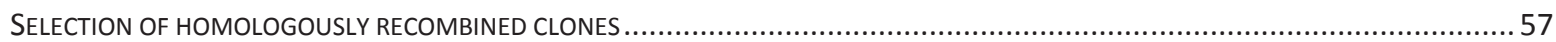

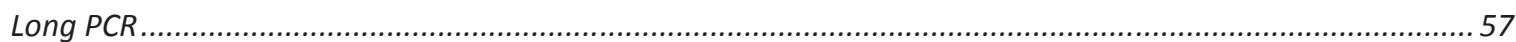

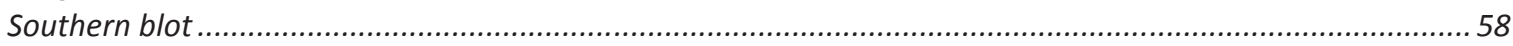

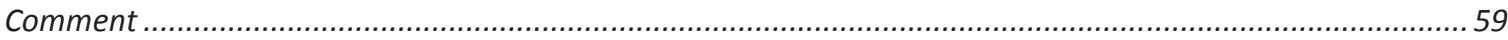

Removal of Selection Tools...........................................................................................59

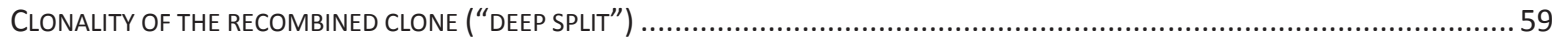

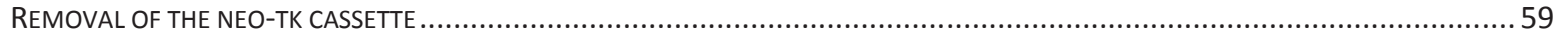

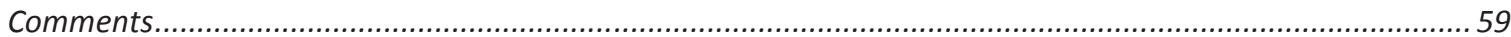

Injection of ES Cells into Blastocysts ..........................................................................61

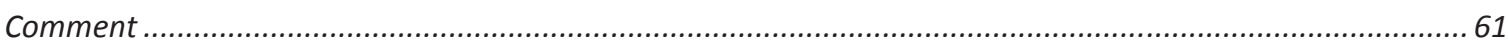

Breeding Schemes..................................................................................................................61

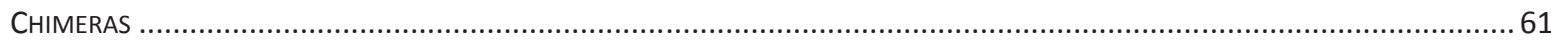

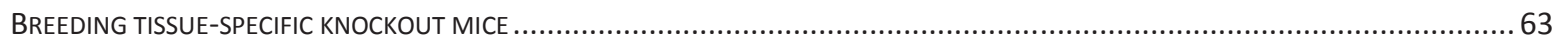

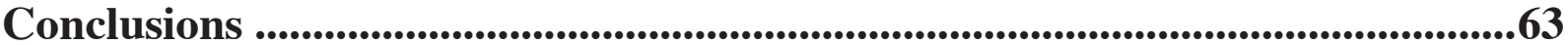

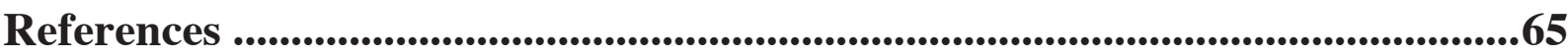




\section{Introduction}

The development of techniques that allow the modification of the DNA sequence of an allele of a gene in embryonic stem cells enables us, in combination with microinjection techniques, to deliberately modify the expression of genes in a living organism, usually the mouse. The deletion (knockout) or replacement (knock-in) of specific genes has proven to be a powerful tool. In this chapter, we comment on our experience with the generation of conditional knockout mice of the genes that code for argininosuccinate synthetase (Ass; VM), arginase 1 (Arg 1; SS) and cationic amino-acid transporter 1 (Cat1; CCdT).

Conventional knockout mice (deletion of a specific gene in every cell of the organism) are often not viable. This problem can be overcome by making "conditional" knockout mice that allow the deletion of a gene in a specific tissue or at a specific developmental stage. Deletion in specific tissues or at a specific time point can be achieved with just one genetic modification of the gene of interest, that is, the insertion of two recognition sites for an enzyme with recombinase activity. Mice harboring such a modified allele are crossed with mice expressing the recombinase under control of a promoter that determines the spatiotemporal expression of the recombinase and thereby the spatiotemporal deletion of the DNA fragment surrounded by the recombinase recognition sites. Two systems are most widely used and discussed in this chapter, viz, the cre/loxP system and the $f l p / f r t$ systems. LoxP and frt refer to the recombinase recognition sites, and CRE and FLP to the respective recombinases (1-4). There are now more than 100 cre mice available (see http://www.mshri.on.ca/nagy/), permitting deletion of genes in specific cell types (macrophages, B-cells, enterocytes, hepatocytes, endothelial cells to name a few) or at specific times using a recombinase that is modified to contain the ligand-binding domain of a member of the steroid-hormone receptor family. Most often, this ligand-binding domain is modified itself to respond only to a ligand that is not endogenously produced. In practice, the combination of a modification of the estrogen-receptor ligand-binding domain and the ligand tamoxifen is most often used.

The first step in the generation of a conditional knockout mouse is the design and construction of an appropriate vector that is then introduced into embryonic stem cells by transfection. This paper describes a PCR-based method for vector construction and specifies screening protocols for the embryonic stem cells after transfection. The approach is summarized in Figure 1.

\section{The Targeting Plasmid}

A targeting plasmid consists of two regions with target homology (hereafter called flanking regions; Figure 2), the region of the gene to be deleted, and genes that are used as selection tool. The flanking regions are placed at either end of the sequence to be deleted and are identical to the 


\section{Chapter II}

\section{I. design target plasmid \\ II. construction of target plasmid \\ III. transfection ES cells \\ IV. selection neo-resistant cells \\ V. selection homologous recombinants \\ VI. removal selection cassette \\ VII. blastocystinjection}

VIII. chimeric mice

IX. breeding knockout mice

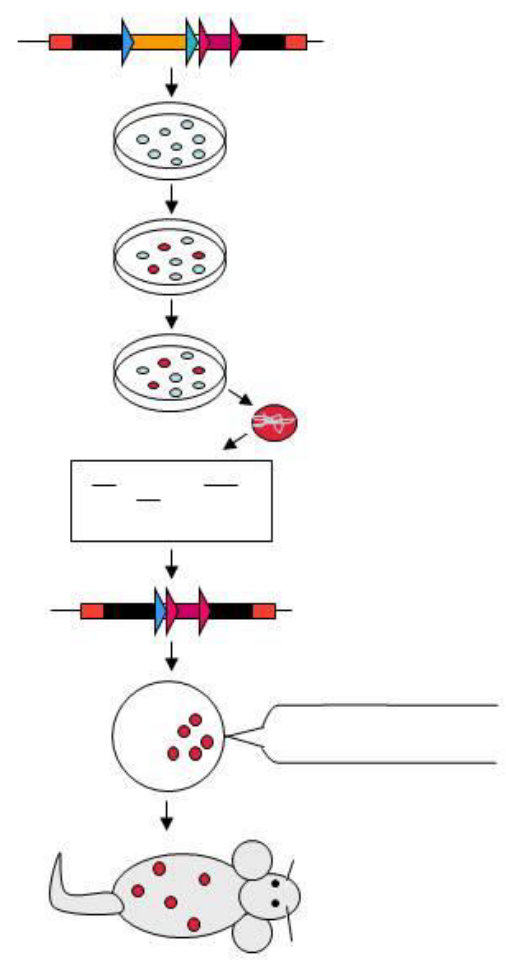

$\square$ target region $\quad$ frt \& loxP sites $\square$ neo-tk $\quad$ flanking regions $\quad \square$ vector sequences

Figure 1: Overview of the design and construction of the targeting plasmid, the selection and characterization of the targeted ES cells, and the procedure to modify the germline of mice.

sequences surrounding the target sequence. The flanking regions are required for homologous recombination, that is, for the site-specific insertion of the construct into genomic DNA. In our strategy, the exon(s) or gene to be deleted are flanked by loxP sites, whereas the selection tools (neomycin phosphotransferase ("neo") and viral thymidine kinase ("tk")) are surrounded by frt sites.

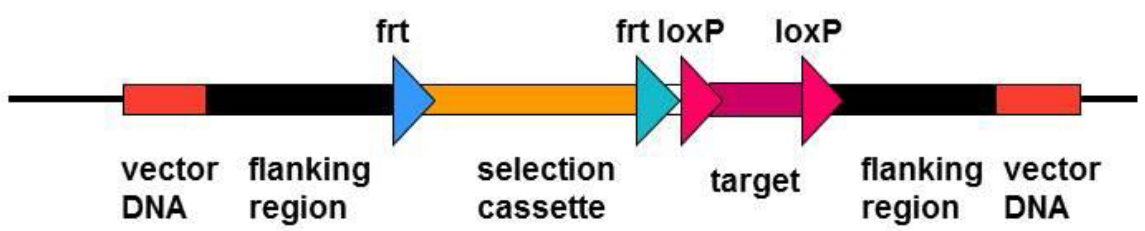

Figure 2: Structure of a targeting construct. The fragment to be deleted is surrounded by "loxP" sequences ("floxed"). Adjacent to the floxed sequence, a selection cassette is inserted, which itself is surrounded by "frt" sequences for later removal. The target sequence and the selection cassette are located in between the "flanking regions", which are identical to the sequences surrounding the part of the gene that is to be deleted. At both ends of the construct, fragments of the vector can be left behind to facilitate selection. See text for details. 
Vector construction has been greatly facilitated by the availability of the complete mouse genome (http://www.ncbi.nlm.nih.gov, http://www.onderzoekinformatie.nl) and additional information on SNPs and strain differences. This made it possible to use a PCR-based approach for vector construction, which also facilitates the introduction of additional restriction sites necessary for later cloning steps. The advantages and pitfalls of this approach will be discussed.

\section{Selection of target region to be excised}

One can delete one or more crucial exons or the entire coding sequence to inactivate the gene of interest. Deletion of one or a few exons is often preferable, since the efficiency of the CRE recombinase seems to be at least partially dependent on the distance between the loxP sites (5).

The region chosen for deletion should either code for domains that are important for the function of the gene product (eg. the active site of an enzyme) or should result in a frame shift with premature stop codons. One should nevertheless be aware of alternative splicing which could result in a partially functional gene product excision (e.g. (6)). Literature data on lethal mutations in man and mouse should be consulted, because they can be very valuable for the development of the knockout strategy. Examples are: natural mutants (in the case of the arginosuccinate synthetase gene, we selected exon 13 for deletion, because the deletion results in a frame shift and natural mutations in this exon led to undetectable levels of enzyme activity (7) or results known from conventional knockout mice (in the case of the arginase-1 gene, we selected exon 4 for deletion, because the conventional arginase I knockout mouse was made by deleting this exon and died between 10-14 days after birth (8)).

\section{Prerequisites for homologous recombination: length of the homologous regions}

Between 2 and $10 \mathrm{~kb}$, the relationship between the length of the homologous region and the frequency of targeting events is exponential and shows saturation at $14 \mathrm{~kb}$ of homology (9). Therefore, a minimum length of $2 \mathrm{~kb}$ is recommended for the flanking region to support optimal homologous recombination. However, $1.5 \mathrm{~kb}$ of homologous region at one end and $5 \mathrm{~kb}$ at the other end proved sufficient for efficient recombination of the Glutamine Synthetase gene (Y. HE, AMC Liver Center, Amsterdam). In our case, we used approximately $4.5 \mathrm{~kb}$ of homologous region on either side of the construct. Although this was thought to be advantageous for homologous recombination, long flanking regions as e.g. found in pROSA26 (10) make screening of clones by Southern or PCR more difficult. For this reason, many constructs contain a long and a short flanking region. 


\section{Chapter II}

\section{Comment}

An important parameter that is often neglected when selecting a target region for vector construction is the presence of repeats in the sequence to be amplified. Such repeats should be avoided since they are troublesome during amplification by PCR.

\section{Recombinase systems}

\section{Cre-loxP system}

The P1 bacteriophage cyclization recombination (cre) recombinase recognizes a pair of loxP sites flanking a DNA sequence. LoxP sites are $34 \mathrm{bp}$ long and composed of an $8 \mathrm{bp}$ core, which determines directionality, flanked by $13 \mathrm{bp}$ of palindromic sequence on either side (Figure 3A). The natural occurrence of this exact sequence is unlikely in any eukaryotic genome. Sequences flanked by loxP sites are said to be "floxed". The cre enzyme brings the two loxP sites into juxtaposition. If the loxP sites flank a DNA segment in a cis arrangement and are oriented in the same direction, CRE recombinase mediates excision and circularization of the flanked segment (Figure 3B). If the loxP sites flank the DNA segment in a cis arrangement and are oriented in opposite directions, CRE recombinase mediates the inversion of the segment (Figure 3C). If the loxP sites are located on different strands of the DNA and are oriented in the same direction, CRE recombinase can mediate translocation of the segment (not shown).

\section{A $\overrightarrow{\text { ATAACTTCGTATA }}$ CATACATTATACGAAGTTAT}

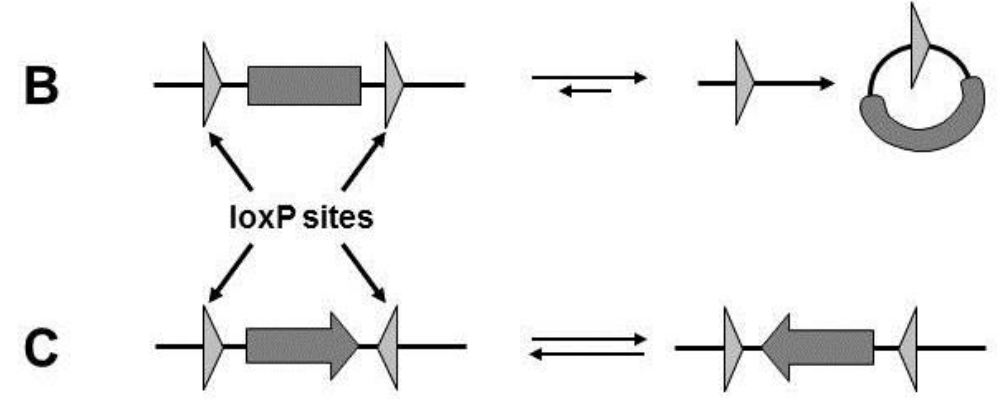

Figure 3: LoxP sites. Panel A: The nucleotide sequence of loxP sites. Note the inverted repeat surrounding the asymmetric core sequence. Due to their asymmetric core, the orientation and position of the loxP sites determines the outcome of the recombination event. In conditional knockout strategies, the aim is excision of the fragment which is achieved by placing 2 loxP sites on each side of the sequence of interest in the same orientation (B). With an opposite orientation of the loxP sites, an inversion of the floxed region is obtained in presence of CRE (C). 


\section{Flp-frt system}

The yeast flp recombinase $(4,11)$ recognizes target sites called frt $(12,13)$. A full-length frt site is $48 \mathrm{bps}$ long and, similar to a loxP site, consists of an asymmetric central 8bp spacer sequence, flanked by $13 \mathrm{bp}$ inverted repeats (Figure 4). However, in contrast to loxP sites, it contains a third $13 \mathrm{bp}$ direct repeat at one side (14). Because the Flp/frt system is derived from S. cerevisiae, its optimal working temperature is $25-30^{\circ} \mathrm{C}$. At $37^{\circ} \mathrm{C}$, the activity of the enzyme is dramatically reduced $(15,16)$, so that Flp is less suitable and less frequently used to engineer genome modifications in mammals. Attempts to overcome this limitation have led to the development of an "enhanced" mutant FLP (FLPe) by cycling mutagenesis. FLPe is said to have a better thermostability and activity $(16,17)$ and a more efficient function in mammalian cells $(16,18)$.

\section{$\overrightarrow{\text { GAAGTTCCTATTCCGAAGTTCCTATTCTCTAGAAAGTATAGGAACTTC }}$}

Figure 4: The nucleotide sequence of frt sites. Note inverted repeat surrounding asymmetric core sequence, which contains a convenient $\mathrm{XbaI}$ restriction site. Also note that the left-sided repeat needs to be present as 2 copies for higher efficiency.

\section{Selection tools}

A homologous recombination is a very rare event compared to random integration. Based on our experience, homologous recombination occurs in $\sim 50 \%$ (ROSA locus; M. Konings) to $0.05 \%$ of all integration events (arginase I locus). Selection is therefore necessary to identify the clones in which homologous recombination has occurred and to distinguish these clones from the clones in which the modified sequence is randomly integrated into the genomic DNA. To achieve this, a positive-negative selection protocol is commonly used (19). The positive selection tool is used to identify ES cells with the targeting sequence integrated into their DNA. Neomycin phosphotransferase (neo) is often used as a positive selection marker to select for ES clones in which the construct is integrated. Only clones that have integrated the construct will be able to grow in G418-containing medium as neomycin phosphotransferase will detoxify the compound.

The negative marker can be used to select for homologous recombination of the targeting construct (Figure 5A) or to select for successful removal of the positive selection marker in the ES cells prior to blastocyst injection (Figure 5B). As a tool to select for homologous recombination, the negative selection marker has to be placed at the outer end of one of the flanking regions, whereas the positive selection marker is placed in the middle of the construct. Positioning the negative selection marker at one extremity of the targeting construct (Figure 5A) will lead to elimination of this marker during homologous recombination. Addition of the selection compound to the medium will then kill all cells that still express the negative selection marker due to random integration, whereas clones with homologous recombination will not be affected. Viral thymidine kinase (tk) is a commonly used negative selection marker, as it confers 


\section{Chapter II}

sensitivity to ganciclovir in the ES cells. Phosphorylated ganciclovir is a toxic substance, so that cells can only grow if thymidine kinase is not or no longer present.

A

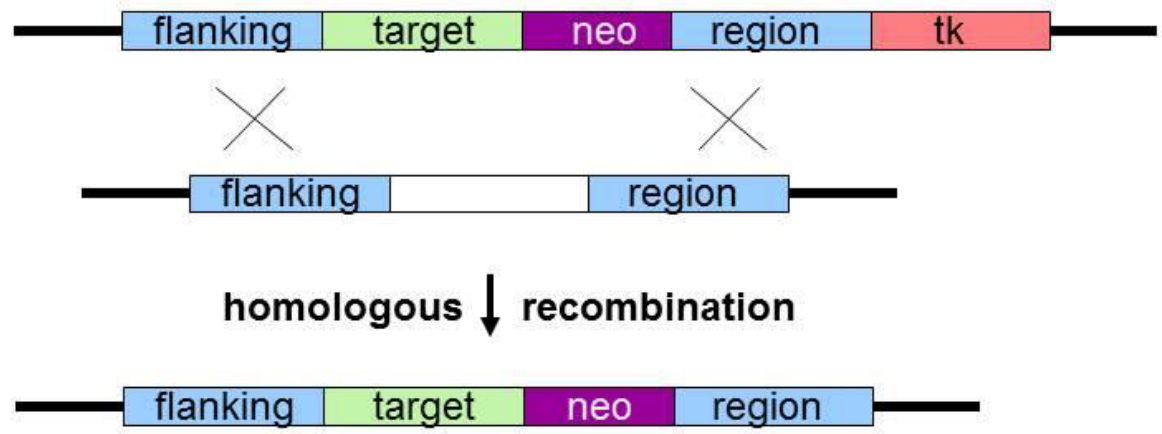

B

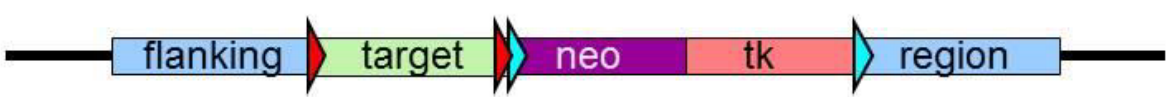

Figure 5: The two applications of a negative selection marker. In panel A, a negative selection marker is placed at either end of the construct to select against random integration. In panel B, the negative marker is placed in the middle of the construct and surrounded by recombinase recognition sites for removal after recombination.

\section{Removal of selection markers}

To select for successful removal of the positive selection marker, both positive and negative selection tools have to be present in between the two flanking regions (Figure 2). There are 2 strategies to remove the selection markers. One approach uses three loxP sites that surround the target sequence and the selection marker. In the other approach, the target sequence and the selection markers are surrounded by loxP and frt sites, respectively. After selection for the positive selection marker and identification of a correct clone by the appropriate screening protocols, the selection tools are removed by transient transfection with either a cre- or flpeexpressing plasmid, depending on whether the selection tools are surrounded by loxP (Figure 6) or frt sites (Figure 2). In vivo, loxP sites are preferable over frt sites as recognition sites for a recombinase, because CRE is a more efficient recombinase than FLP and because there are many more mouse strains harboring tissue-specific expression of cre than flp. Therefore, the gene fragment to be excised in vivo is usually surrounded by loxP sites.

Figure 6 shows the use of 3 loxP sites for gene targeting. Transient transfection of ES cells with a cre-expressing plasmid will ideally yield three products: cell clones, in which only the selection tool is deleted, cell clones in which only the target sequence is deleted, and cell clones with excision of both the selection tools and the target sequence. The first type of clones is the desired 
outcome, whereas the second and third type of clones will generate conventional knockouts. It is unfortunately not yet possible to predict if the desired type of clones can be obtained. We, therefore, chose for an approach in which the targeted gene fragment is placed between loxP sites and both positive and negative selection tools are present in the middle of the construct in between frt sites (Figure 2). This allowed us to first select for integration of our constructs into the genomic DNA and then to select for deletion of the positive-negative selection tool before the injection of ES cells into blastocysts.

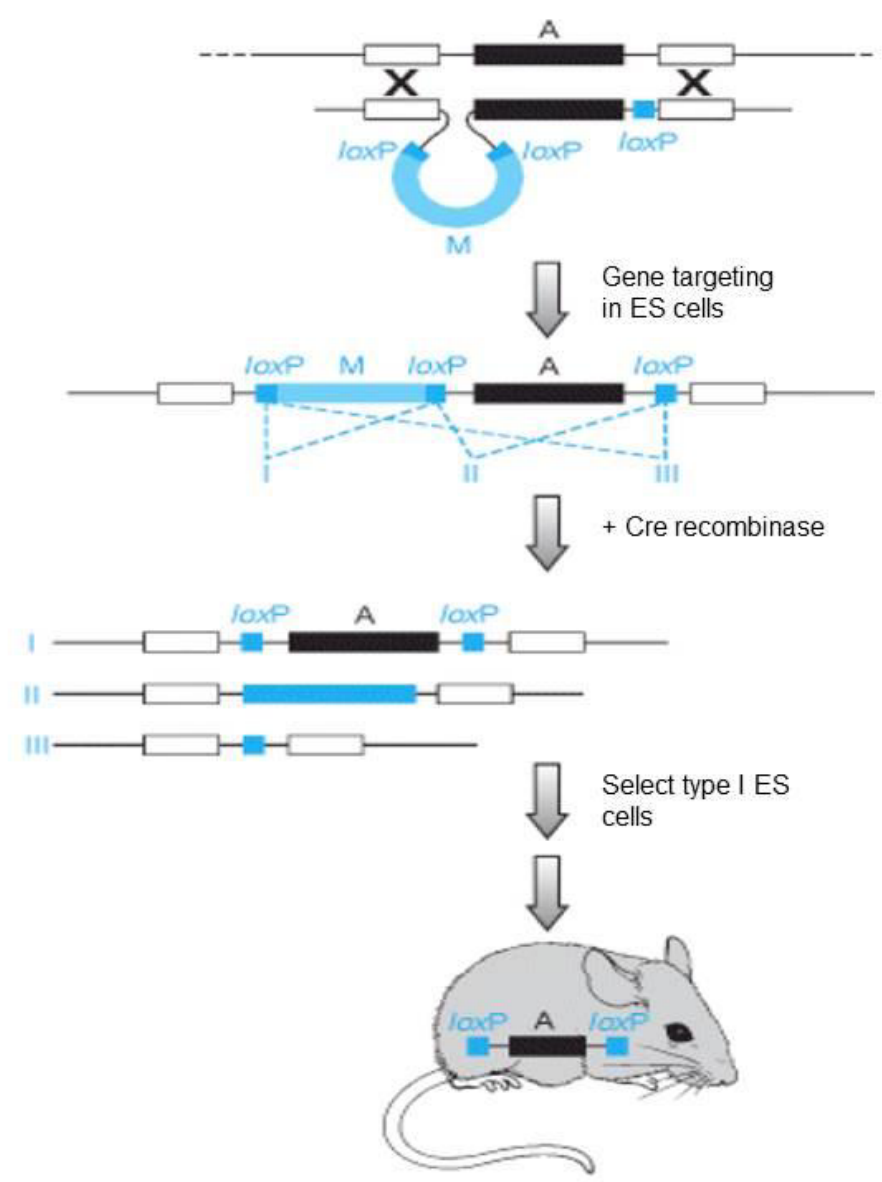

Figure 6: Gene targeting using loxP sites. Gene targeting using solely loxP sites can be used to inactivate a specific gene in a desired cell type. In the standard homolous recombination protocol, three loxP sites are introduced along with a selection tool "M" at the target locus "A". Subsequent transient transfection of a cre recombinase-expression plasmid or breeding a chimeric mouse with a deleter-Cre mouse results in recombination between the three loxP sites. In the desired Type I recombination, only the selection tool is removed. Both other recombinations generate convential unconditional knockouts.

\section{Comments}

1. An alternative to "select" against random integration by including a negative selection marker at the outer end of the targeting construct is the use of a high throughput screening protocol, e.g. a PCR-based screening for the presence of remaining vector sequence. This strategy will be discussed in section III A. 


\section{Chapter II}

2. Multiple copies of loxP can lead to chromosomal instability during expression of cre (20).

3. An alternative to plasmid transient transfection with cre or flp to remove the selection tools is to cross mice carrying the properly recombined targeting construct that still contains the selection marker with a mouse expressing cre or $f l p$ in early development, i.e., before the germline is set apart. An example of a cre-expressing mice is the II $2 \mathrm{a}-\mathrm{Cr}$ mouse (21), while the "flipper" mouse is an example of an often used flpe-expressing mouse (22). The availability of the efficient flipper mouse ( $\sim 50 \%$ frt excision (22) ) has made the use of a negative selection marker like thymidine kinase obsolete, because the positive selection marker can now be removed in vivo. The use of solely the neo selection tool and its removal in vivo has 3 additional advantages:

- one round of in vitro selection can be avoided (see section IV B), which decreases the chance that pluripotency of the ES cell is lost;

- crossing the mice with a flpe-deleter mouse on a pure background spares one round of breeding towards a new background;

- a targeted allele containing neo is available. Such alleles are often cripple (19, 23-26), allowing one to obtain not only animals with $0,50 \%$ and $100 \%$ gene expression of the gene of interest, but also animals with intermediate expression levels (0-50\% and 50$100 \%)$.

\section{Cloning the target and flanking regions}

\section{PCR}

Homologous recombination requires a $1.5 \mathrm{~kb}-5 \mathrm{~kb}$ stretch of DNA on either side of the construct that is identical to the sequence to the wild type DNA (27). The efficiency of homologous recombination depends on the degree of sequence similarity. When the construct is generated by PCR, the use of a high fidelity of the DNA polymerase for the amplification of the flanking regions from genomic DNA is therefore a prerequisite.

The different commercially available thermostable DNA polymerases show a $\sim 20$-fold difference in error rates $(28,29)$. The DNA polymerases from thermophilic bacteria (e.g. Thermus aquaticus) miss proof-reading 3'-5'- exonuclease activity and lack the ability to synthesize products larger than $5 \mathrm{~Kb}$. DNA polymerases from hyperthermophilic archaea (e.g. Thermococcus fumiculans ("Tfu") and litoralis ("Vent") and especially Pyrococcus furiosus ("Pfu") and abyssi) have low error rates, but the stronger the proofreading activity, the lower the product yield of long DNA fragments. Therefore, blends of the non-proofreading Taq and a proof-reading enzyme are often used: "LA" (long and accurate (30) ) PCR. According to the manufacturer, the Accutaq LA DNA Polymerase (Sigma), which we used for amplifying the homologous arms, has a 6.5 -fold greater fidelity than Taq polymerase. However, in 3 different targetings, we observed 27 differences with published sequences in $6.9 \mathrm{~kb}$ of DNA (0.4\%). Some of these differences may reflect strain differences (published sequences are often C57BL/6 or 
$\mathrm{BALB} / \mathrm{c}$, whereas the ES cell line came from 129P2/OlaHsd mice). In the case of arginase I construct, we found 5 mismatches in the exonic sequences, which did not lead to a change in amino-acid coding. We did not correct sequences, if they did not affect a consensus splice site or a coding sequence. However, when a coding sequence was affected (e.g. (GCG (Ala) to GTG (Val) in exon 6 of the arginase-1 gene), we did correct the mismatch.

Another problem of the PCR approach that we encountered was the presence of highly repetitive sequences in the region to be amplified. In the 5'-flanking region of the ASS targeting construct, for instance, a $36 \mathrm{bp}$ TA repeat was present in the middle of the $4.2 \mathrm{~kb}$ fragment. To amplify this sequence, we tried several high-fidelity Taq enzymes (Pfu "Ultra High" Fidelity and "Herculase" DNA Polymerases (Stratagene); AccuTaq Polymerase (Sigma)), but none of them was able to amplify the sequence. Eventually, we had to break up this flanking region into 4 fragments of approx. $1 \mathrm{~kb}$ each.

\section{Comments}

Our choice to amplify the flanking regions using genomic rather than plasmid- (BAC-) derived DNA was based on the limited availability of BAC clones when we designed our approach. However, since BAC-derived DNA is $\sim 30,000$-fold purified per weight unit for a particular 100 $\mathrm{kb}$ fragment relative to primary genomic DNA, the number of PCR cycles necessary to amplifly the DNA is reduced by $\sim 17$, which strongly reduces the fidelity issue.

\section{Electroporation of the targeting construct}

\section{Purification of the targeting construct}

Prior to electroporation in the ES cells, the construct is either linearized by restriction enzymes cutting in the vector backbone or digested with two restriction enzymes to remove the vector backbone. Complete removal of the backbone of the vector has the advantage of working with a "clean" construct without additional sequences that might interfere with homologous recombination in the cell. On the other hand, linearization avoids extra steps of purification of the targeting construct. Furthermore, the additional vector sequences can be used for a PCR screening strategy to eliminate clones with random integration quickly. This approach is described in section III.a (Elimination of randomly integrated clones).

There are several methods to purify large DNA fragments by electrophoresis (purification with commercial kits, electrophoresis in low melting point agarose followed by acid-phenol extraction or electro-elution). We used electroelution, using a bridging system to concentrate the DNA on a dialysis membrane (Figure 7A). The purified DNA was then precipitated in ethanol for electroporation. 


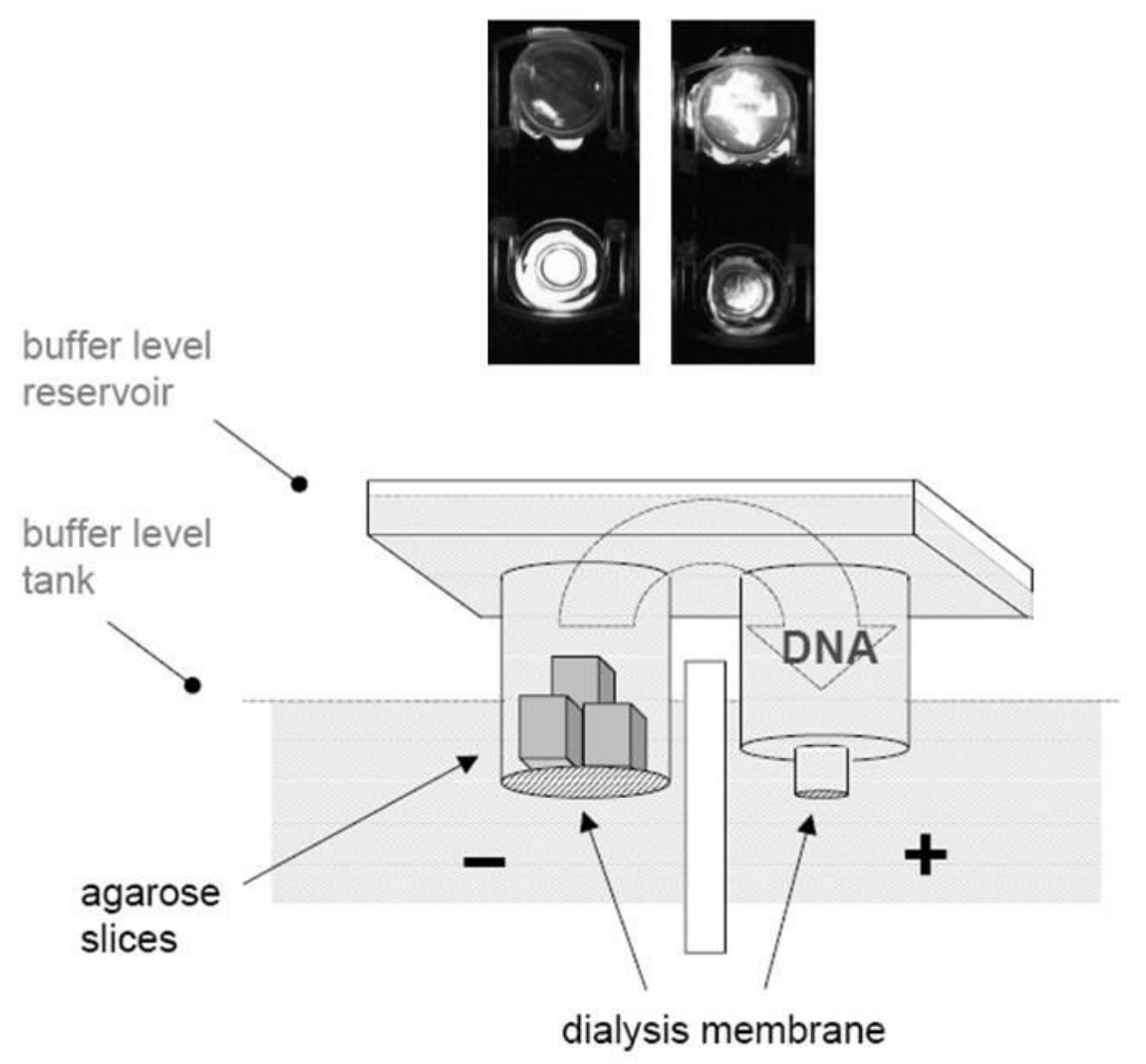

Figure 7: Electroelution. Panel A: Schematic representation of the electro-elution system used to purify the targeting vector prior to electroporation. The two cylindrical reservoirs communicate through a buffer compartment on top. DNA migrates in an electric field (open arrow) from the agarose slices (in large reservoir, left) onto the dialysis membrane (in small reservoir, right). Panel B: after electroelution, the DNA concentrates on the dialysis membrane. The left picture shows an efficient transfer of DNA to the dialysis membrane, whereas the right picture shows an inefficient transfer (a high proportion of DNA remained in the agarose).

\section{Comments}

1. DNA that is to be used to generate transgenic animals should be protected as much as possible from UV light (i.e. day light, UV light box). Long-wave UV light or a Dark Reader ${ }^{\circledR}$ using visible light (Clare chemicals), is recommended to visualize DNA. We are aware of a case in which undue exposure to UV light caused mutations in the majority of otherwise successfully targeted ES cells.

2. Residual ethidium bromide will interfere the efficiency of homologous recombination. Traces of ethidium bromide in a DNA preparation can be easily detected on an agarose gel from which ethidium bromide has been omitted. If DNA is detectable under UV light, the preparation should be re-extracted. For the same reason, working surfaces and equipment (UV tray; scalpels) have to be clean, when isolating fragments from agarose gels. 
3. During electroelution of DNA, the agarose blocks should be stacked properly to ensure efficient transfer (Figure 7B, left picture). Floating pieces of agarose result in inefficient transfer of DNA (Figure 7B, right picture) and are a major source of DNA loss.

\section{Choice of ES cell line}

The choice of ES cell line is an important factor to achieve high success rates. The 129P2/OlaHsd-derived IB10 ES cells (a subclone from (male) E14 ES cells (31)) was used successfully by our group for the generation of 4 conditional knockout and 3 knock-in mice.

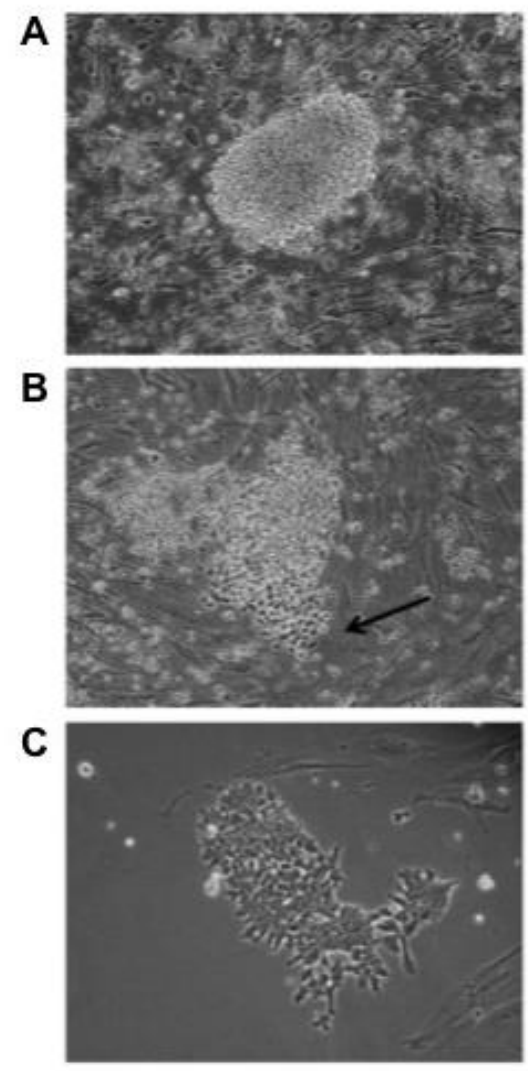

Figure 8: The phenotype of ES cells cultured in vitro. Picture A: a colony of undifferentiated ES cells cultured on mouse embryonic fibroblasts (MEFs). The cells are spherical and show no boundary at the circumference of the colony. Picture B: a colony of differentiated ES cell with part of the cells exhibiting a high degree of differentiation (arrow). The cells are no longer spherical. Picture C: a colony of ES cells grown in BRL-conditioned medium. Although still undifferentiated, this ES colony is very different in appearance from one grown on MEFs.

\section{Electroporation of IBI0 ES cells}

ES cells from an $80 \%$ confluent $25 \mathrm{~cm}^{2}$ culture flask were electroporated with $25 \mu \mathrm{g}$ DNA in a final volume of $200 \mu \mathrm{L}$ sterile PBS. At a setting of the capacitance at $1 \mu \mathrm{F}$, the time constant should not exceed 0.1. After electroporation, the ES cells were seeded in two $10 \mathrm{~cm}$ dishes, containing medium without selection compound.

The exposure of the electroporated ES cells to the selection medium (200 $\mu \mathrm{g} / \mathrm{mL}$ G418) was started 24 hours after electroporation. Five days later, resistant colonies become visible, with individual colonies

becoming visible after 6 to 8 days. The colonies should not be left to grow too big, since this induces differentiation of the ES cells. Figure 8A shows an undifferentiated ES colony with cells retaining their spherical shape. On the other hand, when the ES cells become differentiated, they acquire a rectangular shape (Figure 8B) and should be disgarded. Series of 16 undifferentiated colonies were picked and transferred to 96-well plates containing neomycin-resistant mouse embryonic fibroblasts (neo-MEF). After 2-3 days, when the cultures are around 60\% confluent, they are split onto two plates, one containing neo-MEFs and the other $150 \mu \mathrm{L}$ of BRL (Buffalo Rat Liver) conditioned medium. The cultures on neo-MEFs were grown to semiconfluence (2-3 days) and frozen. The colonies on BRL medium were expanded for isolation of genomic DNA. Note that these ES cells look different from MEF-supported ES cells (Figure 8C). 
Chapter II

\section{Comment}

Recombinant ES cells should be grown under selection pressure until the selection tool has been excised to suppress the growth of wild-type cells. The requirement for a "deep split" (see section IV.a.) shows that selection pressure should be a standard part of the procedure.

\section{Screening for Homologously Recombined Clones}

Once neomycin-resistant clones originating from single cells have been picked, they need to be screened for proper integration of the construct into the targeted gene. The picked clones are seeded individually in 96-well plates. It was common to observe differences in the growth rate among the recombinant cells. Therefore, care was taken not to allow cells to grow too confluent, thereby avoiding differentiation. Because screening is a tedious and time-consuming procedure, it is recommended to temporarily freeze an aliquot of promising ES colonies, while going through the selection with the remaining portion of the clone. Two ways of freezing down the cells were used. A computer-assisted cooling device, in which the cryotubes were placed, in a temperaturecontrolled chamber with a reduction in temperature of $1^{\circ} \mathrm{C}$ per minute to $-80^{\circ} \mathrm{C}$, before transferring the tubes to liquid nitrogen. When this machine was not available, we cooled the cryotubes in a foam box containing liquid isopropanol based on the same principle as the $\mathrm{Mr}$ Frosty labware (Nalgene) in a $-80^{\circ} \mathrm{C}$ freezer before transferring them to liquid nitrogen.

\section{Elimination of randomly integrated clones}

After electropration of the targeting vector, the vector either integrates randomly in the genomic DNA (RI) or recombines homologously with the gene of interest (HR). An interesting difference between these two ways of insertion is that the extremities of the vector are kept during randing integration, but lost during homologous recombination (Figure 9A). We used this difference for a preliminary test to remove clones with randomly integrated DNA. We left the multiple cloning region (MCR) on either end of the linearized fragment or only linearized targeting construct. A MCR- or vector-specific primer and a construct-specific primer were used. Since the outer ends of the construct are lost during homologous recombination, only randomly integrated clones still have the MCR- or vector-specific sequence necessary for primer binding (Figure 9B). This "short" PCR approach worked well for some targeting vectors, e.g. ASS, that is, $\sim 70 \%$ of the clones that were randomly integrated could be eliminated. We therefore suggest linearizing the targeting construct near the shortest flanking sequence. When the construct was restricted at the outer side of the MCRs before electroporation, leaving no backbone, this short PCR did not work efficiently. Probably, the extremities of the construct are nibbled off by nuclease activity before integration. Clones yielding a PCR product were discarded; clones negative for this PCR were treated as potential candidates for proper homologous integration and investigated further. 


\section{Selection of homologously recombined clones}

\section{Long PCR}

Clones negative for the "short PCR" were subjected to a "long PCR". To discriminate the recombined allele from the wild-type allele, the primers for the long PCR were chosen to be specific for the recombined allele. The target-specific primer sequences were chosen in the selection markers, the lox P sites, or the frt sites in the center of the construct and in the genomic sequence outside that present in the targeting vector sequence (Figure 9C). This PCR yields a specific PCR product with a known size, when homologous recombination has taken place. The PCR product is then restricted with appropriate enzymes and sequenced to confirm the exact insertion of the targeting vector. The long PCR yields very detailed information on the integration of the DNA. We, therefore, recommend to perform this long PCR on both sides of the integrated vector, if this is possible. Finally, all crucial sequences are sequenced to check for any mutation.
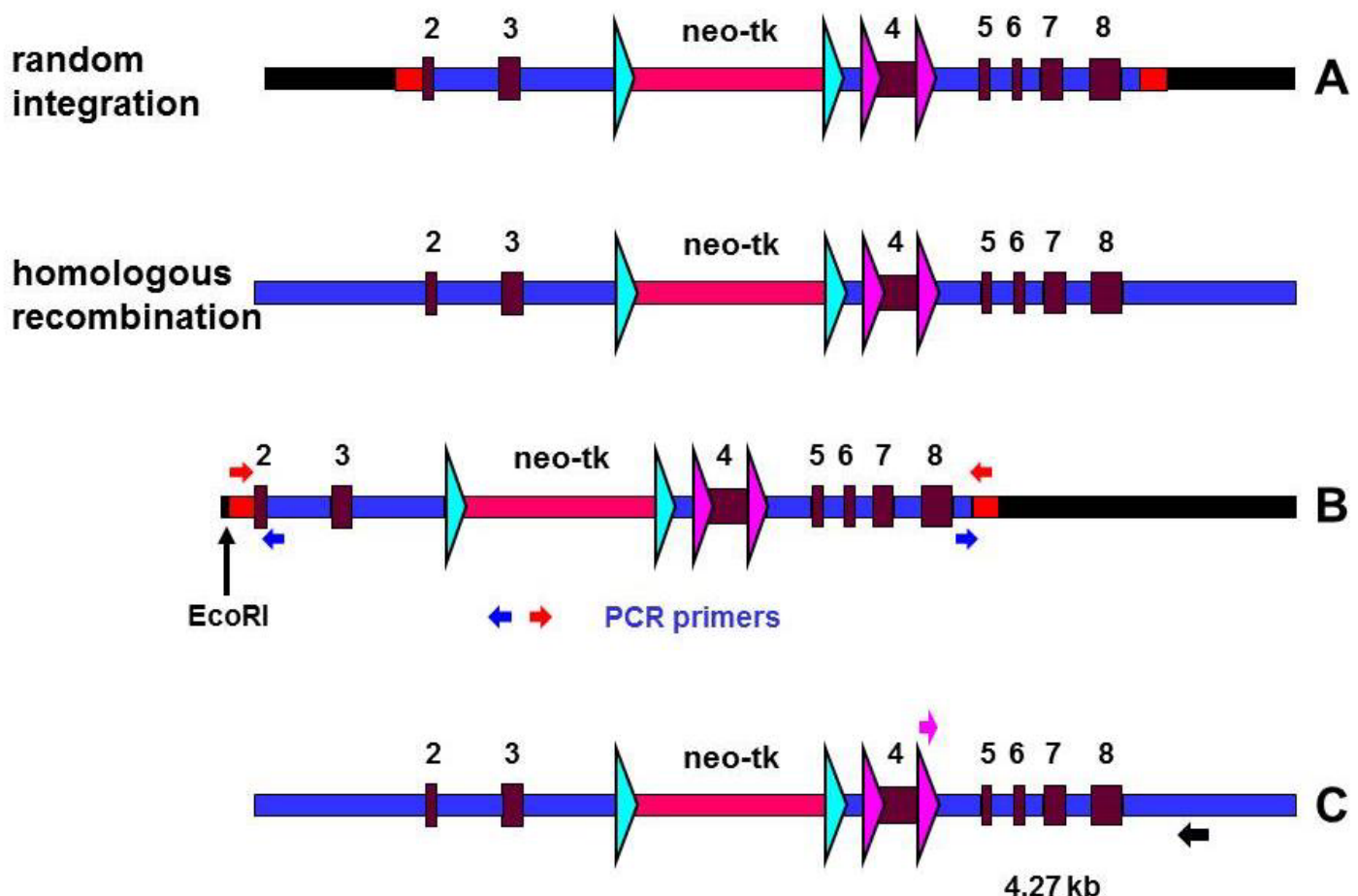

Figure 9: PCR-Screening for homologous recombination. Panel A: Configuration of a targeting construct after random integration or after homologous recombination. The vector-specific sequences at the ends of the targeting construct (black) remain only present if the construct is randomly integrated. Panel B: This structural feature allows a negative selection for properly integrated clones by "short" PCR. Primers are designed specifically for these sequences, which will only give a band for randomly integrated clones. It is obvious that PCR at the right side (long vector sequence left) is less sensitive to "nuclease nibbling" than PCR at the left side. Panel C: Screening for homologous recombination by "long” PCR. By using primers in the endogenous DNA outside the targeting construct and in the selection marker or recombination sites, a PCR product that is unique for the recombined allele is produced. This PCR product can then be used to sequence crucial parts of the modified allele without interference from the wild-type allele. 


\section{Chapter II}

\section{Southern blot}

Clones positive for the long PCR on both sides were further tested by Southern blot to check for clonality, that is, checked for the presence of an equal number of copies of the recombined and the unmodified endogenous allele to test for the presence of wild-type ES cells that were not removed during the positive selection procedure. This Southern-blot does also reveal the presence or absence of additional random integrations.

The DNA sequence used to probe such a Southern blot should be localized external to the flanking regions of the construct. The quality of the probe determines the quality of the result. We found that a relatively short probe that is specific and contains no repetitive elements is more efficient than longer probes containing such repetitive elements. Also, it should be close to the boundaries of the construct to avoid excessively long sequences. Exons are preferable to introns because introns more often contain repetitive sequences and, therefore, bind non-specifically to sequences elsewhere, resulting in smears as depicted in Figure 10, left panel. However, sometimes the next exon is so far away that intronic sequences have to be used as probe. Any candidate probe should be checked for its specificity by blasting for the occurrence of relatively short sequences ( $>12 \mathrm{bp}$ ) that are shared with other regions (comparison with the mouse genomic database) and then tested on a Southern. There is no golden rule to select a sequence for a Southern probe, in the sense that intronic probes can be as good as exonic probes as shown in Figure 10, right panel, where we used an intronic sequence of $300 \mathrm{bp}$ for the Southern probe and obtained high specificity.

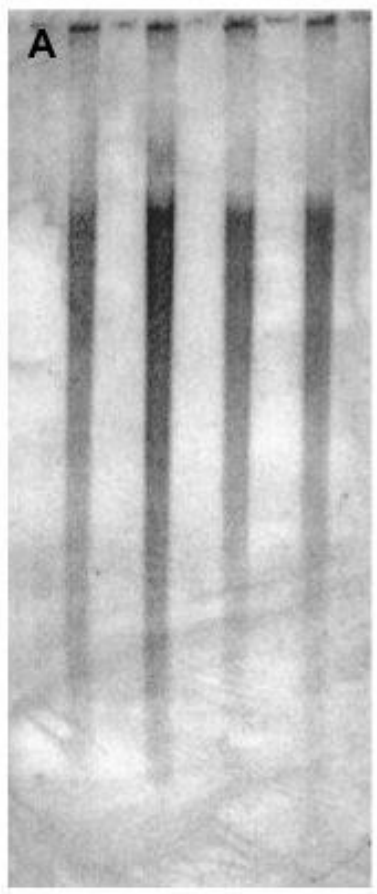

B

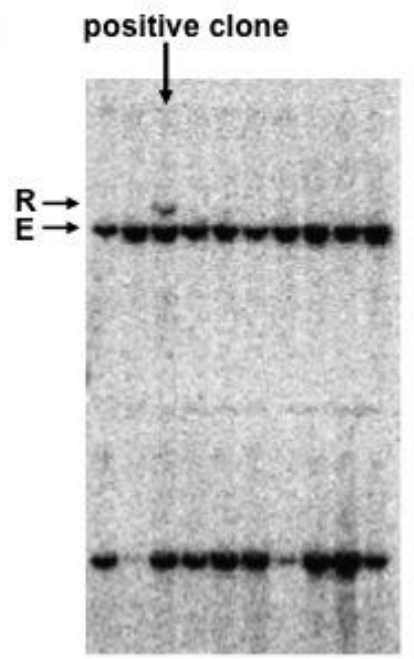

Figure 10: Southern blotting as tool to identify homologous recombination. Panel A: ES-cell DNA was digested with Xmn-I, blotted, and hybridized with an external intronic ASS probe $(1.17 \mathrm{~kb})$. The probe generated the same staining pattern as ethidium bromide, demonstrating nonspecific hybridization. Panel B: ES-cell DNA was digested with Blb-1, blotted, and hybridized with a short $300 \mathrm{bp}$ intronic arginase-1 probe. The wildtype allele is $6.1 \mathrm{~kb}$ long and the recombined allele $8.5 \mathrm{~kb}$. Note the difference in intensity of the wildtype and recombined allele. The excess of wild-type DNA suggests that wild-type cells had escaped removal during neomycin selection.

R: Recombinant DNA fragment; E: Endogenous DNA fragment. 


\section{Comment}

DNA isolated for genotyping may be difficult to dissolve. If the centrifugational force is limited, a more homogenous solution is usually obtained. Prolonged centrifugation during precipitation should, therefore, be avoided.

\section{Removal of Selection Tools}

\section{Clonality of the recombined clone ("deep split")}

The picked ES colonies are often contaminated with WT ES cells. These contaminant cells need to be removed before blastocyst injection. The clonality test, a Southern blot-based technique, allows us to visualize the intensity (that is, the prevalence in the population) of both the endogenous and recombinant alleles and to compare them. If the ES cells used on the blot originate from a pure recombinant clone, the intensities of the two bands should be equal. On the other hand, if the intensity of the endogenous band is stronger than the recombinant one, there is most likely a contamination with wild-type ES cells (Figure 10B). We observed contamination with wild-type ES cells in many cases as long as we stopped the G418 selection after picking the clones. It is therefore highly recommended to continue the drug selection throughout the whole procedure. To remove the remaining wild-type cells, a deep split has to be done and the resulting "single-cell" ES cultures have to be subjected to a new round of G418 selection.

\section{Removal of the neo-tk cassette}

The presence of a selection cassette can interfere with the expression of a nearby gene $(19,23$ 26). Furthermore, ES cells that express tk are less likely to be incorporated into the male germ line $(23,32)$. It is therefore recommended to remove the neo-tk cassette or any other selection cassette in the selected ES-cell clones prior to blastocyst injection. The excision of the cassette can be achieved by transient expression of either flpe or cre recombinase through electroporation of either a flpe- or cre-expressing plasmid. In our constructs, we use the Cre-LoxP system to achieve specific gene inactivation, so that the Flp-Frt system remained to remove our selection cassette.

\section{Comments}

1. The flpe-expression plasmid (Figure 11A) is a fastidious plasmid. After electroporation into e.g DH5- $\alpha$ bacteria according to the Biorad standard electroporation protocol, the incubation temperature of the bacteria should not exceed $30^{\circ} \mathrm{C}$. At $37^{\circ} \mathrm{C}$, the apparent size of the plasmid doubled (Figure 11B). Forty-eight hours after transformation, colonies were picked for inoculation of $5 \mathrm{~mL}$ cultures. When incubated at $30^{\circ} \mathrm{C}$ with a constant agitation of $180 \mathrm{rpm}$ (instead of $270 \mathrm{rpm}$ ), these cultures yielded the proper-sized plasmids (Figure 11C). Large- 


\section{Chapter II}

scale cultures were grown under the same conditions. $25 \mu \mathrm{g}$ aliquots of the plasmid were stored in sterile PBS at $-20^{\circ} \mathrm{C}$ until electroporation.

2. The thymidine kinase protein that is encoded in the neo-tk cassette is as stable as cellular bulk protein with an estimated long half-life of around 40 hours (33), meaning that the deletion of the gene does not make the cell insensitive to ganciclovir for several days. In order to make sure that no tk is left in the cells, they were grown in selection-free medium for 5 days before ganciclovir was added. Due to this long time period, the cultures have to be split between transfection and selection. Care should therefore be taken that independent clones are generated. After the deep split, a pure ES cell clone was expanded to $25 \mathrm{~cm}^{2}$, trypsininzed, and electroporated with $25 \mu \mathrm{g}$ FLPe plasmid. One tenth of the cells were seeded onto the wells of a 6-well plate containing wild-type mouse embryonic fibroblasts (wtMEFs). Two-three days after electroporation, the cells of each 6-well were split onto two 6-well plates at a dilution of 1:30 and 1:100. After another 2-3 days, ganciclovir selection was started.

3. Ganciclovir is a nucleotide analogue that may cause mutations. We therefore resequenced crucial sections of the recombined alleles. In the ASS allele, we did indeed find a mutation in the targeted exon that resulted in a frameshift (ATC to TTT - Ala to Val). This mutation was not present before FLPe-mediated excision and ganciclovir selection, and would have inactivated the enzymatic activity (34).

4. Flpe-deleter ("flipper") mice (22) are available and have already shown their usefulness in excising selection cassettes (see II.d.1, comment 3).
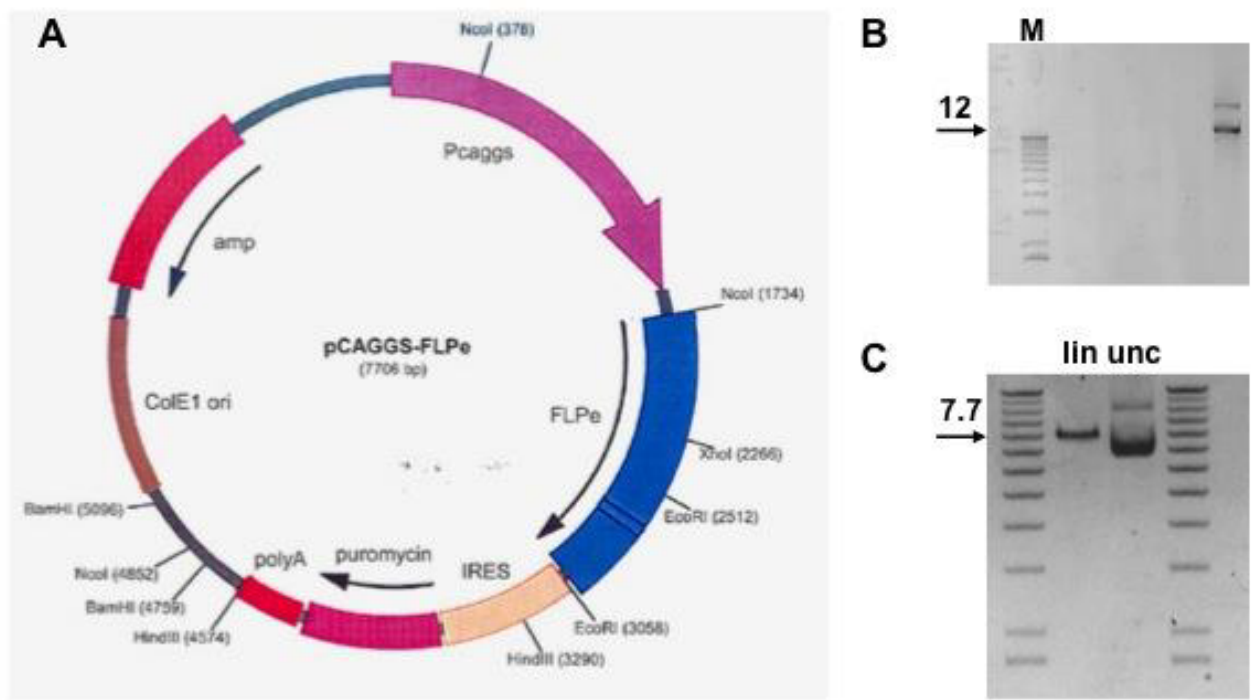

Figure 11: Flpe plasmid. Panel A: Schematic representation of the pCAGGS- expression vector. Flpe expression is driven by the chimeric chicken actin/CMV promoter-enhancer (18). The ampicillin (amp) and puromycin resistance genes are present for selection in bacteria and eukaryotic cells, respectively. The flpe sequence harbours four aminoacid changes (P2S, L33S, Y108N, S294P) that collectively improve the in vitro recombination activity 4 -fold at $37^{\circ} \mathrm{C}$ compared with wild-type flpe (16). Panel B: The plasmid was electroporated into XL-1 Blue bacteria, using a standard mini-preparation. The observed size of the supercoiled form of the $7.7 \mathrm{~kb}$ plasmid appeared to exceed $12 \mathrm{~kb}$ (arrow). M: Size marker. Panel C: Under optimized bacterial culture conditions (180rpm; 30 $\left.{ }^{\circ} \mathrm{C}\right)$, the linearized (lin) plasmid was $7.7 \mathrm{~kb}$ long (arrow) and the uncut (unc), supercoiled form $\sim 5.5 \mathrm{~kb}$. 


\section{Injection of ES Cells into Blastocysts}

A clone that passed all tests was karyotyped before injection into the blastocyst. Despite all quality checks, ES cells may incur damage during transfection, freezing, selection, and culture procedures, that is not detected. Therefore, the karyotype of the ES cells of each ES line was routinely tested. At least 15 metaphase spreads were counted, of which at least $80 \%$ should have the proper karyotype (40 chromosomes).

To exclude artifacts due to DNA modifications in the ES cells, germ-line chimeras of at least two independent modified clones should be generated. To eliminate DNA mutations outside the locus of interest that have accumulated during many generations of in vitro culture of the ES cells, newly generated genetically modified mice should be bred into wild-type mice for several generations.

\section{Comment}

Prior to blastocyst injection, the ES cells should pass the following checklist:

1. Correct DNA stoichiometry by Southern hybridization (1:1 ratio between wild-type and recombinant allele).

2. Morphology check (undifferentiated status, Figure 8B)

3. Karyotyping

\section{Breeding Schemes}

\section{Chimeras}

A rule of the thumb is that the best - in the sense of germline transmission - chimeras should be moderately chimeric. However, we do not know in advance whether the genetically modified ES cells that we produced are still sufficiently pluripotent. In the case of arginase I, the best chimeras gave 5 floxed animals out of 20-25 offspring. Since the percentage of ES cells that populates the germline is always relatively small and since an ES cell can populate the germline without carrying the modified allele, it can be very reassuring to identify a germline transmission of a modified ES cell that, as a result of meiosis, does not carry the floxed allele. This is possible based on the coat colour of the offspring.

The 129P2/HsdOla line carries the coat colour alleles $\mathrm{A} / \mathrm{A}$ and $\mathrm{c}^{\mathrm{ch}} / \mathrm{c}^{\mathrm{ch}}$, whereas the important colour alleles of the $\mathrm{C} 57 \mathrm{~B} 1 / 6$ donors of the blastocysts are $\mathrm{a} / \mathrm{a}$ and $\mathrm{C} / \mathrm{C}$. A stands for agouti and is the normal brown wild-type colour of mice, whereas "a" stands for non-agouti, making the mice black. In addition, however, the $\mathrm{c}$ or $\mathrm{C}$ alleles influence the development of the colour determined by the a/A alleles. $\mathrm{C}$ stands for albino, meaning a c/c mouse will be white, whereas $\mathrm{C}$ will support whatever colour is determined by $\mathrm{A}$. The allele $\mathrm{c}^{\mathrm{ch}}$ stands for chinchilla and will result in 
dilution of the colour determined by the A-allele, yielding beige or grey mice. An a/a, C/C mouse is a black mouse, such as the C57B16. An A/A, $\mathrm{c}^{\mathrm{ch}} / \mathrm{c}^{\mathrm{ch}}$ mouse (donor of the stem cells) shows a beige coat (and red eyes). In the chimera, those cells originating from the donor blastocyst are $\mathrm{a} / \mathrm{a}$ $\mathrm{C} / \mathrm{C}$, whereas those cells originating from the modified ES cells are $\mathrm{A} / \mathrm{A} \mathrm{c}^{\mathrm{ch}} / \mathrm{c}^{\mathrm{ch}}$. The fur coat therefore reveals whether offspring is chimeric.

When chimeric males are bred with C57B16 or 129P2/HsdOla females, the beige coat colour of the offspring will indicate that there was germline transmission of the ES cells injected into the blastocysts, independent of the demonstration of the recombinant gene. This is because the male chimera can donate either $\mathrm{a} / \mathrm{C}$ (wild type) or $\mathrm{A} / \mathrm{c}^{\mathrm{ch}}$ (derived from the ES cells) sperm cells, while a C57B16 mother has a/C eggs. After fertilization, the offspring will either be a/a $\mathrm{C} / \mathrm{C}$ (pure C57B16), yielding a black and therefore wild-type animal. If the offspring is $\mathrm{A} / \mathrm{a} \mathrm{C} / \mathrm{c}^{\mathrm{ch}}$, resulting in a brown (agouti-coloured) animal, germ line transmission of the ES cell line has taken place.

Coat-colour can be used in a similar way to check for germline transmission in a crossing of male chimeras with 129P2/HsdOla mice. Again the male chimera provides sperm cells that are either $\mathrm{a} / \mathrm{C}$ or $\mathrm{A} / \mathrm{c}^{\mathrm{ch}}$, while the female $129 \mathrm{P} 2 / \mathrm{HsdOla}$ has $\mathrm{A} / \mathrm{c}^{\mathrm{ch}}$ egg cells. Two types of offspring colour can be expected: a brown (agouti) animal with the genotype $\mathrm{A} / \mathrm{a} \mathrm{C} / \mathrm{c}^{\mathrm{ch}}$, showing that the chimera donated a wild-type allele, or a cream-coloured, red-eyed animal (like the mother), meaning that the chimera donated the colour alleles from the injected ES-cells. Therefore, cream-coloured animals are evidence for germline transmission.

Animals with a proper coat colour still need to be genotyped for genetic modification, because crossing over may segregate the floxed allele from those conferring coat colours. Nevertheless, an animal with a proper coat colour shows that the chimeric male that sired, is a promising candidate for offspring carrying the floxed allele. A chimeric mouse that only yields black offspring ( $>20$ pubs) should not be used for further breedings. Furthermore, even when brown or light-brown offspring are obtained, one might have to analyze several nests before ever getting a positive offspring showing germline transmission. For the ASS project, a chimeric male breeding with Ola females gave 10 nests with a total of 61 offspring. Although the offspring were predominantly brown, the first 52 offspring (first 9 nests) gave no positive animals for the ASS construct. We had to wait for the $10^{\text {th }}$ nest to get one mouse positive for the ASS construct.

There are actually more alleles determining coat colour, that these alleles do not play a role here. Depending on the ES cell line used, it may be worthwhile to check the genetics beforehand and use this information to decide on crossings that yield a 2-fold higher rate of ES-cell derived offspring. A comprehensive review of coat colour alleles and their interaction can be found on www.jax.org by Willys K. Silvers (1979), The coat Colors of Mice; a model for mammalian gene action and interaction. 


\section{Breeding tissue-specific knockout mice}

The ES cells injected into the blastocysts have one floxed allele and one wild-type allele. The chimeras obtained are bred to find offspring that carry the floxed genotype in their germline. This mouse is then bred to increase the number of floxed offspring. It is also crossed with a Cre mouse, in which $\mathrm{Cre}$ is expressed under control of the EIIa promoter. This promoter is expressed at the zygotic stage, i.e. before the germline is set aside, so that we obtain a hemizygous knockout mouse (35). This hemizygous knockout will be crossed with hemizygous floxed mice.

It takes at least three generations of mice from the chimera to the genetically modified animal (Figure 12). If we first work with a floxed allele and a tissue-specific cre, we will go for a safe breeding protocol, meaning that $\mathrm{X}^{\text {flox/flox }}$ mice are crossed with $\mathrm{X}^{+/-} / \mathrm{Cre}^{+/-}$mice. The advantage of this approach is that $\mathrm{Cre}$ has to inactivate only one allele in the tissue of interest, doubling the chance that the cells in the tissue of interest do not express the gene $\mathrm{X}$. The disadvantage of this approach is that all cells in the body only contain 1 functional allele of gene $\mathrm{X}$ and, hence, usually only $50 \%$ of the normal protein content. If excision proves efficient, we prefer matings between $\mathrm{X}^{\text {flox/flox }}$ and $\mathrm{X}^{\text {flox/flox }} / \mathrm{Cr}^{+/-}$mice, because all cells in these mice, where Cre is not active, contain 2 functional copies of gene $\mathrm{X}$.

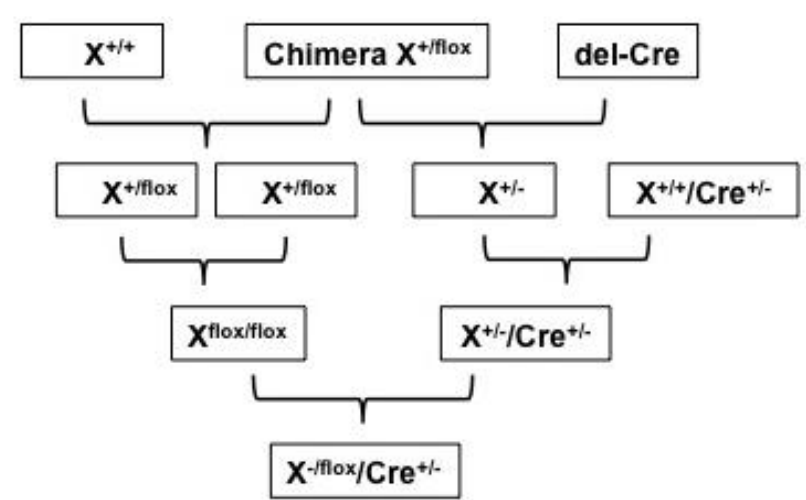

Figure 12: Breeding scheme to generate tissuespecific knockout mice. Chimeras are bred with wildtype mice to obtain mice with $100 \%$ germline transmission and with "del-Cre" mice to obtain mice, which are heterozygous for the target gene. The resulting $\mathrm{X}^{+/ \text {flox }}$ mice (left arm of scheme) are interbred to obtain $X^{\text {flox/flox }}$ mice, which can be produced with a high efficiency. The heterozygous $\mathrm{X}^{+/-}$mice (right arm of scheme) are bred with the desired tissue-specific Cre mice to generate $\mathrm{X}^{+/-} / \mathrm{Cre}^{+/-}$ mice. These mice are then crossed with the $\mathrm{X}^{\text {flox/flox }}$ mice to obtain $\mathrm{X}^{-/ f l o x} / \mathrm{Cre}^{+/-}$mice, which have gene $\mathrm{X}$ deleted in a tissue-specific manner. This scheme is advisable if Cre is suspected to remove the floxed fragment inefficiently. However, all cells in the organism have the $\mathrm{X}^{+/}$genotype. If Cre efficiently removes floxed fragments, one can better use mice with a $\mathrm{X}^{\text {flox/flox }} / \mathrm{Cr}^{+/-}$genotype, because then the targeted sequence is deleted in the tissue of interest only.

\section{Conclusions}

The following are the important factors to be considered from our experience.

1. Constructing the targeting vector: If using the PCR-based approach to amplify the homologous arms from genomic DNA, BAC clones should be used to decrease the number of amplications. Furthermore, repeats in the regions to be amplified should be avoided as they are very difficult to amplify by PCR. Finally, sequence differences between strains should be taken into account when selecting the homologous sequences: 
they may interfere with the efficiency of the homologous recombination and should not be interpreted as mutations.

2. Selection of the recombinant ES clone: The clone to be injected into blastocysts should contain only homologously recombined cells. To achieve this, selected colonies should be continuously cultured in presence of the appropriate selection drug to avoid the growth of wild-type cells.

3. Screening against random integration: The "short" PCR method to eliminate the randomly integrated clones described in III.a. is an easy, fast and reliable method to eliminate randomly integrated clones, if the target DNA is not be located totally at the end of the constructs.

4. Screening for homologous recombination: The "long" PCR procedure to identify and characterize recombination events is faster and more informative than Southern blots. A draw back is that the primer pair cannot be tested and optimized before the recombinant clone is available.

5. Selection of probes for Southern blotting: Intronic probes have to be checked for the presence of repeats. A $300 \mathrm{bp}$ probe can suffice for sensitive and specific detection.

6. Selection with ganciclovir: Ganciclovir causes mutations. It is therefore necessary to resequence the clone after the excision of the selection cassette.

7. Coat colour as a marker for germline transmission: Coat colour as a marker doubles the chance to identify a male with proper germline transmission of the floxed allele.

8. Breeding set-up: The best genotypes to study physiological effects of gene knock out are flox/flox and flox/flox-Cre. In all our modified mice (ASS, Arg-1 and CAT-1), we obtained very good excision efficiency in vivo of both alleles with cre. It is therefore recommended to set up breeding schemes that yield these genotypes. 


\section{References}

1. Sauer B, Henderson N. Site-specific DNA recombination in mammalian cells by the Cre recombinase of bacteriophage P1. Proc Natl Acad Sci U S A 1988;85:5166-5170.

2. Kuhn R, Schwenk F, Aguet M, Rajewsky K. Inducible gene targeting in mice. Science 1995;269:14271429.

3. Dymecki SM. Flp recombinase promotes site-specific DNA recombination in embryonic stem cells and transgenic mice. Proc Natl Acad Sci U S A 1996;93:6191-6196.

4. Sadowski PD. The Flp recombinase of the 2-microns plasmid of Saccharomyces cerevisiae. Prog Nucleic Acid Res Mol Biol 1995;51:53-91.

5. Zheng B, Sage M, Sheppeard EA, Jurecic V, Bradley A. Engineering mouse chromosomes with Cre-loxP: range, efficiency, and somatic applications. Mol Cell Biol 2000;20:648-655.

6. McCright B, Lozier J, Gridley T. Generation of new Notch2 mutant alleles. Genesis 2006;44:29-33.

7. Kobayashi K, Kakinoki H, Fukushige T, Shaheen N, Terazono H, Saheki T. Nature and frequency of mutations in the argininosuccinate synthetase gene that cause classical citrullinemia. Hum Genet 1995;96:454-463.

8. Iyer RK, Yoo PK, Kern RM, Rozengurt N, Tsoa R, O'Brien WE, Yu H, et al. Mouse model for human arginase deficiency. Mol Cell Biol 2002;22:4491-4498.

9. Deng C, Capecchi MR. Reexamination of gene targeting frequency as a function of the extent of homology between the targeting vector and the target locus. Mol Cell Biol 1992;12:3365-3371.

10. Soriano P. Generalized lacZ expression with the ROSA26 Cre reporter strain. Nat Genet 1999;21:70-71.

11. Sadowski PD. \#The Flp double cross system a simple efficient procedure for cloning DNA fragments. BMC Biotechnol 2003;3:9.

12. Kilby NJ, Snaith MR, Murray JA. Site-specific recombinases: tools for genome engineering. Trends Genet 1993;9:413-421.

13. Bode J, Schlake T, Iber M, Schubeler D, Seibler J, Snezhkov E, Nikolaev L. The transgeneticist's toolbox: novel methods for the targeted modification of eukaryotic genomes. Biol Chem 2000;381:801-813.

14. Andrews BJ, Proteau GA, Beatty LG, Sadowski PD. The FLP recombinase of the 2 micron circle DNA of yeast: interaction with its target sequences. Cell 1985;40:795-803.

15. Buchholz F, Ringrose L, Angrand PO, Rossi F, Stewart AF. Different thermostabilities of FLP and Cre recombinases: implications for applied site-specific recombination. Nucleic Acids Res 1996;24:4256-4262.

16. Buchholz F, Angrand PO, Stewart AF. Improved properties of FLP recombinase evolved by cycling mutagenesis. Nat Biotechnol 1998;16:657-662.

17. Rodriguez CI, Buchholz F, Galloway J, Sequerra R, Kasper J, Ayala R, Stewart AF, et al. \#High-efficiency deleter mice show that FLPe is an alternative to Cre-loxP. Nat Genet 2000;25:139-140.

18. Schaft J, Ashery-Padan R, van der Hoeven F, Gruss P, Stewart AF. Efficient FLP recombination in mouse ES cells and oocytes. Genesis 2001;31:6-10.

19. Jaenisch R. Transgenic animals. Science 1988;240:1468-1474.

20. Mansour SL, Thomas KR, Capecchi MR. Disruption of the proto-oncogene int-2 in mouse embryo-derived stem cells: a general strategy for targeting mutations to non-selectable genes. Nature 1988;336:348-352.

21. Holzenberger M, Lenzner C, Leneuve P, Zaoui R, Hamard G, Vaulont S, Bouc YL. Cre-mediated germline mosaicism: a method allowing rapid generation of several alleles of a target gene. Nucleic Acids Res 2000;28:E92.

22. Farley FW, Soriano P, Steffen LS, Dymecki SM. Widespread recombinase expression using FLPeR (flipper) mice. Genesis 2000;28:106-110.

23. Hug BA, Wesselschmidt RL, Fiering S, Bender MA, Epner E, Groudine M, Ley TJ. Analysis of mice containing a targeted deletion of beta-globin locus control region $5^{\prime}$ hypersensitive site 3 . Mol Cell Biol 1996;16:2906-2912. 


\section{Chapter II}

24. Pham CT, MacIvor DM, Hug BA, Heusel JW, Ley TJ. Long-range disruption of gene expression by a selectable marker cassette. Proc Natl Acad Sci U S A 1996;93:13090-13095.

25. Clark AJ, Harold G, Yull FE. Mammalian cDNA and prokaryotic reporter sequences silence adjacent transgenes in transgenic mice. Nucleic Acids Res 1997;25:1009-1014.

26. Kolb AF. Genome engineering using site-specific recombinases. Cloning Stem Cells 2002;4:65-80.

27. Hasty P, Rivera-Perez J, Bradley A. The length of homology required for gene targeting in embryonic stem cells. Mol Cell Biol 1991;11:5586-5591.

28. Cline J, Braman JC, Hogrefe HH. PCR fidelity of pfu DNA polymerase and other thermostable DNA polymerases. Nucleic Acids Res 1996;24:3546-3551.

29. Dietrich J, Schmitt P, Zieger M, Preve B, Rolland JL, Chaabihi H, Gueguen Y. PCR performance of the highly thermostable proof-reading B-type DNA polymerase from Pyrococcus abyssi. FEMS Microbiol Lett 2002;217:89-94.

30. Barnes WM. PCR amplification of up to 35-kb DNA with high fidelity and high yield from lambda bacteriophage templates. Proc Natl Acad Sci U S A 1994;91:2216-2220.

31. Robanus-Maandag E, Dekker M, van der Valk M, Carrozza ML, Jeanny JC, Dannenberg JH, Berns A, et al. p107 is a suppressor of retinoblastoma development in pRb-deficient mice. Genes Dev 1998;12:1599-1609.

32. Hasty P, Rivera-Perez J, Chang C, Bradley A. Target frequency and integration pattern for insertion and replacement vectors in embryonic stem cells. Mol Cell Biol 1991;11:4509-4517.

33. Sherley JL, Kelly TJ. Regulation of human thymidine kinase during the cell cycle. J Biol Chem 1988;263:8350-8358.

34. Gao HZ, Kobayashi K, Tabata A, Tsuge H, Iijima M, Yasuda T, Kalkanoglu HS, et al. Identification of 16 novel mutations in the argininosuccinate synthetase gene and genotype-phenotype correlation in 38 classical citrullinemia patients. Hum Mutat 2003;22:24-34.

35. Lakso M, Pichel JG, Gorman JR, Sauer B, Okamoto Y, Lee E, Alt FW, et al. Efficient in vivo manipulation of mouse genomic sequences at the zygote stage. Proc Natl Acad Sci U S A 1996;93:5860-5865. 


\section{ABLATION OF Arg1 IN HEMATOPOEITIC CELLS IMPROVES RESPIRATORY FUNCTION OF LUNG PARENCHYMA, BUT NOT THAT OF LARGER AIRWAYS OR INFLAMMATION IN ASTHMATIC MICE}

Roy H.E. Cloots ${ }^{1} *$, Selvakumari Sankaranarayanan ${ }^{1}{ }^{*}$, Chiel C. de Theije ${ }^{1}$, Matthew E. Poynter ${ }^{3}$, Els Terwindt ${ }^{1}$, Paul van Dijk ${ }^{1}$, Theodorus B.M. Hakvoort ${ }^{2}$, Wouter H. Lamers $^{1}$ and S. Eleonore Köhler ${ }^{1}$

${ }^{1}$ Department of Anatomy \& Embryology and NUTRIM School for Nutrition, Toxicology and Metabolism, Maastricht University, The Netherlands;

${ }^{2}$ Tytgat Institute for Liver and Intestinal Research, Academic Medical Center, Amsterdam, The Netherlands; and

${ }^{3}$ Department of Medicine, College of Medicine, Division of Pulmonary Disease and Critical Care, University of Vermont, Burlington, Vermont

*: These autors contributed equally 


\title{
Ablation of Argl in hematopoietic cells improves respiratory function of lung parenchyma, but not that of larger airways or inflammation in asthmatic mice
}

\author{
Roy H. E. Cloots, ${ }^{1 *}$ Selvakumari Sankaranarayanan, ${ }^{1 *}$ Chiel C. de Theije, ${ }^{1}$ Matthew E. Poynter, ${ }^{3}$ \\ Els Terwindt, ${ }^{1}$ Paul van Dijk, ${ }^{1}$ Theodorus B. M. Hakvoort, ${ }^{2}$ Wouter H. Lamers, ${ }^{1,2}$ \\ and S. Eleonore Köhler ${ }^{1}$ \\ ${ }^{1}$ Department of Anatomy \& Embryology and NUTRIM School for Nutrition, Toxicology and Metabolism, Maastricht \\ University, The Netherlands; ${ }^{2}$ Tytgat Institute for Liver and Intestinal Research, Academic Medical Center, Amsterdam, The \\ Netherlands; and ${ }^{3}$ Department of Medicine, College of Medicine, Division of Pulmonary Disease and Critical Care, \\ University of Vermont, Burlington, Vermont
}

Submitted 9 October 2012; accepted in final form 25 June 2013

Cloots RH, Sankaranarayanan S, de Theije CC, Poynter ME, Terwindt E, van Dijk P, Hakvoort TB, Lamers WH, Köhler SE. Ablation of Argl in hematopoietic cells improves respiratory function of lung parenchyma, but not that of larger airways or inflammation in asthmatic mice. Am J Physiol Lung Cell Mol Physiol 305: L364-L376, 2013. First published July 5, 2013; doi:10.1152/ajplung.00341.2012.-Asthma is a chronic inflammatory disease of the small airways, with airway hyperresponsiveness (AHR) and inflammation as hallmarks. Recent studies suggest a role for arginase in asthma pathogenesis, possibly because arginine is the substrate for both arginase and NO synthase and because NO modulates bronchial tone and inflammation. Our objective was to investigate the importance of increased pulmonary arginase 1 expression on methacholine-induced AHR and lung inflammation in a mouse mode of allergic asthma. Arginase 1 expression in the lung was ablated by crossing Arg ${ }^{f / f t}$ with Tie $2 \mathrm{Cr} e^{t g /-}$ mice. Mice were sensitized and then challenged with ovalbumin. Lung function was measured with the Flexivent. Adaptive changes in gene expression, chemokine and cytokine secretion, and lung histology were quantified with quantitative PCR, ELISA, and immunohistochemistry. Argl deficiency did not affect the allergic response in lungs and large-airway resistance, but it improved peripheral lung function (tissue elastance and resistance) and attenuated adaptive increases in mRNA expression of arginine-catabolizing enzymes Arg2 and Nos2, arginine transporters Slc7al and Slc7a7, chemokines Ccl2 and Ccll1, cytokines Tnfa and Ifing, mucus-associated epithelial markers Clca3 and Muc5ac, and lung content of IL-13 and CCL11. However, expression of Il4, Il5, IllO, and Il13 mRNA; lung content of IL-4, IL-5, IL-10, TNF- $\alpha$, and IFN- $\gamma$ protein; and lung pathology were not affected. Correlation analysis showed that Argl ablation disturbed the coordinated pulmonary response to ovalbumin challenges, suggesting arginine (metabolite) dependence of this response. Arg 1 ablation in the lung improved peripheral lung function and affected arginine metabolism but had little effect on airway inflammation.

airway hyperresponsiveness; arginine; inflammation

ALLERGIC ASTHMA IS A CHRONIC inflammatory disorder of the lung that is characterized by a reversible limitation of the airflow due to an allergic reaction in the airways with the characteristics of a $\mathrm{T}_{\mathrm{H}}$ 2-predominant airway inflammation. The airway inflammation is initiated by the binding of inhaled allergens to complementary IgEs on IgE receptor-bearing cells. Upon activation, these cells release histamine, cytokines, and proteases, resulting in the activation of the inflammatory cascade with

* R. H. E. Cloots and S. Sankaranarayanan contributed equally.

Address for reprint requests and other correspondence: S. E. Köhler, Dept of Anatomy \& Embryology, Maastricht Univ., P.O. Box 616, 6200MD Maastricht, The Netherlands (e-mail: leo.koehler@maastrichtuniversity.nl). lung infiltration of eosinophils and mononuclear cells. Increased mucus production, mucosal edema, and a disproportionate smooth-muscle contraction lead to airway hyperresponsiveness (AHR). As a result of the recurring inflammation, airway remodeling develops as a consequence of fibrosis and airway wall thickening $(2,3,6,36)$.

Recent studies in animal models and patients revealed a potential role for the arginine-catabolizing enzyme arginase in the pathogenesis of asthma $(28,53)$. Arginase exists as two isoforms, arginase 1 and arginase 2 . The expression of cytoplasmic arginase 1 and mitochondrial arginase 2 is undetectable in healthy mouse lungs but is strongly upregulated in mouse models of allergic asthma $(50,59)$. Arginase 1 is only found in cells with the morphological characteristics of macrophages that are present in the inflammatory infiltrates of asthmatic lungs $(50,59)$. Arginases catabolize L-arginine to urea and ornithine, but arginine is also the substrate for nitric oxide (NO) synthesis by NO synthase (NOS). A deficient NO production represents a key feature of AHR (36), since NO modulates bronchial and vascular tone by inducing relaxation of smooth muscle cells. NOS enzymes have a higher affinity for arginine $\left(K_{\mathrm{mI}}: 2-20 \mu \mathrm{M}\right)$ than arginases $\left(K_{\mathrm{mI}}: 1-5 \mathrm{mM}\right)$, but the $V_{\text {max }}$ of arginase is $\sim 1,000$-fold higher than that of NOS, which confers the capability for regional substrate depletion of arginine (56).

The role of arginases in the development and symptoms of allergic asthma is still incompletely understood. We, therefore, examined the effects of Argl deletion in the lung on methacholine-induced AHR and lung inflammation in a mouse model of asthma. In rodents, extensive arginase 1 expression in the myeloid lineage of blood cells is confined to macrophages and dendritic cells (37). For that reason, we generated cell-specific arginase 1 knockouts by flanking exon 4 of $A r g 1$ with loxP sites and crossing Arg $1^{f l y t}$ mice with either LysMCre ${ }^{t g /-}$ (9) or Tie $2 \mathrm{Cre}^{\text {tg/- }}$ mice (23) to delete Argl in myeloid cells (9), or in all hematopoietic and endothelial cells (47), respectively. We sensitized and then exposed these mice to ovalbumin to induce allergic asthma (26) and measured their responsiveness to increasing doses of methacholine. The adaptive changes in gene expression, chemokine and cytokine secretion, and lung histology were quantified. We report that selective Argl ablation improves peripheral lung function, without affecting lung inflammation.

\section{MATERIALS AND METHODS}

Plasmid construction and recombinant ES cell selection. The mouse Argl gene is located on chromosome 10. Since deletion of exon 4 causes a frame shift, we targeted this exon. The targeting 
vector (17.515 kb; Fig. 1A) consisted of Argl exons and introns 2 and $3(4.6 \mathrm{~kb})$ at the $5^{\prime}$ end, a Neo-TK selection cassette flanked by frt sites (10), exon 4 (160 bp) flanked by loxP sites (46), introns 4-7, exons 5-8, and a small fragment downstream of the gene (in total 4.3 $\mathrm{kb})$ at the $3^{\prime}$ end. The targeting construct was sequence verified with respect to exons, splice junctions, and recombinase-recognition sites; digested with AscI (introduced by PCR for cloning purposes); and purified by electrophoresis and electroelution. Twenty-five micrograms of the targeting fragment was electroporated into the mouse ES cell line E14IB10 (129/Ola). Selection with G418 (200 $\mu \mathrm{g} / \mathrm{ml})$ was started $24 \mathrm{~h}$ after electroporation. Vector sequences that were left on either end of the targeting construct allowed a PCR-based negative screen against random integrations. Proper recombination of the $3^{\prime}$ end was demonstrated with Southern blotting after Blp1 digestion (Fig. 1A) and probing with a 300-bp external genomic fragment, and by long-distance PCR, using AccuTaq (Sigma), an Argl-specific primer $3^{\prime}$ outside the targeting construct and a $\operatorname{lox} P$-specific primer (Fig. 1A). Proper recombination of the $5^{\prime}$ end was demonstrated by long-distance PCR, using AccuTaq, a $5^{\prime}$ frt-specific primer, and an Argl-specific primer $5^{\prime}$ outside the targeting construct (Fig. 1A). Exons and junctions of candidate ES clones were sequence verified by using those long-PCR products. After a "deep split" to ensure the presence of recombined ES clones only (the recombined $8.5-\mathrm{kb}$ band in the initial isolate was much less intense than the endogenous $6.1 \mathrm{~kb}$ band), the Neo-TK cassette was removed by transient transfection with an FLPe recombinase expression vector (kindly provided by Dr.

A

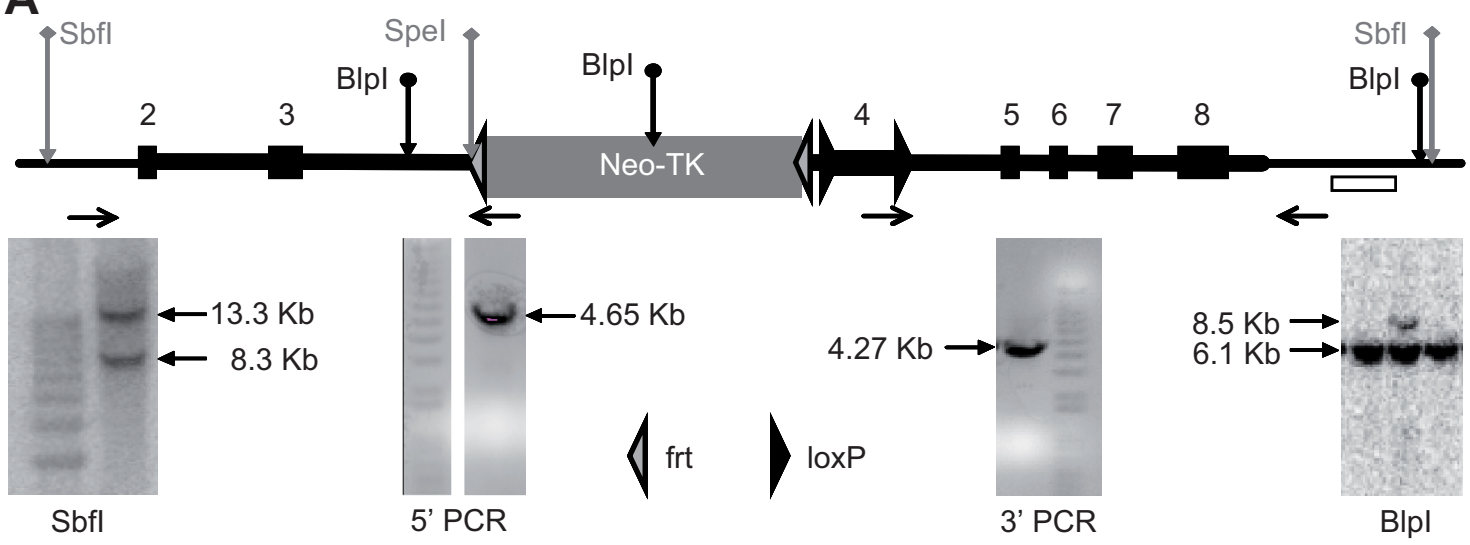

B

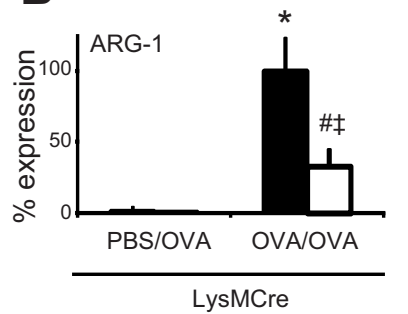

D

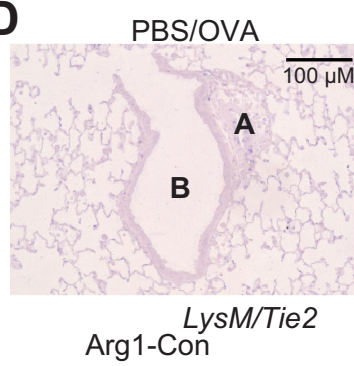

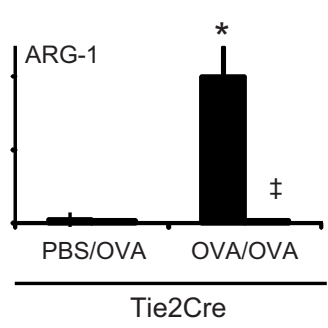

OVAVOVA

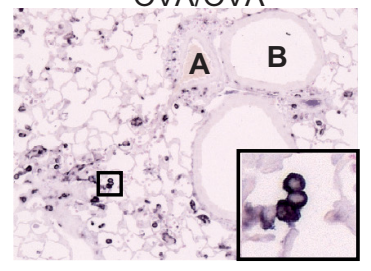

Arg1-Con
C

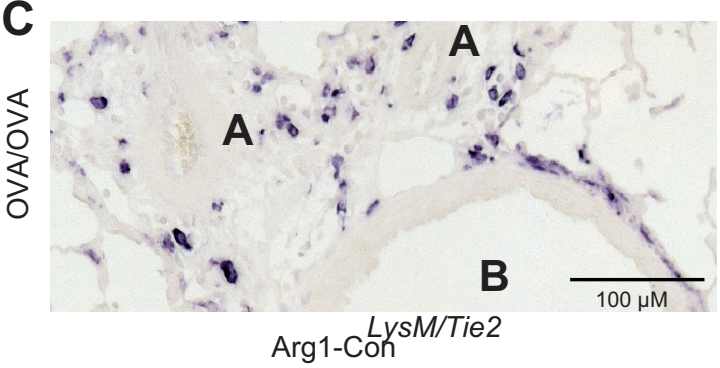

OVA/OVA

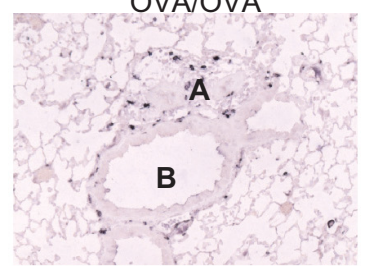

Arg1-KOsM
OVA/OVA

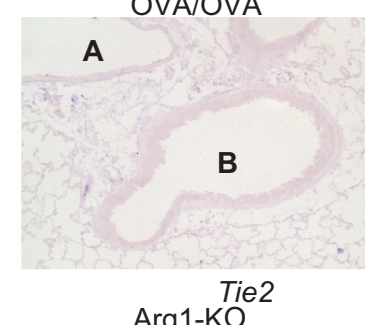

Fig. 1. Construction of $\mathrm{Arg} \mathrm{I}^{f l f l}$ mice and validation of Argl elimination in lung. A: targeting construct of murine Argl gene. The Frt-flanked Neo-TK selection cassette in intron 3, floxed exon 4, and the positions of relevant restriction enzymes are indicated. Blp 1 was used to differentiate the recombined allele ( $8.5 \mathrm{~kb}$ ) from the wild-type allele $(6.1 \mathrm{~kb}$; right Southern blot); Sbf1 and SpeI, both introduced during cloning, were used to demonstrate a 1:1 ratio between the recombined $(8.3 \mathrm{~kb})$ and wild-type $(13.3 \mathrm{~kb}) \mathrm{Arg} 1$ alleles in the blastocyst-injected ES cells (left Southern blot). The 3' 300-bp DNA fragment used as Southern probe is shown as a white box. The products of the $5^{\prime}$ and $3^{\prime}$ long-distance PCRs ( 4.65 and $4.27 \mathrm{~kb}$, respectively), used to validate the sequence of the recombined allele, are shown in between the Southern blots. Note that in the picture of the 5' PCR 3 empty lanes were removed between the marker lane and the lane with the $5^{\prime}$ PCR product. $B$ : reduced arginase 1 protein levels in the lungs of ovalbumin (OVA)/OVA-treated $\operatorname{Arg} 1-\mathrm{KO}^{\mathrm{LysM}}(n=9)$ or $\operatorname{Arg} 1-\mathrm{KO}{ }^{\mathrm{Tie} 2}$ mice $(n=9)$, open bars, compared with the corresponding Arg1-Con mice (solid bars). $C$ : detail of arginase 1 expression in OVA/OVA-treated Arg1-Con lung. Note absence of expression in arterial endothelium. A, artery; B, bronchus. Bar: $100 \mu \mathrm{m}$. D: sections of PBS/OVA- and OVA/OVA-treated lungs of Arg1-Con mice (left 2

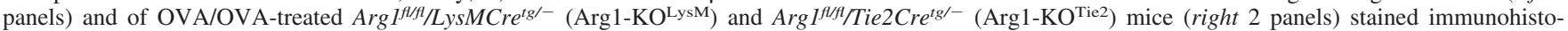
chemically for the presence of arginase 1-positive cells. Note reduction of arginase 1-positive cells in $\mathrm{Arg} 1-\mathrm{KO}^{\mathrm{LysM}}$ mice and absence in Arg1-KO ${ }^{\mathrm{Tie} 2}$ mice. $* P<0.05$ OVA/OVA vs. PBS/OVA Arg1-Con ${ }^{\text {LysM/Tie2 }} \# P<0.05$ OVA/OVA vs. PBS/OVA Arg1-KO ${ }^{\text {LysM/Tie2 }} ; \ddagger P<0.05$ OVA/OVA Arg1-Con ${ }^{\text {LysM/Tie2 }}$ vs. Arg1-KO $\mathrm{KysM}^{\mathrm{LT}} \mathrm{Tie}$. 
Francis Stewart, Biotechnology Center, TU Dresden, Germany). Selection with ganciclovir $(5 \mu \mathrm{M})$ was started 5 days after electroporation. The recombined allele was again sequence verified [ganciclovir introduces mutations in $\sim 25 \%$ of clones (our unpublished observations)]. Two clones with 40 chromosomes and a 1:1 ratio of wild-type and recombined Argl alleles [tested after digestion with Sbf1 (restriction sites outside targeting construct) and Spe1 (sites present in targeting construct only) and hybridization with the 300-bp external genomic fragment] (Fig. 1A) were selected for blastocyst injection.

Generation of transgenic mice and husbandry. All animal experiments were approved by the Committee for Animal Care and Use of Maastricht University. Argl-recombinant ES cells were injected into C57BL/6J blastocysts. Chimeric male mice were bred with female 129P2/OlaHsd mice (Harlan, The Netherlands) and with deleter-Cre females on a C57BL/6J background (48; kindly provided by Dr. Ursula Lichtenberg, University of Cologne, Cologne, Germany) to delete the Argl exon 4 in the germ line. Mice were genotyped with primers Arg1-F1 and Arg1-R1 (Table 1), yielding a 351-bp wild-type allele and a 384-bp floxed allele. The Cre-excised allele (298 bp) was detected by PCR with the primers Arg1-F2 (Table 1) and Arg1-R1. To specifically delete the floxed $\mathrm{Argl}$ allele $\left(\operatorname{Arg} \mathrm{I}^{H}\right)$ in macrophages, mice were crossed with $\mathrm{LysMCr} e^{\mathrm{tg} /-}$ (9) or Tie $2 \mathrm{Cre}^{\mathrm{tg} /-}$ mice (23). The

Table 1. Primers pairs used for genotyping and quantitative PCR

\begin{tabular}{|c|c|c|}
\hline Gene & Primer Name & Primer Sequence $\left(5^{\prime}-3^{\prime}\right)$ \\
\hline \multirow[t]{2}{*}{ Excised arginase- 1} & Arg1-F2 & TCTAGAACTAGTGGATCACCTCAG \\
\hline & Arg1-R1 & GTGCCTTGGTCTACATTGAACATAC \\
\hline \multirow[t]{2}{*}{ Cre } & CRE-F & GGTTCGCAAGAACCTGATGGACAT \\
\hline & CRE-R & GCTAGAGCCTGTTTTGCACGTTCA \\
\hline \multirow[t]{2}{*}{ Tie-2-Cre } & Tie2-F & CGCATAACCAGTGAAACAGCATTGC \\
\hline & Tie2-R & CCCTGTGCTCAGACAGAAATGAGA \\
\hline \multirow[t]{2}{*}{ LysMCre } & LysM-F & GGTTCGCAAGAACCTGATGGACAT \\
\hline & LysM-R & GCTAGAGCCTGTTTTGCACGTTCA \\
\hline \multirow[t]{2}{*}{ Arginase-1 } & Arg1-F1 & GGAGAGCCTTCCTGCACTTT \\
\hline & Arg1-R1 & GTGCCTTGGTCTACATTGAACATAC \\
\hline \multirow[t]{2}{*}{ Arginase-2 } & Arg2-F & CCAGCTGCCATTCGAGAAG \\
\hline & Arg2-R & ATCATCTTGTGGGACATTAGTAAACTC \\
\hline \multirow[t]{2}{*}{ Nos-2 } & Nos $2-\mathrm{F}$ & GCCACCAACAATGGCAACA \\
\hline & Nos2-R & CGTACCGGATGAGCTGTGAATT \\
\hline \multirow[t]{2}{*}{ Scl7al } & Cat1-F & CTGGTGGACCTCATGTCCATT \\
\hline & Cat1-R & GCTCATTCTGATCTACTCGATCTAGCT \\
\hline \multirow[t]{2}{*}{ Slc $7 a 2 b$} & Cat $2 b-F$ & GATCCATTTTCCCAATGCCTC \\
\hline & Cat $2 b-R$ & TGGAATTGATTTGAGCTAGACATTTG \\
\hline \multirow[t]{2}{*}{ Slc7a7 } & Lat1-F & GAAGGACCCCGACCGG \\
\hline & Lat1-R & AACAGCCACCAGGAAGATGG \\
\hline \multirow[t]{2}{*}{ Il4 } & IL4-F & TGGAATGTACCAGGAGCCATATCC \\
\hline & IL4-R & CTCTGTGGTGTTCTTCGTTGCTGT \\
\hline \multirow[t]{2}{*}{ Ill3 } & IL13-F & CACACAAGACCAGACTCCCCTG \\
\hline & IL13-R & GGTTACAGAGGCCATGCAATATCC \\
\hline \multirow[t]{2}{*}{ Il5 } & IL5-F & ATCAAACTGTCCGTGGGGGTACT \\
\hline & IL5-R & TCTCTCCTCGCCACACTTCTCTTT \\
\hline \multirow[t]{2}{*}{ Illo } & IL10-F & GGACAACATACTGCTAACCGACTCCT \\
\hline & IL10-R & CTGCTCCACTGCCTTGCTCTTATT \\
\hline \multirow[t]{2}{*}{ Ccl2 } & MCP1-F & GCTGGAGAGCTACAAGAGGAT \\
\hline & MCP1-R & ACAGACCTCTCTCTTGAGCTTGGT \\
\hline \multirow[t]{2}{*}{ Ccll1 } & Eotaxin $1-\mathrm{F}$ & CTGCTGCTCACGGTCACTTCCT \\
\hline & Eotaxin1-R & CAGGGTGCATCTGTTGTTGGTG \\
\hline \multirow[t]{2}{*}{ Ifng } & IFNG-F & GGTTGCTCCTCTTACCGTCTTT \\
\hline & IFNG-R & CGTGGCACTTTTTACCACAGA \\
\hline \multirow[t]{2}{*}{ Tnfa } & TNFA-F & TCAATCGGCCCGACTATCTC \\
\hline & TNFA-R & CAGGGCAATTGATCCCAAAGT \\
\hline \multirow[t]{2}{*}{ Мuc5ac } & MUC5AC-F & GATGACTTCCAGACTATCAGTG \\
\hline & MUC5AC-R & TGGCGTTAGTCAGCAGA \\
\hline \multirow[t]{2}{*}{ Clca3 } & CLCA3-F & CCGGCTGCCGCTAAAGAG \\
\hline & CLCA3-R & CAGAAGCATCAACAAGACCATTG \\
\hline \multirow[t]{2}{*}{$18 S$} & $18 \mathrm{~S}-\mathrm{F}$ & AGTTAGCATGCCAGAGTCTCG \\
\hline & $18 \mathrm{~S}-\mathrm{R}$ & TGCATGGCCGTTCTTAGTTG \\
\hline
\end{tabular}

Tie2Cre ${ }^{t g /-}$ and LysMCre $e^{t g /-}$ mice are available from Jackson Laboratories as B6.Cg- $\mathrm{Tg}^{(\text {TekCre)1Ywa } / \mathrm{J}}$ and B6.129P2-Lyz2 $2^{\text {tml(cre)Ifo } / \mathrm{J}}$

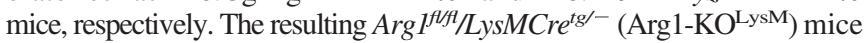
and their $\operatorname{Arg} I^{f t H t} / L y s M C r e^{-/-}$littermates (Arg1-Con) or Arg $I^{f l f t /}$ $\mathrm{Tie}^{2} \mathrm{Cre}^{\text {tg } /-}\left(\mathrm{Arg} 1-\mathrm{KO}^{\mathrm{Tie} 2}\right)$ mice and $\mathrm{Arg} \mathrm{I}^{\mathrm{HLH} /} / \mathrm{Tie} 2 \mathrm{Cre}^{-1-}$ littermates [Arg1-Con were genotyped for the presence of LysMCre or Tie2Cre by PCR with primers LysM-F and LysM-R or Tie2-F and Tie2-R (Table 1)], yielding 300-bp- or 510-bp-positive bands, respectively, for Cre-positive animals. Arg1-Con and Arg1-KO ${ }^{\text {LysM }}$ were $75 \%$ C57BL/6J and 25\% 129P2OlaHsd, whereas Arg1-Con and Arg1$\mathrm{KO}^{\mathrm{Tie} 2}$ were $50 \%$ C57BL/6J, 25\% 129P2OlaHsd, and 25\% FVB.

Antigen sensitization and challenge. Ten-week-old male Arg1$\mathrm{KO}^{\mathrm{LysM}}$ mice or Arg1-KO ${ }^{\mathrm{Tie} 2}$ mice, and their Arg1-Con littermates were injected intraperitoneally on days 0 and 14 with $10 \mu \mathrm{g}$ of ovalbumin (OVA), grade V (Sigma-Aldrich, Zwijndrecht, The Netherlands) in a total volume of $100 \mu \mathrm{PBS}$, containing $1 \mathrm{mg} / \mathrm{ml}$ of $\mathrm{AlOH}_{3}$ (alum) as adjuvant (Imject Alum, Thermo Scientific, Rockford, IL). On days 21-27, mice were exposed daily for $30 \mathrm{~min}$ to $1 \%$ $(\mathrm{wt} / \mathrm{vol})$ aerosolized OVA in PBS in custom-made inhalation chambers. The experimental groups consisted of two to three mice per genotype and treatment and the experiments were repeated on at least three different time points. AHR was assessed $12 \mathrm{~h}$ after the last challenge (41). Lung airway resistance $\mathrm{R}_{\mathrm{N}}$, tissue elastance $H$, and tissue resistance $G$ in response to inhaled aerosolized methacholine were measured by use of a Flexivent apparatus (Scireq, Montreal, Canada).

Airway hyperresponsiveness. Mice were anesthetized with pentobarbital sodium. A total dose of $120 \mathrm{mg} / \mathrm{kg}$ was administered per mouse. First $80 \mathrm{mg} / \mathrm{kg}$ was administered to induce anesthesia and 40 $\mathrm{mg} / \mathrm{kg} \sim 30 \mathrm{~min}$ later to maintain anesthesia. An 18-gauge blunt needle was inserted into the trachea and connected to a mechanical small animal ventilator (FlexiVent, Scireq, Montreal, Canada). Mice were ventilated at 200 breaths/min with a delivered tidal volume of $0.25 \mathrm{ml}$ against a positive end-expiratory pressure of $3 \mathrm{cmH}_{2} \mathrm{O}$ applied by a water trap for $10 \mathrm{~min}$ before the experiment was started. Aerosolized methacholine (Sigma, Steinheim, Germany) challenges were performed by delivering successively $0,3.1,12.5$, and $50 \mathrm{mg} / \mathrm{ml}$ methacholine in PBS. Following each methacholine challenge, ventilation was interrupted every $10 \mathrm{~s}$ to allow for 1 -s passive expiration followed by 2 -s broad-band $(1-19.6 \mathrm{~Hz})$ volume perturbation. The peak-to-peak excursion of the ventilator piston during delivery of these perturbations was $0.17 \mathrm{ml}$, resulting in a delivery of $\sim 0.14 \mathrm{ml}$ after correcting for gas compression in the ventilator cylinder and connecting tubing. Pressure and flow were recorded during application of the perturbations and used to calculate the input impedance (Zrs) of the respiratory system. Zrs was then fitted to the uniformly ventilated model of the lung with constant-phase tissue impedance $(12,16)$.

$$
\mathrm{Z}_{\mathrm{rs}}(f)=\mathrm{R}_{\mathrm{N}}+i 2 \pi f \mathrm{I}_{\mathrm{aw}}+\frac{G-i H}{(2 \pi f)^{\mathrm{a}}}
$$

$R_{N}$ is the Newtonian resistance composed mostly of the flow resistance of the conducting pulmonary airways; $I_{\mathrm{aw}}$ is the inertance of the gas in the central airways; $H$, also known as elastance, reflects the elastic energy stored in the tissues; $G$, also known as tissue resistance, reflects viscous dissipation of energy in the respiratory tissues as well as airflow heterogeneity; $f$ is frequency; $i=\mathcal{V}-1$; and $\alpha$ couples $G$ and $H . \mathrm{R}_{\mathrm{N}}, G$, and $H$ all have units of $\mathrm{cmH}_{2} \mathrm{O} \cdot \mathrm{s} \cdot \mathrm{ml}^{-1}$. $\mathrm{R}_{\mathrm{N}}$ and $G$ are shown as maximal resistance and tissue damping after application of the methacholine challenge, whereas $H$ is shown as the plateau value of the elastance following the initial peak response after the methacholine challenge.

Plasma collection and analysis. At the end of the experiment, blood was collected from the inferior caval vein in heparin-coated tubes, centrifuged for $3 \mathrm{~min}$ at $5,000 \mathrm{~g}$, snap frozen in liquid nitrogen, and stored at $-80^{\circ} \mathrm{C}$. Plasma OVA-specific IgE levels were deter- 
Table 2. Amino acid concentrations in venous plasma of 8-day-old Arg1-KO delCre

\begin{tabular}{|c|c|c|}
\hline Amino Acid & Arg1-Con & Arg1-KO $\mathrm{KO}^{\text {delCre }}$ \\
\hline Glu & $115 \pm 8$ & $210 \pm 49^{*}$ \\
\hline Asn & $97 \pm 3$ & $138 \pm 33$ \\
\hline Ser & $361 \pm 19$ & $327 \pm 85$ \\
\hline Gln & $611 \pm 26$ & $1344 \pm 279 *$ \\
\hline His & $143 \pm 7$ & $200 \pm 24$ \\
\hline Gly & $417 \pm 23$ & $326 \pm 61$ \\
\hline Thr & $293 \pm 9$ & $276 \pm 57$ \\
\hline Cit & $94 \pm 3$ & $176 \pm 12 *$ \\
\hline Arg & $251 \pm 13$ & $2185 \pm 295^{*}$ \\
\hline Ala & $452 \pm 31$ & $303 \pm 120$ \\
\hline Tyr & $190 \pm 8$ & $211 \pm 68$ \\
\hline Tau & $511 \pm 55$ & $743 \pm 96$ \\
\hline Val & $322 \pm 24$ & $300 \pm 69$ \\
\hline Met & $126 \pm 3$ & $234 \pm 52$ \\
\hline Ile & $125 \pm 11$ & $142 \pm 26$ \\
\hline Phe & $106 \pm 5$ & $82 \pm 9 *$ \\
\hline Orn & $175 \pm 16$ & $112 \pm 30$ \\
\hline Leu & $191 \pm 13$ & $206 \pm 46$ \\
\hline $\operatorname{Trp}$ & $92 \pm 2$ & $68 \pm 10 *$ \\
\hline Lys & $833 \pm 38$ & $404 \pm 31 *$ \\
\hline Total amino acids & $5,506 \pm 208$ & $7,987 \pm 1259$ \\
\hline
\end{tabular}

Values are $\mu \mathrm{M} \pm \mathrm{SE} . * P<0.05 \mathrm{Arg} 1-\mathrm{Con}^{\mathrm{delCre}}\left(\mathrm{Argl}^{+/ f t} / \mathrm{delCre}^{-/-}\right) \mathrm{vs}$. Arg1-KO ${ }^{\text {delCre }}\left(\right.$ ArgI $^{-H} /$ delCre $\left.e^{\text {tg } /-}\right)$.

mined by ELISA (MD Biosciences, M036005, Zürich, Switzerland). For the determination of plasma amino acids, $50 \mu \mathrm{l}$ of plasma was added to $4 \mathrm{mg}$ sulfosalicylic acid, vortexed, snap frozen in liquid nitrogen, and stored at $-80^{\circ} \mathrm{C}$ until use. Plasma amino acid concentrations were measured with a fully automated HPLC system (54).

Tissue isolation. Immediately following euthanasia, lungs were isolated. The left lung was filled with $4 \%$ formaldehyde (Klinipath, Deventer, The Netherlands) for $10 \mathrm{~min}$ at a pressure of $20 \mathrm{cmH}_{2} \mathrm{O}$ and submersed overnight in $4 \%$ formaldehyde at room temperature (RT) prior to paraffin embedding. The right lung was snap frozen in liquid nitrogen and pulverized in a liquid-nitrogen-chilled mortar and pestle. Tissue powder was stored at $-80^{\circ} \mathrm{C}$ until further use.

Histology and immunohistochemistry. Paraffin-embedded tissue was cut into $4 \mu \mathrm{m}$ thick sections and stained with hematoxylin \& eosin (H\&E), Sirius red (collagen fibers), or ammoniacal silver nitrate (reticular fibers). For immunostaining, epitopes were retrieved by heating the slides for $5 \mathrm{~min}$ in $10 \mathrm{mM}$ sodium citrate $(\mathrm{pH} \mathrm{6})$ at $95^{\circ} \mathrm{C}$ and cooling to RT for 30 min before blocking endogenous peroxidases with peroxidase block (DAKO, S2001, Enschede, the Netherlands) for $10 \mathrm{~min}$ at RT. This step was omitted if antibody binding was visualized with the alkaline phosphatase (AP) system. Sections were blocked with $10 \%$ normal goat serum for 30 min. After washing in PBS, slides were incubated with anti-arginase 1 (Amsterdam Liver Center, AMS40.11.13), anti-arginase 2 (sc-20151Santa Cruz Biotechnology, California), anti-myeloperoxidase (MPO; DAKO), or antimajor basic protein (MBP; kindly provided by Dr. James Lee, MT14.3.7, Mayo Clinic Scottsdale, AZ) (27). After washing, sections were incubated with a 1:200 diluted biotinylated rabbit anti-rat secondary antibody (DAKO) for $45 \mathrm{~min}$ at RT. Sections were washed, incubated with streptavidin/horseradish peroxidase (HRP; Vector) for $30 \mathrm{~min}$ at RT and developed with 3,3'-diaminobenzidine (Sigma, Steinheim, Germany) for $10 \mathrm{~min}$. Sections stained for arginase 1 and 2 were incubated with an AP-labeled secondary antibody (1:200, Sigma A-3687) for $45 \mathrm{~min}$, developed for $30 \mathrm{~min}$ with nitrobluetetrazolium and 5-bromo-4-chloro-3-indolyl phosphate (Roche, Almere, The Netherlands), dissolved in $50 \mathrm{mM} \mathrm{MgSO}_{4}, 100 \mathrm{mM}$ Tris $\cdot \mathrm{HCl}$ ( $\mathrm{pH}$ 9.5), and coverslipped with an aqueous mounting medium (DAKO)

Histological assessment. The H\&E-stained slides were used to identify inflammation in general. Sirius red- and silver nitrate-stained slides, which visualize collagen and reticular fibers, respectively, were used to assess tissue remodeling in the lungs of OVA/OVA-treated mice. MBP-, MPO-, and ARG2-positive cells in full-face sections of the lung were imaged with a panoramic 3DHISTECH slide scanner and counted with 3DHISTECH software (3DHISTECH, Budapest,
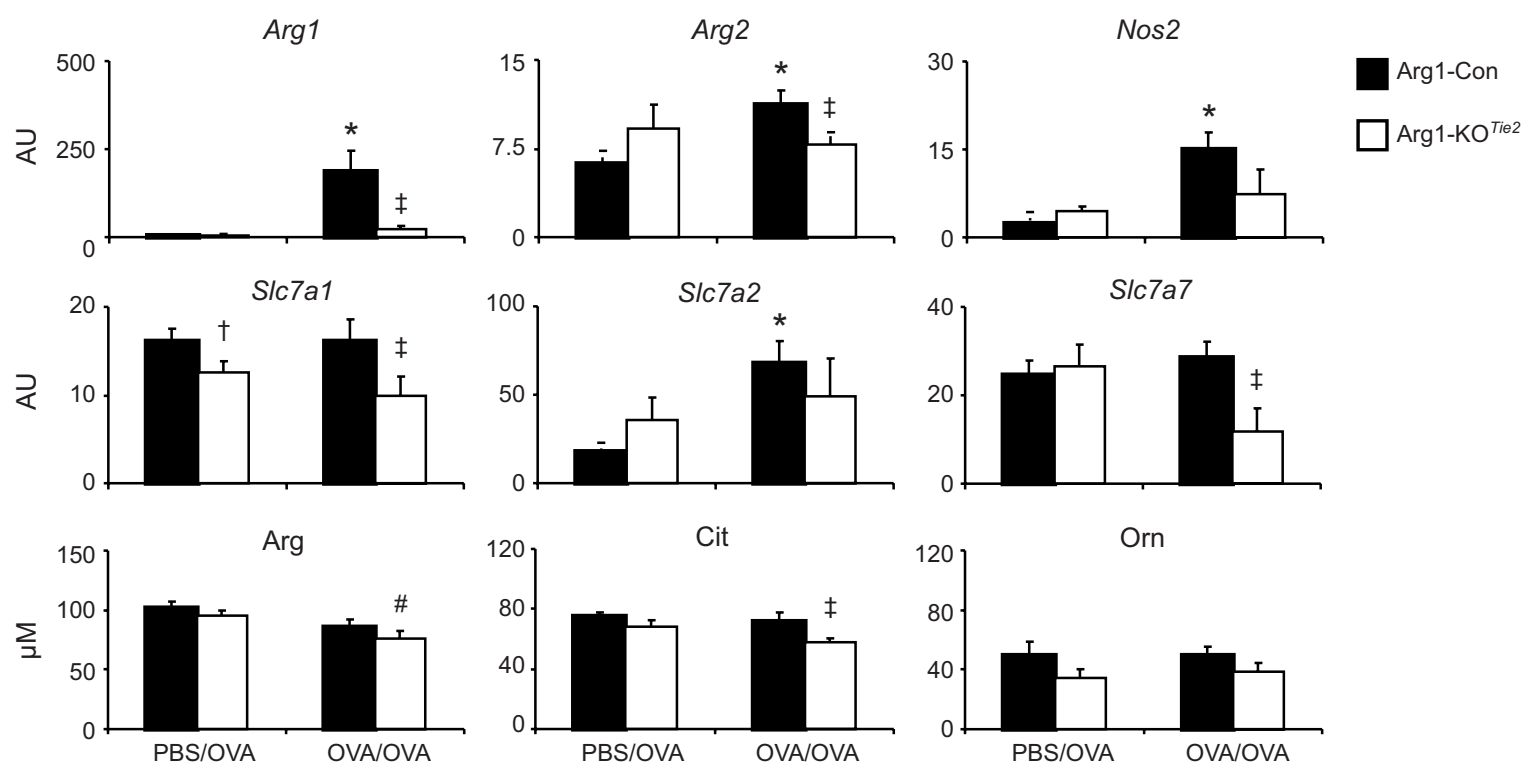

Fig. 2. Expression of arginine-metabolizing enzymes and transporters in mouse lungs that are or are not Arg1 deficient. Arg1-Con and Arg1-KOTie2 are represented by solid and open bars, respectively. Treatment (PBS/OVA or OVA/OVA) is indicated below the bars. The mRNA abundance (AU; number of mRNA copies normalized for 18S rRNA expression and multiplied by 10,000) of the arginine-metabolizing enzymes Arg1, Arg2, and Nos 2 and the arginine transporters Slc7al, Slc7a2, and Slc7a7 is shown as means \pm SE of 7-8 mice per group. Amino acid concentrations ( $\mu \mathrm{M}$ ) of arginine, citrulline, and ornithine are shown as means \pm SE (PBS/OVA-treated Arg1-Con: $n=7$; Arg1-KO ${ }^{\text {Tie } 2} ; n=8$; OVA/OVA-treated Arg1-Con: $n=10 ;$ Arg1-KO ${ }^{\text {Tie2 }} ; n=9$ ). $* P<0.05$ PBS/OVA vs. OVA/OVA Arg1-Con; $\dagger P<0.05$ PBS/OVA Arg1-KO ${ }^{\text {Tie } 2}$ vs. Arg1-Con, \#P $<0.05$ OVA/OVA vs. PBS/OVA Arg1-KO ${ }^{\text {Tie2}} ; \neq P<0.05$ OVA/OVA Arg1-Con vs. Arg1-KO $\mathrm{KO}^{\mathrm{Tie}}$. 
Hungary). Detection limits were set to count cells positive for diaminobenzidine with a diameter between 10 and $15 \mu \mathrm{m}$. The density of cells is expressed per $\mathrm{mm}^{2}$.

Milliplex assay. Tissue powder was homogenized in PBS, pH 7.6, in the presence of a proteinase inhibitor cocktail (Complete, Roche). Cytokines [CCL11 (a.k.a. eotaxin-1), IL-4, IL-5, IL-10, IL-13, TNF- $\alpha$, and IFN- $\gamma$ ] were quantified by using a Luminex xMAP multiplex platform, combined with a customized Milliplex mouse chemokine/cytokine panel from Millipore (Billerica, MA).

RNA isolation and quantification. Tissue powder was homogenized in Tri reagent (Sigma) with the Mini Bead-Beater (Biospec Products, Bartlesville, OK). To remove genomic DNA, RNA was precipitated with $2 \mathrm{M} \mathrm{LiCl}$ for at least $30 \mathrm{~min}$ at $-20^{\circ} \mathrm{C}$. RNA integrity was checked by denaturing gel electrophoresis. RNA concentration was determined with a NanoDrop-ND-1000 spectrophotometer at $260 \mathrm{~nm}$ (Isogen Life Sciences, Wilmington, DE), and $400 \mathrm{ng}$ of total RNA was transcribed using a first-strand synthesis kit (Roche). Quantitative PCR was performed in a Lightcycler 480 (Roche), using Lightcycler 480 SYBRgreen Master Mix (Roche) and the following settings: denaturation $30 \mathrm{~s}$ at $95^{\circ} \mathrm{C}$, annealing $30 \mathrm{~s}$ at $60^{\circ} \mathrm{C}$, elongation $30 \mathrm{~s}$ at $72^{\circ} \mathrm{C}, 45$ cycles, and a final elongation step for $5 \mathrm{~min}$ at $72^{\circ} \mathrm{C}$. If reverse transcriptase was omitted, no product was formed. Primary fluorescent data were exported and analyzed with the Lin-Reg Analysis program (44). mRNA abundance was expressed relative to $18 \mathrm{~S}$ rRNA abundance. Primer sequences are given in Table 1.

Western blot. Tissue powder was homogenized in RIPA buffer [25 $\mathrm{mM}$ Tris $\cdot \mathrm{HCl}(\mathrm{pH}$ 7.6), $150 \mathrm{mM} \mathrm{NaCl}, 1 \%$ Nonidet P-40, $1 \%$ Na-deoxycholate, $0.1 \%$ SDS, containing Complete cocktail (Roche)]. Protein concentration was measured with the bicinchoninic-acid assay (Pierce, Rockford, IL). Twenty-five micrograms protein was separated on an SDS-polyacrylamide gel, transferred onto $0.45 \mu \mathrm{m}$ nitrocellulose membranes by use of a wet transfer system (Bio-Rad, Hercules, $\mathrm{CA}$ ), stained with Ponceau $\mathrm{S}$ to confirm equal loading of lanes, washed with TBS (50 mM Tris, $150 \mathrm{mM} \mathrm{NaCl}, \mathrm{pH}$ 7.6), and blocked with 5\% skimmed milk in TBS/0.5\% Tween-2. Arginase 1 was visualized with rabbit anti-arginase 1 antibody (1:200), followed by an HRP-conjugated swine anti-rabbit secondary antibody (DAKO). The signal was developed using the Super Signal West Pico Substrate (Pierce) and quantified with the Fuji systems darkbox (Fuji Film Life Sciences, Tokyo, Japan).

Statistical analyses. Statistical analysis of the groups was performed using the Kruskal-Wallis test for PBS/OVA- vs. OVA/OVA-
Fig. 3. Arginase 2 expression in mouse lungs that are or are not Argl deficient. A: sections of PBS/OVA- (top row) and OVA/OVAtreated (bottom row) lungs of Arg1-Con mice (left 2 panels) and of $\mathrm{Arg} 1-\mathrm{KO}^{\mathrm{Tie} 2}$ mice (right 2 panels) stained immunohistochemically for the presence of arginase 2-positive cells. Main panels, $\times 10$ objective; insets, $\times 40$ objective. Note the increase of arginase 2-positive cells in OVA/OVA-treated mice without difference between Arg1-Con and Arg1-KO ${ }^{\mathrm{Tie} 2}$ mice. Bar: $200 \mu \mathrm{m}$. B: quantification of arginase 2-positive cells per $\mathrm{mm}^{2}$ lung tissue in PBS/ OVA- and OVA/OVA-treated Arg1-Con (solid bars) and Arg1-KO ${ }^{\mathrm{Tie} 2}$ mice (open bars). Sections were stained simultaneously. Values are shown as means $\pm \mathrm{SE}$ (PBS/ OVA-treated Arg1-Con: $n=7$; Arg1-KO ${ }^{\mathrm{Tie} 2}$; $n=8$; OVA/OVA-treated Arg1-Con: $n=10$; $\left.\operatorname{Arg} 1-\mathrm{KO}^{\mathrm{Tie} 2} ; n=9\right) . * P<0.05$ PBS/OVA vs. OVA/OVA Argl-Con; \#P $<0.05$ OVA/OVA vs. PBS/OVA Arg1-KO ${ }^{\text {Tie2 }}$.
A
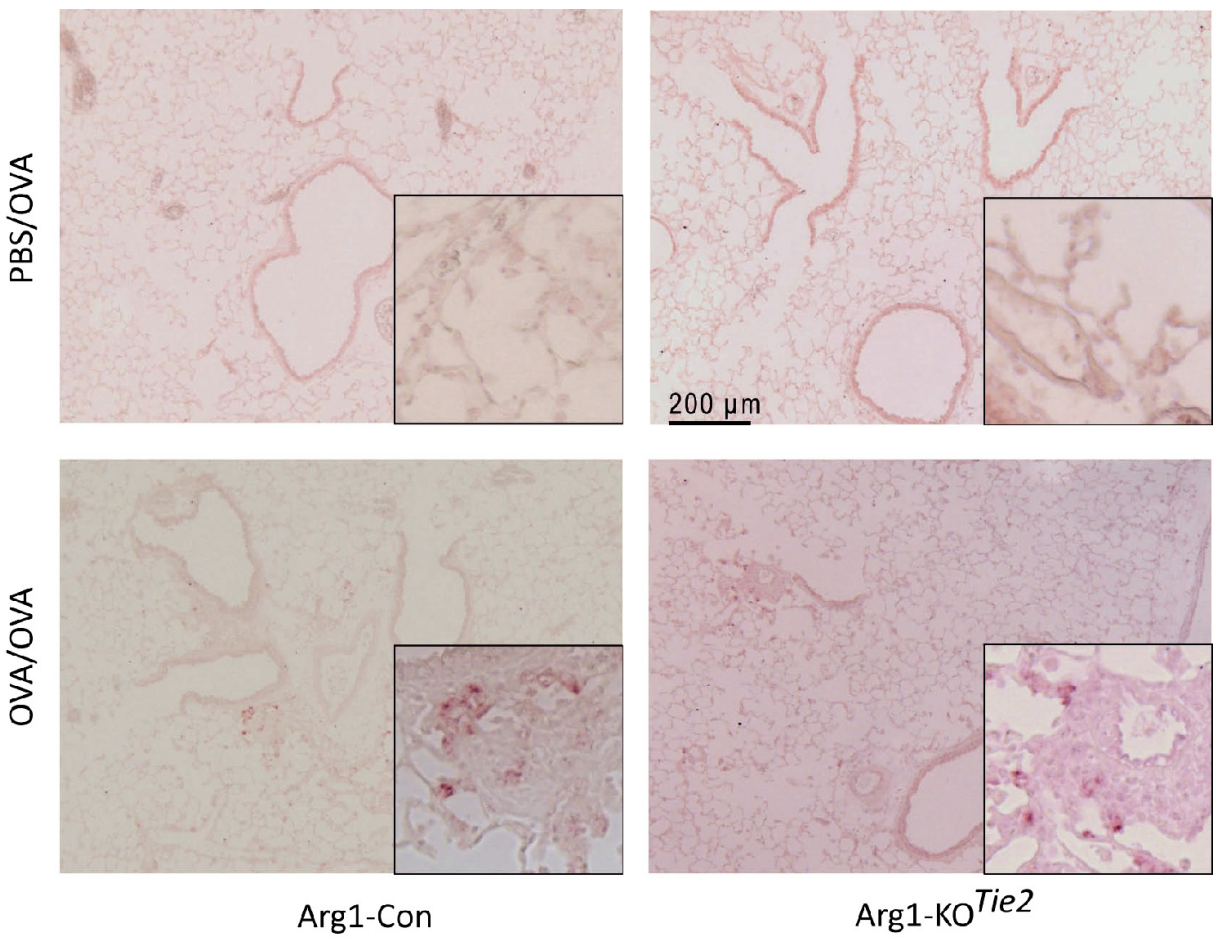

B

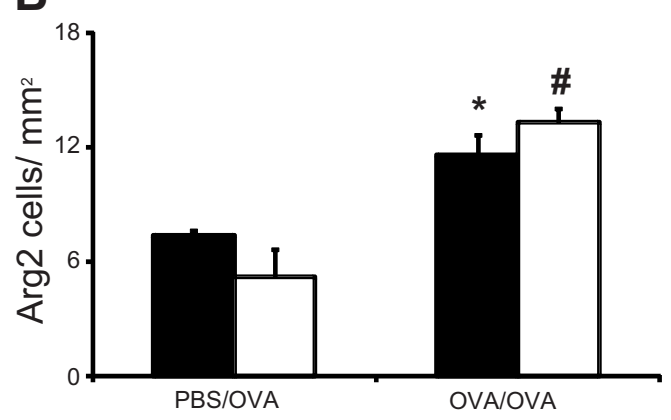

Arg1-Con

$\operatorname{Arg} 1-\mathrm{KO}^{\mathrm{Tie} 2}$ 
treated, and Arg1-Con vs. Arg1-KO mice. Only if this nonparametric test indicated the presence of a difference among experimental groups, a multiple comparison of the groups was carried out. Values were considered statistical significant if $P<0.05$, and as indicating a trend if $P<0.1$.

Pearson's bivariate two-tailed correlation coefficients between each of the lung function parameters, mRNA and protein concentrations, histology scores, and plasma amino-acid concentrations were determined after combining the data from the comparable PBS/OVA and OVA/OVA groups. In Fig. 9, $P$ values of the resulting correlation coefficients were color coded, with red indicating a $P<0.001$, orange $0.01>P>0.001$, and yellow $0.05>P>0.01$

\section{RESULTS}

Generation of conditionally Arg1-deficient mice. We flanked exon 4 with $\operatorname{lox} P$ sites to create a conditionally Argl-deficient mouse. When these $\operatorname{Arg} 1^{f l / t}$ mice were crossed with deleterCre females (48) to delete exon 4 in the germ line, the resulting Arg1 $1^{-/-}$mice died between postnatal days 10 and 14 , as reported for constitutive Arg1-deficient mice (20). At postnatal day 8, plasma levels of arginine and glutamine were approximately nine- and approximately twofold higher, respectively, whereas lysine levels were decreased to $\sim 50 \%$ in $\mathrm{Arg} 1^{-1-}$ (Arg1-KO ${ }^{\text {DelCre }}$ ) compared with $\mathrm{Arg}^{+/ f l}$ (wild-type) mice (Table 2). Although these changes, with the exception of the increased plasma arginine concentration, differ from those reported for Arg1-deficient mice in the moribund phase (20), the data show unambiguously that excision of the floxed exon 4 results in a nonfunctional Arg1 allele.

Arginase expression in the lungs of asthmatic Arg1-Con and Arg 1-KO mice. Half of the Arg1-KO ${ }^{\mathrm{LysM}}$ or Arg1-KO ${ }^{\mathrm{Tie} 2}$ mice and their Arg1-Con littermates were sensitized and then challenged with ovalbumin (OVA/OVA). The other $50 \%$ of the mice were only challenged with ovalbumin (PBS/OVA). In lungs of OVA/OVA-treated Arg1-Con mice, numerous peribronchiolar, parenchymal, and perivenous arginase 1-positive cells were found, whereas lungs of similarly treated Arg1$\mathrm{KO}^{\mathrm{LysM}}$ mice showed fewer peribronchiolar ARG1-positive cells, while no ARG1-positive cells were found in lungs of OVA/OVA-treated Arg1-KO ${ }^{\mathrm{Tie} 2}$ mice (Fig. 1D). Arginase 1 mRNA and protein were hardly detectable in the lungs of mice undergoing the PBS/OVA protocol, whereas a robust increase of arginase $1 \mathrm{mRNA}$ and protein was found in the lungs of OVA/OVA-treated Arg1-Con mice (Figs. $1 B$ and 2). The lungs of Arg1-KO ${ }^{\text {LysM }}$ OVA/OVA mice contained residual arginase 1 mRNA and protein, but the expression of arginase 1 in the lungs of Arg1-KO ${ }^{\text {Tie2 }}$ OVA/OVA mice did not exceed that seen in PBS/OVA mice (Figs. $1 B$ and 2). Quantification showed that arginase $1 \mathrm{mRNA}$ and protein concentrations in Arg1-KO ${ }^{\text {LysM }}$ OVA/OVA lungs were reduced to $40 \pm 7$ and $32 \pm 8 \%$, respectively, of that found in Arg1-Con OVA/OVA mice, and in Arg1-KO ${ }^{\text {Tie } 2}$ OVA/OVA mice to $4 \pm 2$ and $2 \pm$ $0.2 \%$, respectively, of that found in Arg1-Con OVA/OVA mice. Of note, we did not observe ARG1-positive endothelial cells in PBS/OVA or OVA/OVA-treated lung arteries (Fig. $1 C)$. Since the cell type specificity of the LysM-Cre and Tie2-Cre overlap with respect to Arg1-expressing cells, we conclude from these findings that the Arg1 allele was virtually completely deleted in the lungs of Arg1-KO $\mathrm{Kie}^{\mathrm{Ti} 2}$ mice, including their macrophages, but incompletely in $\mathrm{Arg} 1-\mathrm{KO}^{\mathrm{LysM}}$ mice. Since the phenotype of $\operatorname{Arg} 1-K^{L y s M}$ mice was minimal, we limited the description of our study to $\mathrm{Arg} 1-\mathrm{KO}^{\mathrm{Tie} 2}$ mice and their Arg1-Con littermates.

Effect of Arg1 ablation on arginine-metabolizing and -transporting genes in lung and on circulating amino acids. We next investigated to what extent Argl ablation caused adaptive changes in the expression of arginine-metabolizing or -transporting proteins (Fig. 2). Compared with PBS/OVA treatment, OVA/OVA induced increases in expression of Arg1, Arg2, Nos2, and Slc7a2 mRNA in the lungs of Arg1-Con mice, whereas the expression of $S l c 7 a 1$ and Slc $7 a 7$ was not changed. In contrast, OVA/OVA treatment failed to induce an increase in expression of Arg1, Arg2, Nos2, and Slc7a2, and decreased that of Slc7al and Slc7a7 in $\operatorname{Arg} 1-\mathrm{KO}^{\mathrm{Tie} 2}$ mice. Furthermore, we evaluated the expression pattern of arginase 2 protein in sections of PBS/OVA and OVA/OVA-treated Arg1-Con and Arg1-KO ${ }^{\mathrm{Tie} 2}$ mice (Fig. 3). As expected (59) arginase 2-positive cells with the morphology of macrophages accumulated in the lungs of OVA/OVA-treated mice. Quantification revealed a small increase in the number of ARG2-positive cells after OVA/OVA treatment, compared with PBS/OVA treatment, but no difference was detected between Arg1-Con and Arg1$\mathrm{KO}^{\mathrm{Tie} 2}$ mice.

Relative to PBS/OVA, OVA/OVA treatment caused a decrease in the concentration of circulating arginine and citrulline (Fig. 2), and asparagine, serine, histidine, glycine, tyrosine, and methionine (Table 3) in Arg1-KO $\mathrm{KO}^{\mathrm{Tie} 2}$ mice, whereas that of glutamate increased. When OVA/OVA-treated Arg1-Con and $\operatorname{Arg} 1-\mathrm{KO}^{\mathrm{Tie} 2}$ mice were compared, the latter had lower concentrations of glycine, citrulline, and isoleucine (Table 3).

Argl ablation improves peripheral lung function in OVA/ OVA-treated mice. To determine whether Arg1 ablation has an effect on respiratory mechanics, we measured responsiveness

Table 3. Amino-acid concentrations in venous plasma of Arg1-Con and Arg1-KO Tie2 mice

\begin{tabular}{lcccc}
\hline \hline & Arg1-Con & Arg1-KO & Arg1-Con & Arg1-KO \\
\hline Amino 2 \\
Glu & PBS/OVA & PBS/OVA & OVA/OVA & OVA/OVA \\
Asn & $15 \pm 2$ & $13 \pm 2$ & $28 \pm 1 *$ & $26 \pm 2 \dagger$ \\
Ser & $39 \pm 3$ & $38 \pm 3$ & $30 \pm 2$ & $26 \pm 2 \dagger$ \\
Gln & $136 \pm 31$ & $118 \pm 22$ & $87 \pm 13$ & $52 \pm 5 \dagger$ \\
His & $834 \pm 48$ & $822 \pm 25$ & $823 \pm 46$ & $752 \pm 67$ \\
Gly & $110 \pm 6$ & $107 \pm 5$ & $96 \pm 5$ & $84 \pm 3 \dagger$ \\
Thr & $297 \pm 63$ & $279 \pm 30$ & $199 \pm 9$ & $155 \pm 7 \dagger \S$ \\
Cit & $131 \pm 6$ & $121 \pm 6$ & $125 \pm 8$ & $112 \pm 5$ \\
Arg & $75 \pm 2$ & $68 \pm 3$ & $71 \pm 6$ & $57 \pm 3 \S$ \\
Ala & $102 \pm 4$ & $95 \pm 5$ & $85 \pm 6$ & $76 \pm 6 \dagger$ \\
Tyr & $750 \pm 59$ & $702 \pm 31$ & $686 \pm 17$ & $604 \pm 51$ \\
Tau & $174 \pm 5$ & $179 \pm 11$ & $161 \pm 10$ & $134 \pm 9 \dagger$ \\
Val & $189 \pm 13$ & $184 \pm 13$ & $166 \pm 12$ & $144 \pm 12$ \\
Met & $262 \pm 13$ & $219 \pm 9 \ddagger$ & $256 \pm 14$ & $218 \pm 9$ \\
Ile & $51 \pm 2$ & $50 \pm 2$ & $46 \pm 3$ & $40 \pm 2 \dagger$ \\
Phe & $142 \pm 9$ & $114 \pm 6 \ddagger$ & $136 \pm 9$ & $111 \pm 5 \S$ \\
Orn & $32 \pm 3$ & $28 \pm 2$ & $31 \pm 1$ & $25 \pm 2$ \\
Leu & $49 \pm 9$ & $34 \pm 6$ & $49 \pm 5$ & $38 \pm 5$ \\
Trp & $184 \pm 11$ & $154 \pm 8$ & $178 \pm 12$ & $153 \pm 7$ \\
Lys & $235 \pm 10$ & $229 \pm 10$ & $219 \pm 10$ & $214 \pm 9$ \\
Total amino acids & $4,233 \pm 264$ & $3,959 \pm 154$ & $3,865 \pm 107$ & $3,379 \pm 169$ \\
\hline
\end{tabular}

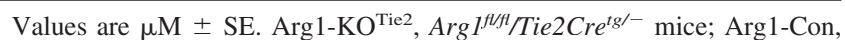
their Arg $I^{f l y t} / T_{i e} 2 \mathrm{Cr}^{-/-}$littermates. ${ }^{*} P<0.05$ PBS/OVA vs. OVA/OVA Arg1-Con; $\dagger P<0.05$ PBS/OVA vs. OVA/OVA Arg1- $\mathrm{KO}^{\mathrm{Tie} 2} ; \ddagger P<0.05$ Arg1-Con vs. Arg1-Con ${ }^{\text {Tie2 }}$ PBS/OVA; $\$ P<0.05$ Arg1-Con vs. Arg1Con $^{\text {Tie2 }}$ OVA/OVA. 
to inhaled methacholine (Fig. 4). Compared with PBS/OVA, OVA/OVA treatment of $\mathrm{Arg} 1-\mathrm{KO}^{\mathrm{Tie} 2}$ and Arg1-Con mice resulted in an increase in $R_{N}$ upon exposure to methacholine $(P<0.04)$, albeit without difference between the $\operatorname{Arg} 1-\mathrm{KO}^{\mathrm{Tie} 2}$ and Arg1-Con mice. $H$, which was higher in OVA/OVA- than in PBS/OVA-treated Arg1-Con mice, was attenuated in OVA/ OVA-treated Arg1-KO ${ }^{\mathrm{Tie} 2}$ mice $(P<0.0009)$. Compared with PBS/OVA, OVA/OVA treatment also increased $G$ in Arg1Con and Arg1-KO ${ }^{\mathrm{Tie} 2}$ mice upon exposure to methacholine, but the response in $\mathrm{Arg} 1-\mathrm{KO}^{\mathrm{Tie} 2}$ mice was significantly lower $(P<0.001)$ than in Arg1-Con mice. In aggregate, these findings show that the absence of arginase 1 in the lung does not affect $\mathrm{R}_{\mathrm{N}}$ but does affect $H$ and $G$, which reflect properties of the lung parenchyma rather than of the larger airways $(12,16)$.

Arg1 ablation affects levels of $m R N A$ and selected proteins of inflammatory genes in lung. We next investigated whether Argl ablation in the lung had an effect on the expression of asthma-associated cytokines (Fig. 5). As expected, OVA/OVA treatment resulted in an increased abundance of $I l 4, I l 13, I l 5$,

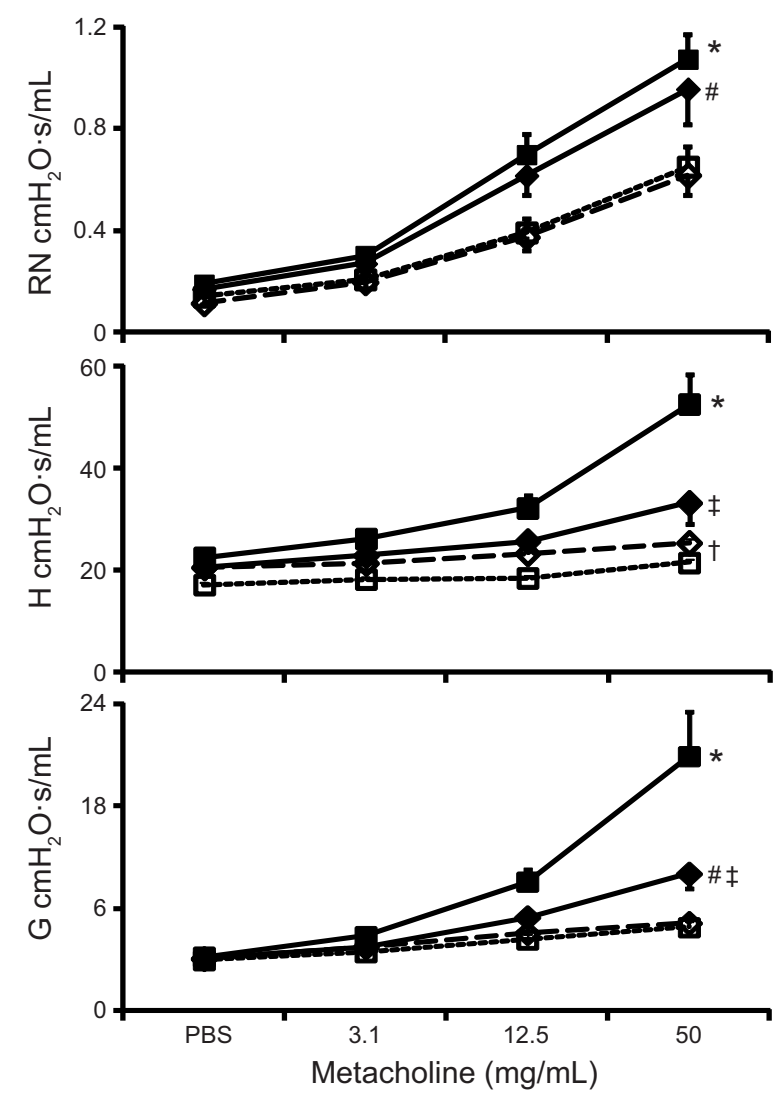

Fig. 4. Lung function in mouse lungs that are or are not Argl deficient. The responsiveness to increasing doses of aerosolized methacholine on airway resistance $\left(\mathrm{R}_{\mathrm{N}}\right)$, tissue elastance $(H)$, and tissue resistance $(G)$ was measured. PBS/OVA-treated Arg1-Con mice: $\square$ and dotted line; PBS/OVA-treated Arg1$\mathrm{KO}^{\mathrm{Tie} 2}$ mice: $\diamond$ and dashed line. OVA/OVA-treated Arg1-Con mice: $\mathbf{\square}$ and solid line; OVA/OVA-treated Arg1-KO ${ }^{\mathrm{Tie} 2}$ mice: $\bullet$ and solid line. Values on the $x$-axis represent the aerosolized methacholine concentrations used $(\mathrm{mg} / \mathrm{ml})$.

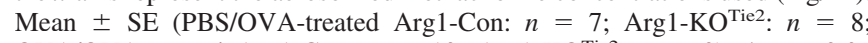
OVA/OVA-treated Arg1-Con: $n=10$, Arg1-KO $\left.{ }^{\text {Tie2 }}: n=9\right) . * P<0.05$ OVA/OVA vs. PBS/OVA Arg1-Con ${ }^{\text {Tie2}}$; \#P $<0.05$ OVA/OVA vs. PBS/OVA Arg1-KO ${ }^{\mathrm{Tie} 2} ; \ddagger P<0.01$ OVA/OVA Arg1-KO ${ }^{\mathrm{Tie} 2}$ vs. Arg1-Con ${ }^{\mathrm{Tie} 2} ; \dagger P<$ $0.001 \mathrm{PBS} / \mathrm{OVA}$ Arg1-KO ${ }^{\mathrm{Tie} 2}$ vs. Arg1-Con ${ }^{\mathrm{Tie} 2}$.
Ccll1, Ccl2, and Ill0 mRNAs in Arg1-Con mice. The OVA/ OVA-induced increase in Ccll1 expression was markedly reduced in $\operatorname{Arg} 1-\mathrm{KO}^{\mathrm{Tie} 2}$ mice. Furthermore, the expression of the inflammatory markers Tnfa and Ifng was strongly suppressed. The expression of the respiratory epithelium-specific Muc5ac and Clca3 genes was increased upon OVA/OVA treatment in both Arg1-Con and Arg1-KO animals, but the response was markedly attenuated in $\operatorname{Arg} 1-\mathrm{KO}^{\mathrm{Tie} 2}$ mice, in particular with respect to Clca3.

To investigate whether Argl deletion in the lung also affected the pulmonary protein concentration of cytokines and chemokines, we performed ELISAs for IL-4, IL-13, IL-5, CCL11 (eotaxin-1), IL-10, TNF- $\alpha$, and IFN- $\gamma$ on whole lung extracts (Fig. 6). Except for IL-10 and IFN- $\gamma$, the pulmonary concentration of these proteins increased after OVA/OVA treatment, but the increase in IL-13 and CCL11 concentration was significantly lower in $\mathrm{Arg} 1-\mathrm{KO}^{\mathrm{Tie} 2}$ than in $\mathrm{Arg} 1-\mathrm{Con}$ mice. These data show that the production of most asthmaassociated cytokines proceeded independently of Argl deficiency in the lung.

Effect of Arg1 deletion on the production of OVA-specific IgE. OVA-specific IgE was undetectable in plasma of PBS/ OVA-treated mice but increased to easily detectable concentrations after OVA/OVA treatment in both wild-type and knockout mice, without significant differences between animals with or without Arg1 ablation (Fig. 6). Apparently, ablation of Argl in Arg1-KO ${ }^{\mathrm{Tie} 2}$ mice did not affect the adaptive immune response to ovalbumin.

Effects of Argl deletion on tissue inflammation. Finally, we investigated whether Argl ablation in the lung modified the allergic asthma-induced inflammatory response of the lung (Fig. 7). We did not observe any inflammatory cells in H\&Eor ARG1-stained lung sections of PBS/OVA-treated mice (Fig. $7 A$, top row, and Fig. $1 D$ ). Furthermore, there were no cells that contained MBP and MPO, which are markers for eosinophils and neutrophils, respectively (Fig. 7A, middle and bottom rows). In lungs of OVA/OVA-treated mice, on the other hand, many inflammatory cells were present, without discernible differences between Arg1-KO $\mathrm{Kie}^{\mathrm{Ti}}$ mice and their Arg1-Con littermates. In lung sections stained for Sirius red and reticulin we found no differences between the OVA/OVA-treated Arg1Con and $\operatorname{Arg} 1-\mathrm{KO}^{\mathrm{Tie} 2}$ mice in the amount of stained fibers (Fig. 8). We quantified the number of MBP- and MPO-positive cells, and did not find differences between Arg1-KO ${ }^{\text {Tie2 } 2}$ mice and their Arg1-Con littermates either (Fig. 7B). Furthermore, lung sections stained for the presence of collagen and reticular fibers showed a similar degree of remodeling upon OVA/OVA treatment between Arg1-Con and Arg1-KO ${ }^{\text {Tie2 }}$ mice (Fig. 8). Apparently, Argl ablation in the lung does not affect the infiltration of inflammatory cells or tissue remodeling in response to experimental asthma, nor does it induce or reduce remodeling effects.

Comparison of the adaptive responses of Arg1-Con and Arg1-KO Tie2 mice. To answer the question whether arginase 1 activity exerted a coherent influence on the adaptive responses to asthma, we also investigated the correlation coefficients between each of the lung-function parameters, mRNA and protein concentrations, histology scores and plasma aminoacid concentrations (Fig. 9). In Arg1-Con mice, lung function parameters $H$ and $G$ corresponded well mutually and with IL-5, IL-13, and CCL11. Except for Slc7a7, Slc7a1, Tnfa, and Ifng 

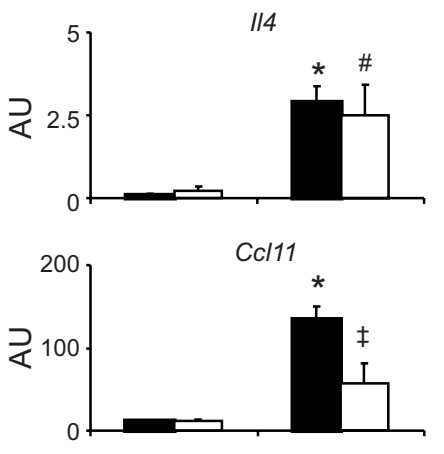

Tnf
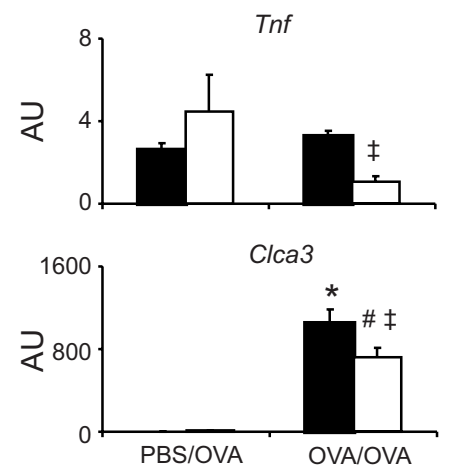
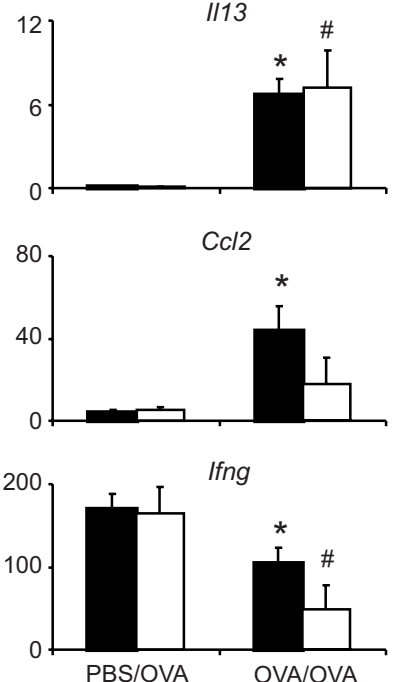

Arg1-Con

Arg1-KO ${ }^{\text {Tie2 }}$
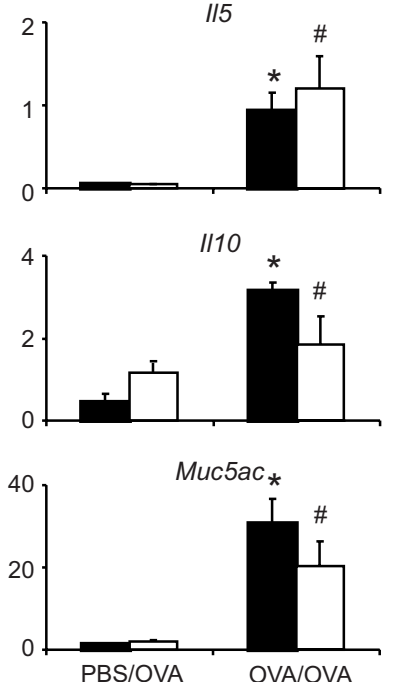

PBS/OVA OVA/OVA

Fig. 5. Inflammatory gene expression in mouse lungs that are or are not Argl deficient. Arg1-Con and Arg1-KO ${ }^{\mathrm{Tie} 2}$ are represented by solid and open bars, respectively. Treatment (PBS/OVA or OVA/OVA) is indicated below the bars. Pulmonary expression of $\mathrm{T}_{\mathrm{H}}$ 2-related inflammatory genes $\mathrm{Il4}$, Il13, Il5, and Ccll1, macrophage-chemotactic protein $\mathrm{Ccl} 2$, anti-inflammatory gene Illo, $\mathrm{T}_{\mathrm{H}} 1$-related inflammatory genes Ifng and Tnfa, and marker genes for the activation of bronchiolar epithelium Muc5ac and Clca3 is shown as means \pm SE (PBS/OVAtreated Arg1-Con: $n=7$; $\operatorname{Arg} 1-\mathrm{KO}^{\mathrm{Tie} 2}: n=$ 8; OVA/OVA-treated Arg1-Con: $n=10$; Arg1-KO ${ }^{\text {Tie2 }}: n=9$ ). The number of mRNA copies was normalized for $18 \mathrm{~S}$ rRNA expression and multiplied by 10,000 . $* P<$ 0.05 PBS/OVA vs. OVA/OVA Arg1-Con; $\# P<0.05$ PBS/OVA vs. OVA/OVA Arg $1-$ $\mathrm{KO}^{\mathrm{Tie} 2} ; \ddagger P<0.05$ OVA/OVA $\mathrm{Arg} 1-\mathrm{KO}^{\mathrm{Tie} 2}$ vs. Arg1-Con.

mRNAs, mRNA concentrations correlated very well mutually and with the corresponding proteins (including ARG1). Tissue concentrations of IL-4, IL-13, IL-5, CCL11, and TNF- $\alpha$ correlated mutually. Finally, it should be mentioned that IL-10, IFN- $\gamma$, and OVA-specific IgE did not correlate tightly with any of the other markers investigated. In aggregate, these data show that H, Slc7a2b, Arg1, Nos2, Il4, Ill3, Il5, Ccl11, Ill0, Ccl2, Muc5ac, and Clc3a mRNA, ARG1, IL-4, IL-13, IL-5, CCL11, and TNF- $\alpha$ protein are sensitive parameters to assess quantitative differences in the allergic pulmonary response to OVA. The best overall cross-correspondence was seen for $H, I l 4$, Il13, and Il5 mRNA, IL-13, IL-5, CCL11, and TNF- $\alpha$ protein. Striking were the weak cross-correspondences of these parameters with $R_{N}$ and mRNAs coding for arginine-metabolizing and transporting proteins, Furthermore, only the density of MBP-positive cells in the lung correlated weakly with lung function and gene expression, whereas virtually no correlation was found for MPO-positive cells.

Relative to $\mathrm{Arg} 1-\mathrm{Con}$ mice, $\mathrm{Arg} 1-\mathrm{KO}^{\mathrm{Tie} 2}$ mice showed a pronounced general loss of correspondence of OVA/OVAsensitive parameters (Fig. 9). A few correlations became stronger, such as that of $H$ with Nos 2 mRNA, IL-4 protein, and plasma citrulline concentrations and that of $\mathrm{Arg} 1 \mathrm{mRNA}$ with IL-4, IL-5, CCL11, and TNF- $\alpha$ protein concentrations. In aggregate, the data show that the near complete elimination of Argl expression from the lung disturbed the coordinated pulmonary response to OVA/OVA treatment, that is, showed that some aspect of arginine metabolism coordinated this response.
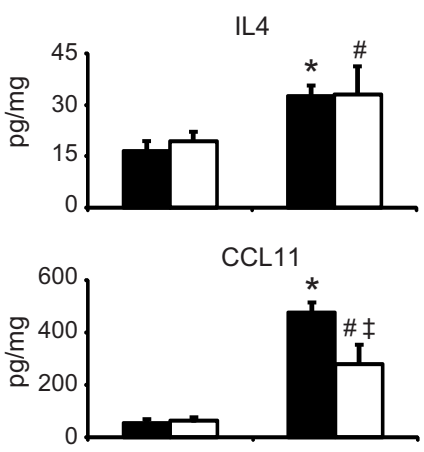

IFN-y

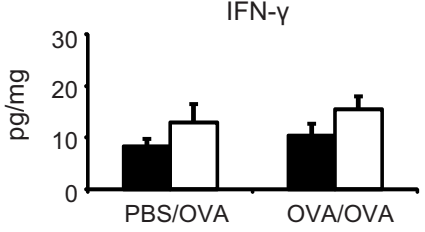

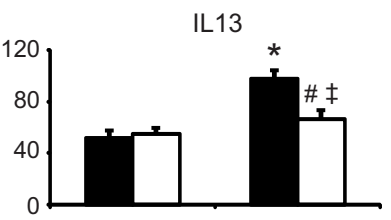

IL10

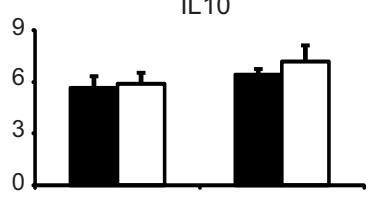

$\lg \mathrm{E}$

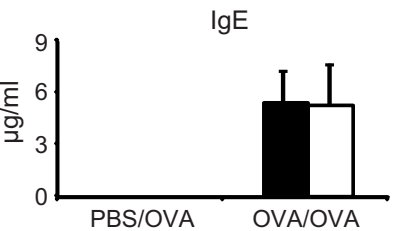

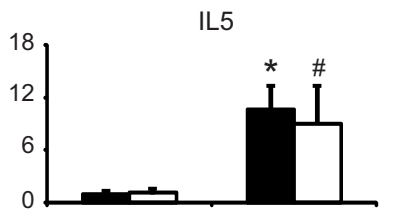

TNF- $\alpha$

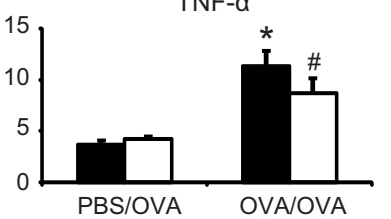

Arg1-Con

Arg1-KO ${ }^{\text {Tie2 }}$
Fig. 6. Pulmonary concentration of inflammatory cytokines, chemokines, and OVAspecific $\operatorname{IgE}$ in mouse lungs that are or are not Argl deficient. Arg1-Con (solid bars) and Arg1-KO ${ }^{\mathrm{Tie} 2}$ (open bars) mice. Treatment of the mice (PBS/OVA or OVA/OVA) is indicated. The pulmonary concentration of IL-4, IL-13, IL-5, CCL11, IL-10, TNF- $\alpha$, and IFN- $\gamma$, and OVA-specific IgE in plasma is shown as means $\pm \mathrm{SE}$ (PBS/OVA-treated Arg1-Con: $n=7$; $\operatorname{Arg} 1-\mathrm{KO}^{\mathrm{Tie} 2}: n=8$; OVA/OVA-treated Arg1-Con: $n=10$; Arg1-KO $\left.{ }^{\text {Tie2}}: n=9\right)$. ${ }^{*} P<0.01$ vs. PBS/ OVA Arg1-Con; $\# P<0.01$ vs. PBS/OVA Arg1-KO ${ }^{\text {LysM/Tie } 2} ; \ddagger P<0.001$ vs. OVA/ OVA Arg1-Con. 
A
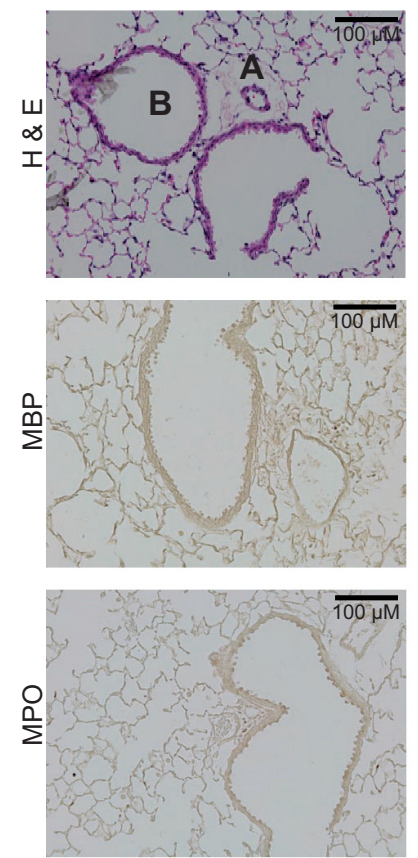

PBS/OVA
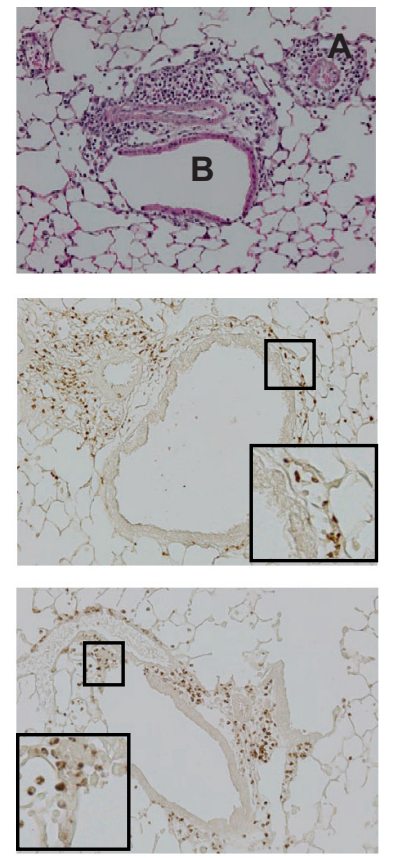

OVA/OVA
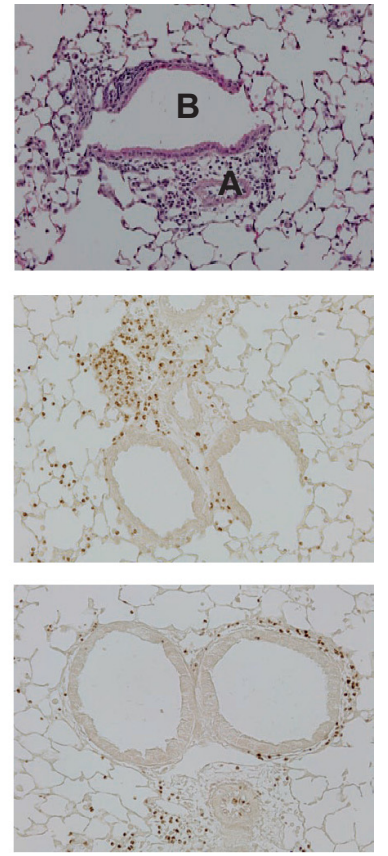

OVA/OVA

$\operatorname{Arg} 1-\mathrm{KO}^{\mathrm{Tie} 2}$

B

Arg1-Con ${ }^{\text {Tie } 2}$
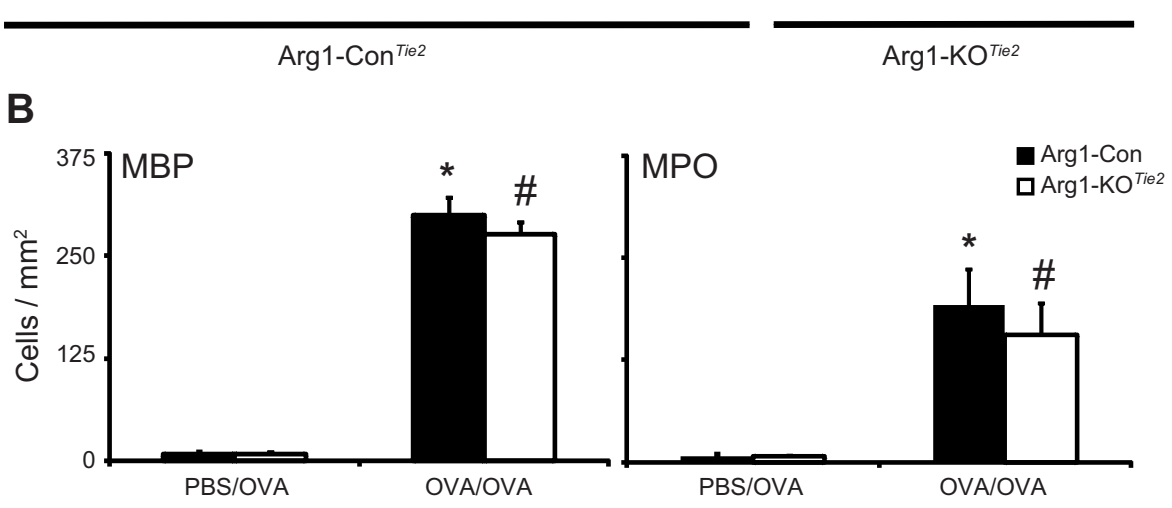

\section{DISCUSSION}

We generated mice in which exon 4 of the Argl gene was floxed and effectively ablated arginase 1 expression in the lung by crossing them with Tie2Cre mice. Ablation of Arg1 in hematopoietic and endothelial cells did not affect OVA sensitization, as reflected in a similar increase in OVA-specific IgE in plasma of Arg1-Con and Arg1-KO mice. OVA sensitization and challenge of Arg1-KO mice did not affect $\mathrm{R}_{\mathrm{N}}$ but attenuated $H$ and $G$, indicating that $\operatorname{Arg} 1$ ablation mainly affected the lung parenchyma. Furthermore, it reduced the mRNA abundance of Arg2, Slc7a1, Slc7a7, Ccl11, Tnfa and Clca3 in OVA/OVA-treated mice. Correlation analysis revealed that Arg1 ablation in the lung disturbed the coordinated pulmonary response to OVA/OVA treatment and made it more dependent on adaptive changes in arginine metabolism.

All our experiments were carried out in mice constructed in the 129Sv strain and backcrossed to the C57BL/6J strain. Since allergic asthma is considered a $\mathrm{T}_{\mathrm{H}} 2$-dominated immune disorder, it is sometimes argued that the $\mathrm{T}_{\mathrm{H}} 1$-responsive $\mathrm{C} 57 \mathrm{BL} / 6 \mathrm{~J}$ mouse strain is less suitable to OVA sensitization and challenges than e.g., the $\mathrm{T}_{\mathrm{H}}$ 2-responsive $\mathrm{BALB} / \mathrm{c}$ mouse strain. However, (nearly) all genetically modified mice are bred in the C57BL/6J strain. To avoid undue influence of the genetic background of the

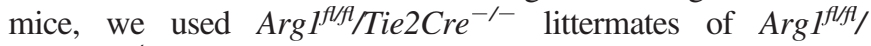
Tie $2 \mathrm{Cre}^{\mathrm{tg} /-}$ mice as reference throughout the study.

Macrophages are the main myeloid-derived cells that express arginase upon induction by $\mathrm{T}_{\mathrm{H}} 2$ cytokines in rodents (37). Because no macrophage-selective Cre line exists, we used both LysMCre (9) and Tie2Cre (23) mice to bring about Argl ablation in macrophages. Whereas the expression of LysMCre is confined to macrophages and granulocytes (9), that of Tie2Cre includes all hematopoietic and endothelial cells (47). However, we found that the endothelium of lung arteries does not contain arginase 1, whereas, to the best of our knowledge, murine lymphocytes also do not express arginase. Furthermore, Tie2Cre-mediated ablation is usually complete $(15,23,25,47)$, whereas LysMCre-mediated ablation is notably less effective, with target excision in 50-80\% of the target cells $(9,14,21,58)$. In agreement with these earlier findings, we observed a much smaller reduction of arginase 1 protein in the lungs of OVA/OVA-treated Arg1-KO ${ }^{\mathrm{LysM}}$ mice (to 

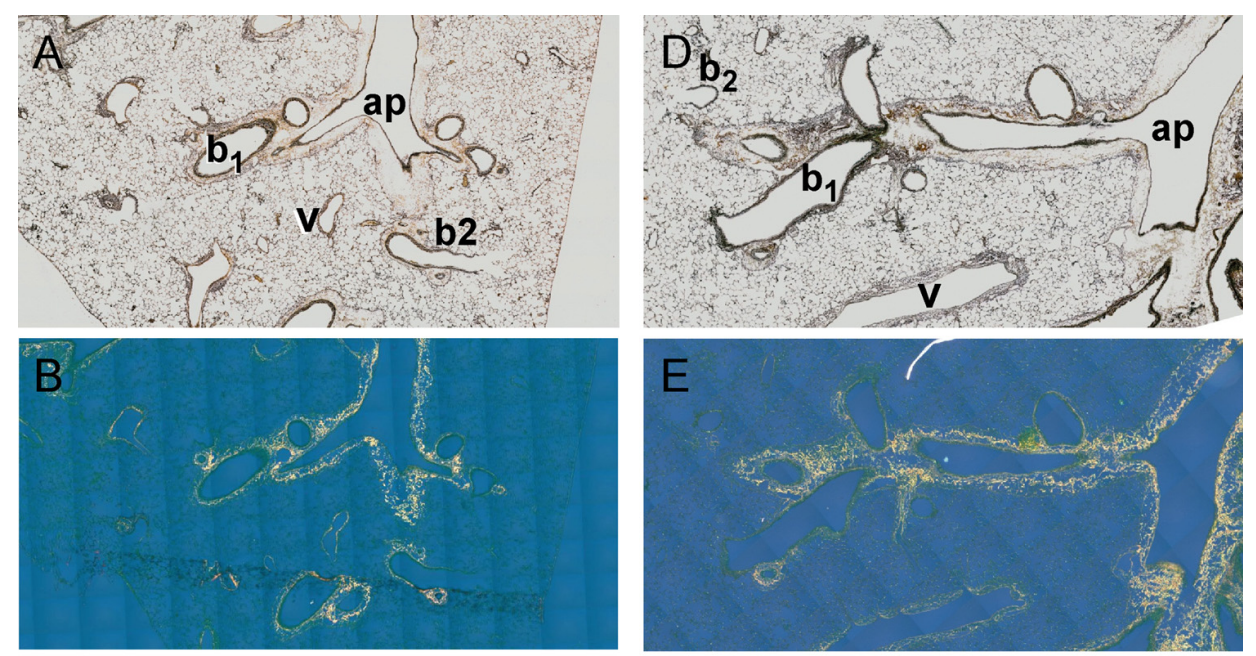

C

$1 \mathrm{~mm}$
F

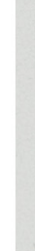

Fig. 8. Lung sections of OVA/OVA-treated mice stained for the presence of reticular and collagen fibers, and NOS2. Serial sections of Argl-KO $(A-C)$ and Arg1-Con mice $(D-F)$ were stained with silver nitrate (reticular fibers; $A$ and $D$ ), Sirius red (collagen fibers; $B$ and $E$ ), or NOS2 $(C$ and $F$ ). Note presence of additional reticular and collagen fibers in the cuff around main bronchi (b1) and arteries of OVA/OVA-treated mice, but the absence of such fibers around these structures in the parenchyma (b2). NOS2 was only found in the epithelium of bronchi that were not enveloped in connective-tissue sheaths. ap, Pulmonary artery; v, pulmonary vein. $\sim 30 \%$ ) than in the lungs of similarly treated $\mathrm{Arg} 1-\mathrm{KO}^{\mathrm{Tie} 2}$ mice or in thioglycollate-elicited peritoneal macrophages of these mice (53) (to $\sim 2 \%$ ). Of interest, a recent study (9a) identified the ARG1-positive macrophages as $\mathrm{CD}_{11} \mathrm{~b}^{+} \mathrm{Gr} 1^{+} \mathrm{F} 4 / 80^{+} \mathrm{Ly}-$ $6 \mathrm{C}^{-} \mathrm{Ly}-6 \mathrm{G}^{+}$myeloid-derived suppressor cells and ascribed to them, together with the $\mathrm{CD} 11 \mathrm{~b}^{+} \mathrm{Gr} 1^{+} \mathrm{F} 4 / 80^{+} \mathrm{Ly}-6 \mathrm{C}{ }^{-} \mathrm{Ly}-6 \mathrm{G}^{+}$ monocytoid cells, which mainly produce $\mathrm{NO}$, a key coordinating role in the manifestation of allergic asthma. The expression of arginase 1 in cells that resemble lung macrophages and the near-complete elimination of Argl expression from the lung and from peritoneal macrophages in $\operatorname{Arg} 1-\mathrm{KO}^{\mathrm{Tie} 2}$ mice, therefore, shows that we did target arginase 1 expression in macrophages and that the present study allows conclusions with respect to the role of arginase 1 in allergic asthma of mice. Since the described phenotype was only observed in the Tie2 line, Argl deletion in macrophages apparently had to be near complete to mediate pronounced effects.

Arg1 ablation affects the expression of genes coding for arginine-metabolizing and-transporting proteins. The genetic elimination of Arg1 in macrophages of OVA/OVA-treated mice decreased the expression of Arg2, Slc7a1 (Cat1), and Slc7a7 (Lat1) mRNAs. These effects point to an arginase 1-dependent, and, hence, probably an arginine concentration-dependent decline in expression of genes involved in arginine transport and metabolism. The OVA/OVA-mediated increase in pulmonary arginase activity is reported to reduce parenchymal arginine content approximately twofold (22), but did not prevent an approximately twofold increase in NO production (4).

Effect of Argl ablation on lung mechanics. $\mathrm{R}_{\mathrm{N}}$ in the large airways of OVA/OVA-treated Argl-deficient mice was not different from that in similarly treated animals without the deletion, but $H$ and $G$ were markedly lower in the Arg-KO ${ }^{\text {Tie2 }}$ mice. $H$ and $G$ primarily reflect peripheral lung function (1) and may, in allergic asthma, reflect "closure" of peripheral airways by mucous bridges $(30,31,55)$. In agreement, the mRNA abundance of Clca3 (Gob5), which regulates mucus production, and the mucin Muc5ac were lower in OVA/OVAtreated Arg1-KO ${ }^{\mathrm{Tie} 2}$ than Arg1-Con mice. Overexpression of Clca3 exacerbates AHR in OVA/OVA-treated mice, whereas downregulation attenuates peak airway pressure (resistance) after methacholine $(29,38)$, strongly suggesting a role for this gene in the development of peripheral responsiveness. On the basis of our observations in sections stained for the presence of collagen and reticular fibers, the improved peripheral lung function could not be caused by less remodeling in OVA/OVA-treated Arg1-KO ${ }^{\mathrm{Tie} 2}$ mice compared with Arg1-Con mice.

The effects of arginase 1 activity on the biomechanics of asthmatic lungs were also studied pharmacologically. Inhibitors of arginase activity decreased airway resistance in OVA/OVAtreated guinea pigs $(33,34)$ and mice, but did not change $(19,40)$ or even increased (7) $H$ and $G$ in mice. These pharmacological findings differ from the present findings in a genetic model and suggest that systemic and, in our case, macrophage-specific suppression of arginase activity has different effects. In fact, the presence or absence of arginase 1 in lung macrophages seems to be more important than its concentration, because the strong increase in Arg1 and Arg2 expression that was observed in OVA/OVA-treated Nos2-deficient mice compared with control (C57BL/6) mice (4) did not affect AHR (and eosinophil influx) (42). On the basis of our findings in an OVA/OVA-treated arginine-deficient mouse model (our unpublished observations), we speculate that changes in the circulating concentration of arginine primarily affect the function of the larger airways, whereas the local presence or absence of arginase 1 primarily affects the function of the peripheral airways. This explanation 


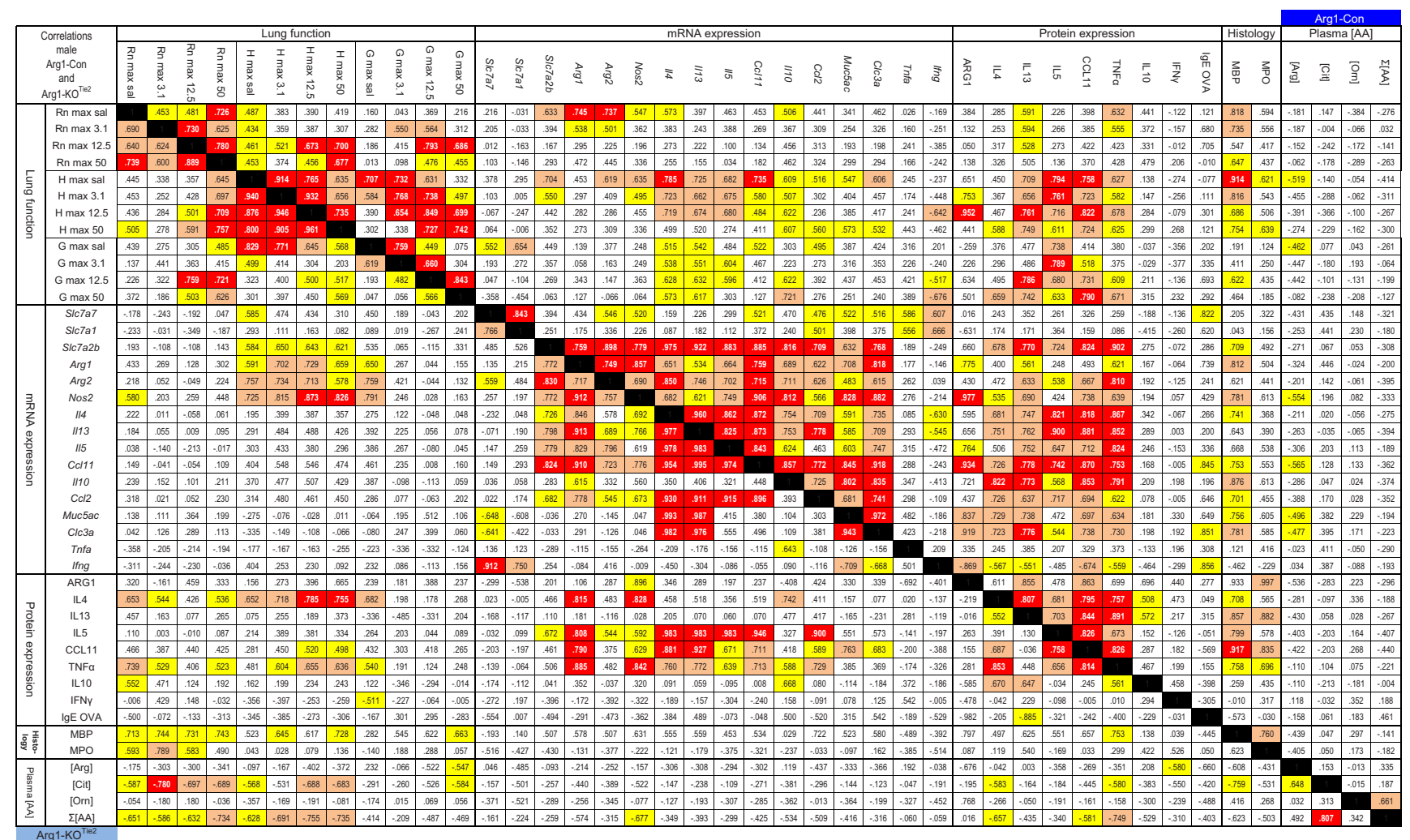

Fig. 9. Correlation of lung function, abundance of pulmonary mRNAs and proteins, pulmonary histopathology, and concentrations of plasma amino acids in mice with lungs that are or are not Argl deficient. Top right triangle refers to data obtained in Arg1-Con mice and bottom left triangle to data from Arg1-KO ${ }^{\text {Tie2 }}$ mice. Numbers show the correlation coefficients between parameters indicated above and to the left of the columns and rows, respectively, as measured in all 15 or 16 mice of the Arg1-Con or Arg1-KO ${ }^{\text {Tie } 2}$ genotype studied, that is, both the PBS/OVA- and the OVA/OVA-treated groups. The significance of the correlations is color coded according to the $P$ value of the correlation coefficient: yellow $0.05>P>0.01$, orange $0.01>P>0.001$, and red $P<0.001$. Note the decline of the number or degree of significant correlations in Arg1-KO ${ }^{\mathrm{Tie} 2}$ compared with Arg1-Con mice, in particular with respect to lung function and abundance of pulmonary mRNAs and proteins.

would accommodate the observed differences between the pharmacological and genetic interventions.

Effect of Arg1 ablation in the lung on pulmonary inflammation. The allergic response to OVA challenge is at least partly mediated by OVA-specific IgE (49). Unexpectedly, therefore, circulating anti-OVA IgE concentrations did not correlate with any other parameter of allergic asthma (Fig. 9). OVA/OVA treatment resulted in a pan-pulmonary cellular inflammation in all mice, with participation of both eosinophils (MBP) and neutrophils (MPO). The relatively low number neutrophils relative to eosinophils in the lung of OVA/OVA-treated mice can be ascribed to our treatment protocol, as neutrophils preferentially infiltrate the lung shortly after a challenge $(<24$ h) and eosinophils later (43). For the same reason, our relatively extended challenge protocol (6 consecutive days) probably accounts for the observation that only the number of eosinophils corresponded with the functional and biochemical sequels of OVA/OVA treatment (Fig. 9). One or more of the inflammatory cell types produced and induced an increased expression of mRNAs of cytokines and chemokines that are involved in $\mathrm{T}_{\mathrm{H}} 2$ responses $(I l 4, \mathrm{Ill3}, \mathrm{Il} 5, \mathrm{Ccll1})$, macrophage function $(\mathrm{Ccl} 2, \mathrm{Ill} 10)$, and mucus production in the respiratory epithelium (Muc5ac, Clca3). The expression of Muc5ac and Clca3 correlated well with the expression of genes coding for arginine-metabolizing and -transporting proteins in Arg1-Con mice, but this coordination was largely lost in $\operatorname{Arg} 1-\mathrm{KO}^{\mathrm{Tie} 2}$ mice, implying that cellular arginine concentration plays a role in their expression. In contrast, the abundance of $I l 4, I l 13, I l 5, C c l 2$, and $C c l 11$ mRNA remained coordinated irrespective of the presence or absence of Arg1, implying no or a limited role of arginase 1. Arg1 deficiency in OVA/OVA-treated mice led to reduced Ccl11, Tnfa and Clca3 expression and CCL11 protein accumulation. The lower CCL11 (eotaxin-1) content, however, did not result in the recruitment (13) of fewer eosinophils to the lungs. Furthermore, the pulmonary content of IL-13, a cytokine associated with AHR induction (35), was reduced.

Posttranscriptional regulation of genes in OVA/OVA-treated mice. For arginase 1, IL-4, IL-13, IL-5, IL-10, CCL11, TNF- $\alpha$, and IFN- $\gamma$, we measured both mRNA and protein concentrations in lung homogenates. Correlations varying from reasonable $(P<0.05)$ to good $(P<0.01)$ were found between mRNA and protein levels in Arg1-Con animals for IL-4, IL-13, IL-5, and CCL11 (Fig. 9), but in Arg1-KO ${ }^{\text {Tie2 }}$ mice, only mRNA and protein concentrations of IL-5 and CCL11 still correlated. Posttranscriptional control is well established for the expression of cytokines (8), but we were not aware of such extensive posttranscriptional regulation of Argl expression. Because we wanted to study the coordinated pulmonary response to ovalbumin sensitization and challenges in the pres- 
ence or absence of arginase 1 enzyme activity, we have only determined changes in mRNA levels.

Comparison with other animal models with macrophagespecific Arg1 deletion. Recently, the effects of macrophagespecific Argl deficiency on lung function and inflammation were studied in OVA/OVA-treated wild-type mice after bone marrow transplantation with constitutively Arg1-deficient cells (39), a procedure that also involves Argl elimination in all bone marrow-derived cells. Comparable to our results, infiltration of the lungs with eosinophils and neutrophils was similar in mice with or without Argl ablation in hematopoietic cells. Lung function was assessed with the airway pressuretime index, which is less sensitive to changes in peripheral lung function (45) and may explain why no differences in lung function were found in that study (39).

The effects of arginase 1 activity on the biomechanics of asthmatic lungs were also studied with RNA interference and administration of arginase inhibitors. Inhibition of Argl expression by instilling anti-Arg1 shRNA in the trachea of mice attenuated IL-13-induced airway resistance (Raw) (57), whereas we found that genetic ablation did not have this effect. The discrepancy may be caused by the amount of rIL13 instilled into the lung $(10 \mu \mathrm{g})$, which exceeds the content of IL-13 in OVA/OVAtreated lungs $(\sim 100 \mathrm{pg} / \mathrm{mg}$ lung protein) by three orders of magnitude. Pharmacological inhibition of arginase activity decreased $R_{N}$ in OVA/OVA-treated guinea pigs $(32,34)$ and mice $(19,40)$ but did not change $H$ or $G$, although one mouse study found no change $\mathrm{R}_{\mathrm{N}}$ and an increase in $H$ and $G(7)$.

Both Nos1- and Nos3-deficient mice suffer from a more pronounced AHR than wild-type mice $(17,18)$, whereas in Nos3overexpressing mice, allergen-induced AHR to methacholine is completely abolished $(11,51)$, indicating a prime role for $\mathrm{NO}$ in airway relaxation. In agreement, inhibition of arginase activity in OVA/OVA-treated Nos $2^{-1-}$ mice did not induce AHR, suggesting that NOS1 and -3 used the increased tissue arginine levels to produce more $\mathrm{NO}$ and relax the smooth muscles of the larger airways (42). Similarly, inhibition of NOS2 almost completely abolished OVA/OVA-induced AHR in BALB/c mice (24). Since Nos2 overexpression also decreases airway resistance (Raw) (17a), the source of NO is apparently less important.

The use of strong arginase inhibitors like nor-NOHA increase tissue arginine levels and corresponding decreases in AHR and eosinophil influx in C57BL/6 mice $(5,39)$. In another series of experiments with arginine- rather than Argl-deficient mice (our unpublished observations), we found that circulating arginine concentrations primarily affected $\mathrm{R}_{\mathrm{N}}$ in the larger airways. We, therefore, hypothesize that ablation of Argl in lung macrophages increases the parenchymal arginine concentration, which, in turn, facilitates NO production and smoothmuscle relaxation in the peripheral airways, but not the larger conducting airways.

Conclusion. Ablation of Argl in macrophages leads to an improvement of peripheral lung function in OVA/OVA-treated $\operatorname{Arg} 1-\mathrm{KO}^{\mathrm{Tie} 2}$ mice, without altering air hyperreactivity and lung inflammation.

\section{ACKNOWLEDGMENTS}

We thank Jelly Soffers for help with preparing one of the figures. We thank the members of the transgenic facility of Maastricht University (Iris Partouns, Vivian van Leeuwen, and Dr Willem Voncken) for their contribution to the generation of the $\operatorname{Arg} I^{f / f l}$ mouse.

\section{GRANTS}

This study was supported by a grant from the Transnational University Limburg.

\section{DISCLOSURES}

No conflicts of interest, financial or otherwise, are declared by the author(s).

\section{AUTHOR CONTRIBUTIONS}

R.H.E.C., S.S., C.C.d.T., M.E.P., E.T., P.v.D., and T.B.M.H. performed experiments; R.H.E.C., S.S., and S.E.K. analyzed data; R.H.E.C., S.S., and W.H.L. interpreted results of experiments; R.H.E.C. and S.E.K. prepared figures; R.H.E.C. and S.S. drafted manuscript; R.H.E.C., S.S., C.C.d.T., M.E.P., E.T., P.v.D., T.B.M.H., W.H.L., and S.E.K. approved final version of manuscript; C.C.d.T., M.E.P., W.H.L., and S.E.K. edited and revised manuscript; W.H.L. and S.E.K. conception and design of research.

\section{REFERENCES}

1. Bates JH, Rincon M, Irvin CG. Animal models of asthma. Am J Physiol Lung Cell Mol Physiol 297: L401-L410, 2009.

2. Benson RC, Hardy KA, Morris CR. Arginase and arginine dysregulation in asthma. J Allergy (Cairo) 2011: 736319, 2011.

3. Bousquet J, Jeffery PK, Busse WW, Johnson M, Vignola AM. Asthma. From bronchoconstriction to airways inflammation and remodeling. Am J Respir Crit Care Med 161: 1720-1745, 2000.

4. Bratt JM, Franzi LM, Linderholm AL, Last MS, Kenyon NJ, Last JA. Arginase enzymes in isolated airways from normal and nitric oxide synthase 2-knockout mice exposed to ovalbumin. Toxicol Appl Pharmacol 234: 273-280, 2009.

5. Bratt JM, Franzi LM, Linderholm AL, O'Roark EM, Kenyon NJ, Last JA. Arginase inhibition in airways from normal and nitric oxide synthase 2-knockout mice exposed to ovalbumin. Toxicol Appl Pharmacol 242: 1-8, 2010 .

6. Busse WW, Lemanske RF Jr. Asthma. N Engl J Med 344: 350-362, 2001.

7. Ckless K, Lampert A, Reiss J, Kasahara D, Poynter ME, Irvin CG, Lundblad LK, Norton R, van der Vliet A, Janssen-Heininger YM. Inhibition of arginase activity enhances inflammation in mice with allergic airway disease, in association with increases in protein S-nitrosylation and tyrosine nitration. J Immunol 181: 4255-4264, 2008.

8. Clark A. Post-transcriptional regulation of pro-inflammatory gene expression. Arthritis Res 2: 172-174, 2000.

9. Clausen BE, Burkhardt C, Reith W, Renkawitz R, Forster I. Conditional gene targeting in macrophages and granulocytes using LysMcre mice. Transgenic Res 8: 265-277, 1999.

9a.Deshane J, Zmijewski JW, Luther R, Gaggar A, Deshane R, Lai JF, Xu X, Spell M, Estell K, Weaver CT, Abraham E, Schwiebert LM, Chaplin DD. Free radical-producing myeloid-derived regulatory cells: potent activators and suppressors of lung inflammation and airway hyperresponsiveness. Mucosal Immunol 4: 503-518, 2011.

10. Dymecki SM. Flp recombinase promotes site-specific DNA recombination in embryonic stem cells and transgenic mice. Proc Natl Acad Sci USA 93: 6191-6196, 1996.

11. Feletou M, Lonchampt M, Coge F, Galizzi JP, Bassoullet C, Merial C, Robineau P, Boutin JA, Huang PL, Vanhoutte PM, Canet E. Regulation of murine airway responsiveness by endothelial nitric oxide synthase. Am J Physiol Lung Cell Mol Physiol 281: L258-L267, 2001.

12. Fredberg JJ, Stamenovic D. On the imperfect elasticity of lung tissue. $J$ Appl Physiol 67: 2408-2419, 1989.

13. Garcia-Zepeda EA, Rothenberg ME, Ownbey RT, Celestin J, Leder P, Luster AD. Human eotaxin is a specific chemoattractant for eosinophil cells and provides a new mechanism to explain tissue eosinophilia. Nat Med 2: 449-456, 1996.

14. Gordy C, Pua H, Sempowski GD, He YW. Regulation of steady-state neutrophil homeostasis by macrophages. Blood 117: 618-629, 2011.

15. Hamada K, Sasaki T, Koni PA, Natsui M, Kishimoto H, Sasaki J, Yajima N, Horie Y, Hasegawa G, Naito M, Miyazaki J, Suda T, Itoh H, Nakao K, Mak TW, Nakano T, Suzuki A. The PTEN/PI3K pathway governs normal vascular development and tumor angiogenesis. Genes Dev 19: 2054-2065, 2005

16. Hantos Z, Daroczy B, Suki B, Nagy S. Low-frequency respiratory mechanical impedance in the rat. J Appl Physiol 63: 36-43, 1987.

17. Hasaneen NA, Foda HD, Said SI. Nitric oxide and vasoactive intestinal peptide as co-transmitters of airway smooth-muscle relaxation: analysis in neuronal nitric oxide synthase knockout mice. Chest 124: 1067-1072, 2003. 
17a.Hjoberg J, Shore S, Kobzik L, Okinaga S, Hallock A, Vallone J, Subramaniam V, De Sanctis GT, Elias JA, Drazen JM, Silverman ES. Expression of nitric oxide synthase-2 in the lungs decreases airway resistance and responsiveness. J Appl Physiol 97: 249-259, 2004.

18. Iijima H, Tulic MK, Duguet A, Shan J, Carbonara P, Hamid Q, Eidelman DH. NOS 1 is required for allergen-induced expression of NOS 2 in mice. Int Arch Allergy Immunol 138: 40-50, 2005.

19. Ilies M, Di Costanzo L, North ML, Scott JA, Christianson DW. 2-Aminoimidazole amino acids as inhibitors of the binuclear manganese metalloenzyme human arginase I. J Med Chem 53: 4266-4276, 2010.

20. Iyer RK, Yoo PK, Kern RM, Rozengurt N, Tsoa R, O'Brien WE, Yu H, Grody WW, Cederbaum SD. Mouse model for human arginase deficiency. Mol Cell Biol 22: 4491-4498, 2002.

21. Jakubzick C, Bogunovic M, Bonito AJ, Kuan EL, Merad M, Randolph GJ. Lymph-migrating, tissue-derived dendritic cells are minor constituents within steady-state lymph nodes. J Exp Med 205: 2839-2850, 2008

22. Kenyon NJ, Bratt JM, Linderholm AL, Last MS, Last JA. Arginases I and II in lungs of ovalbumin-sensitized mice exposed to ovalbumin: sources and consequences. Toxicol Appl Pharmacol 230: 269-275, 2008.

23. Kisanuki YY, Hammer RE, Miyazaki J, Williams SC, Richardson JA, Yanagisawa M. Tie2-Cre transgenic mice: a new model for endothelial cell-lineage analysis in vivo. Dev Biol 230: 230-242, 2001.

24. Koarai A, Ichinose M, Sugiura H, Yamagata S, Hattori T, Shirato K. Allergic airway hyperresponsiveness and eosinophil infiltration is reduced by a selective iNOS inhibitor, 1400W, in mice. Pulm Pharmacol Ther 13 : 267-275, 2000

25. Koni PA, Joshi SK, Temann UA, Olson D, Burkly L, Flavell RA. Conditional vascular cell adhesion molecule 1 deletion in mice: impaired lymphocyte migration to bone marrow. J Exp Med 193: 741-754, 2001.

26. Kumar RK, Herbert C, Foster PS. The "classical" ovalbumin challenge model of asthma in mice. Curr Drug Targets 9: 485-494, 2008.

27. Lee JJ, McGarry MP, Farmer SC, Denzler KL, Larson KA, Carrigan PE, Brenneise IE, Horton MA, Haczku A, Gelfand EW, Leikauf GD, Lee NA. Interleukin-5 expression in the lung epithelium of transgenic mice leads to pulmonary changes pathognomonic of asthma. J Exp Med 185: 2143-2156, 1997.

28. Li H, Romieu I, Sienra-Monge JJ, Ramirez-Aguilar M, Del RioNavarro BE, Kistner EO, Gjessing HK, del Carmen Lara-Sanchez I, Chiu GY, London SJ. Genetic polymorphisms in arginase I and II and childhood asthma and atopy. J Allergy Clin Immunol 117: 119-126, 2006.

29. Long AJ, Sypek JP, Askew R, Fish SC, Mason LE, Williams CM, Goldman SJ. Gob-5 contributes to goblet cell hyperplasia and modulates pulmonary tissue inflammation. Am J Respir Cell Mol Biol 35: 357-365, 2006

30. Lundblad LK, Rinaldi LM, Poynter ME, Riesenfeld EP, Wu M, Aimi S, Barone LM, Bates JH, Irvin CG. Detrimental effects of albuterol on airway responsiveness requires airway inflammation and is independent of betareceptor affinity in murine models of asthma. Respir Res 12: 27, 2011.

31. Lundblad LK, Thompson-Figueroa J, Allen GB, Rinaldi L, Norton RJ, Irvin CG, Bates JH. Airway hyperresponsiveness in allergically inflamed mice: the role of airway closure. Am J Respir Crit Care Med 175: $768-774,2007$

32. Maarsingh H, Bossenga BE, Bos IS, Volders HH, Zaagsma J, Meurs H. L-Arginine deficiency causes airway hyperresponsiveness after the late asthmatic reaction. Eur Respir J 34: 191-199, 2009.

33. Maarsingh H, Zaagsma J, Meurs H. Arginase: a key enzyme in the pathophysiology of allergic asthma opening novel therapeutic perspectives. Br J Pharmacol 158: 652-664, 2009.

34. Maarsingh H, Zuidhof AB, Bos IS, van Duin M, Boucher JL, Zaagsma J, Meurs H. Arginase inhibition protects against allergen-induced airway obstruction, hyperresponsiveness, and inflammation. Am J Respir Cri Care Med 178: 565-573, 2008.

35. Mattes J, Yang M, Siqueira A, Clark K, MacKenzie J, McKenzie AN, Webb DC, Matthaei KI, Foster PS. IL-13 induces airways hyperreactivity independently of the IL-4R alpha chain in the allergic lung. $J$ Immunol 167: 1683-1692, 2001.

36. Meurs H, Gosens R, Zaagsma J. Airway hyperresponsiveness in asthma: lessons from in vitro model systems and animal models. Eur Respir J 32 487-502, 2008

37. Munder M. Arginase: an emerging key player in the mammalian immune system. Br J Pharmacol 158: 638-651, 2009.

38. Nakanishi A, Morita S, Iwashita H, Sagiya Y, Ashida Y, Shirafuji H, Fujisawa Y, Nishimura $\mathbf{O}$, Fujino M. Role of gob-5 in mucus overproduction and airway hyperresponsiveness in asthma. Proc Natl Acad Sci USA 98: 5175-5180, 2001.
39. Niese KA, Collier AR, Hajek AR, Cederbaum SD, O'Brien WE, Wills-Karp M, Rothenberg ME, Zimmermann N. Bone marrow cell derived arginase I is the major source of allergen-induced lung arginase but is not required for airway hyperresponsiveness, remodeling and lung inflammatory responses in mice. BMC Immunol 10: 33, 2009.

40. North ML, Khanna N, Marsden PA, Grasemann H, Scott JA. Functionally important role for arginase 1 in the airway hyperresponsiveness of asthma. Am J Physiol Lung Cell Mol Physiol 296: L911-L920, 2009.

41. Poynter ME, Cloots R, van Woerkom T, Butnor KJ, Vacek P, Taatjes DJ, Irvin CG, Janssen-Heininger YM. NF-kappa B activation in airways modulates allergic inflammation but not hyperresponsiveness. J Immunol 173: 7003-7009, 2004.

42. Redington AE. Modulation of nitric oxide pathways: therapeutic potential in asthma and chronic obstructive pulmonary disease. Eur J Pharmacol 533: 263-276, 2006.

43. Riesenfeld E, Allen GB, Bates JH, Poynter ME, Wu M, Aimiand S, Lundblad LK. The temporal evolution of airways hyperresponsiveness and inflammation. J Allergy Ther 1: 1-7, 2012

44. Ruijter JM, Ramakers C, Hoogaars WM, Karlen Y, Bakker O, van den Hoff MJ, Moorman AF. Amplification efficiency: linking baseline and bias in the analysis of quantitative PCR data. Nucleic Acids Res 37: e45, 2009.

45. Sarpong SB, Zhang LY, Kleeberger SR. A novel mouse model of experimental asthma. Int Arch Allergy Immunol 132: 346-354, 2003.

46. Sauer B, Henderson N. Site-specific DNA recombination in mammalian cells by the Cre recombinase of bacteriophage P1. Proc Natl Acad Sci USA 85: 5166-5170, 1988.

47. Schlaeger TM, Mikkola HK, Gekas C, Helgadottir HB, Orkin SH. Tie2Cre-mediated gene ablation defines the stem-cell leukemia gene (SCL/tal1)-dependent window during hematopoietic stem-cell development. Blood 105: 3871-3874, 2005.

48. Schwenk F, Baron U, Rajewsky K. A cre-transgenic mouse strain for the ubiquitous deletion of loxP-flanked gene segments including deletion in germ cells. Nucleic Acids Res 23: 5080-5081, 1995.

49. Shum BO, Rolph MS, Sewell WA. Mechanisms in allergic airway inflammation-lessons from studies in the mouse. Expert Rev Mol Med 10: e15, 2008.

50. Takemoto K, Ogino K, Shibamori M, Gondo T, Hitomi Y, Takigawa T, Wang DH, Takaki J, Ichimura H, Fujikura Y, Ishiyama H. Transiently, paralleled upregulation of arginase and nitric oxide synthase and the effect of both enzymes on the pathology of asthma. Am J Physiol Lung Cell Mol Physiol 293: L1419-L1426, 2007.

51. Ten Broeke R, De Crom R, Van Haperen R, Verweij V, Leusink-Muis T, Van Ark I, De Clerck F, Nijkamp FP, Folkerts G. Overexpression of endothelial nitric oxide synthase suppresses features of allergic asthma in mice. Respir Res 7: 58, 2006.

53. Van den Bossche J, Lamers WH, Koehler ES, Geuns JM, Alhonen L, Uimari A, Pirnes-Karhu S, Van Overmeire E, Morias Y, Brys L, Vereecke L, De Baetselier P, Van Ginderachter JA. Pivotal Advance: Arginase-1-independent polyamine production stimulates the expression of IL-4induced alternatively activated macrophage markers while inhibiting LPSinduced expression of inflammatory genes. J Leukoc Biol 91: 685-699, 2012.

54. van Eijk HM, Rooyakkers DR, Deutz NE. Rapid routine determination of amino acids in plasma by high-performance liquid chromatography with a 2-3 microns Spherisorb ODS II column. J Chromatogr 620: 143-148, 1993.

55. Wagers S, Lundblad LK, Ekman M, Irvin CG, Bates JH. The allergic mouse model of asthma: normal smooth muscle in an abnormal lung? $J$ Appl Physiol 96: 2019-2027, 2004.

56. Wu G, Morris SM Jr. Arginine metabolism: nitric oxide and beyond. Biochem J 336: 1-17, 1998.

57. Yang M, Rangasamy D, Matthaei KI, Frew AJ, Zimmermann N, Mahalingam S, Webb DC, Tremethick DJ, Thompson PJ, Hogan SP, Rothenberg ME, Cowden WB, Foster PS. Inhibition of arginase I activity by RNA interference attenuates IL-13-induced airways hyperresponsiveness. J Immunol 177: 5595-5603, 2006.

58. Zhang Z, Zhang F, An P, Guo X, Shen Y, Tao Y, Wu Q, Zhang Y, Yu Y, Ning B, Nie G, Knutson MD, Anderson GJ, Wang F. Ferroportin1 deficiency in mouse macrophages impairs iron homeostasis and inflammatory responses. Blood 118: 1912-1922, 2011.

59. Zimmermann N, King NE, Laporte J, Yang M, Mishra A, Pope SM, Muntel EE, Witte DP, Pegg AA, Foster PS, Hamid Q, Rothenberg ME. Dissection of experimental asthma with DNA microarray analysis identifies arginase in asthma pathogenesis. J Clin Invest 111: 1863-1874, 2003. 


\section{CHAPTER IV}

\section{THE HUMAN NEONATAL SMALL INTESTINE HAS THEPOTENTIAL FOR ARGININE SYNTHESIS; DEVELOPMENTAL CHANGES IN THE EXPRESSION OF ARGININE-SYNTHESIZING AND -CATABOLIZING ENZYMES}

S. Eleonore Köhler ${ }^{1}$, Selvakumari Sankaranarayanan ${ }^{1}$, Christa J. van Ginneken ${ }^{2}$, Paul van Dijk ${ }^{1}$, Jacqueline LM Vermeulen ${ }^{3}$, Jan M. Ruijter ${ }^{4}$, Wouter H. Lamers ${ }^{1,3}$ and Elisabeth Bruder ${ }^{5}$

${ }^{1}$ Department of Anatomy \& Embryology, Maastricht University, Maastricht, The Netherlands,

${ }^{2}$ Department of Veterinary Medicine, Veterinary Anatomy \& Embryology, University of Antwerp, Belgium,

${ }^{3}$ AMC Liver Center Academic Medical Center, University of Amsterdam, The Netherlands,

${ }^{4}$ Department of Anatomy \& Embryology, Academic Medical Center, University of Amsterdam, The Netherlands,

${ }^{5}$ Department of Pathology, Basel University Hospital, Basel, Switzerland 


\title{
The human neonatal small intestine has the potential for arginine synthesis; developmental changes in the expression of arginine-synthesizing and -catabolizing enzymes
} Eleonore S Köhler*1, Selvakumari Sankaranarayanan ${ }^{1}$, Christa J van Ginneken ${ }^{2}$, Paul van Dijk리 Jacqueline LM Vermeulen ${ }^{3}$, Jan M Ruijter ${ }^{4}$, Wouter H Lamers ${ }^{1,3}$ and Elisabeth Bruder ${ }^{5}$

Address: ${ }^{1}$ Department of Anatomy \& Embryology, Maastricht University, Maastricht, The Netherlands, ${ }^{2}$ Department of Veterinary Medicine, Veterinary Anatomy \& Embryology, University of Antwerp, Belgium, ${ }^{3}$ AMC Liver Center Academic Medical Center, University of Amsterdam, The Netherlands, ${ }^{4}$ Department of Anatomy \& Embryology, Academic Medical Center, University of Amsterdam, The Netherlands and ${ }^{5}$ Department of Pathology, Basel University Hospital, Basel, Switzerland

Email: Eleonore S Köhler* - leo.koehler@ae.unimaas.nl; Selvakumari Sankaranarayanan - Selvi@ae.unimaas.nl; Christa J van Ginneken - chris.vanginneken@ua.ac.be; Paul van Dijk - p.vanDijk@ae.unimaas.nl; Jacqueline LM Vermeulen - J.L.Vermeulen@amc.uva.nl; Jan M Ruijter - J.M.Ruijter@amc.uva.nl; Wouter H Lamers - W.H.Lamers@amc.uva.nl; Elisabeth Bruder - elisabeth.bruder@unibas.ch

* Corresponding author

This article is available from: http://www.biomedcentral.com/I47|-2।3X/8/I07

(c) 2008 Köhler et al; licensee BioMed Central Ltd.

This is an Open Access article distributed under the terms of the Creative Commons Attribution License (http://creativecommons.org/licenses/by/2.0), which permits unrestricted use, distribution, and reproduction in any medium, provided the original work is properly cited.

\begin{abstract}
Background: Milk contains too little arginine for normal growth, but its precursors proline and glutamine are abundant; the small intestine of rodents and piglets produces arginine from proline during the suckling period; and parenterally fed premature human neonates frequently suffer from hypoargininemia. These findings raise the question whether the neonatal human small intestine also expresses the enzymes that enable the synthesis of arginine from proline and/or glutamine. Carbamoylphosphate synthetase (CPS), ornithine aminotransferase (OAT), argininosuccinate synthetase (ASS), arginase-I (ARGI), arginase-2 (ARG2), and nitric-oxide synthase (NOS) were visualized by semiquantitative immunohistochemistry in 89 small-intestinal specimens.
\end{abstract}

Results: Between 23 weeks of gestation and 3 years after birth, CPS- and ASS-protein content in enterocytes was high and then declined to reach adult levels at 5 years. OAT levels declined more gradually, whereas ARG-I was not expressed. ARG-2 expression increased neonatally to adult levels. Neurons in the enteric plexus strongly expressed ASS, OAT, NOSI and ARG2, while varicose nerve fibers in the circular layer of the muscularis propria stained for ASS and NOSI only. The endothelium of small arterioles expressed ASS and NOS3, while their smooth-muscle layer expressed OAT and ARG2.

Conclusion: The human small intestine acquires the potential to produce arginine well before fetuses become viable outside the uterus. The perinatal human intestine therefore resembles that of rodents and pigs. Enteral ASS behaves as a typical suckling enzyme because its expression all but disappears in the putative weaning period of human infants. 


\section{Background}

Arginine is a precursor for the synthesis of proteins, creatine, agmatine, and nitric oxide (NO). It further plays an essential role in ammonia and bicarbonate detoxification, and stimulates the secretion of growth hormone, prolactin, insulin, and glucagon. Arginine is also a 'conditionally essential' amino acid, meaning that endogenous arginine production covers metabolic requirements in healthy, unstressed individuals, but becomes an essential amino acid under conditions of increased need, e.g. growth or tissue repair, or in catabolic states such as sepsis and starvation.

In the adult, endogenous arginine biosynthesis is an interorgan 'affair': the net production of citrulline occurs almost exclusively in the enterocytes of the small intestine [1], also in man [2], but absorption of citrulline from the circulation and subsequent biosynthesis of arginine can take place in many tissues [3]. Of these, the cortex of the kidney provides approximately $20 \%$ of whole-body requirements [4]. In perinatal mice [5,6] and piglets [7-9], however, all enzymes necessary for arginine biosynthesis from proline and glutamine (Figure 1) are expressed in the enterocytes of the small intestine, while ARG1, the main cytosolic arginine-catabolizing enzyme, is not detectable prior to weaning $[5,6,10]$. In agreement, the small intestine plays a prominent role in net arginine production in suckling piglets [11-14]. In rodents, intestinal expression of the enzymes that synthesize arginine from citrulline, ASS and argininosuccinate lyase, ceases completely after weaning $[6,15]$. In pigs, on the other hand, net synthesis of arginine declines more gradually and is still present at 7 weeks of age [16]. It has been speculated that enteric arginine synthesis is necessary to cover neonatal requirements, because mammalian milk is a relatively poor source of arginine, whereas its precursors proline and glutamine are abundant [17].

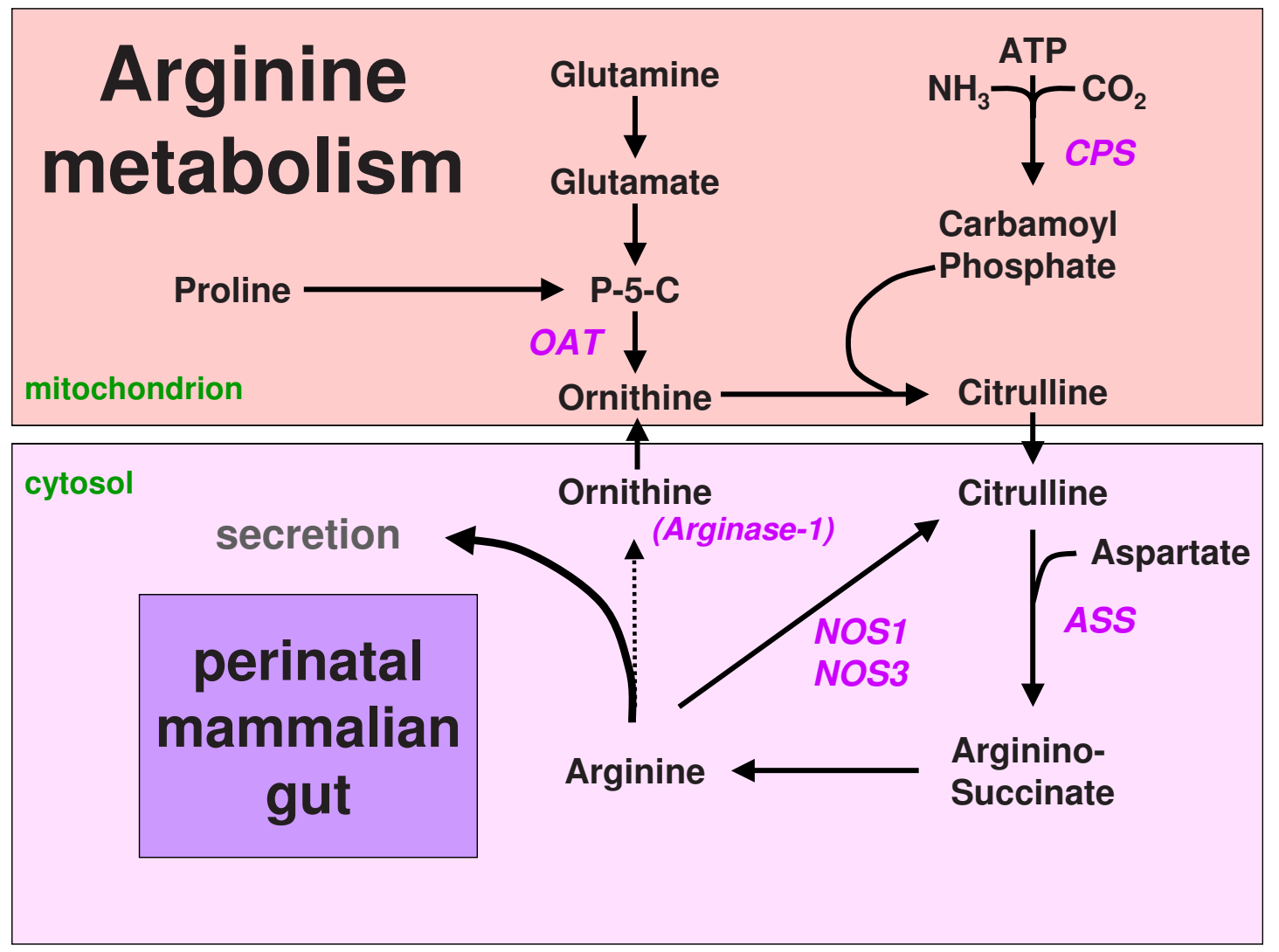

Figure I

Arginine synthesis from proline or glutamine in the mammalian neonatal gut. Since arginase-I is not expressed, arginine can either be secreted or metabolized to $\mathrm{NO}$ and citrulline. Names of enzymes investigated in this study are indicated in italics. P-5-C = pyrroline5-carboxylate synthetase. 
In prematurely born human neonates, hypoargininemia is frequently observed [18] and hypothesized to predispose such infants to the development of necrotizing enterocolitis [19-21]. Although hypoargininemia in premature human neonates has been associated with failing intestinal arginine biosynthesis as found in suckling rodents and piglets [22], no evidence to support this association exists thus far. To confirm or reject the hypothesis that the perinatal human gastrointestinal tract resembles that of rodents or pigs with respect to arginine production, we studied the developmental changes in the expression of CPS, OAT and ASS, three key enzymes with a high control of de novo intestinal synthesis of citrulline and arginine, and ARG1 and ARG2, the main arginine-catabolizing enzymes in full-thickness and mucosal biopsies of the human small intestine. The findings demonstrate that the epithelium of the fetal and neonatal small intestine abundantly expresses CPS (as we reported earlier $[23,24])$, OAT and ASS, whereas cytosolic ARG1 is not detectable. These data show that the perinatal human intestine resembles that of rodents and, in particular, pigs with respect to its capacity to produce arginine. We also show that the expression of the controlling enzyme, ASS, all but disappears between 3 and 5 years of age, that is, the putative weaning age of human infants [25]. Finally, we show that the enteric ganglia and arteriolar endothelium co-express ASS and the constitutive NO-synthases NOS1 and NOS3, respectively, which both use arginine as substrate for NO synthesis.

\section{Methods}

\section{Tissue}

A total of 89 samples were included in the study (Table 1). Formalin-fixed, paraffin-embedded samples originated from the archives of the Institute of Pathology, University Hospital Basel, Switzerland, and the Department of Pathology, AMC, Amsterdam, the Netherlands. Full-thickness duodenal, jejunal and ileal samples were from infants, who presented with gastroschisis, atresia, meco- nium ileus or Meckel's diverticulum, whereas the samples from adults were from patients who underwent surgery for tumors. Duodenal mucosal biopsies were collected from patients who underwent endoscopy for various gastrointestinal complaints. Furthermore, full-thickness intestinal samples of 9 fetuses between 14 and 40 gestational weeks were examined. For each sample, age, gender and diagnosis were available, but in all other respects, the samples had been anonymized to avoid patient identification. Under this condition, residual tissue could be used for the research reported here [26]. In addition, approval has been obtained from the Ethikkommission beider Basel EKbB, Switzerland, reference number EK 135/08 for the samples obtained from the Institute of Pathology in Basel.

\section{Immunohistochemistry}

Tissue was fixed in $4 \%$ formaldehyde and embedded in paraffin following standard protocols. 5-7 $\mu \mathrm{m}$-thick sections were used. Section thickness does not affect immunohistological staining intensity, since antibodies only bind to the surface of the sections [27]. As an additional cautionary measure to avoid staining differences due to differences in fixation, we used neuronal staining as an internal reference. Sections were deparaffinized, hydrated in graded ethanols, and heated in $10 \mathrm{mM}$ sodium citrate (pH 6.0) to $98^{\circ} \mathrm{C}$ for 10 minutes followed by 90 minutes cool-down to room-temperature to retrieve antigens. After this treatment, endogenous alkaline phosphatases are denatured and no longer active. Remaining activity of endogenous peroxidases (catalase) was inactivated where appropriate by exposing the sections for $30 \mathrm{~min}$ to $3 \%$ $\mathrm{H}_{2} \mathrm{O}_{2}$ in PBS. After blocking with TENG-T (10 mM Tris $\mathrm{pH}$ 7.4, $5 \mathrm{mM}$ EDTA, $150 \mathrm{mM} \mathrm{NaCl}, 0.25 \%$ gelatin, $0.05 \%$ Tween-20) plus $10 \%$ goat serum, sections were incubated overnight at room temperature with the first antibody, washed in $0.5 \mathrm{M} \mathrm{Na-acetate}$ and incubated with an alkaline phosphatase- or peroxidase-coupled secondary antibody for 60 to 90 minutes. Sections were developed with

Table I: Human gut samples

\begin{tabular}{|c|c|c|c|c|c|c|c|c|}
\hline \multirow[t]{2}{*}{ Group } & \multirow[t]{2}{*}{ Age } & \multirow[t]{2}{*}{ \# of samples } & \multicolumn{4}{|c|}{ Sample origin } & \multirow[t]{2}{*}{ Resections } & \multirow[t]{2}{*}{ Biopsies } \\
\hline & & & SI & $D$ & $J$ & I & & \\
\hline I & $-\mid 82 /-3$ days & 9 & 7 & & 2 & & 9 & 0 \\
\hline 2 & I - II days & 14 & I & 4 & 3 & 6 & 14 & 0 \\
\hline 3 & $6 w k s-1 y r$ & 10 & 4 & I & & 5 & 9 & I \\
\hline 4 & $1,5-3$ yrs & 12 & 2 & 7 & & 3 & 5 & 7 \\
\hline 5 & $3-5$ yrs & $16 *$ & & 15 & & 3 & 0 & 16 \\
\hline 6 & $5-7$ yrs & $18 *$ & & 16 & & 5 & 2 & 16 \\
\hline 7 & $14-22$ yrs & 5 & & I & & 4 & 4 & I \\
\hline 8 & $50-80$ yrs & 5 & & 4 & & I & 5 & 0 \\
\hline
\end{tabular}

The table shows the number of samples that were analyzed per age group, the topographic location of the samples $(\mathrm{SI}=\mathrm{small}$ intestine, $\mathrm{D}=$ duodenum, J = jejunum, I = ileum), and whether they were mucosal biopsies and full-thickness resections. For age groups 5 and 6 , parallel samples were available from two different regions of the small intestine. These were used to check for the effect of location on enzyme expression, but only one sample per patient was taken into account for the statistical analysis. This is the reason for the discrepancy between "\# of samples" (marked by an asterisk) and the sum of all samples listed under "Sample origin". 
NBT/BCIP (alkaline phosphatase; Roche) or DAB (peroxidase; Sigma). An incubation without primary antibody served as negative control for all incubations [see Additional file 1]. This protocol allows semi-quantitative assessment on sections [28].

The following rabbit primary antibodies were used: ASS $(1: 10,000)$ [15]; ARG1 and ARG2 (1:500, sc-20150 and 1:400, sc-20151, respectively, Santa Cruz Biotechnology, California); CPS (1:500) [29]; OAT $(1: 1,500)$ [30]. Antibody binding was visualized with alkaline phosphatasecoupled goat anti-rabbit IgG (1:200, Sigma A-3687). NOS1 and NOS3 were detected with mouse monoclonal antibodies (NOS1 1:400, IgG2a clone \#16; NOS3 1:200, IgG1 clone \#3, BD Transduction Laboratories) and visualized with an alkaline phosphatase-coupled goat antimouse secondary antibody (1:200, Sigma A3562) and a peroxidase-coupled rabbit anti-mouse secondary antibody (1:200, Sigma A3682), respectively. Single NOS1 positive cells in the lamina propria were further characterized by staining for the presence of CD68 (monocytes/ macrophages 1:200, Dako M0876), CD3 (T-lymphocytes 1:600, Dako A0452), CD20 (B-cells 1:500, Dako M0755 clone L26), CD1A (dendritic cells 1:10, Neomarkers MS1856-P1), and CD138 (plasma cells 1:100, Dako M7228 clone MI15).

\section{Western Blotting}

Villus epithelium was scraped off fresh duodenal resection material and lysed in SDS-PAGE sample buffer. After separation of samples on 10\% SDS-polyacrylamide gels and blotting to PVDF membranes, proteins were visualized with antisera to ARG1 (1:200); ARG2 (1:500); NOS1 $(1: 2500) ; \operatorname{NOS} 3$ (1:2500); $\alpha$-SMA, (1:1000). The appropriate secondary horse-radish peroxidase-coupled antibodies were used at a dilution of 1:10,000. The signal was amplified using the chemiluminescent Super Signal West Pico reagent (Pierce, Perbio Science, The Netherlands) and pictures were taken with a LAS3000 imaging system (Fujifilm). $\alpha$-smooth muscle actin was used to determine the contribution of the submucosa to the scrapings.

\section{Evaluation of samples}

Sections were scored for staining intensity in random sequence by 3 investigators with the readers of the slides blinded. Villi and crypts were scored separately. The intensity of ASS, OAT and ARG2 staining in enterocytes was expressed on a scale of $0-3$ ( 0 : absent; 1 : weak; 2 : intermediate; and 3: strong expression) relative to their expression in the ganglia of the myenteric plexus, which always contained both strongly and weakly positive neurons for ASS, OAT, and ARG2. Expression in the strongly staining neurons was set at 3 . Samples without ganglia (mucosal biopsies from the duodenum) were compared to simultaneously stained samples that did contain ganglia to assign an intensity score from 0 to 3 . Because CPS expression in the small intestine is restricted to enterocytes, all samples were stained simultaneously and then compared to each other using the same scale of $0-3$ as described above. There was never more than one scoring unit difference between the 3 investigators.

\section{Statistics}

We used box-plots to visualize distribution and developmental changes of enzyme expression in enterocytes. Two-way analysis of variance (ANOVA) on rank-transformed data showed age-group and structure (crypt or villus) differences as well as age and structure interactions per enzyme. Sex (male or female) was not a factor associated with differences in enzyme expression. To pin-point which age-groups and crypts or villi differed, non-parametric one-way ANOVA (Kruskal-Wallis) tests were performed between age-groups per structure. Multiple comparison (Mann-Whitney) tests between structures per age-group were performed, when the null hypothesis was rejected. $P$ values were considered significant if $<0.05$.

\section{Results}

The earliest sample studied was a small intestine of a 14week-old fetus, whereas the oldest sample was from a 79 year-old patient. Most of the samples examined were from patients younger than 7 years. At 14 weeks of gestation, all structural components of the epithelium, enteric nerves, and smooth muscle layers have formed [31,32]. Specimens were from the duodenum, jejunum, or ileum, with the majority of samples originating from the duodenum and ileum (Table 1). From 4 patients (age groups 5 and 6; 3-7 years), parallel samples of duodenum and ileum were available. In these samples, no differences in staining intensities of the enzymes investigated were observed between the proximal and distal small intestine or between males and females. For these 2 reasons, we felt justified to pool the samples of one age group. Of necessity, the studied specimens included both mucosal biopsies and full-thickness specimens, were all obtained to diagnose gastrointestinal conditions, and were contributed by different institutions. Because the gastrointestinal conditions were diverse in nature and the observed changes in enzyme levels concordant, our conclusions reflect developmental biology rather than pathology. Based on the staining patterns in these samples, we describe the developmental changes in the expression of arginine-synthesizing enzymes CPS, ASS and OAT, and the arginine-metabolizing enzymes ARG1, ARG2, NOS1 and NOS3 in the enterocytes of the small intestine.

\section{Expression of CPS, ASS, OAT, ARG, NOSI and NOS3 in enterocytes}

Carbamoylphosphate synthetase (Figures $2 \mathrm{~A}$ and 3; [see also

Additional files 2 and 3])

CPS protein was exclusively found in the enterocytes. Prior to birth (group 1), CPS expression was uniformly 
high in the enterocytes of both crypts and villi (Figure 3A). Between birth and 3 years of age (groups 2-4), CPS expression did not change significantly in the enterocytes on the villi, but declined thereafter to reach adult levels by 5 years of age (difference in villous expression between groups $1-4$ vs. groups $5-8$ : $\mathrm{P} \leq 0.0001$ ). Between birth and 1 year of age, expression was higher in the villus than in the crypt enterocytes $(\mathrm{P}<0.005$; Figure 3B [see Additional file 2]). Thereafter, staining differences between villi and crypts disappeared again (Figure 3C-F). No expression of CPS was found in the epithelium of Brunner's glands [see Additional file 3].

\section{Ornithine aminotransferase (Figures 2B and 4; [see also Additional} files 2 and 3])

OAT expression in the epithelium was uniform prior to birth. The youngest samples that could be investigated were from gestational week 23 (Figure 4A). Fetal expression was significantly higher in both crypts and villi than in the other age groups $(\mathrm{P} \leq 0.004)$. Directly after birth, OAT expression remained strong in the epithelium covering the villi, but declined in the crypts $(\mathrm{P} \leq 0.017)$, with the exception of age group 4 (1, 5-3 years). In some preparations, expression was stronger at the base of the villi, just above the crypts (Figure 4B, D). Above 40 years of age, OAT expression again resembled the fetal pattern, with crypt and villus enterocytes expressing OAT almost evenly albeit at a lower level (Figure 4E). The epithelium of Brunner's glands did not express OAT [see Additional file 3].

Argininosuccinate synthetase (Figures 2C and 5; [see also Additional files 2 and 3])

With the exception of the age groups 5 and 6 (3-7 years), ASS protein accumulated to a much higher concentration in the enterocytes on the villi than in the crypts $(\mathrm{P}<$ $0.014)$, especially before 3 years of age $(P<0.004)$. This pattern was already found in gestational week 14, where epithelial expression of ASS was still low (Figure 5A). From week 23 onward, expression in the villus epithelium was intermediate to strong. ASS expression remained high during the first postnatal year (groups 2 and 3 vs. groups $5-8, \mathrm{P}<0.0001)$, and then declined via an intermediate score between 1.5 and 3 years (group 4) to a near-absent score between 3 and 5 years (group 5). ASS expression in the crypts slowly declined after birth to become undetectable after 3 years of age (Figure 5B-F; [see also Additional file 2]) (Groups $1-4$ vs. groups 5-8 in a multiple comparison of groups: $\mathrm{P}<0.0001)$. As long as ASS expression was high (i.e. in the first 3 years), ASS protein was present throughout the enterocytes (Figure $5 \mathrm{~A}-\mathrm{C}$ ), but in children and young adults, it gradually became concentrated at the basal side of the enterocytes (Figure 5D-F). No expression of ASS was found in the epithelium of Brunner's glands [see Additional file 3].
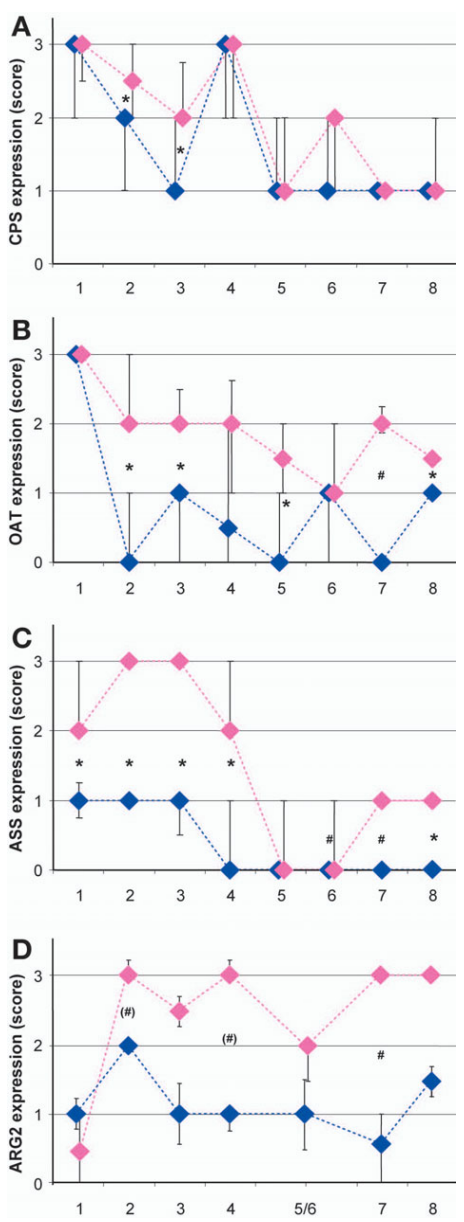

Figure 2

Developmental changes in expression of CPS, ASS, OAT and ARG2 in enterocytes of the small intestine. Sections represented in the top three panels (CPS, ASS and OAT) were stained simultaneously, whereas a subset of the samples with 2-4 individual sections per age group was stained later and is represented in the bottom panel (ARG2). The staining intensities were graded on a scale of 0 to 3 . Medians of all observations of each age-group are indicated by diamonds and are plotted for villi (pink) and crypts (blue) separately. The vertical bars represent the first and third quartiles of each age group. When not drawn, the quartile coincides with the median. Age groups are: I: fetus (1 $4^{\text {th }}$ 39th week of pregnancy); 2: I-II postnatal days; 3: 42-365 days; 4: I.5-3 years; 5 : 3-5 years; $6: 5-7$ years; 7 : 14-22 years; 8: 39-79 years; for details, consult Table I. For CPS and ASS, expression in groups I-4 was significantly higher than in groups 5-8, whereas for OAT, expression in prenatal groupl was higher than in the postnatal groups (for details, see main text). Significant differences in expression between villus and crypt enterocytes are indicated by an asterisk if $P \leq$ 0.005 , a "\#" if $P \leq 0.017$, and a "+" if $P \leq 0.04$. Significant differences between age groups are described in the Results section. 


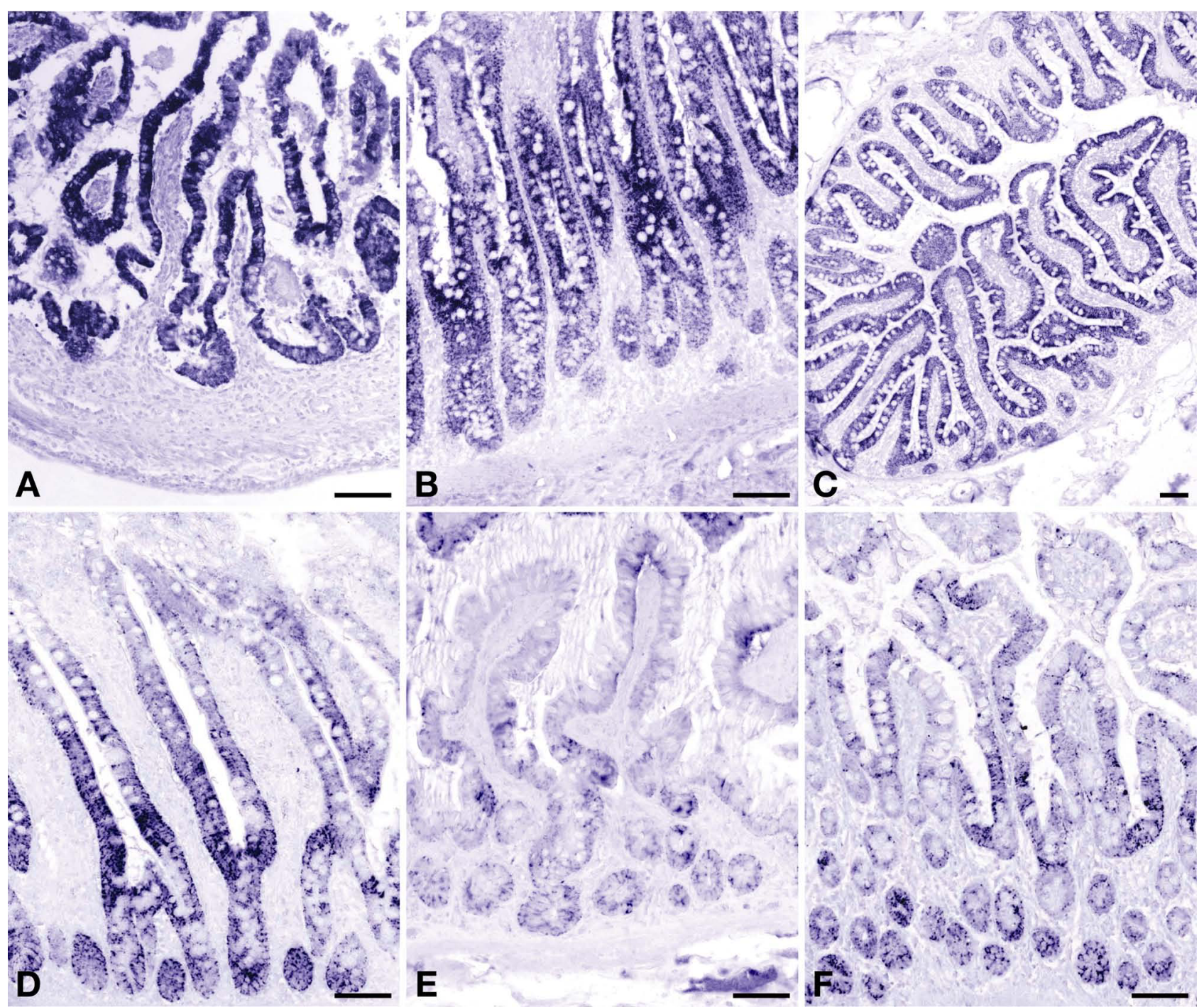

Figure 3

Developmental changes in expression of carbamoylphosphate synthetase in human small intestine. Panel A: gestational week 14; panel B: jejunum of a 3-day-old term male neonate; panel C: ileum of a 3-year-old male toddler; panel D: ileum of a 6-year-old male child; panel E: ileum of a 22-year-old female patient; panel F: ileum of a 70-year-old female patient. Scale bar: $100 \mu \mathrm{m}$.

Arginase-I (Figure 6A)

ARG1, the major arginine-catabolizing enzyme, was not detectable immunohistochemically in the epithelium of the small intestine at any of the ages investigated. Western-blot analysis of samples from an adult duodenum (age: 60 years) were also negative for ARG1, confirming the immunohistochemical findings.

Arginase-2 (Figures 2D, 6A, and 7)

Western blots of the adult duodenum showed, instead, expression of the mitochondrial isoform of arginase
(Figure 6A). We therefore investigated expression of ARG2 in a subset of samples (2-4/group) from all agegroups analyzed for ASS, CPS and OAT expression. ARG2 expression in fetal enterocytes was very weak (Figure 7A) or absent, but in neonates and all older age groups, expression was significantly higher $(P<0.02)$. After birth, protein expression in enterocytes was stronger on the villi than in the crypts (Figure $7 \mathrm{~B}-\mathrm{F}$; $\mathrm{P}<0.0001$ for all groups in a multiple comparison; due to the relatively small sample size this difference was not significant for all individual groups). 


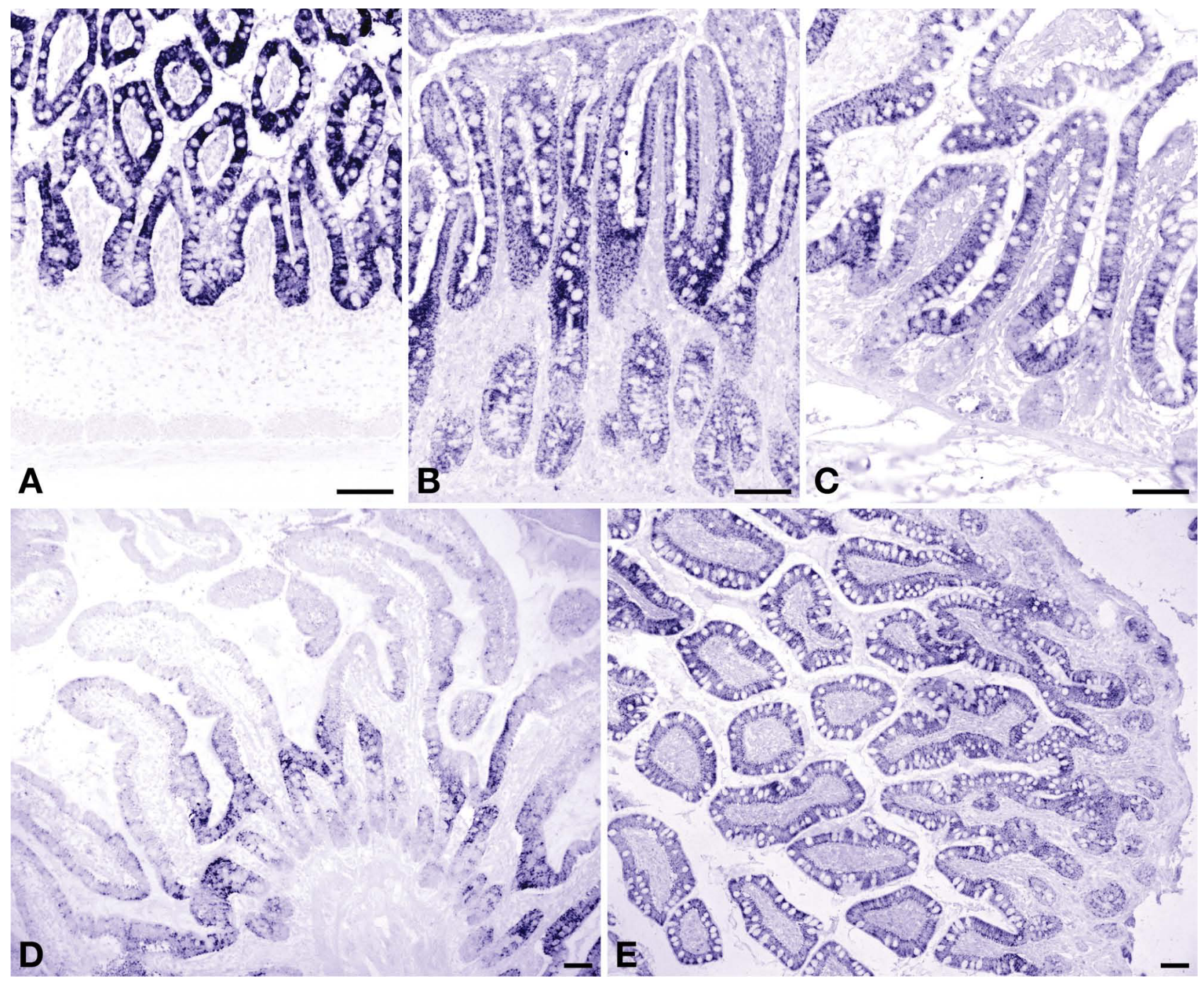

Figure 4

Developmental changes in expression of ornithine aminotransferase in human small intestine. Panel $A$ : gestational week 23; panel B: jejunum of a 3-day-old term male neonate; panel C: ileum of a 3-year-old male toddler; panel D: ileum of a 6-year-old male child; panel E: ileum of a 70-year-old female patient. Scale bar: $100 \mu \mathrm{m}$.

\section{NOSI (Figure 6A)}

Over-staining of sections with NOS1 yielded weak epithelial staining. Enterocytes of the human small intestine express high levels of NOS1 mRNA, but protein was not detected [33]. In agreement, a Western blot of a protein extract from villus epithelium did not show staining for NOS1, demonstrating that the observed staining of the sections was due to non-specific antibody binding.

\section{NOS3 (Figure 6A)}

We found weakly positive staining of villus epithelium with our NOS3 antibody. NOS3 mRNA is not expressed in enterocytes [33]. We, therefore, incubated a Western blot of a protein extract from epithelial cells with the same antibody as used for immunohistochemistry, but no immunoreactivity with NOS3 could be demonstrated, showing that the observed staining of the sections was due to non-specific antibody binding.

Localization of enzymes involved in arginine biosynthesis (Figure 8) Serial sections of the distal duodenum at postnatal day 1 demonstrated that the highest expression of CPS, ASS, and OAT was found in the enterocytes covering the villi (Figure 8A, D, G). CPS-, OAT-, and ASS-positive enterocytes did not express ARG1 (not shown). The positive staining of the ARG1-rich lysed erythrocytes [34] inside vessels served as an internal positive control for the absence of ARG1 staining in enterocytes. ASS was also expressed in 

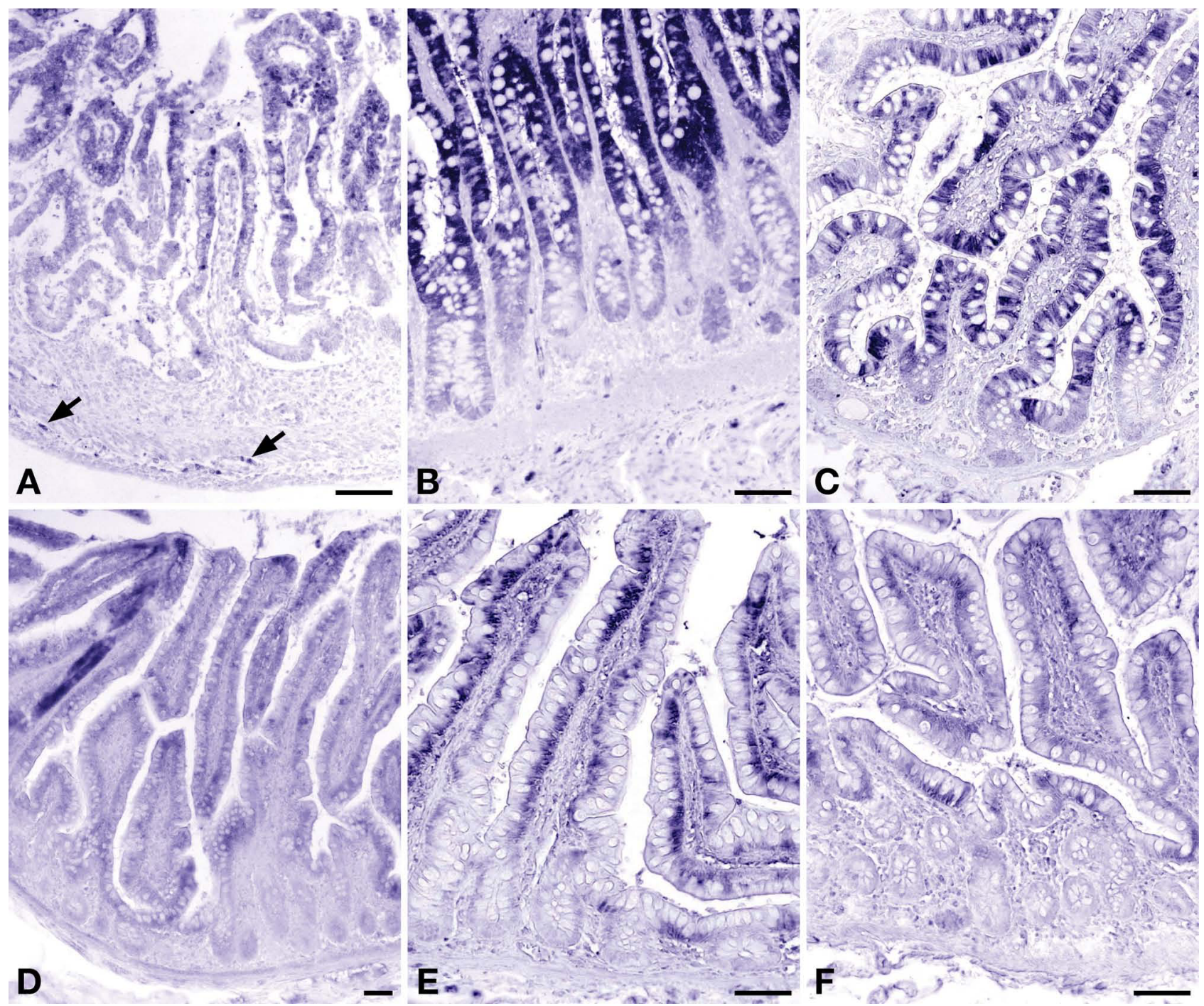

Figure 5

Developmental changes in expression of argininosuccinate synthetase in human small intestine. Panel $A$ : gestational week 14; panel B: jejunum of a 3-day-old term male neonate; panel C: ileum of a 3-year-old male toddler; panel D: ileum of a 6-year-old male child; panel E: ileum of a 22-year-old female patient; panel F: ileum of a 70-year-old female patient. Arrows in panel A indicate ASS-positive neurons in the myenteric plexus. Scale bar: $100 \mu \mathrm{m}$.

the endothelium of the small arteries (Figure 8E, arrow), while OAT was present in the smooth muscle wall of these vessels (Figure $8 \mathrm{H}$, white arrowhead). In addition, ASS and OAT were expressed in the ganglia of the myenteric plexus (Figure 8F, I, arrows). Only ASS was prominent in the varicose nerves of the circular muscle layer (Figure $8 \mathrm{~F}$, arrow head) and, to a lesser extent, in those of the longitudinal muscle layer.

Expression of enzymes in enteric nerves (Figure 6B)

Single neurons in the ganglia of both the myenteric and the submucosal plexus stained very strongly for ASS, OAT,
ARG2, and NOS1, whereas other neurons in the same ganglion stained weaker or not at all. The strongly OATpositive neurons were also positive for ASS and NOS1 (Figure 6B, black arrows), but some ganglia that were positive for both NOS1 and ASS did not express OAT (Figure $6 \mathrm{~B}$, white arrows). ASS- and NOS1-negative neuronal bodies were not observed in ganglia. Considerable staining of varicose nerve fibers for ASS and NOS1, but not for OAT, was observed in the circular and, to a lesser extent, the longitudinal smooth-muscle layer (Figures 6B and $8 \mathrm{~F}$ ). Positive staining for ASS of single neurons in myenteric ganglia was already found in gestational week 14 


\section{Human small control intestine}
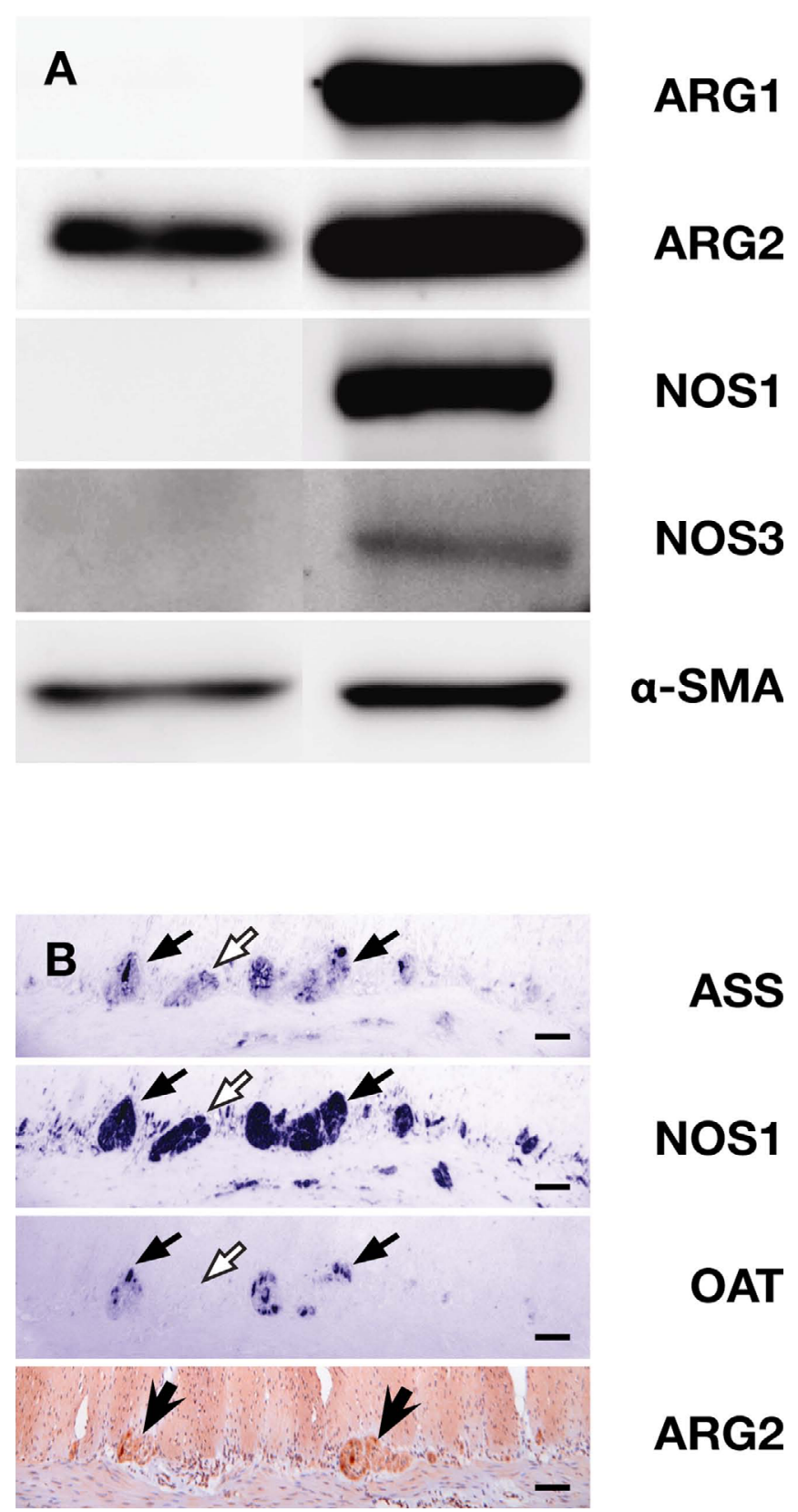

\section{ASS}

NOS1

\section{OAT}

ARG2

\section{Figure 6}

Expression of ASS, ARG and NOS in villus epithelium and neurons. Panel A: $40 \mu \mathrm{g}$ of protein isolated from smallintestinal scrapings of a 60-year-old patient were loaded per lane (left column). Positive controls (right column) included $25 \mu \mathrm{g}$ of human liver extract for ARGI, NOSI and $\alpha$-SMA, $25 \mu \mathrm{g}$ of human kidney extract for ARG2, and $25 \mu \mathrm{g}$ of mouse brain extract for NOS3. Absence of ARGI, NOSI and NOS3 expression in the adult small-intestinal enterocytes is demonstrated. The density of the ARG2 band is approx. $10 \%$ of that in kidney. Panel B: Serial sections $(5 \mu \mathrm{m})$ of the ileal myenteric plexus of a 6-year-old male child were stained for ASS, NOSI, and OAT. Note colocalization of ASS, NOSI, and OAT in intensely staining neurons (black arrows). Also note OAT-negative ganglia (white arrows). Another section of the same specimen was stained for ARG2. Scale bar: $100 \mu \mathrm{m}$. 

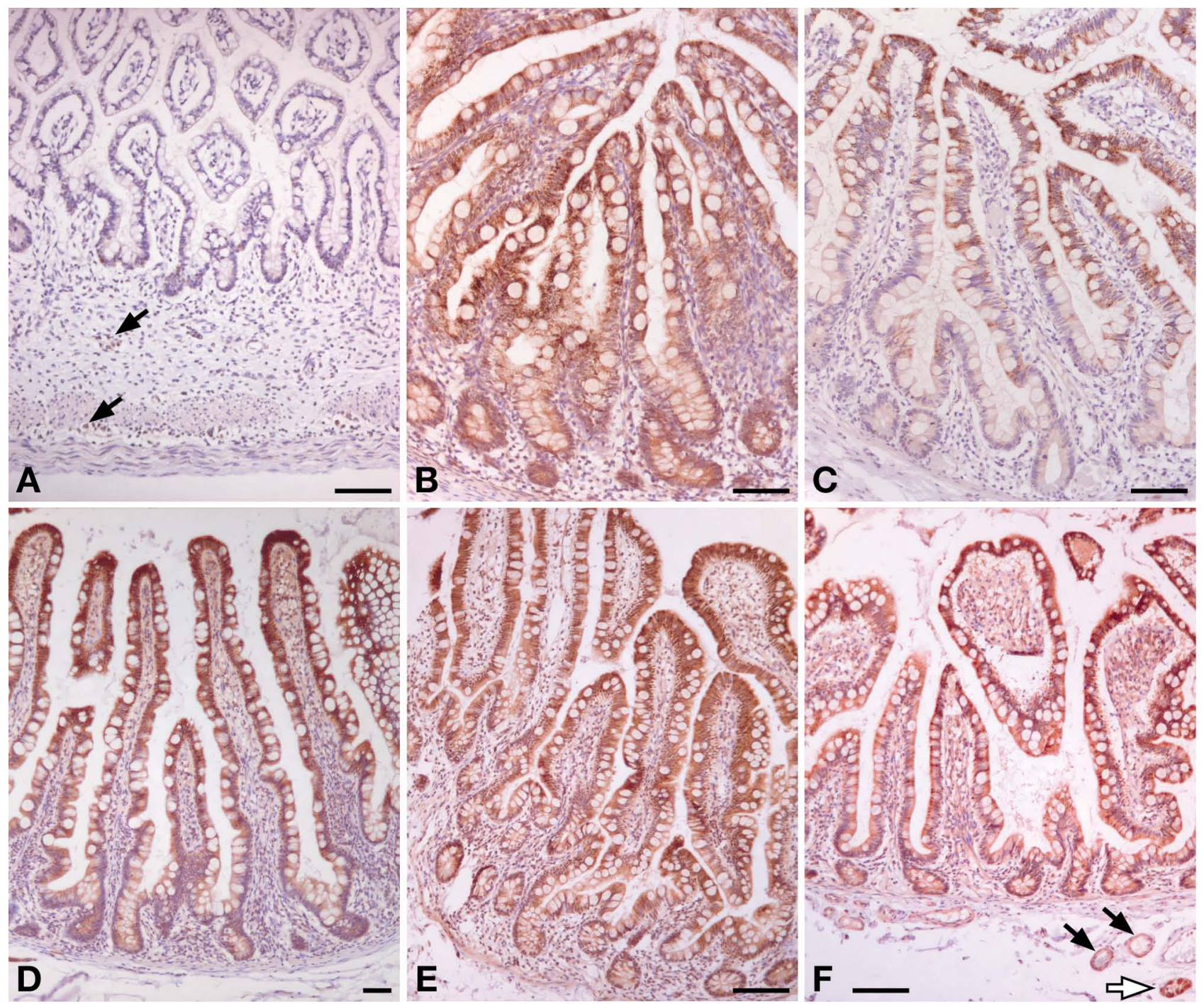

\section{Figure 7}

Developmental changes in expression of arginase-2 in human small intestine. Panel A: gestational week 23; arrows indicate positive neurons in submucosal and myenteric plexus; panel B: jejunum of a 3-day-old term male neonate; panel C: ileum of a 3-year-old male toddler; panel D: ileum of a 6-year-old male child; panel E: ileum of a 22-year-old female patient; panel F: ileum of a 70-year-old female patient; the white arrow shows staining of a submucosal ganglion, the black arrows indicate staining of smooth muscle cells in the wall of arterioles. Scale bar: $100 \mu \mathrm{m}$.

(Figure 5A, arrows), whereas NOS1 (data not shown) and ARG2 were detectable in gestational week 23 (Figure 7A, arrows). ASS, OAT, and ARG2 expression was also found in ganglia of the outer and inner submucosal plexus (Figures $6 \mathrm{~B}$ and $7 \mathrm{~F}$ ). The neurons of the myenteric plexus stained stronger than those of the submucosal plexus, except those positive for ARG2, which stained equally strong in both.

\section{Expression of enzymes in the wall of intestinal vessels}

The endothelium of the small arterioles in the submucosa and serosa always stained positive for the presence of ASS
(Figure 8E, arrow) and NOS3, but that of the larger arteries, veins and lymph vessels was negative for both enzymes. After birth, OAT and ARG2 expression was demonstrable in the smooth-muscle cell layer of arterioles (Figures 7F). No expression was found in the smoothmuscle cell layer of veins.

\section{Expression of enzymes elsewhere in the intestine}

Single cells in the lamina propria that were strongly positive for NOS1 were also positive for CD68, a marker for macrophages, but not for CD3, CD20, CD138, or CD1A (lymphocytes and dendritic cells (not shown). Germinal 


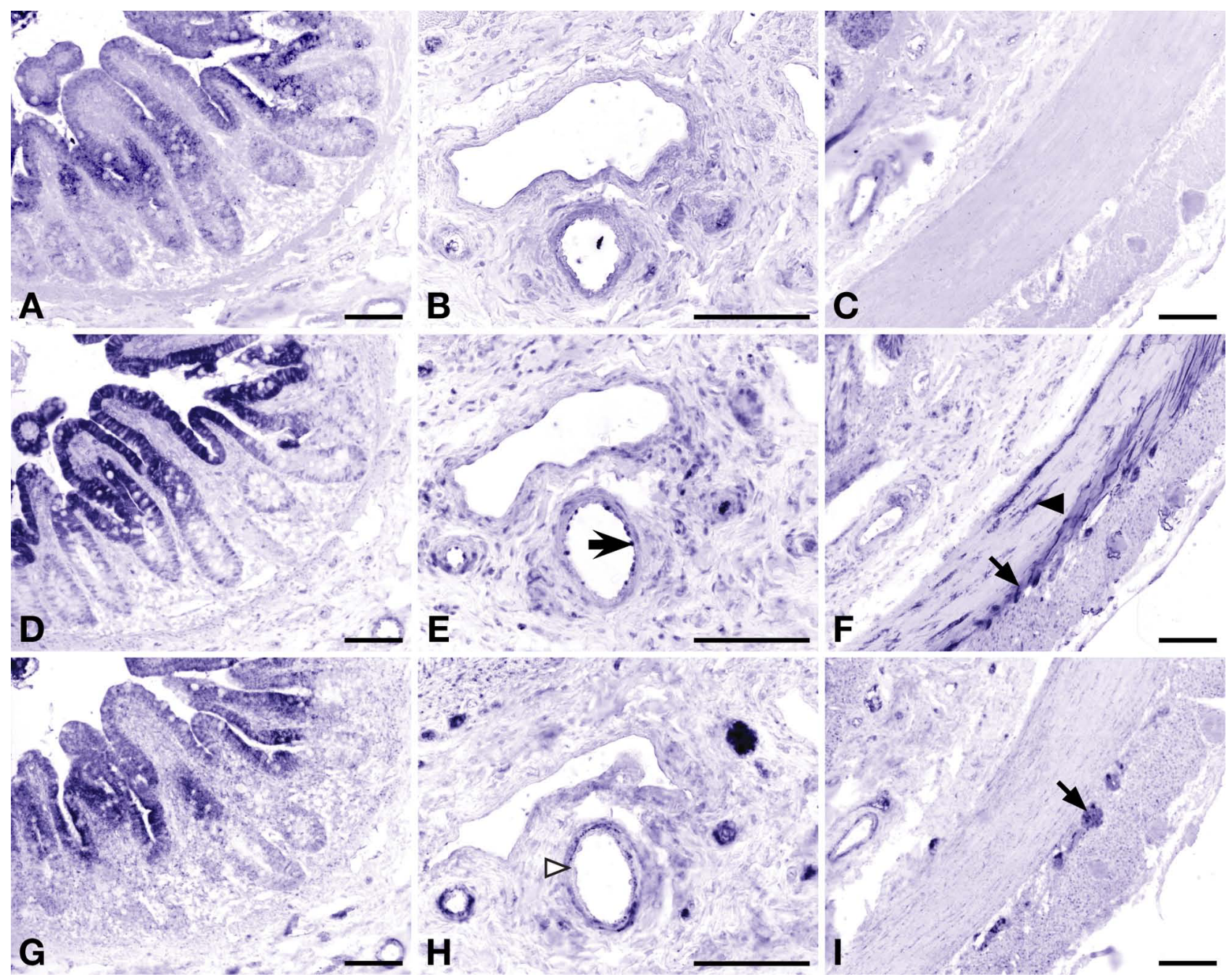

Figure 8

Expression of enzymes involved in arginine synthesis in human small intestine at postnatal day I. Serial sections of the distal duodenum of a I-day-old female neonate. Panels A-C show the expression of CPS; panels D-F: ASS; and panels GI: OAT. Endothelial expression of ASS in panel $E$ is indicated by block arrows, while OAT expression in the smooth muscle layer of the same vessels is indicated by a white arrowhead (panel $\mathrm{H}$ ). Panels $\mathrm{C}, \mathrm{F}$ and I show the muscularis propria with the inner circular and outer longitudinal layer. Myenteric ganglia are indicated by black arrows in panels $\mathrm{F}$ and I. Varicose nerves in the circular muscle layer are indicated by an arrowhead in panel F. Scale bar: $100 \mu \mathrm{m}$.

centers within lymphocyte aggregates also stained positive for NOS1 (not shown).

\section{Discussion}

The main result of this study is the observation that the epithelium of the perinatal human small intestine expresses the enzymes that exert control over the biosynthesis of arginine from proline, bicarbonate, and ammonia, viz. CPS, OAT and ASS (See Figure 1), and that the major arginine-degrading enzyme ARG1 is absent during that period. We deduced this conclusion from an enzyme-histochemical analysis of 79 specimens less than 8 years old.

\section{The human small intestine expresses key enzymes of} arginine synthesis at midgestation

Although the developmental appearance of CPS, OAT, and ASS in the enterocytes of the piglet and rodent small intestine has been reported [6-9,35-38], such information was only incompletely available for the human small intestine. CPS expression in the human small intestine starts as early as the $8^{\text {th }}$ week of gestation $[23,24]$. Accordingly, CPS was expressed in the enterocytes of all our samples. To our knowledge, OAT expression in human enterocytes has not yet been reported, but its developmental profile resembles that of CPS, ornithine car- 
bamoyltransferase and pyrroline-5-carboxylate reductase in fetal piglets [37]. In agreement, OAT was, like CPS, expressed in the enterocytes of all our samples. ASS, finally, is expressed in Caco2 cells [39], but its expression in normal human small intestinal enterocytes has not yet been reported. ASS differed from CPS and OAT in that its expression declined profoundly between 3 and 5 years of age (Figure 2). The time course in ASS expression in the postnatal human gut resembles that in piglets, which declines towards weaning and then rises again [10]. In rodents, on the other hand, ASS expression disappears completely at weaning $[6,40]$. Concurrent with the developmental decline in ASS expression, its homogeneous cytosolic distribution changed to one that is restricted to the basal side of the enterocytes (Figure 5E, F). Asymmetric localization of proteins in enterocytes has been previously described as a consequence of mRNA sorting [41], but a change in enzyme localization during late postnatal development has, to our knowledge, not yet been demonstrated.

The crypt-villus gradient of postnatal CPS and ASS expression in the suckling human intestine resembles that in piglets (our unpublished observations), but markedly differs from that in rodents. In both rats and mice [5,6], ASS expression is confined to the enterocytes occupying the apical half of the villi, whereas CPS is expressed in all enterocytes. This expression pattern suggested to us that the basal enterocytes synthesized citrulline, whereas the apical enterocytes synthesized arginine [6]. A possible explanation for this spatial separation of cells capable to produce citrulline only and cells also capable of arginine production is that the small-intestinal enterocytes are the only cells in the body that can synthesize citrulline and that this citrulline is necessary as substrate for arginine synthesis elsewhere, e.g. the kidney and the endothelium. Apparently, such a zonation of arginine metabolism is not necessary in newborn pigs and humans.

The net production of ornithine by the small intestine is a prerequisite for citrulline and arginine biosynthesis [42]. The severe deficiency of circulating ornithine and arginine that develops in neonates lacking OAT $[38,43]$ demonstrates that, in the neonatal intestine, OAT indeed serves to produce ornithine. Citrulline is exported from the mitochondria in exchange for ornithine via the ornithine carrier ORNT. Accordingly, the ORNT1 isoform is expressed at elevated levels in the small intestine of the mouse during the suckling period [44]. However, the relatively high expression of ARG2, the mitochondrial isoform of arginase, in the neonatal and adult human small intestine could potentially nullify the cytosolic synthesis of arginine (in the mouse small intestine, ARG2 becomes only expressed at weaning [5,6]). Extensive degradation of cytosolic arginine due to import into the mitochondria is, nevertheless, unlikely, because the affinity of arginine for the ORNT carrier is $~ 10$-fold lower than that of ornithine [45].

Together, our findings indicate that the human fetal intestine has acquired the potential to produce arginine at 23 weeks of gestation and probably as early as 14 weeks, that is, well before fetuses become viable outside the uterus. Furthermore, NOS1, NOS3 and their downstream target soluble guanylate cyclase (not shown) were expressed at term levels in fetuses of $\sim 23$ weeks of pregnancy. This indicates that at this time in gestation the fetus not only has the potential to synthesize arginine, but also to use it for NO and cyclic GMP production. Hypoargininemia, nevertheless, often develops in preterm infants, in particular if they are maintained on total parenteral nutrition $[5,6,15]$, and appears to predispose them to the respiratory distress syndrome [46] and necrotizing enterocolitis $[19,20]$. The hyperammonemia that frequently accompanies hypoargininemia in preterms responds to intravenous arginine supplementation [18], which indicates that endogenous arginine biosynthesis is deficient. The strong association with parenteral nutrition points to the intestines and indicates that the intestines only produce arginine if substrate is supplied from the intestinal lumen, as was shown for the newborn piglet $[11,12]$.

\section{Intestinal neurons and arterioles express key enzymes of arginine synthesis}

The neurons of the myenteric plexus abundantly express OAT, ASS, and NOS1. Since the neurons do not express CPS and, therefore, cannot synthesize citrulline from ornithine, OAT most likely functions to produce glutamate, while ASS probably functions to (re-)synthesize arginine from citrulline [47]. It is conceivable that these neurons require under certain conditions additional arginine (synthesized by enterocytes) above their endogenous production. Such metabolic cooperation has been demonstrated for the intestinal sphincters: neurons in these sphincters can resynthesize arginine from citrulline, but become dependent on external arginine during prolonged activity [48]. The expression pattern of soluble guanylate cyclase (not shown) demonstrated that there are many target cells for the NO produced by the neurons of the myenteric plexus. In this respect, the inner, circular layer of the muscularis propria differed markedly from the outer, longitudinal layer both by the far more abundant distribution of ASS- and NOS1-positive nerve fibres and its much stronger expression of soluble guanylate cyclase (not shown). The much stronger immunoreactivity for NOS1 of the nerve fibers in the circular muscle has been described [49]. Although nerve cell content and density of the NOS-positive ganglia of the myenteric plexus [49-51] markedly declines in the peri- and postnatal period, this structural difference between both layers of the muscularis propria is maintained throughout development. 
The constantly fed state of the neonatal small intestine causes absorptive hyperemia, that is, a high intestinal blood flow and a low intestinal vessel resistance [52]. NO production in the vessel wall is the main determinant of this vascular relaxation [53], in particular during the suckling period [54]. Since neonatal hypoargininemia is closely associated with the risk to develop necrotizing enterocolitis, a disease of the intestinal vessels [55], we speculate that arginine biosynthesis in both the enterocytes and the endothelial cells of the small vessels of the intestinal submucosa is necessary to support this hyperemic state and to protect the neonatal intestine from ischemia. Unfortunately, only one intervention trial [56] without a conclusive outcome [57] has tested the predicted beneficial effect of arginine supplementation to preterm neonates thus far. Although arteries of the $1^{\text {st }}$ to $2^{\text {nd }}$ order (out of 4 size categories) are considered to be the major sites of resistance and blood flow regulation of the gut [58], we did not observe ASS and NOS3 expression in the endothelium of $1^{\text {st }}$ order (largest) arteries. Furthermore, the downstream target of $\mathrm{NO}$, soluble guanylate cyclase, was found in the smooth-muscle layer of arterioles only (not shown), suggesting that these $2^{\text {nd }}$ order vessels materially contribute to the peripheral vascular resistance in the gut. A recent study showed a deficiency in NO production but not in NOS3 expression as judged by immunohistochemistry of intestinal arterioles of patients with NEC [59], supporting our hypothesis that NOS substrate deficiency plays a role in intestinal ischemia. In addition to NO production, other factors are involved in neonatal vascular dysfunction, such as the pro-inflammatory cytokine IL-1 $\beta$ and endothelin-1 [60], but their effects are mediated at least in part via a blunting of NOS3-mediated NO production.

\section{The decline of arginine-synthesizing enzymes in enterocytes and "weaning"}

The age-dependent postnatal decline in the expression of ASS in the enterocytes of the human small intestine is most pronounced between 3 and 5 years of age. The time course in ASS expression in the developing human gut resembles that in piglets, where activity is highest during the suckling period, declines to low levels around weaning (under natural conditions occurring at 12-15 weeks [61]) and then rises again [10]. In rodents, on the other hand, ASS expression disappears completely at weaning $[5,6,15]$. In humans, approximately 6 months of age is considered to be an optimal time point for weaning, but the natural weaning age for humans may be as late as 2.53 years [25]. The prominent reduction of ASS expression that we observed after three years of age, therefore, coincides with this assumed natural weaning age.

There is a remarkable similarity in the developmental timing of the decline in expression of ASS and lactase- phlorizin hydrolase (hereafter called lactase), another small-intestinal enzyme that is closely associated with breast-feeding. In rodents, lactase expression declines to undetectable levels at weaning [62], whereas in piglets, the decline occurs more gradually during the first 8-16 weeks of life [63]. In lactase-nonpersistent humans, lactase activity begins to decline between 2 and 3 years [64]. The temporal coincidence of the intestinal capacity to digest lactose and to produce arginine does support a relation to milk as the main source of food and underscores the notion that mammalian milk does not contain enough arginine to support rapid postnatal growth [17], so that intestinal arginine synthesis is necessary. Although we did find low levels of ASS in adult intestine, it was recently reported that the human intestine (age range 37-69 years) does not produce arginine [65]. This finding does not exclude a role for local arginine synthesis in e.g. neurons and endothelial cells that is directly coupled to NO production within the same cell.

\section{Conclusion}

Our data show that CPS, ASS, and OAT expression is strong in the enterocytes of fetuses, neonates, infants and toddlers. Humans, therefore, resemble other mammals in that the enterocytes of their small intestine are major producers of arginine during the suckling period. Although the relative deficiency of arginine in milk seems to underlie this temporary function of the gut, the intestinal or systemic functions that require the arginine that is produced in the gut remain to be delineated. We submit that relaxation of the circular smooth muscle layer of the muscularis propria $[49,66]$ and that of the intestinal arterioles [54] stand out in this respect.

\section{Abbreviations}

ARG: arginase (E.C. 3.5.3.1); ASS: argininosuccinate synthetase (E.C. 6.3.4.5); CPS: carbamoylphosphate synthetase (E.C. 6.3.4.16); NOS: nitric oxide synthase (E.C. 1.14.13.39); OAT: ornithine aminotransferase (E.C. 2.6.1.13).

\section{Authors' contributions}

EK participated in the design of the study and carried out the data analysis and drafted the manuscript. SS assisted in data analysis and processing. CG assisted in the study design, data analysis and critically revised the manuscript. PD carried out immunoassays. JV carried out immunoassays. JR assisted in the design of data analysis and performed the statistical analysis. WL conceived of the study, participated in analysis and interpretation, and critically revised the manuscript for important intellectual content. EB is the pediatric pathologist of this study, was responsible for the diagnoses and data interpretation and critically revised the manuscript. 


\section{Additional material}

\section{Additional file 1}

Representative negative controls.

Click here for file

[http://www.biomedcentral.com/content/supplementary/1471-

213X-8-107-S1.pdf]

\section{Additional file 2}

Expression of ASS, CPS and OAT in a group 3 patient.

Click here for file

[http://www.biomedcentral.com/content/supplementary/1471-

213X-8-107-S3.pdf]

\section{Additional file 3}

Brunner glands in a group 5 patient.

Click here for file

[http://www.biomedcentral.com/content/supplementary/1471-

213X-8-107-S2.pdf]

\section{Acknowledgements}

We thank Dr. T. Matsuzawa (Fujita-Gakuen Health University, Toyoake, Aichi, Japan) for his generous gift of OAT antiserum. We are grateful to the staff of the biopsy laboratory of the Institute of Pathology of the University Hospital Basel for retrieval of archival paraffin blocks. We further thank Dr. F.J. ten Kate (AMC, Amsterdam, The Netherlands) for making additional intestinal biopsies available for this study. Chiel de Theije is gratefully acknowledged for preparing the Western blots and Rogier Trompert for preparing the layout of the figures.

\section{References}

I. Windmueller HG: Glutamine utilization by the small intestine. Adv Enzymol Relat Areas Mol Biol 1982, 53:201-237.

2. Crenn P, Messing B, Cynober L: Citrulline as a biomarker of intestinal failure due to enterocyte mass reduction. Clin Nutr 2008, 27:328-339.

3. Wu G, Morris SM Jr: Arginine metabolism: nitric oxide and beyond. Biochem / 1998, 336(Pt I): I-I7.

4. Brosnan ME, Brosnan JT: Renal arginine metabolism. J Nutr 2004, I 34:279|S-2795S. discussion 2796S-2797S

5. Hurwitz R, Kretchmer N: Development of arginine-synthesizing enzymes in mouse intestine. Am 」 Physiol 1986, 25I:GI03-GIIO.

6. De Jonge WJ, Dingemanse MA, de Boer PA, Lamers WH, Moorman AF: Arginine-metabolizing enzymes in the developing rat small intestine. Pediatr Res 1998, 43:442-45I.

7. Wu G: Synthesis of citrulline and arginine from proline in enterocytes of postnatal pigs. Am J Physiol 1997, 272:GI382-GI390.

8. Wu G, Knabe DA: Arginine synthesis in enterocytes of neonatal pigs. Am J Physiol 1995, 269:R62I-R629.

9. $\mathrm{Wu} G$, Knabe DA, Flynn NE: Synthesis of citrulline from glutamine in pig enterocytes. Biochem J 1994, 299(Pt I): II5-12I.

10. Wu G: Urea synthesis in enterocytes of developing pigs. Biochem J 1995, 3 I 2(Pt 3):717-723.

II. Bertolo RF, Brunton JA, Pencharz PB, Ball RO: Arginine, ornithine, and proline interconversion is dependent on small intestinal metabolism in neonatal pigs. Am J Physiol Endocrinol Metab 2003, 284:E915-E922.

12. Brunton JA, Bertolo RF, Pencharz PB, Ball RO: Proline ameliorates arginine deficiency during enteral but not parenteral feeding in neonatal piglets. Am J Physiol 1999, 277:E223-E23I.
13. Urschel KL, Shoveller AK, Uwiera RR, Pencharz PB, Ball RO: Citrulline is an effective arginine precursor in enterally fed neonatal piglets. I Nutr 2006, I36:1806-13.

14. Wu G, Borbolla AG, Knabe DA: The uptake of glutamine and release of arginine, citrulline and proline by the small intestine of developing pigs. J Nutr 1994, I 24:2437-2444.

15. de Jonge WJ, Hallemeesch MM, Kwikkers KL, Ruijter JM, de Gier-de Vries C, van Roon MA, Meijer AJ, Marescau B, de Deyn PP, Deutz NE, Lamers WH: Overexpression of arginase I in enterocytes of transgenic mice elicits a selective arginine deficiency and affects skin, muscle, and lymphoid development. Am J Clin Nutr 2002, 76: I 28-140.

16. Stoll B, Henry J, Reeds PJ, Yu H, Jahoor F, Burrin DG: Catabolism dominates the first-pass intestinal metabolism of dietary essential amino acids in milk protein-fed piglets. J Nutr 1998, | 28:606-6|4

17. Davis TA, Nguyen HV, Garcia-Bravo R, Fiorotto ML, Jackson EM, Lewis DS, Lee DR, Reeds PJ: Amino acid composition of human milk is not unique. I Nutr 1994, I 24: | | 26- I | 32.

18. Batshaw ML, Wachtel RC, Thomas GH, Starrett A, Brusilow SW: Arginine-responsive asymptomatic hyperammonemia in the premature infant. I Pediatr 1984, 105:86-91.

19. Zamora SA, Amin HJ, McMillan DD, Kubes P, Fick GH, Butzner JD, Parsons HG, Scott RB: Plasma L-arginine concentrations in premature infants with necrotizing enterocolitis. J Pediatr 1997, I 3 |:226-232.

20. Becker RM, Wu G, Galanko JA, Chen W, Maynor AR, Bose CL, Rhoads JM: Reduced serum amino acid concentrations in infants with necrotizing enterocolitis. J Pediatr 2000, 137:785-793.

21. Nankervis CA, Giannone PJ, Reber KM: The neonatal intestinal vasculature: contributing factors to necrotizing enterocolitis. Semin Perinatol 2008, 32:83-91.

22. Wu G, Jaeger LA, Bazer FW, Rhoads JM: Arginine deficiency in preterm infants: biochemical mechanisms and nutritional implications. J Nutr Biochem 2004, I 5:442-45I.

23. Dingemanse MA, Lamers WH: Expression patterns of ammoniametabolizing enzymes in the liver, mesonephros, and gut of human embryos and their possible implications. Anat Rec 1994, 238:480-490.

24. Van Beers EH, Rings EH, Posthuma G, Dingemanse MA, Taminiau JA, Heymans HS, Einerhand AW, Buller HA, Dekker J: Intestinal carbamoyl phosphate synthase I in human and rat. Expression during development shows species differences and mosaic expression in duodenum of both species. J Histochem Cytochem 1998, 46:23I-240.

25. Kramer MS, Kakuma R: Optimal duration of exclusive breastfeeding. Cochrane Database Syst Rev 2002:CD0035I7.

26. van Veen EB, Riegman PH, Dinjens WN, Lam KH, Oomen MH, Spatz A, Mager R, Ratcliffe C, Knox K, Kerr D, van Damme B, Vijver M van de, van Boven $\mathrm{H}$, Morente MM, Alonso S, Kerjaschki D, Pammer J, Lopez-Guerrero JA, Llombart Bosch A, Carbone A, Gloghini A, Teodorovic I, Isabelle M, Passioukov A, Lejeune S, Therasse P, Oosterhuis $\mathrm{JW}$ : TuBaFrost 3: regulatory and ethical issues on the exchange of residual tissue for research across Europe. Eur J Cancer 2006, 42:2914-2923.

27. Geerts WJ, Verburg M, Jonker A, Das AT, Boon L, Charles R, Lamers WH, Van Noorden Cl: Gender-dependent regulation of glutamate dehydrogenase expression in periportal and pericentral zones of rat liver lobules. J Histochem Cytochem 1996, 44:II53-II59.

28. van Straaten HW, He Y, van Duist MM, Labruyere WT, Vermeulen JL, van Dijk PJ, Ruijter JM, Lamers WH, Hakvoort TB: Cellular concentrations of glutamine synthetase in murine organs. Biochem Cell Biol 2006, 84:2I5-23I.

29. Charles R, de Graaf A, Moorman AF: Radioimmunochemical determination of carbamoyl-phosphate synthase (ammonia) content of adult rat liver. Biochim Biophys Acta 1980, 629:36-49.

30. Matsuzawa T, Katsunuma T, Katunuma N: Crystallization of ornithine transaminase and its properties. Biochem Biophys Res Commun 1968, 32:161-166.

3I. Fu M, Tam PK, Sham MH, Lui VC: Embryonic development of the ganglion plexuses and the concentric layer structure of human gut: a topographical study. Anat Embryol (Berl) 2004, 208:33-4I. 
32. Wallace AS, Burns AJ: Development of the enteric nervous system, smooth muscle and interstitial cells of Cajal in the human gastrointestinal tract. Cell Tissue Res 2005, 3 19:367-382.

33. Daniels I, Cavill D, Murray IA, Long RG: Elevated expression of iNOS mRNA and protein in coeliac disease. Clin Chim Acta 2005, 356:134-142.

34. Kim PS, lyer RK, Lu KV, Yu H, Karimi A, Kern RM, Tai DK, Cederbaum SD, Grody WW: Expression of the liver form of arginase in erythrocytes. Mol Genet Metab 2002, 76:100-110.

35. Davis PK, Wu G: Compartmentation and kinetics of urea cycle enzymes in porcine enterocytes. Comp Biochem Physiol B Biochem Mol Biol 1998, I | 9:527-537.

36. Dekaney CM, Wu G, Jaeger LA: Ornithine aminotransferase messenger RNA expression and enzymatic activity in fetal porcine intestine. Pediatr Res 2001, 50:104-109.

37. Dekaney CM, Wu G, Jaeger LA: Gene expression and activity of enzymes in the arginine biosynthetic pathway in porcine fetal small intestine. Pediatr Res 2003, 53:274-280.

38. Wang T, Lawler AM, Steel G, Sipila I, Milam AH, Valle D: Mice lacking ornithine-delta-aminotransferase have paradoxical neonatal hypoornithinaemia and retinal degeneration. Nat Genet 1995, II:185-190.

39. Selamnia M, Robert V, Mayeur C, Delpal S, Blachier F: De novo synthesis of arginine and ornithine from citrulline in human colon carcinoma cells: metabolic fate of L-ornithine. Biochim Biophys Acta 1998, 1425:93-102.

40. Crenn P, Coudray-Lucas C, Thuillier F, Cynober L, Messing B: Postabsorptive plasma citrulline concentration is a marker of absorptive enterocyte mass and intestinal failure in humans. Gastroenterology 2000, I I 9:| |496-I505.

4I. Rings EH, Buller HA, de Boer PA, Grand RJ, Montgomery RK, Lamers $\mathrm{WH}$, Charles R, Moorman AF: Messenger RNA sorting in enterocytes. Co-localization with encoded proteins. FEBS Lett 1992, 300:183-187.

42. Wakabayashi Y: Tissue-selective expression of enzymes of arginine synthesis. Curr Opin Clin Nutr Metab Care 1998, I:335-339.

43. Cleary MA, Dorland L, de Koning TJ, Poll-The BT, Duran M, Mandell R, Shih VE, Berger R, Olpin SE, Besley GT: Ornithine aminotransferase deficiency: diagnostic difficulties in neonatal presentation. J Inherit Metab Dis 2005, 28:673-679.

44. Begum L, Jalil MA, Kobayashi K, lijima M, Li MX, Yasuda T, Horiuchi $M$, del Arco A, Satrustegui J, Saheki T: Expression of three mitochondrial solute carriers, citrin, aralarl and ornithine transporter, in relation to urea cycle in mice. Biochim Biophys Acta 2002, I 574:283-292.

45. Indiveri C, Palmieri L, Palmieri F: Kinetic characterization of the reconstituted ornithine carrier from rat liver mitochondria. Biochim Biophys Acta 1994, I I 88:293-30I.

46. Castillo L, DeRojas-Walker T, Yu YM, Sanchez M, Chapman TE, Shannon D, Tannenbaum S, Burke JF, Young VR: Whole body arginine metabolism and nitric oxide synthesis in newborns with persistent pulmonary hypertension. Pediatr Res 1995, 38:17-24.

47. Toda N, Herman AG: Gastrointestinal function regulation by nitrergic efferent nerves. Pharmacol Rev 2005, 57:315-338.

48. Chakder S, Rattan S: L-arginine deficiency causes suppression of nonadrenergic noncholinergic nerve-mediated smooth muscle relaxation: role of L-citrulline recycling. J Pharmacol Exp Ther 1997, 282:378-384.

49. Timmermans JP, Barbiers M, Scheuermann DW, Bogers |J, Adriaensen D, Fekete E, Mayer B, Van Marck EA, De Groodt-Lasseel MH: Nitric oxide synthase immunoreactivity in the enteric nervous system of the developing human digestive tract. Cell Tissue Res 1994, 275:235-245.

50. van Ginneken C, van Meir F, Sys S, Weyns A: Stereologic description of the changing expression of constitutive nitric oxide synthase and heme oxygenase in the enteric plexuses of the pig small intestine during development. J Comp Neurol 200I, 437: $118-128$

51. Wester T, O'Briain DS, Puri P: Notable postnatal alterations in the myenteric plexus of normal human bowel. Gut 1999, 44:666-674.

52. Velasquez OR, Granger DN, Crissinger KD: Intestinal microcirculation in the neonate. Pediatr Surg Int 1992, 7:408-4 I4.

53. Bohlen HG: Mechanism of increased vessel wall nitric oxide concentrations during intestinal absorption. Am J Physiol 1998 , 275: $\mathrm{H} 542-\mathrm{H} 550$.
54. Reber KM, Nankervis CA, Nowicki PT: Newborn intestinal circulation. Physiology and pathophysiology. Clin Perinatol 2002, 29:23-39.

55. Ballance WA, Dahms BB, Shenker N, Kliegman RM: Pathology of neonatal necrotizing enterocolitis: a ten-year experience. J Pediatr 1990, II 7:S6-SI3.

56. Amin HJ, Zamora SA, McMillan DD, Fick GH, Butzner JD, Parsons $H G$, Scott RB: Arginine supplementation prevents necrotizing enterocolitis in the premature infant. J Pediatr 2002, I 40:425-43|.

57. Shah $\mathrm{P}$, Shah $\mathrm{V}$ : Arginine supplementation for prevention of necrotising enterocolitis in preterm infants. Cochrane Database Syst Rev 2007:CD004339.

58. Nowicki PT: Ischemia and necrotizing enterocolitis: where, when, and how. Semin Pediatr Surg 2005, 1 4:152-158.

59. Nowicki PT, Caniano DA, Hammond S, Giannone PJ, Besner GE, Reber KM, Nankervis CA: Endothelial nitric oxide synthase in human intestine resected for necrotizing enterocolitis. J Pediatr 2007, I 50:40-45.

60. Nowicki PT: IL-I beta alters hemodynamics in newborn intestine: role of endothelin. Am J Physiol Gastrointest Liver Physiol 2006, 29I:G404-G4I3.

61. Stolba A, Woodgush DGM: The behaviour of pigs in a semi-natural environment. Anim Prod 1989, 48:419-425.

62. Kretchmer N: Lactose and lactase - $\mathbf{a}$ historical perspective. Gastroenterology 1971, 6 I:805-813.

63. Shulman RJ, Henning SJ, Nichols BL: The miniature pig as an animal model for the study of intestinal enzyme development. Pediatr Res 1988, 23:3 II-315.

64. Campbell AK, Waud JP, Matthews SB: The molecular basis of lactose intolerance. Sci Prog 2005, 88:157-202.

65. Poll MC van de, Siroen MP, van Leeuwen PA, Soeters PB, Melis GC, Boelens PG, Deutz NE, Dejong $\mathrm{CH}$ : Interorgan amino acid exchange in humans: consequences for arginine and citrulline metabolism. Am / Clin Nutr 2007, 85: I67-172.

66. Rolle $U$, Nemeth L, Puri P: Nitrergic innervation of the normal gut and in motility disorders of childhood. J Pediatr Surg 2002, 37:551-567.

Publish with Bio Med Central and every scientist can read your work free of charge

"BioMed Central will be the most significant development for disseminating the results of biomedical research in our lifetime. "

Sir Paul Nurse, Cancer Research UK

Your research papers will be:

- available free of charge to the entire biomedical community

- peer reviewed and published immediately upon acceptance

- cited in PubMed and archived on PubMed Central

- yours - you keep the copyright

\section{BioMedcentral}




\section{CHAPTER V}

\section{HEPATIC ADAPTATION COMPENSATES INACTIVATION OF INTESTINAL ARGININE BIOSYNTHESIS IN SUCKLING MICE}

Vincent Marion ${ }^{1,2}$, Selvakumari Sankaranarayanan ${ }^{1}$, Chiel C. de Theije ${ }^{1}$, Paul van Dijk $^{1}$, Theodorus B.M. Hakvoort ${ }^{3}$, Wouter H. Lamers ${ }^{1,3}$ and S. Eleonore Köhler ${ }^{1}$

${ }^{1}$ Department of Anatomy \& Embryology, Maastricht University, Maastricht, The Netherlands,

${ }^{2}$ Laboratoire de Génetique Médicale, Institut National de la Santé et de la Recherche Médicale (INSERM) U1112, Strasbourg Cedex, France,

${ }^{3}$ AMC Liver Center Academic Medical Center, University of Amsterdam, The Netherlands 


\title{
Hepatic Adaptation Compensates Inactivation of Intestinal Arginine Biosynthesis in Suckling Mice
}

\author{
Vincent Marion ${ }^{1,2}$, Selvakumari Sankaranarayanan ${ }^{1}$, Chiel de Theije ${ }^{1}$, Paul van Dijk ${ }^{1}$, \\ Theo B. M. Hakvoort ${ }^{1,3}$, Wouter H. Lamers ${ }^{1,3}$, Eleonore S. Köhler ${ }^{1 *}$
}

1 Department of Anatomy \& Embryology, Maastricht University, Maastricht, The Netherlands, 2 Laboratoire de Génetique Médicale, Institut National de la Santé et de la Recherche Médicale (INSERM) U1112, Strasbourg Cedex, France, 3 Tytgat Institute for Liver and Gastrointestinal Research, Academic Medical Center University of Amsterdam, Amsterdam, The Netherlands

\begin{abstract}
Suckling mammals, including mice, differ from adults in the abundant expression of enzymes that synthesize arginine from citrulline in their enterocytes. To investigate the importance of the smallintestinal arginine synthesis for whole-body arginine production in suckling mice, we floxed exon 13 of the argininosuccinate synthetase (Ass) gene, which codes for a key enzyme in arginine biosynthesis, and specifically and completely ablated Ass in enterocytes by crossing Ass ${ }^{f l}$ and Villin-Cre mice. Unexpectedly, Ass fl/fi/VilCretg/- mice showed no developmental impairments. Amino-acid fluxes across the intestine, liver, and kidneys were calculated after determining the blood flow in the portal vein, and hepatic and renal arteries $(86 \%, 14 \%$, and 33\%, respectively, of the transhepatic blood flow in 14-

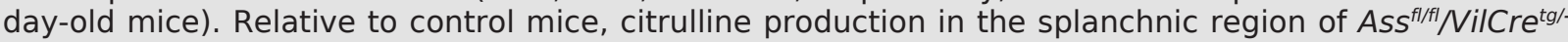
mice doubled, while arginine production was abolished. Furthermore, the net production of arginine and most other amino acids in the liver of suckling control mice declined to naught or even changed to consumption in Ass ${ }^{f / f l} / \mathrm{NilCr} \mathrm{C}^{\mathrm{tg} / \mathrm{-}}$ mice, and had, thus, become remarkably similar to that of post-weaning wild-type mice, which no longer express arginine-biosynthesizing enzymes in their small intestine. The adaptive changes in liver function were accompanied by an increased expression of genes involved in arginine metabolism (Asl, Got1, Gpt2, Glud1, Arg1, and Arg2) and transport (Slc25a13, Slc25a15, and Slc3a2), whereas no such changes were found in the intestine. Our findings suggest that the genetic premature deletion of arginine synthesis in enterocytes causes a premature induction of the postweaning pattern of amino-acid metabolism in the liver.
\end{abstract}

Citation: Marion V, Sankaranarayanan S, de Theije C, van Dijk P, Hakvoort TBM, et al. (2013) Hepatic Adaptation Compensates Inactivation of Intestinal Arginine Biosynthesis in Suckling Mice. PLoS ONE 8(6): e67021. doi:10.1371/journal.pone.0067021

Editor: François Blachier, National Institute of Agronomic Research, France

Received February 07, 2013; Accepted May 13, 2013; Published June 13, 2013

Copyright: (c) 2013 Marion et al. This is an open-access article distributed under the terms of the Creative Commons Attribution License, which permits unrestricted use, distribution, and reproduction in any medium, provided the original author and source are credited.

Funding: This study was supported by a grant from the graduate school NUTRIM, Maastricht University, to WHL. The funders had no role in study design, data collection and analysis, decision to publish, or preparation of the manuscript.

Competing interests: The authors have declared that no competing interests exist.

*E-mail: Leo.Koehler@maastrichtuniversity.nl

\section{Introduction}

Arginine is a substrate for the synthesis of nitric oxide, urea, ornithine, citrulline, creatine, agmatine, glutamate and proline [1]. The rate-determining enzyme of arginine synthesis from citrulline and aspartate is argininosuccinate synthetase (ASS) (EC 6.3.4.5) [2]. The endogenous biosynthetic capacity for arginine suffices to meet the daily requirement under normal conditions, but a dietary source of arginine becomes necessary when demand increases under anabolic or catabolic conditions [3-5]. For this reason, arginine is a conditionally essential amino acid.
These general conclusions apply to post-weaning individuals that can adapt their sources of food. However, arginine metabolism in the early postnatal period differs considerably from that in the adult, probably because the rapidly growing suckling animals have no choice of food. Since the supply of arginine via the milk is not sufficient to support optimal protein synthesis [6-8], suckling animals need a higher endogenous capacity for arginine synthesis. The abundant expression of the enzymes necessary for de novo arginine biosynthesis in the enterocytes of the small intestine of perinatal rodents [9-11], piglets $[12,13]$ and humans [14] and the absence of cytosolic arginase expression [9,15-18] suggest that the 
intestine is an important site for early postnatal arginine production in mammals. In fact, it has been demonstrated that the small-intestinal mucosa accounts for $\sim 50 \%$ of the endogenous production of arginine in normally fed suckling piglets, while hypoargininemia develops if this source of arginine production is bypassed as during parenteral feeding [19-21]. In addition, we have shown that suckling mice that transgenically overexpress arginase 1 in the smallintestinal enterocytes suffer from deficient hair and muscle growth, and underdevelopment of Peyer's patches due to impaired B-cell maturation $[15,16]$. Interestingly, the capacity of the intestine to produce arginine becomes limited to citrulline synthesis in the weaning period, when the expression of argininosuccinate synthetase and lyase in the intestines declines in humans and pigs $[14,17,18]$, and stops in rodents [9]. Although these findings suggest that intestinal arginine biosynthesis is essential for suckling animals, this hypothesis remains to be tested.

To assess to what extent the small-intestinal arginine synthesis is essential for suckling mice, we have eliminated the expression of argininosuccinate synthetase (Ass) in the enterocytes, using the Cre-loxP recombinase system. Since the total-body deletion of Ass is lethal [22], exon 13 of the Ass gene was surrounded by loxp sites. Enterocyte-specific excision of the "floxed" exon was accomplished by breeding $A s s^{f l}$ mice with VilCre mice [23]. Suckling Ass ${ }^{f / f l} /$ VilCre $^{t g /-}$ mice (Ass-KO/l) were completely devoid of Ass expression in their enterocytes, but unexpectedly did not suffer from growth retardation or any other detectable functional impairment. Whereas Ass elimination from enterocytes did not cause adaptive changes in gene expression in enterocytes, it did change the expression of several amino acidmetabolizing and transporting genes in the liver with as result that arginine deficiency did not develop. Our findings highlight a homeostatic regulatory interaction of the gut-liver axis with respect to arginine metabolism.

\section{Methods}

\section{Plasmid construction and recombinant ES cell selection}

The mouse Ass gene is located on chromosome 2. The targeting vector $(14.384 \mathrm{~Kb})$ consisted of the $3^{\prime} 4.2$ $\mathrm{Kb}$ of intron 12, a Neo-TK selection cassette flanked by frt sites, exon 13 flanked by loxP sites and the 5 ' $3.5 \mathrm{~Kb}$ of intron 13 (Figure S1A). The targeting construct was sequence verified with respect to splice junctions, exon 13 and recombinase-recognition sites, digested with Ascl and Pmel (introduced by PCR for cloning purposes), and purified by electrophoresis and electroelution. Twenty-five $\mu \mathrm{g}$ of the targeting fragment was electroporated into the 129P2/OlaHsd-derived mouse ES cell line E14IB10, a subclone of E14 cells [24].
Selection with G418 $(200 \mu \mathrm{g} / \mathrm{mL})$ was started 24 hours after electroporation. Short vector sequences that were left on either end of the targeting construct allowed a PCR-based negative screen against random integrations (Figure S1B, upper panels). Long-distance PCR with an Ass-specific primer outside the targeting construct and a loxP-specific primer was used to demonstrate homologous recombination at the $3^{\prime}$ side in the remaining clones (Figure S1B, middle panel). Proper recombination of the $5^{\prime}$ end was demonstrated with Southern blotting and probing with a Neo fragment (Figure S1B, lower panel). The Neo-TK cassette was removed by transient transfection with an $F L P e$ recombinase expression vector (kindly provided by Dr. Francis Stewart, EMBL, Germany). Selection with ganciclovir $(5 \mu \mathrm{M})$ was started 5 days after electroporation. The recombined allele was again sequence verified (ganciclovir introduced a mutation in 1 of 4 clones tested). Two clones containing 40 chromosomes were selected for blastocyst injection.

\section{Generation of transgenic mice and husbandry}

Ass-recombinant ES cells were injected into C57BL/6] blastocysts. Chimeric male mice were bred with female 129P2/OlaHsd mice (Harlan, The Netherlands) and with deleter-Cre females on a C57BL/6 background (kindly provided by Dr. Ursula Lichtenberg, University of Cologne, Germany) to delete Ass exon 13 in the germ line [25]. Mice were genotyped with primers Ass-FI and Ass-R1 (Table S1 Figure S1C and D, upper subpanel), yielding a $360 \mathrm{bp}$ wild-type allele and a $390 \mathrm{bp}$ floxed allele. The Cre-excised allele (340 bp) was detected by PCR with the primers Ass-F2 and Ass-R1 (Figure S1C and $D$, middle subpanel). To specifically delete the $A s s^{f l}$ allele in the enterocytes of the small intestine, mice were crossed with VilCre mice [23]. Animals were genotyped for the presence of VilCre by PCR with primers Vil-F and Vil-R (see: Table S1 and Figure S1D, lower subpanel), yielding a 1,100 bp band for VilCrepositive animals. All mice used in this study except the controls in Figure $1 \mathrm{~A}$ had the same genetic background.

Animals were housed in humidity- and temperaturecontrolled rooms on a 12-hour light/ 12-hour dark cycle with food and water ad libitum. The animal studies were reviewed and approved by the institutional Animal Care and Ethical committee (DEC) of Maastricht University.

\section{Blood and tissue collection}

Animals were sacrificed by decapitation on neonatal days (ND) $14,18,21$, and 35 . Blood samples from the hepatic vein, portal vein, renal vein and left ventricular cavity were taken from 14- and 35-day-old mice under $2 \%$ isoflurane (Abbott, \# B506)/ $90 \% \mathrm{O}_{2}$ anesthesia, as described for adult mice [26]. Tissues were fixed in $4 \%$ buffered formalin and embedded in Paraplast ${ }^{\circledR}$. 

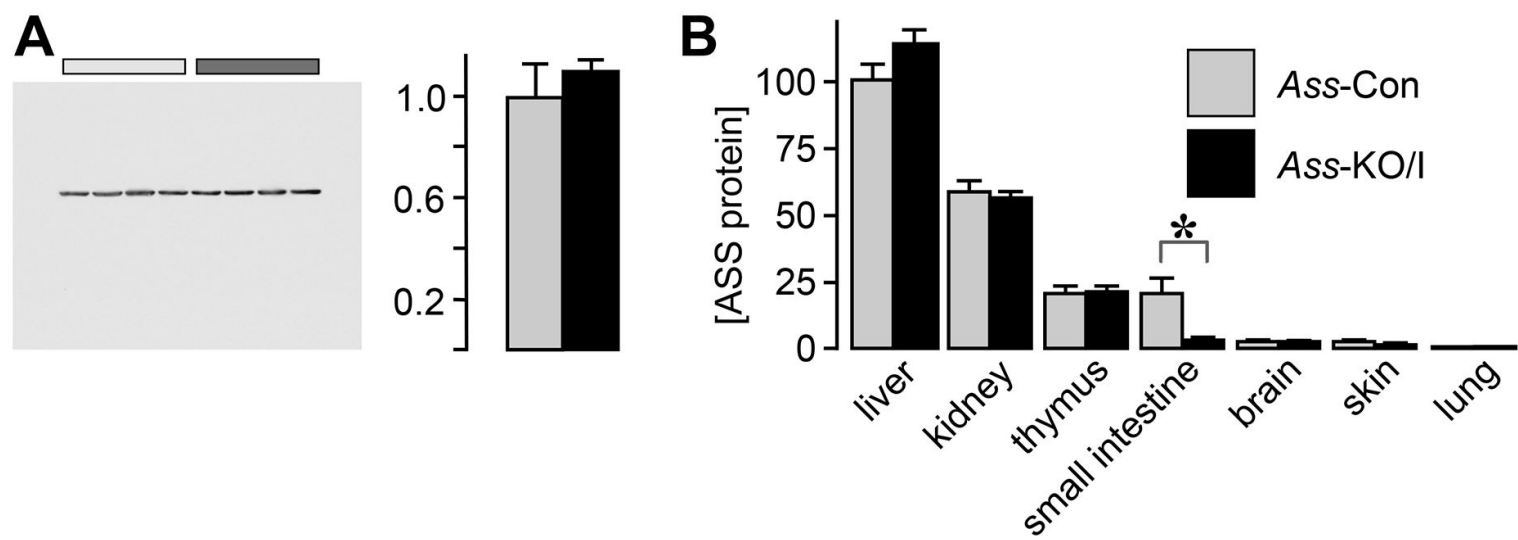

Figure 1. Expression of the Ass ${ }^{f l}$ allele is not compromised and allows efficient excision. Panel A: Western blot demonstrating that the loxP sites surrounding exon 13 do not affect ASS expression at the protein level (liver extract with $25 \mu \mathrm{g}$ total protein was loaded per lane; quantification of band intensity on right subpanel). Panel B: ASS protein in ND14 Ass-KO/l mice is eliminated in the enterocytes of the small intestine only. Note that the residual ASS in the small intestine reflects the presence of the ASS-positive enteric ganglia (Figure 2). Light gray bars indicate Ass-Con mice and dark gray bars Ass-KO/I mice ( $\mathrm{N}=4$ each).

doi: 10.1371/journal.pone.0067021.g001

\section{Amino-acid concentration}

Blood was collected into heparin-coated tubes and centrifuged at $2,000 * \mathrm{~g}$ for $5 \mathrm{~min}$ at $4^{\circ} \mathrm{C}$. $80 \mu \mathrm{L}$ of plasma was added to $6.4 \mathrm{mg}$ of lyophilized sulphosalicylic-acid, vortexed and stored at $-20^{\circ} \mathrm{C}$. Amino-acid concentrations were determined by HPLC as described [27]. Amino-acid fluxes were calculated as described [26]. Because only the relative distribution of flows across organs could be measured (next section), fluxes were expressed as the product of the arteriovenous differences in amino-acid concentrations and the relative flow across the respective organs.

\section{Blood flow distribution using radioactive microspheres}

Radioactive microspheres (15 $\mu \mathrm{m}$ diameter), labeled with ${ }^{103} \mathrm{Ru}$, were purchased from PerkinElmer USA (NEM082A100UC). Fourteen-day-old mice (6-8 gram body weight) were anesthetized by intraperitoneal injection of $100 \mu \mathrm{g} / \mathrm{g}$ ketamine (Pfizer) + $20 \mu \mathrm{g} / \mathrm{g}$ xylazine. After opening the thorax through the fourth left intercostal space, $50 \mu \mathrm{L}$ of a $0.01 \%$ Tween-80/ saline solution containing 10,000 microspheres $(\sim 20$ $\mathrm{KBq}$ ) was injected into the left ventricle. Organs were isolated, transferred to a plastic counting vial containing $2 \mathrm{~mL}$ of saline and measured with a gamma counter (Wallac Wizard 1480; PerkinEImer, USA).

\section{Western blotting and histology}

Tissues were crushed in a liquid nitrogen-cooled mortar, sonicated in RIPA buffer (25 mM Tris. $\mathrm{HCl}(\mathrm{pH}=7.6), 150 \mathrm{mM} \mathrm{NaCl}, 1 \% \mathrm{NP}-40,1 \% \mathrm{Na}-$ deoxycholate, $0.1 \% \mathrm{Na}$-dodecylsulfate), containing a protease inhibitor cocktail (Complete; Roche, The
Netherlands). Twenty-five $\mu \mathrm{g}$ of protein was loaded per lane. Equal protein loading per lane was verified by Ponceau-S staining of the blots prior to incubation with antiserum. ASS was visualized by incubating the blots with rabbit anti-mouse ASS antiserum $(1: 1,500$ $[15,16])$, followed by alkaline phosphatase-coupled goat anti-rabbit antibody and "Super Signal West Femto Maximum Sensitivity Substrate" (Pierce \# 34095)

Duodenal ( $2 \mathrm{~cm}$ distal to the pyloric sphincter) and ileal ( $2 \mathrm{~cm}$ proximal to the ileocecal junction) segments were fixed in ice-cold buffered $4 \%$ formaldehyde, embedded in Paraplast ${ }^{\circledR}$, and sectioned at $7 \mu \mathrm{m}$. Goblet cells were visualized with $1 \%$ Alcian blue $(\mathrm{BDH}$, The Netherlands) in $3 \%$ acetic acid $(\mathrm{pH}=2.5)$ for 30 min. Nuclei were visualized with $1 \%$ Nuclear Fast Red (Chroma, Fluka) for $3 \mathrm{~min}$. For immunostaining, sections were subjected to antigen retrieval (10 min at $100^{\circ} \mathrm{C}$ in $10 \mathrm{mM} \mathrm{Na-citrate}(\mathrm{pH} \mathrm{6.0)})$, blocked with Teng-T (10 mM Tris ( $\mathrm{pH}=7.6), 5 \mathrm{mM}$ EDTA, $150 \mathrm{mM}$ $\mathrm{NaCl}, 0.25 \%$ gelatin, $0.05 \%$ Tween-20) $/ 10 \%$ normal goat serum (NGS, Gibco, The Netherlands) for $30 \mathrm{~min}$, and incubated overnight in a 1:1,000 dilution of the ASS antibody [15,16] in Teng-T/10\% NGS. After washing with PBS and another blocking step with TengT /10\% NGS for $15 \mathrm{~min}$, sections were incubated with goat anti-rabbit antiserum (Sigma A3687; diluted 1:200 in Teng-T /10\% NGS) for 90 min. After washing, the slides were incubated with nitroblue tetrazolium chloride/5-bromo-4-chloro-3-indolyl phosphate (NBT/ $\mathrm{BCIP}$; Roche 169471 ) at $37^{\circ} \mathrm{C}$ until staining reached an optical density not exceeding 0.8 . 


\section{Visualization of Peyer's patches}

The small intestine was immersed for $5 \mathrm{~min}$ in $10 \%$ acetic acid $(\mathrm{v} / \mathrm{v})$ before fixation in $10 \%$ neutral-buffered formalin, as described previously [16].

\section{PCR assays}

RNA was extracted from cells and tissues with guanidinium thiocyanate (TRI Reagent, Sigma). RNA integrity was assessed by denaturing gel electrophoresis and RNA concentration with a NanoDrop-ND1000 spectrophotometer (Isogen Life Sciences). One $\mu \mathrm{g}$ of total RNA was reverse transcribed with the iScript cDNA synthesis kit (Bio-Rad). The cDNA preparation was diluted $1: 10(\mathrm{v} / \mathrm{v})$ with milliQ water prior to addition to the PCR mixtures.

Quantitative PCR. PCR was performed using iQTM SYBR ${ }^{\circledR}$ Green Supermix (Biorad 170-8882) in an iQ5 real-time PCR detection system (Biorad). The extension temperature was $60^{\circ} \mathrm{C}$ for all primer pairs. CDNA samples were diluted 60 -fold before use for mRNAs and 600 -fold for $18 \mathrm{~S}$ rRNA. Primary fluorescent data were exported and analyzed using the Lin-RegPCR program [28]. All primers (Table S1) were obtained from Genosys (Sigma).

PCR array. TaqMan ${ }^{\circledR}$ OpenArray ${ }^{\circledR}$ Real-Time PCR Plates containing validated primers for mRNAs of 42 different genes involved in arginine metabolism or transport (Table S2) were ordered from Life Technologies (Saint-Aubin, France). The PCR assays were run according to the "rapid" program in an $A B I$ cycler.

\section{Statistics}

Between-session variation in replicate experiments was corrected using "Factor Correction" [29]. All quantitative values are presented as means \pm SEM. Statistical differences for the amino acids fluxes between genotypes were based on homogeneity of variances between the blood sources per genotype followed by one-way analysis of variances using known means and standard deviations. P-values were calculated through multiple comparisons [30].

\section{Results}

\section{Characterization of Ass ${ }^{\mathrm{fl}}$ mice}

To study the function of ASS in the enterocytes of the small intestine, we generated a conditional Ass knockout, in which the critical exon 13 is flanked by loxP sites (Figure S1). Mice with $A s s^{/ f f l}$ and $A s s^{f / f l}$ genotypes were healthy and fertile. In agreement, Figure $1 \mathrm{~A}$ shows that flanking exon 13 with loxP sites did not affect ASS protein content in the liver, an organ with very high Ass expression (Figure 1B). To test if deletion of exon 13 in the mouse was as effective (lethal) as deletion of exon 4 [22], we interbred $\mathrm{Ass}^{+/}$ mice (generated by crossing Ass $^{+f f l}$ mice with deleter-
Cre mice [25]). Figure S2A demonstrates that none of the Ass exon13-deficient Ass $^{-/}$neonates survived longer than 1 day after birth, as was found for the constitutive Ass exon4-deficient mice [22]. Together, these data show that mice harboring the Ass $^{f l}$ allele are a good model to investigate the effects of tissuespecific Ass deletions. Ass ${ }^{f / f l} / \mathrm{NilCre}^{-/}$mice are indicated as Ass-Con and Ass ${ }^{f / f l} /$ VilCre $^{\text {tg/- }}$ as Ass-KO/l.

\section{VilCre efficiently and specifically eliminates Ass in the enterocytes}

To evaluate the development of the small intestine in the absence of Ass expression in the enterocytes, sections of the intestines of ND14, ND18, and ND21 mice were stained with haematoxylin and eosin or with Alcian blue and Nuclear Fast Red. No qualitative differences in the architecture of the duodenum and ileum were found between Ass-Con and Ass-KO/I mice at any of the ages investigated (not shown). Staining the duodenum and the ileum for the presence of ASS revealed a complete elimination of ASS in the enterocytes of Ass-KO/I mice only (Figure 2A-H), whereas ASS in the enteric ganglia remained unaffected. Although both Ass and Vil are also expressed in the proximal tubules of the kidney [31,32], the VilCre transgene is not [23]. Accordingly, we did not observe the disappearance of ASS protein in the kidney (Figure 1B Figure $2 \mathrm{l}, \mathrm{J}$ ). Both Ass and Vil are also expressed in the epidermis [33,34]. Although ASS

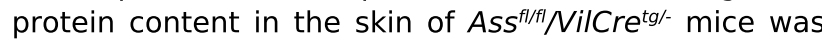
lower than in $\mathrm{Ass}^{\mathrm{fl} / \mathrm{fl}} / \mathrm{NilCre}^{-}$mice (Figure 1B), the difference was not significant.

\section{Development in the absence of Ass expression in the enterocytes}

F/A2 mice, which have no net production of arginine in their enterocytes due to the transgenic overexpression of arginasel in these cells, suffer from impaired hair and muscle growth and underdevelopment of Peyer's patches due to impaired B-cell development during the suckling period $[15,16]$. Despite the complete elimination of Ass expression in their enterocytes, Ass-KO/l mice show a normal increase in body weight (Figure S2B), hair growth (Figure S2C), and development of Peyer's patches (Figure S2D).

\section{Changes in plasma amino-acid concentrations in the absence of Ass expression in enterocytes}

Circulating amino acids in arterial, portal, hepatic and renal blood of Ass-Con and Ass-KO/I mice were determined at ND14 and ND35 (Table S3), with those of arginine, citrulline, ornithine and lysine in ND14 shown in Figure 3A-D. Lysine was included, because it is, like arginine, positively charged and transported by the same transporters, so that differences in the prevalence of arginine would probably be reflected in 


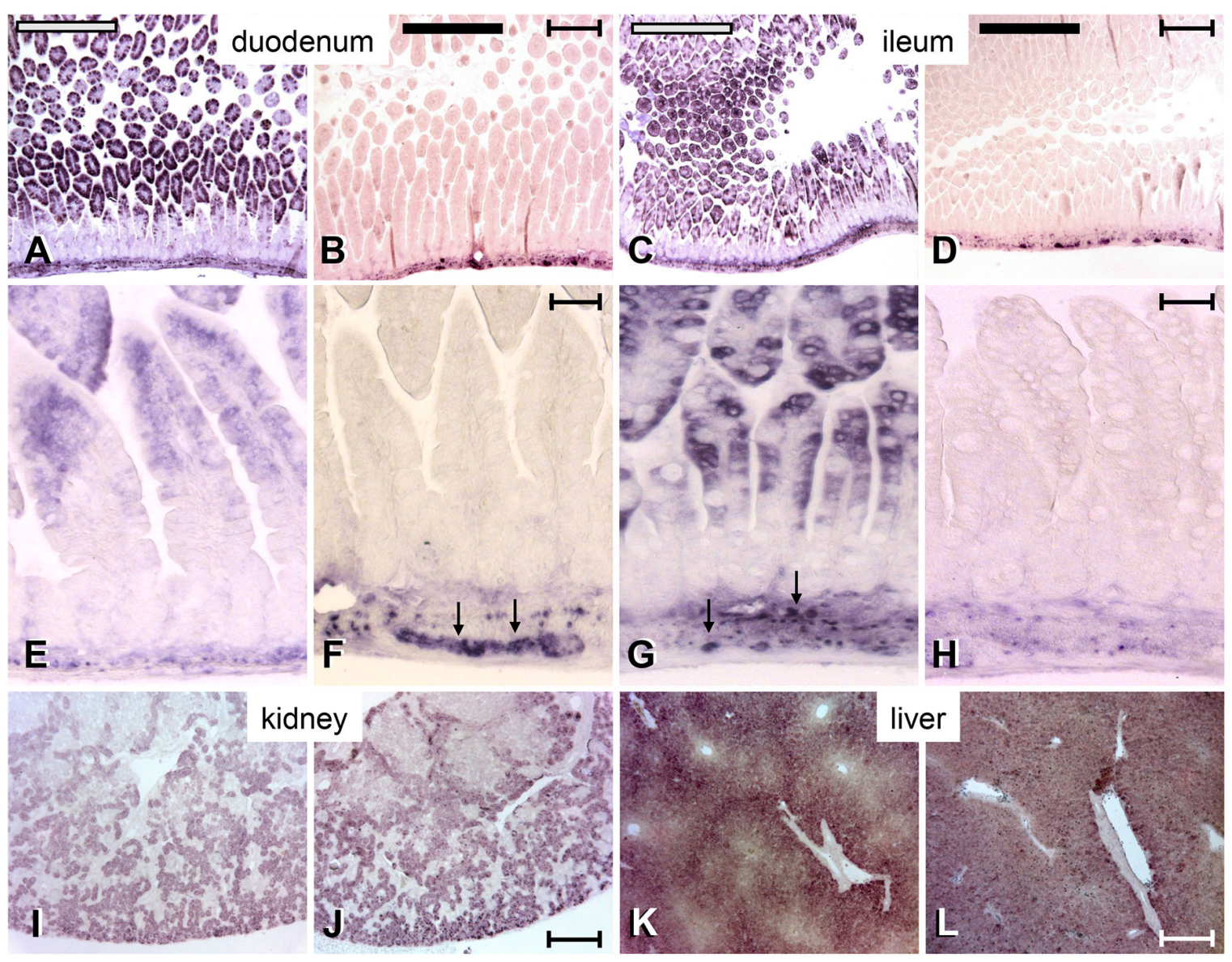

Figure 2. Expression of ASS in the small intestine, kidney and liver of ND14 mice. ASS protein in the duodenum (panels A, B, E, F) and ileum (panels C, D, G, H) of Ass-Con or Ass-KO/l animals is visualized by semiquantitative immunohistochemistry. The second row of panels shows magnifications of the top row. Note that expression of ASS in Ass-Con mice is limited to the top portion of the villus. Further note that the elimination of Ass expression is complete in the enterocytes of Ass-KO/I mice, but unaffected in their enteric ganglia (arrows). The bottom panels show unperturbed ASS protein in the S3 segment of the proximal tubule of the kidney $(\mathrm{J}, \mathrm{K})$ and in the periportal region of the liver (L, M) of Ass-KO/I mice. Gray bars identify Ass-Con and black bars Ass-KO/I mice. Bars: $8 \mu \mathrm{m}$ (overviews) and $1 \mu \mathrm{m}$ (magnifications).

doi: 10.1371/journal.pone.0067021.g002

those of lysine [3536.-37]. Compared to Ass-Con mice, the circulating concentration of arginine in plasma of Ass-KO/I mice did not change significantly in the aorta and portal vein, but decreased to $\sim 65 \%$ in the hepatic vein and increased $\sim 35 \%$ in the renal vein (Figure $3 \mathrm{~A}$ ). Circulating concentrations of the arginine precursor citrulline changed more profoundly, being $\sim 1.5$-fold higher in the aorta and hepatic vein and $\sim 2$-fold higher in the portal and renal veins of Ass-KO/I than of AssCon mice (Figures $3 \mathrm{~B}$ and $4 \mathrm{D}$ ). The concentration of ornithine was decreased in the hepatic vein and increased in the renal vein of Ass-KO/l compared to Ass-Con mice (Figure 3C). Plasma lysine concentrations were not different between control and experimental animals (Figure 3D). With respect to the other amino acids and compared to Ass-Con mice, glutamate, alanine and taurine increased in the aorta, glutamate, glutamine, threonine, alanine, taurine, valine, and leucine increased in the portal vein, and alanine, taurine, valine, isoleucine, leucine in the renal vein of Ass-KO/I mice, whereas glutamate, valine, isoleucine, tryptophan, and leucine decreased in the hepatic vein (Table S3). In agreement with these findings, the sum of amino acids was higher in the aorta, and portal and renal veins, and lower in the hepatic vein of Ass-KO/I than of Ass-Con mice. Strikingly, the data of the experimental group were more heterogeneous than those of the control group. 

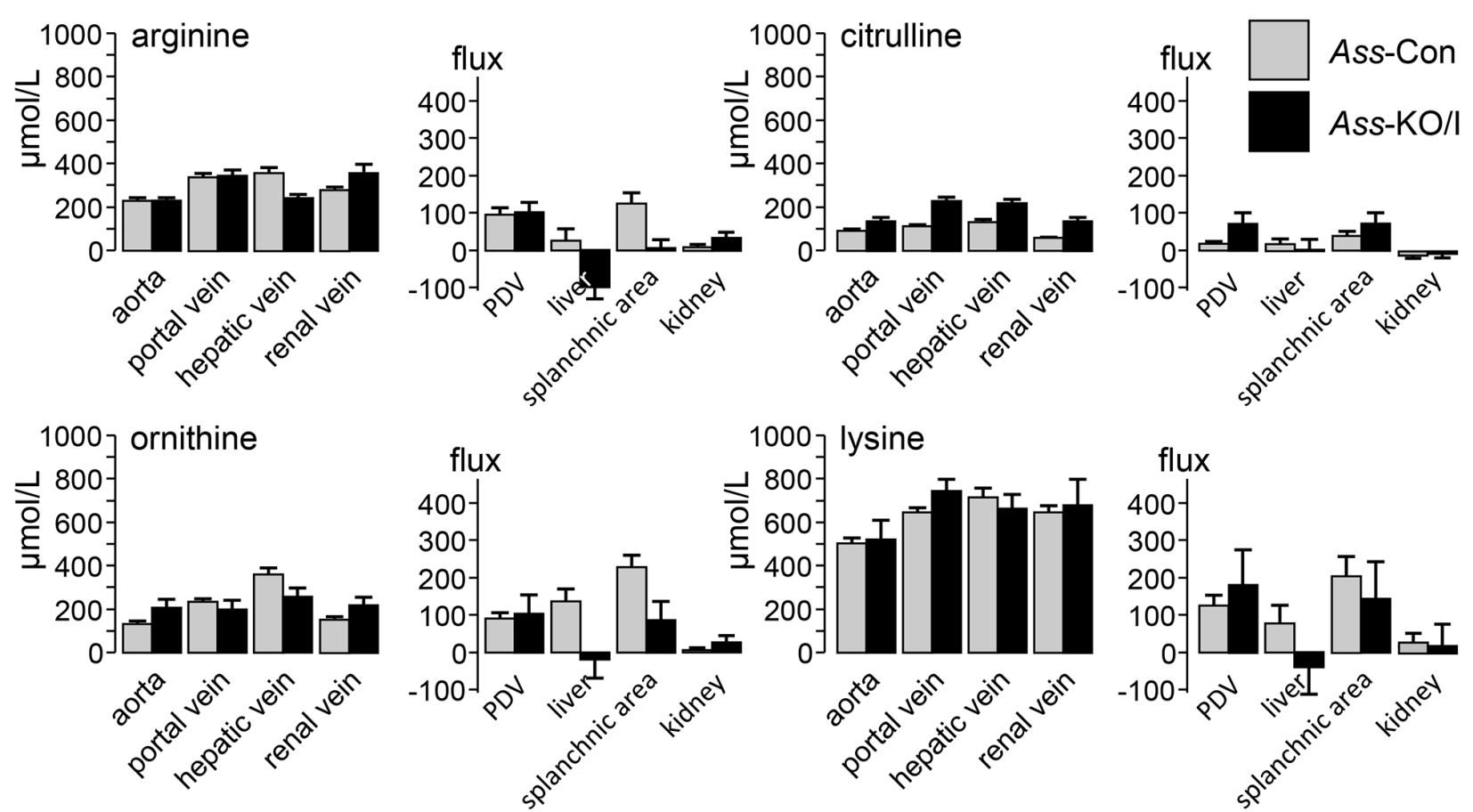

Figure 3. Circulating levels and fluxes of arginine, citrulline, ornithine, and lysine in ND14 mice. Left panels: Circulating concentrations of the indicated amino acids in Ass-Con (light gray) and Ass-KO/I (black) mice. The source of the blood is indicated. Right panels: Production or consumption of the indicated amino acids across the splanchnic region, portal-drained viscera (PDV) and liver.

doi: 10.1371/journal.pone.0067021.g003

\section{Changes in amino-acid fluxes in the absence of ASS in enterocytes}

The uptake or release of amino acids across the intestine, liver and kidneys of suckling ND14 mice was determined by multiplying the veno-arterial concentration differences and the blood flow across these organs. To measure the blood flow across the organs, we determined the distribution of radioactive microspheres injected into the left ventricular cavity (Figure 4A). Since we were not able to harvest reference samples from the abdominal aorta of these small mice ( $~ 8$ gram), only the relative distribution of the cardiac output across organs and, hence, the metabolic fluxes in the portal drained viscera, liver, and kidneys could be calculated. At ND14, $\sim 86 \%$ of the transhepatic blood flow originated in the portal vein and $\sim 14 \%$ in the hepatic artery, while blood flow through the kidneys amounted to $\sim 33 \%$ of that through the liver, without significant differences between genotypes. Relative to Ass-Con mice, the production of arginine, ornithine, and lysine in the portal-drained viscera had not changed in Ass-KO/I mice, but the liver had become an arginine- and lysineconsuming organ (significance at the trend level), so that the contribution of the splanchnic region to systemic arginine even became non-existent (Figure
$3 \mathrm{~A}$, right panel). Arginine production in the kidney had more than doubled, but this compensated only $\sim 25 \%$ of the decrease in arginine production in the splanchnic area. Citrulline was the only amino acid with an increased ( $\sim$-fold) production in the portal drained viscera of Ass-KO/I mice, due to the absence of ASS (Figure 3B, right panel). The trends of arginine and lysine were followed by the other amino acids: only the production of glycine and taurine decreased significantly in the portal drained viscera, whereas the liver changed from production to uptake for glutamate, glutamine, taurine, valine, isoleucine, leucine, and the sum of all amino acids (Table S3 Figure 4B). Furthermore, a trend with the same effect was seen for serine, threonine, and methionine. These data therefore show that deletion of Ass from the enterocytes of the small intestine has little effect on the small intestine itself, but exerts a major effect on the liver, significantly decreasing the hepatic production of 6 amino acids (glutamate, glutamine, taurine, valine, isoleucine, and leucine) and that of 5 more amino acids (serine, threonine, arginine, methionine, and lysine) at the trend level, that is, changing the liver from an amino acid-producing into an amino acid-consuming organ. Due to the relatively small blood flow through the kidneys $(\sim 33 \%$ of that 


\begin{tabular}{|c|c|}
\hline \multicolumn{2}{|c|}{$\begin{array}{l}\text { perfusion of some } \\
\text { vascular compartments } \\
\text { in ND14 mice }(\mathrm{N}=19)\end{array}$} \\
\hline vessel & $\begin{array}{l}\text { perfusion } \\
\text { (\% of sum) }\end{array}$ \\
\hline $\begin{array}{l}\text { PDV } \\
\text { liver } \\
\text { viscera } \\
\text { kidneys } \\
\text { hindquarter }\end{array}$ & $\begin{array}{r}36 \pm 1 \\
6 \pm 1 \\
42 \pm 2 \\
14 \pm 2 \\
28 \pm 2\end{array}$ \\
\hline brain & $14 \pm 1$ \\
\hline
\end{tabular}
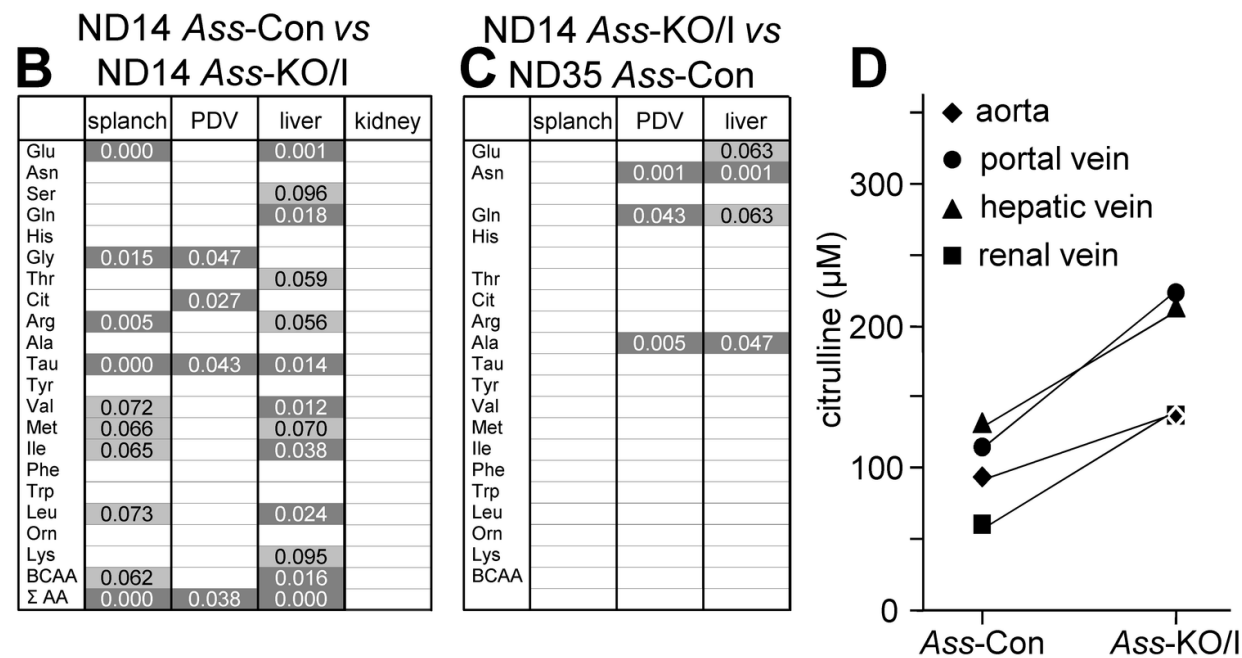

Figure 4. Regional perfusion, differences in amino-acid fluxes and citrulline concentration in ND14 Ass-Con and Ass-KO/I mice. Panel A: Blood flow in portal vein ("Portal Drained Viscera"), hepatic artery (liver), hepatic vein (viscera), renal arteries (kidneys), femoral arteries (hindquarter) and brain as assessed by microsphere distribution after intracardiac injection. Panel B: Significant differences in the flux of amino acids across the splanchnic region, portal drained viscera, liver, and kidneys of ND14 Ass-KO/I compared to ND14 Ass-Con mice. C: Significant differences in the flux of amino acids across the splanchnic region, portal drained viscera and liver of ND14 Ass-KO/I compared to ND35 Ass-Con mice. In panels B and C, dark gray fields represent differences with P $\leq$ 0.05 . Differences with $0.05 \leq P \leq 0.10$ (light gray) are also shown, because the power of our calculations was weakened by the fact that we could take only one blood sample from a vessel in each ND14 pup. Panel D: Average concentration of citrulline in the respective vessels (cf. also Table S3).

doi: 10.1371/journal.pone.0067021.g004

through the splanchnic region), the contribution of the kidney to amino-acid metabolism was still minor at 14 days after birth (Table S3) and not different between controls and knockouts (Figure 4B).

\section{Changes in plasma amino-acid concentrations and fluxes in the absence of ASS in enterocytes}

We also measured amino-acid concentrations in arterial, portal and hepatic venous blood of postweaning (35-days old) mice, that is, when Ass is no longer expressed in the small intestine of mice. Table S4A shows that, at this age, Ass-KO/I mice no longer differed from Ass-Con mice in the concentration of blood amino-acid concentrations. In agreement, the fluxes of amino acids across the portal-drained viscera and liver also differed no longer (Table S4B). Furthermore, it should be noted that, with the exception of glutamine, the liver had become an amino-acid consuming organ in both Ass-KO/I and AssCon mice. Compared to ND14 Ass-KO/I mice, ND35 (Figure 4C) mice merely differed in a further increase in the hepatic consumption of glutamate, asparagine, and alanine, and in the production of glutamine, probably reflecting the detoxification of ammonia in pericentral hepatocytes.

\section{Changes in gene expression in small intestine and liver in the absence of ASS in enterocytes}

We designed a PCR array to measure the expression of 45 genes involved in arginine metabolism and arginine, citrulline, or ornithine transport (Table S2). These arrays were tested on 3 small intestines and 3 livers of Ass-Con and of Ass-KO/I mice. Of these, none except Ass differed in intestinal expression between ND14 Ass-Con and Ass-KO/I mice. In 3 ND14 Ass-KO/I livers, however, the expression of Ass, Asl, Got1, Gpt2, Glud1, Arg1, Arg2, Slc3a2, Slc7a7, Slc7a10, Slc25a13, Slc25a15, and Slc38a2 was increased. These results were then confirmed by standard qPCR assays in 5 additional livers of Ass-Con and of Ass-KO/I mice (Figure 5). In this assay, significant upregulation of gene expression was found for Asl, Got1, Gpt2, Arg1, Arg2, Slc3a2, Slc25a15, and S/c38a2, demonstrating that the liver adapts to the loss of Ass expression in the gut. These 9 genes encode enzymes (Asl, Got1, Gpt2, Glud1, Arg1, and Arg2) and transporters (S/c25a13 (aspartate/glutamate carrier), Slc25a15 (ornithine transporter), and Slc3a2 (light subunit of LAT1 transporter)) that are all directly linked to amino-acid catabolism and urea synthesis. 


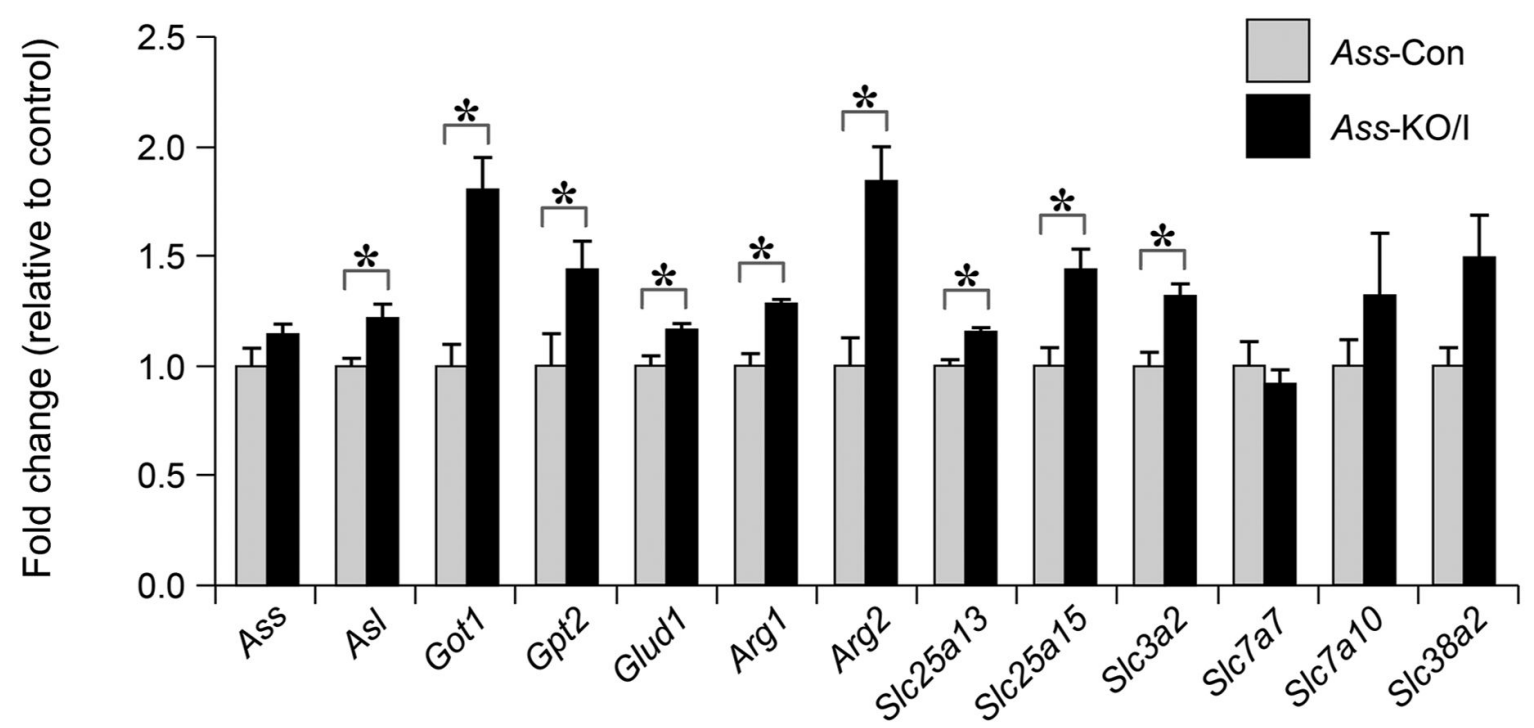

Figure 5. Adaptive changes in arginine transporting or metabolizing genes in the liver of Ass-KO/I mice. The 13 genes were selected from a panel of 45 genes (Table S2) and tested on cDNA preparations from 8 Ass-Con (light-gray bars) and 8 Ass-KO/I mice (black bars). *: $\mathrm{P}<0.05$ between Ass-Con and Ass-KO/l. doi: 10.1371/journal.pone.0067021.g005

\section{Discussion}

Since milk is relatively deficient in arginine [6-8], endogenous synthesis is necessary to ensure optimal growth and development of neonates during the suckling period. Studies in mice, pigs and humans have identified the enterocytes of the small intestine as a site with a potentially large biosynthetic capacity for arginine that disappears after weaning [9-21,38]. Interestingly, our findings demonstrate that this temporary function of the small intestine is dispensable in mice and compensated for by the liver and, to a lesser extent, the kidneys. Indeed, the genetic ablation of Ass from enterocytes did not depress the arterial concentration of arginine. Whereas the change in intestinal function was not associated with a change in gene expression, that of the liver was mediated by a wide-spread upregulation of the expression of genes involved in amino-acid metabolism and transport.

\section{Comparison of Ass-KO/I mice with other arginine-deficient mouse models}

Elimination of Ass exon 13 by VilCre-mediated excision in the small-intestinal enterocytes resulted in undetectable levels of ASS protein in the targeted cells only (Figures $1 B$ and 2 ). ASS in other tissues, such as the enteric ganglia, kidney tubules, and hepatocytes remained unchanged (Figures $1 \mathrm{~B}$ and 2). Suckling Ass$\mathrm{KO} / \mathrm{I}$ mice showed, nevertheless, none of the features of suckling "F/A2" mice, in which intestinal arginine synthesis was annulled by transgenic overexpression of arginase 1 in the enterocytes $[15,16]$. F/A2 mice suffer from a selective decline in circulating arginine, deficient hair and muscle growth, and underdevelopment of Peyer's patches. The discrepancy of the phenotypes of Ass-KO/I and F/A2 mice suggests that overexpression of arginase1 causes the gut to function additionally as a sink for circulating and dietary arginine that passes the intestine. Clearly, the capacity of this sink exceeded the endogenous arginine production. The absolute requirement for arginine supplementation of neonatal mice that are constitutively deficient for ornithine aminotransferase (Oat) [39] also contrasts with the absence of a phenotype in Ass-KO/I mice. OAT converts glutamate to ornithine, is expressed at $\sim 5$-fold higher levels in the suckling than the weaned small intestine and results in a severe deficiency of ornithine, citrulline and arginine if absent in the neonatal period [39]. Similarly, the Spf mutation in ornithine transcarbamoylase (Otc), which severely decreases its capacity to convert ornithine into citrulline, causes a deficiency in circulating citrulline and arginine levels in suckling mice [40]. In aggregate, these mouse models demonstrate that intestinal citrulline is crucial to ensure optimal development whereas intestinal arginine production is, against expectations, expendable to maintain normal circulating arginine levels prior to weaning. 


\section{The metabolic consequences of intestinal deletion of Ass}

The absence of hypoargininemia or any other detectable sign of arginine-dependent deficiency, therefore, disproved our hypothesis that intestinal arginine synthesis was necessary to supplement endogenous and dietary arginine sources to sustain growth in the suckling. Only for citrulline, we found a significant $\sim 1.8$-fold increase in the circulating concentration in Ass-KO/I mice. The assessment of the fluxes of amino acids across the portal drained viscera, liver and kidney in the suckling mice (Table S3B) was more laborious than that in adult mice, because only a single vessel could be cannulated per mouse. Furthermore, we could only determine the relative contribution of the intestine and the liver to splanchnic perfusion, because it was not possible to take a reference sample in the suckling mice to determine cardiac output. Our measurements of the blood flow showed, nevertheless, that the contribution of the hepatic artery to liver perfusion $(\sim 14 \%)$ was similar to that found in adult mice ([41]; Hakvoort \& Lamers, unpublished observations). Furthermore, the perfusion of the ND14 kidney was, relative to adult mice, still small $(30-35 \%$ instead of $70-90 \%$ of the total hepatic blood flow ([41]; Hakvoort \& Lamers, unpublished). The contribution of the hepatic artery to liver perfusion in mice is, therefore, only $\sim 50 \%$ of that in humans. Apart from a $\sim 4$-fold increase in citrulline and similarly pronounced decreases in glycine and taurine production, none of the amino-acid fluxes across the portal drained viscera changed, but the flux of 11 individual amino acids and the sum of all amino acids across the liver all changed from production to consumption. It should be emphasized that it is the veno-arterial concentration difference of metabolites and not the blood flow that determines whether an organ produces (positive difference) or consumes (negative difference) metabolites. Despite the sizable concentration of ASS in the kidneys, these organs did not contribute to the metabolic adaptation of Ass-KO/I mice. These findings made us investigate the liver as the organ that compensated for the lack of Ass expression in the enterocytes.

\section{The liver exerts its homeostatic function with adaptive changes in gene expression}

Whereas no changes in gene expression could be detected in suckling intestines from which the capacity to produce arginine had been removed, extensive adaptive changes in gene expression were concurrently induced in the liver, which resulted in the maintenance of a normal plasma arginine concentration in the systemic circulation. Such a homeostatic function of the liver with respect to circulating arginine concentrations was also noticed in metabolic studies of suckling and adolescent pigs. In suckling piglets, plasma arginine concentrations remained similar irrespective of whether they were fed via the gut, the portal vein or the caval vein, even though endogenous arginine synthesis is high only in enterically fed animals [42]. Similarly, arginine-enriched foods, such as soy, increased the concentration of arginine in the portal vein of 2-months old pigs, but this dietary "excess" was neutralized by uptake in the liver [43]. In fact, the switch of liver function from that of amino-acid production to that of amino-acid consumption decreased the net production of amino-acids in the splanchnic region of fed suckling Ass-KO/I mice to $\sim 35 \%$ of that of their control littermates. Our data show that this switch in liver function was mediated, among others, by widespread increases in expression of arginine-metabolizing and transporting genes. Although the signals that mediate these changes in gene expression in the liver remain to be identified, it is of note that the function of the liver of ND14 Ass-KO/I and ND35 Ass-Con mice was remarkably similar in the sense that the liver was an amino-acid consuming organ in the absence of arginine biosynthesis in the intestine. The major differences in hepatic function between ND14 Ass-KO/I and ND35 Ass-Con mice were that the consumption of 3 amino acids, of which alanine was quantitatively the most important, was higher in ND35 mice, and that the production of glutamine had increased. In all likelihood, hepatic glutamine production after weaning reflects the detoxification of ammonia in pericentral hepatocytes. This finding implies that the elimination of arginine synthesis from enterocytes, as occurs naturally after weaning, also induces a post-weaning pattern of amino-acid metabolism in the liver if this capacity is eliminated genetically before birth.

\section{Function of intestinal arginine biosynthesis in neonatal mammals}

Although the analysis of genetic mouse models demonstrated that intestinal citrulline synthesis is necessary to maintain normal circulating arginine levels during the suckling period, studies in piglets [20] and (premature) infants [44,45] show that total parenteral nutrition, a condition that is associated with a pronounced decrease in intestinal arginine synthesis in suckling piglets [20], is associated with hypoargininemia and hyperammonemia. These data indicate that intestinal arginine synthesis has a function in piglets and (premature) infants. Extra arginine stimulates, for instance, the synthesis of $\mathrm{N}$ acetylglutamate, a required co-factor for carbamoylphosphate synthetase-1, in enterocytes and hepatocytes [46]. In agreement, some polymorphisms in the carbamoylphosphate synthetase (Cps1) gene [47] and hypoargininemia $[48,49]$ predispose premature infants to the development of necrotizing enterocolitis. Similarly, parenteral feeding of premature piglets, which annuls enteral arginine synthesis $[9-21,38,42]$, sensitizes them to a condition that 
closely resembles necrotizing enterocolitis [50]. To the best of our knowledge, however, a condition resembling necrotizing enterocolitis is not yet described in neonatal mice. In fact, even though the circulating arginine concentration in neonatal F/A2 mice was only $\sim 30 \%$ of control values $[15,16,51]$, we never observed any sign of ischemic lesions in their intestines. Apparently, enteric arginine synthesis is less vital to rodents, possibly because neonatal mice and rats hardly produce urea [52].

\section{Supporting Information}

Figure S1. Production and molecular analysis of conditional Ass knockout mice. Panel A: Schematic representation of the Ass-targeting construct (Ascl Pmel). The Ascl and Pmel sites flanking the construct (14.38 Kb) were introduced by PCR. The Xmnl and EcoRI sites upstream from the recombination arms of the targeting construct were used for Southern-blot characterization. Panel B: Identification of successfully targeted ES cells. Top subpanel: PCR amplification of vector sequences downstream of Ascl (left) or upstream of Pmel (right) identify clones that carried random integrations of the targeting vector. Middle subpanel: Long PCR to demonstrate homologous recombination on $3^{\prime}$ side with primer in loxP site and primer downstream of Pmel, yielding a band of $3.7 \mathrm{~kb}$. Bottom subpanel: Southern blot of ES cell DNA with proper 3' homologous recombination after digestion with $\mathrm{Xmnl}$ and EcoRI. Two fragments of the expected size $(8.663 \mathrm{~kb}$ and $10.158 \mathrm{~kb})$ were detected with the internal Neo probe. Panel C: Wild-type $\left(\mathrm{Ass}^{+}\right)$exon-13 allele, floxed $\left(A s s^{f l}\right)$ allele, and Ass-deficient (Ass) allele, together with remnant frt and loxP sites. F1, F2, and R1 indicate the position of the primers used to identify these genotypes (for sequences, see Table S1). Panel D: Mouse genotyping. Top subpanel: The F1 and R1 primer pair yield a band of $360 \mathrm{bp}$ for the $\mathrm{Ass}^{+}$allele and $390 \mathrm{bp}$ for the $A s s^{f l}$ allele. Middle subpanel: The F2 and R1 primer pair yield a band of $340 \mathrm{bp}$ for the Ass allele. Bottom subpanel: The presence of the VilCre construct was detected with primer pair Vil-F and Vil-R, giving a band of $\sim 1,100 \mathrm{bp}$.

Figure S2. Biological effects of deletion of exon 13 of the mouse Ass gene. Panel A: Cre-mediated homozygous germ-line elimination of exon 13 causes neonatal death, as was previously shown for constitutive elimination of exon 4 [44,45]. Panels B-D: Ass-KO/I mice grow normally during the first 4 postnatal weeks ( $\mathrm{B}, \mathrm{N}=8$ for the wild type and the knockout mice), have normal hair growth (ND14; C) and normal development of Peyer's patches in the small intestine (ND14; D). Light gray bars indicate AssCon and black symbols Ass-KO/I mice.

Table S1. Primer sequences, annealing temperatures and expected PCR-product lengths.

Table S2. Genes tested for expression in the small intestine and liver of ND14 Ass-Con and Ass-KO/I mice.

Table S3. Plasma amino-acid concentrations and fluxes in ND14 Ass-Con and Ass-KO/I mice. Panel A: Amino acid concentrations in plasma $(\mu \mathrm{M}$; mean \pm SEM). Panel B: Amino-acid fluxes (mean \pm SEM) of AssCon and Ass-KO/I mice are expressed in arbitrary units (arterio-venous difference in concentration * relative flow across the respective organs). Production is indicated in black and consumption in red numbers. Statistical evaluation was performed by ANOVA (see Figure 4B).

Table S4. Plasma amino-acid concentrations and fluxes in ND35 Ass-Con and Ass-KO/I mice. Panel A: Amino acid concentrations in plasma $(\mu \mathrm{M}$; mean \pm SEM). Panel B: Amino-acid fluxes (mean \pm SEM) of AssCon and Ass-KO/I mice are expressed in arbitrary units (arterio-venous difference in concentration * relative flow across the respective organs). Production is indicated in black and consumption in red numbers. Statistical evaluation was performed by ANOVA. At this age, no significant differences in intestinal and hepatic amino-acid metabolism were observed between AssCon and Ass-KO/l mice (all $\mathrm{P}>0.1$ ). For a comparison of ND14 Ass-KO/I and ND35 Ass-Con, see Figure 4C.

\section{Acknowledgements}

We thank the members of the transgenic facility of Maastricht University (Iris Partouns, Vivian van Leeuwen and Dr Willem Voncken) for their contribution to the generation of the Ass ${ }^{f / f l}$ mouse.

\section{Author Contributions}

Conceived and designed the experiments: WHL ESK Performed the experiments: VM SS CdT PVD TBH. Analyzed the data: VM TH ESK. Wrote the manuscript: WHL VM ESK. 


\section{References}

1. Wu G, Morris SM Jr. (1998) Arginine metabolism: nitric oxide and beyond. Biochem J 336(1): 1-17PubMed: 9806879

2. Meijer AJ, Lamers WH, Chamuleau RA (1990) Nitrogen metabolism and ornithine cycle function. Physiol Rev 70: 701-748. PubMed: 2194222.

3. Flynn NE, Meininger CJ, Haynes TE, Wu G (2002) The metabolic basis of arginine nutrition and pharmacotherapy. Biomed Pharmacother 56: 427-438. doi:10.1016/ S0753-3322(02)00273-1. PubMed: 12481979

4. Southern LL, Baker DH (1983) Arginine requirement of the young pig. J Anim Sci 57: 402-412. PubMed: 6684656.

5. Visek WJ (1986) Arginine needs, physiological state and usual diets. A reevaluation. J Nutr 116: 36-46. PubMed: 3080558.

6. Davis TA, Fiorotto ML, Reeds PJ (1993) Amino acid compositions of body and milk protein change during the suckling period in rats. J Nutr 123: 947-956. PubMed: 8487106.

7. Davis TA, Nguyen HV, Garcia-Bravo R, Fiorotto ML, Jackson EM et al. (1994) Amino acid composition of human milk is not unique. J Nutr 124: 1126-1132. PubMed: 8027865.

8. Wu G, Knabe DA (1994) Free and protein-bound amino acids in sow's colostrum and milk. J Nutr 124: 415-424. PubMed: 8120661.

9. De Jonge WJ, Dingemanse $M A$, de Boer PA, Lamers $W H$, Moorman AF (1998) Arginine-metabolizing enzymes in the developing rat small intestine. Pediatr Res 43: 442-451. doi: 10.1203/00006450-199804000-00002. PubMed: 9544996.

10. Hurwitz R, Kretchmer N (1986) Development of argininesynthesizing enzymes in mouse intestine. Am J Physiol 251: G103-G110. PubMed: 3728668.

11. Nagy LE, Kretchmer N (1988) Utilization of glutamine in the developing rat jejunum. J Nutr 118: 189-193. PubMed: 3123618.

12. Wu G (1997) Synthesis of citrulline and arginine from proline in enterocytes of postnatal pigs. Am J Physiol 272: G1382G1390. PubMed: 9227473.

13. Wu G, Knabe DA (1995) Arginine synthesis in enterocytes of neonatal pigs. Am J Physiol 269: R621-R629. PubMed: 7573565.

14. Köhler ES, Sankaranarayanan S, van Ginneken CJ, van Dijk P, Vermeulen JL et al. (2008) The human neonatal small intestine has the potential for arginine synthesis; developmental changes in the expression of arginine-synthesizing and catabolizing enzymes. BMC Dev Biol 8: 107. doi: 10.1186/1471-213X-8-107. PubMed: 19000307.

15. de Jonge WJ, Hallemeesch MM, Kwikkers KL, Ruijter JM, de Gier-de Vries C et al. (2002) Overexpression of arginase I in enterocytes of transgenic mice elicits a selective arginine deficiency and affects skin, muscle, and lymphoid development. Am J Clin Nutr 76: 128-140. PubMed: 12081826.

16. de Jonge WJ, Kwikkers $K L$, te Velde $A A$, van Deventer SJ, Nolte MA et al. (2002) Arginine deficiency affects early B cell maturation and lymphoid organ development in transgenic mice. J Clin Invest 110: 1539-1548. doi:10.1172/JCI200216143. PubMed: 12438451

17. Blachier F, M'Rabet-Touil H, Posho L, Darcy-Vrillon B, Duée PH (1993) Intestinal arginine metabolism during development. Evidence for de novo synthesis of L-arginine in newborn pig enterocytes. Eur J Biochem 216: 109-117. doi:10.1111/j. 1432-1033.1993.tb18122.x. PubMed: 8365397.

18. Wu G, Borbolla AG, Knabe DA (1994) The uptake of glutamine and release of arginine, citrulline and proline by the small intestine of developing pigs. J Nutr 124: 2437-2444. PubMed: 16856325.

19. Bertolo RF, Brunton JA, Pencharz PB, Ball RO (2003) Arginine, ornithine, and proline interconversion is dependent on small intestinal metabolism in neonatal pigs. Am J Physiol Endocrinol Metab 284: E915-E922. PubMed: 12527558.

20. Brunton JA, Bertolo RF, Pencharz PB, Ball RO (1999) Proline ameliorates arginine deficiency during enteral but not parenteral feeding in neonatal piglets. Am J Physiol 277: E223E231. PubMed: 10444416.

21. Urschel KL, Rafii M, Pencharz PB, Ball RO (2007) A multitracer stable isotope quantification of the effects of arginine intake on whole body arginine metabolism in neonatal piglets. Am J Physiol Endocrinol Metab 293: E811-E818. doi:10.1152/ ajpendo.00290.2007. PubMed: 17595215.
22. Patejunas G, Bradley A, Beaudet AL, O'Brien WE (1994) Generation of a mouse model for citrullinemia by targeted disruption of the argininosuccinate synthetase gene. Somat Cell Mol Genet 20: 55-60. doi:10.1007/BF02257486. PubMed: 8197477.

23. Madison BB, Dunbar L, Qiao XT, Braunstein K, Braunstein E et al. (2002) Cis elements of the villin gene control expression in restricted domains of the vertical (crypt) and horizontal (duodenum, cecum) axes of the intestine. J Biol Chem 277: 33275-33283. doi:10.1074/jbc.M204935200. PubMed: 12065599.

24. Hooper M, Hardy K, Handyside A, Hunter S, Monk M (1987) HPRT-deficient (Lesch-Nyhan) mouse embryos derived from germline colonization by cultured cells. Nature 326: 292-295. doi:10.1038/326292a0. PubMed: 3821905.

25. Schwenk F, Baron U, Rajewsky K (1995) A cre-transgenic mouse strain for the ubiquitous deletion of loxP-flanked gene segments including deletion in germ cells. Nucleic Acids Res 23: 5080-5081. doi:10.1093/nar/23.24.5080. PubMed: 8559668.

26. Hallemeesch MM, Ten Have GA, Deutz NE (2001) Metabolic flux measurements across portal drained viscera, liver, kidney and hindquarter in mice. Lab Anim 35: 101-110. doi: 10.1258/0023677011911426. PubMed: 11201286.

27. van Eijk HM, Rooyakkers DR, Deutz NE (1993) Rapid routine determination of amino acids in plasma by high-performance liquid chromatography with a 2-3 microns Spherisorb ODS II column. J Chromatogr 620: 143-148. PubMed: 8106581.

28. Ramakers C, Ruijter JM, Deprez RH, Moorman AF (2003) Assumption-free analysis of quantitative real-time polymerase chain reaction (PCR) data. Neurosci Lett 339: 62-66. doi: 10.1016/S0304-3940(02)01423-4. PubMed: 12618301.

29. Ruijter JM, Thygesen HH, Schoneveld OJ, Das AT, Berkhout B et al. (2006) Factor correction as a tool to eliminate betweensession variation in replicate experiments: application to molecular biology and retrovirology. Retrovirology 3: 2. doi: 10.1186/1742-4690-3-S1-P2. PubMed: 16398936

30. Altman DG (1991) Practical statistics for medical research. London: Chapman \& Hall.

31. Levillain O, Hus-Citharel A, Morel F, Bankir L (1993) Arginine synthesis in mouse and rabbit nephron: localization and functional significance. Am J Physiol 264: F1038-F1045. PubMed: 8322890.

32. Maunoury R, Robine S, Pringault E, Léonard N, Gaillard JA et al. (1992) Developmental regulation of villin gene expression in the epithelial cell lineages of mouse digestive and urogenital tracts. Development 115: 717-728. PubMed: 1425351.

33. Goldblum OM, Brusilow SW, Maldonado YA, Farmer ER (1986) Neonatal citrullinemia associated with cutaneous manifestations and arginine deficiency. J Am Acad Dermatol 14: 321-326. doi:10.1016/S0190-9622(86)70035-2. PubMed: 3950131

34. Toyoshima K, Seta Y, Takeda S, Harada H (1998) Identification of Merkel cells by an antibody to villin. J Histochem Cytochem 46: 1329-1334. doi:10.1177/002215549804601113. PubMed: 9774632

35. Borsani G, Bassi MT, Sperandeo MP, De Grandi A, Buoninconti A et al. (1999) SLC7A7, encoding a putative permease-related protein, is mutated in patients with lysinuric protein intolerance. Nat Genet 21: 297-301. doi:10.1038/6815. PubMed: 10080183.

36. Palacín M, Borsani G, Sebastio G (2001) The molecular bases of cystinuria and lysinuric protein intolerance. Curr Opin Genet Dev 11: 328-335. doi:10.1016/S0959-437X(00)00198-2. PubMed: 11377971 .

37. Torrents D, Mykkänen J, Pineda M, Feliubadaló L, Estévez R et al. (1999) Identification of SLC7A7, encoding $y+L A T-1$, as the lysinuric protein intolerance gene. Nat Genet 21: 293-296. doi: 10.1038/6809. PubMed: 10080182.

38. Urschel $\mathrm{KL}$, Evans AR, Wilkinson $\mathrm{CW}$, Pencharz $\mathrm{PB}$, Ball RO (2007) Parenterally fed neonatal piglets have a low rate of endogenous arginine synthesis from circulating proline. J Nutr 137: 601-606. PubMed: 17311947.

39. Wang T, Lawler AM, Steel G, Sipila I, Milam AH et al. (1995) Mice lacking ornithine-delta-aminotransferase have paradoxical neonatal hypoornithinaemia and retinal 
degeneration. Nat Genet 11: 185-190. doi:10.1038/ ng1095-185. PubMed: 7550347

40. Malo C (1994) Free amino acid levels in serum and small intestine during the post-natal development of normal and sparse-fur mutant mice. Comp Biochem Physiol A Physiol 109: 1049-1057. doi:10.1016/0300-9629(94)90254-2. PubMed: 7828023.

41. Sarin SK, Sabba C, Groszmann RJ (1990) Splanchnic and systemic hemodynamics in mice using a radioactive microsphere technique. Am J Physiol 258: G365-G369. PubMed: 2316651.

42. Bertolo RF, Pencharz PB, Ball RO (2000) Organ and plasma amino acid concentrations are profoundly different in piglets fed identical diets via gastric, central venous or portal venous routes. J Nutr 130: 1261-1266. PubMed: 10804082.

43. Deutz NE, Bruins MJ, Soeters PB (1998) Infusion of soy and casein protein meals affects interorgan amino acid metabolism and urea kinetics differently in pigs. J Nutr 128: 2435-2445. PubMed: 9868192.

44. Batshaw ML, Wachtel RC, Thomas GH, Starrett A, Brusilow SW (1984) Arginine-responsive asymptomatic hyperammonemia in the premature infant. J Pediatr 105: 86-91. doi:10.1016/ S0022-3476(84)80369-8. PubMed: 6737153.

45. Wu G, Jaeger LA, Bazer FW, Rhoads JM (2004) Arginine deficiency in preterm infants: biochemical mechanisms and nutritional implications. J Nutr Biochem 15: 442-451. doi: 10.1016/j.jnutbio.2003.11.010. PubMed: 15302078 .

46. Geng M, Li T, Kong X, Song X, Chu W et al. (2011) Reduced expression of intestinal $\mathrm{N}$-acetylglutamate synthase in suckling piglets: a novel molecular mechanism for arginine as a nutritionally essential amino acid for neonates. Amino Acids 40: 1513-1522. doi:10.1007/s00726-010-0761-6. PubMed: 20931344.

47. Moonen RM, Paulussen AD, Souren NY, Kessels AG, RubioGozalbo ME et al. (2007) Carbamoyl phosphate synthetase polymorphisms as a risk factor for necrotizing enterocolitis.
Pediatr Res 62: 188-190. doi:10.1203/PDR. Ob013e3180a0324e. PubMed: 17597649.

48. Becker RM, Wu G, Galanko JA, Chen W, Maynor AR et al. (2000) Reduced serum amino acid concentrations in infants with necrotizing enterocolitis. J Pediatr 137: 785-793. doi: 10.1067/mpd.2000.109145. PubMed: 11113834.

49. Zamora SA, Amin HJ, McMillan DD, Kubes P, Fick GH et al (1997) Plasma L-arginine concentrations in premature infants with necrotizing enterocolitis. J Pediatr 131: 226-232. doi: 10.1016/S0022-3476(97)70158-6. PubMed: 9290608.

50. Sangild PT, Siggers RH, Schmidt M, Elnif J, Bjornvad CR et al. (2006) Diet- and colonization-dependent intestinal dysfunction predisposes to necrotizing enterocolitis in preterm pigs. Gastroenterology 130: 1776-1792. doi:10.1053/j.gastro. 2006.02.026. PubMed: 16697741.

51. de Jonge WJ, Marescau B, D'Hooge R, De Deyn PP Hallemeesch MM et al. (2001) Overexpression of arginase alters circulating and tissue amino acids and guanidino compounds and affects neuromotor behavior in mice. J Nutr 131: 2732-2740. PubMed: 11584097.

52. Illnerová H (1965) Urea formation in rats during postnata development. Biol Neonat 9: 197-202. doi: 10.1159/000239990. PubMed: 5872074 


\section{CHAPTER VI}

\section{ARGININE DEFICIENCY CAUSES RUNTING IN THE SUCKLING PERIOD BY SELECTIVELY ACTIVATING THE STRESS KINASE GCN2}

Vincent Marion $^{1 *}$, Selvakumari Sankaranarayanan ${ }^{1 *}$, Chiel C. de Theije ${ }^{1^{*}}$, Paul van Dijk $^{1}$, Patrick Lindsey ${ }^{2}$, Marinus C. Lamers ${ }^{3}$, Heather P. Harding ${ }^{4}$, David Ron ${ }^{4}$, Wouter H. Lamers ${ }^{1,5}$ and S. Eleonore Köhler ${ }^{1}$

${ }^{1}$ Department of Anatomy \& Embryology, NUTRIM School for Nutrition, Toxicology, and Metabolism, Maastricht University, Maastricht, The Netherlands,

${ }^{2}$ Department of Population Genetics, Genomics and Bioinformatics, Maastricht University, Maastricht, The Netherlands,

${ }^{3}$ Max-Planck Institute of Immunobiology, Freiburg, Germany,

${ }^{4}$ Institute of Metabolic Science, University of Cambridge, Cambridge, United

Kingdom

${ }^{5}$ AMC Liver Center Academic Medical Center, University of Amsterdam, The

Netherlands

*: these authors contributed equally to the study 


\title{
Arginine Deficiency Causes Runting in the Suckling Period by Selectively Activating the Stress Kinase GCN2*[s
}

\author{
Received for publication, December 23, 2010, and in revised form, January 13, 2011 Published, JBC Papers in Press, January 14, 2011, DOI 10.1074/jbc.M1 10.2161 19
}

\author{
Vincent Marion ${ }^{\ddagger 1}$, Selvakumari Sankaranarayanan ${ }^{\ddagger 1}$, Chiel de Theije $^{\ddagger 1}$, Paul van Dijk ${ }^{\ddagger}$, Patrick Lindsey $^{\S}$, \\ Marinus C. Lamers", Heather P. Harding ", David Ron ${ }^{\| 2}$, Wouter H. Lamers ${ }^{\ddagger * *}$, and S. Eleonore Köhler ${ }^{\ddagger 3}$ \\ From the ${ }^{\ddagger}$ Dept of Anatomy \& Embryology and NUTRIM School for Nutrition, Toxicology, and Metabolism, and the ${ }^{\S}$ Department of \\ Population Genetics, Genomics \& Bioinformatics, Maastricht University, P.O. Box 616, 6200 MD, Maastricht, The Netherlands, the \\ "Max-Planck Institute of Immunobiology, P.O. Box 1169, D-79011 Freiburg, Germany, the IInstitute of Metabolic Science, University \\ of Cambridge, Cambridge CB2 OQQ, United Kingdom, and the ${ }^{* *} A M C$ Liver Center, Academic Medical Center, University of \\ Amsterdam, P.O. Box 22660, 1100 DD, Amsterdam, The Netherlands
}

Suckling "F/A2" mice, which overexpress arginase-I in their enterocytes, develop a syndrome (hypoargininemia, reduced hair and muscle growth, impaired B-cell maturation) that resembles IGF1 deficiency. The syndrome may result from an impaired function of the GH-IGF1 axis, activation of the stresskinase GCN2, and/or blocking of the mTORC1-signaling pathway. Arginine deficiency inhibited GH secretion and decreased liver Igf $1 \mathrm{mRNA}$ and plasma IGF1 concentration, but did not change muscle IGF1 concentration. GH supplementation induced $I g f 1 \mathrm{mRNA}$ synthesis, but did not restore growth, ruling out direct involvement of the GH-IGF1 axis. In $\mathrm{C} 2 \mathrm{C} 12$ muscle cells, arginine withdrawal activated GCN2 signaling, without impacting mTORC1 signaling. In F/A2 mice, the reduction of plasma and tissue arginine concentrations to $\sim 25 \%$ of wild-type values activated GCN2 signaling, but mTORC1-mediated signaling remained unaffected. Gcn2-deficient F/A2 mice suffered from hypoglycemia and died shortly after birth. Because com mon targets of all stress kinases (eIF2 $\alpha$ phosphorylation, Chop mRNA expression) were not increased in these mice, the effects of arginine deficiency were solely mediated by GCN2.

Arginine is a substrate for the synthesis of proteins, creatine agmatine, ornithine, and nitric oxide (1). In addition, it functions as a secretagogue for hormones, such as growth hormone $(\mathrm{GH})$ and insulin (2-4). Under normal conditions, endogenous arginine synthesis in adult mammals suffices to sustain daily requirements (5), but a dietary source of arginine may become necessary when demand increases under anabolic or catabolic conditions (5). For this reason, arginine is considered a conditionally essential amino acid.

Arginine deficiency represents a significant metabolic problem in premature infants (6), but its cause remains unknown. In rapidly growing suckling rodents, endogenous arginine biosynthesis is crucial to compensate for the insufficient supply of

* This study was supported by the graduate school NUTRIM

s. The on-line version of this article (available at http://www.jbc.org) contains supplemental Tables S1 and S2 and Figs. S1-S7.

'These authors contributed equally to the study.

2 Principal Research Fellow of the Wellcome Trust.

${ }^{3}$ To whom correspondence should be addressed: Maastricht University, Dept. of Anatomy \& Embryology, P. O. Box 616, 6200MD Maastricht, The Netherlands.Tel.:31-43-3881191;Fax:31-43-3884134;E-mail:leo.koehler@ maastrichtuniversity.n arginine via the milk (7). The intestine rather than the kidney is primarily responsible for endogenous arginine synthesis in suckling piglets $(8,9)$. In suckling rodents, the enterocytes of the small intestine also express all enzymes necessary to synthesize arginine (10-13), while arginase is not expressed, thus allowing efficient de novo arginine biosynthesis. To examine the function of intestinal arginine synthesis, a transgenic mouse model that overexpresses arginase-I in the enterocytes of the small intestine was produced (14-17). During the suckling period, these "F/A2" ${ }^{4}$ mice suffer from a selective deficiency of circulating arginine (which declines to $\sim 25 \%$ of controls), reduced growth of hair and skeletal muscle, and inhibition of B-cell maturation (14). The phenotype can be rescued with arginine supplementation (14), but could not be ascribed to a deficiency of arginine metabolites, such as creatine or polyamines, or to arginine-dependent ADP-ribosylation of proteins (14-17). Furthermore, the features of the "arginine-deficiency syndrome" are not seen in mice that are deficient in all three nitric-oxide synthases (18). This leaves two functions of arginine as likely candidates to account for the highly characteristic phenotype of arginine deficiency in suckling mice, viz. its role as a building block in protein synthesis and as a secretagogue of hormones.

Amino acids, including arginine, control translation by two well-established mechanisms. Whenever the intracellular concentration of free arginine decreases below $\sim 20 \mu \mathrm{M}$, the charging process of its corresponding tRNA slows down and the concentration of uncharged tRNA increases (19). Uncharged tRNAs activate the ubiquitously expressed "general control

\footnotetext{
${ }^{4}$ The abbreviations used are: F/A2, mice overexpressing arginase-I under control of the Fabp promoter: ATF4, activating transcription factor 4 (Atf4); Atrogin1, muscle atrophy F-box E3 ubiquitin-protein ligase or F-box-only protein 32 (Fbxo32); CAT-1, cationic amino-acid transporter-1 or Solute carrier 7A1 (S/C7A1); CHOP, C/EBP-homologous protein or growth arrest and DNA damage-inducible protein 135 or DNA-damage inducible transcript 3 (Ddit3); 4EBP1, eukaryotic translation initiation factor (eIF)4E-binding protein-1 (Eif4ebp 1); GADD34, growth arrest and DNA damage-inducible protein 34 or protein phosphatase-1 regulatory subunit $15 \mathrm{~A}$ (Ppp1r15a); GCN2, general control non-derepressible 2 kinase or eukaryotic translation initiation factor $2 \alpha$ kinase 4 (Eif2ak4); IGF1, insulin-like growth factor 1 (Igf1); CKM, muscle-specific creatine kinase $(C \mathrm{~km})$; mTORC1, mammalian target of rapamycin complex-1; MURF1, musclespecific RING finger-1 or E3 ubiquitin-protein ligase (Trim63); MyHC1, myosin heavy chain-I or heavy polypeptide 7 (Myh7); MyHC2B, myosin heavy chain-Ilb or heavy polypeptide 4 (Myh4); ND, neonatal day; S6K1, p70 ribosomal protein 56 kinase-1 or polypeptide 5 (Rps6ka5).
} 
The Arginine Deficiency Syndrome

non-derepressible2" (GCN2) stress kinase, which then phosphorylates the $\alpha$-subunit of the eukaryotic initiation factor 2 $(\mathrm{eIF} 2 \alpha)$ and thereby initiates the "integrated stress response" $(20-22)$. This response blocks cap-dependent protein synthesis, facilitates the translation of specific mRNAs, such as Atf4 and Cat-1, from internal ribosome entry sites, and increases expression of specific transcription factors such as ATF2, ATF4, and CHOP (23), which, in turn, induce the transcription of genes necessary for amino acid synthesis and transport. The other mechanism senses, instead, increases in amino acid concentration, probably via the Rag GTPase complex (24), and results in the activation of the mTORC1 kinase. mTORC1, in turn, regulates cap-dependent translation through the phosphorylation of 4EBP1 and S6K1 $(25,26)$. The essential amino acid leucine is the prototypic regulator of both branches of amino acid-dependent translational regulation $(22,27)$. However, for a non-essential amino acid, arginine has an unexpectedly strong effect on mTORC1-dependent signaling (28) and quantitatively rivals leucine in vitro $(29,30)$. The F/A2 phenotype could, therefore, be mediated by activation of GCN2 signaling and/or inhibition of mTORC1-mediated signaling.

The more remarkable phenotypic features of F/A2 mice, namely impaired muscle and hair growth and impaired B-cell maturation, are all also affected by insulin-like growth factor-1 (IGF1) signaling (31-35). Like amino acids, growth factor signals, including those arising from IGF1, stimulate protein synthesis via the mTORC1 pathway (36). The production of IGF1, in turn, is largely dependent on growth-hormone (GH) signaling (37). Arginine, finally, is also a potent growth-hormone secretagogue (38). Arginine deficiency could, therefore, also cause insufficient signaling via the mTORC1 pathway due to an inactive somatotropic axis.

In the present study, we used a combination of in vivo and in vitro approaches to test the hypotheses that arginine deficiency activates GCN2 signaling or blocks mTORC1 signaling, or both. Our findings demonstrate that arginine deficiency in the neonatal and suckling period activates the GCN2 stress-kinase pathway, without affecting the mTORC1 pathway.

\section{EXPERIMENTAL PROCEDURES}

Transgenic Mouse Lines and Animal Husbandry-Transgenic mice that overexpress arginase-I in their small-intestinal enterocytes (F/A2 line (14)) were bred hemizygously. Gcn2 ${ }^{-1}$ mice (39) originated from the colony of D. Ron (New York, NY). Control animals were littermates of the experimental animals. Animal studies were reviewed and approved by the committee for animal care and use of Maastricht University.

GH Administration-Litters were limited to 5 animals on neonatal day 1 (ND1) and weighed daily. Starting on ND3, 3 $\mathrm{mg} / \mathrm{kg}$ body weight of human recombinant growth hormone (hrGH; Humatrope, Lilly, Indianapolis, IN) was administered subcutaneously in $25 \mu \mathrm{l}$ of vehicle twice daily (40). Control animals were injected with vehicle alone.

Blood and Tissue Collection-Animals were sacrificed by decapitation. Blood was collected into heparin-containing tubes and centrifuged at $2,000 \times g$ for $5 \mathrm{~min}$ at $4{ }^{\circ} \mathrm{C}$. IGF- 1 protein concentrations were measured in plasma, whereas amino acids were measured in deproteinized plasma. $80 \mu \mathrm{l}$ of plasma was added to $6.4 \mathrm{mg}$ of lyophilized sulfosalicylic acid, vortexed, and stored at $-20^{\circ} \mathrm{C}$. For amino acid measurements, the tissues were homogenized with silica mini-beads in $0.33 \mathrm{M}$ sulfosalicylic acid. Tissues were collected at ND0, ND10, ND17, and ND21. Amino acid concentrations were determined by HPLC (41). Tissues for protein and mRNA analysis were isolated, snap frozen in liquid nitrogen and stored at $-80{ }^{\circ} \mathrm{C}$. For histological analysis, tissues were fixed in $4 \%$ buffered formalin and embedded in paraffin.

IGF-1 Assay-Mouse IGF-1 concentration in plasma and muscle was measured by the m/r IGF-1 E25 enzyme immunoassay, as detailed by the manufacturer (Mediagnost, Reutlingen, Germany). This assay eliminates IGFBP interference with the IGF-1 measurement.

RNA Extraction and Quantitative PCR-Total RNA was extracted with Trizol (Sigma). $1 \mu \mathrm{g}$ of total RNA was reverse transcribed with the iScript cDNA synthesis kit (Bio-Rad). Primer sequences (supplemental Table S1) were optimized for an annealing temperature of $60^{\circ} \mathrm{C}$, except for the $\operatorname{Igf} 1$ primers that were annealed at $70{ }^{\circ} \mathrm{C}$. cDNA samples for mRNA determination were diluted 60-fold before use and those for $18 \mathrm{~S}$ rRNA 200 -fold. Primary fluorescent data were exported and analyzed with the Lin-Reg Analysis program (42). If reverse transcriptase was omitted, no product formed. mRNA concentrations were expressed relative to $18 \mathrm{~S}$ rRNA content. Between session variations in replicate experiments were corrected using factor correction (43)

Western Blots, Immunostaining, and ImmunofluorescenceFor Western blot assays, $100 \mu \mathrm{g}$ of protein were loaded per lane. Antibody (supplemental Table S2) binding was visualized using the Super Signal West Femto Maximum Sensitivity Substrate (Pierce). For detection of the phosphorylated and unphosphorylated forms of eIF2 $\alpha$, the Odyssey Infrared Imaging system (Li-cor Bioscience, UK) was used.

For immunostaining, 5- $\mu \mathrm{m}$ sections of tissues were prepared. After deparaffinization, sections were preincubated with Teng-T (10 mu Tris (pH 7.6), 5 mm EDTA, 150 mm NaCl, 0.25\% gelatin, $0.05 \%$ Tween-20)/10\% normal goat serum (NGS) for 30 min, followed by an overnight incubation with the primary antibody diluted in Teng-T/10\% NGS. Slides were then washed with PBS and incubated with Teng-T/10\% NGS for 15 min, followed by 90 min incubation with the secondary antibody (supplemental Table S2) in Teng-T/10\% NGS. After washing, the slides were incubated with alkaline phosphatase substrate (NBT/BCIP tablets; Roche) at $37^{\circ} \mathrm{C}$. Digital images of the sections were analyzed with the Leica Quantimet 500 Image Analysis System, v3.2 (44).

Statistical Analysis-The significant difference for one variable between two distinct groups was analyzed using an unpaired Student's $t$ test. For more complex analyses of significance for variables with different controls, each gene was analyzed using Gaussian linear regression, including $18 \mathrm{~S}$ as housekeeping gene. When appropriate, additional explanatory variables such as tissue type, strain, and time were included in the model. Finally, interactions among the included variables were considered. The inference criterion used for comparing the models is their ability to predict the observed data, i.e. models are compared directly through their minimized minus log- 


\section{The Arginine Deficiency Syndrome}

A

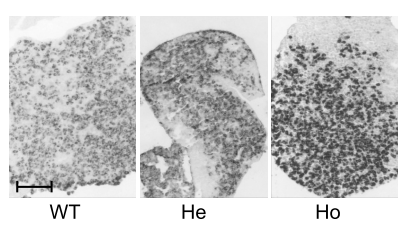

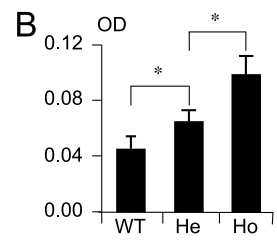

$\mathrm{D}_{6}$

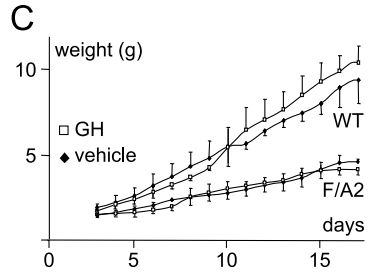

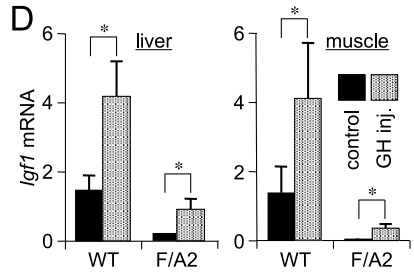

FIGURE 1. Role of growth hormone in the phenotype of F/A2 mice. Panels $A$ and $B$ : Detection of GH in pituitary somatotropes of ND21 mice. $A$, sections of pituitary glands of ND21 WT, hemizygous F/A2 mice $(\mathrm{He})$, and homozygous F/A2 mice $(\mathrm{Ho})$ were stained for the presence of $\mathrm{GH}$. Bar: $5 \mu \mathrm{m}$. B, optical density $(O D)$ in GH-positive cells ( $n=3$ mice per genotype) increases from wild-type via hemizygous to homozygous F/A2 mice. Panels $C$ and $D$, effect of $\mathrm{GH}$ treatment on weight gain in suckling F/A2 mice. $C$, change in body weight of F/A2 mice and their wild-type littermates during treatment with $\mathrm{GH}$ (twice daily $3 \mathrm{mg} \mathrm{rhGH} / \mathrm{kg}$ body weight subcutaneously) between ND3 and ND21 ( $n=6$ mice per genotype). Note that F/A2 mice show a $\sim 3$-fold lower growth rate compared with wild-type mice. $D$, quantification of Igf1 mRNA in liver (left) and muscle (right) of vehicle and GH-injected ND17 mice. $n=3$ mice per genotype. ${ }^{*}, p<0.01$

likelihood. When the numbers of parameters in models differ, they are penalized by adding the number of estimated parameters, a form of the Akaike information criterion (45). If the most likely model contains the treatment effect, the fold change representing the ratio between the variable of the treated group and the same variable for the control is computed, as well as its $95 \%$ confidence interval.

\section{RESULTS}

The GH/IGF1 Axis Is Functional but Repressed in F/A2 MiceThe phenotype of F/A2 mice is compatible with a deficiency of $\mathrm{GH}$ and/or IGF1. We, therefore, investigated the GH content in the pituitary gland by quantitative immunohistochemistry (Fig. $1 A)$. The somatotropes of 3-week-old hemi- and homozygous F/A2 mice contained 1.4- and 2.2-fold more GH, respectively, than those of their wild-type counterparts (Fig. 1B), indicating an inverse correlation with the severity of the F/A2 phenotype $(14,16)$.

We then used the rat pituitary cell line $\mathrm{GH} 3$, which produces GH $(46,47)$, to assess the direct effects of arginine on GH production and secretion. GH content in the GH3 cells was assessed by quantitative immunohistochemistry (supplemental Fig. S1, $A$ and $B$ ) and ELISA (supplemental Fig. S1C). Both assays showed that, after $24 \mathrm{~h}$ of culture, the cellular GH content was inversely correlated with extracellular arginine concentration and decreased from $\sim 50$ to $\sim 25 \mathrm{pg}$ of GH per cell at 0 and $200 \mu \mathrm{M}$ arginine in the medium, respectively (supplemental Fig. S1C; significant at $\geq 50 \mu \mathrm{m}$ arginine). This decrease in cellular GH content was accounted for by a 1.5-fold increase in concentration of $\mathrm{GH}$ in the medium (significant at $\geq 25 \mu \mathrm{M}$ arginine). Because the total GH content of the cells and the medium combined did not vary with arginine concentration in the medium, these findings reveal a pronounced concentra-
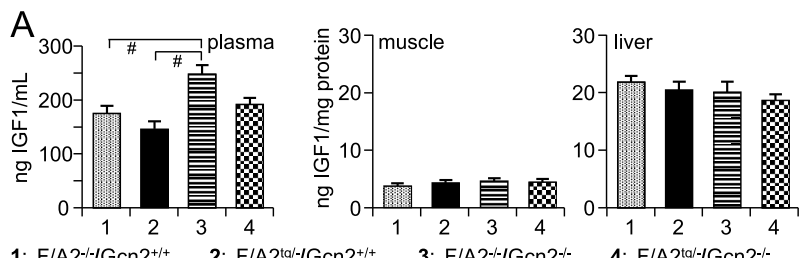

1: $\mathrm{F} / \mathrm{A} 2^{-1-} / \mathrm{Gcn}^{+/+} \quad$ 2: $\mathrm{F} / \mathrm{A} 2$ (wild type)

(F/A2) (Gcn2-KO)

(F/A2/Gcn2-KO)
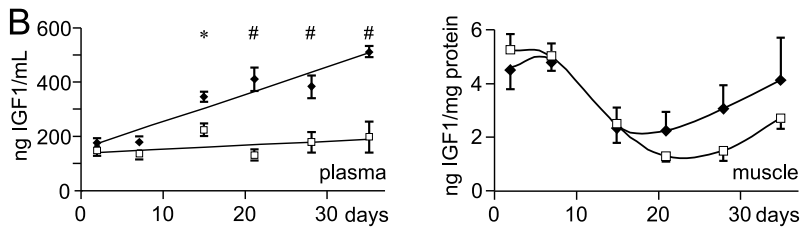

FIGURE 2. Plasma and tissue IGF1 protein concentrations in F/A2 mice. Panel $A$, differences in plasma, muscle and liver IGF1 protein concentration in ND1 F/A2 $2^{-/-} / \mathrm{Gcn} 2^{+/+}$(wild-type), $\mathrm{F} / \mathrm{A} 2^{\mathrm{tg} /-} / \mathrm{Gcn} 2^{+/+}$(F/A2 transgenic), $\mathrm{F} / \mathrm{A} 2^{-1-} / \mathrm{Gcn} 2^{-1-}(\mathrm{Gcn} 2-\mathrm{KO})$, and F/A2 ${ }^{\mathrm{tg} /-} / \mathrm{Gcn} 2^{-/-}$(F/A2/Gcn2-KO double mutant) mice ( $n=6$ per genotype). The plasma IGF1 concentration in F/A2 ${ }^{\mathrm{tg} /-} /$ $\mathrm{Gcn} 2^{-1-}$ tended to be lower than in $\mathrm{F} / \mathrm{A} 2^{-1-} / \mathrm{Gcn} 2^{-1-}$ mice $(p=0.055)$. Panel $B$, changes in plasma and muscle IGF1 protein concentration during the first 5 postnatal weeks in wild-type (black diamonds) and F/A2 mice (white squares); $\left(n=3\right.$ per genotype except at ND1). ${ }^{*}, p<0.05 ; \#, p<0.01$. The age-dependent changes in muscle IGF1 content were highly significant $(p<0.01)$.

tion-dependent effect of arginine on GH secretion. The dependence of GH secretion on the ambient concentration of arginine after $72 \mathrm{~h}$ of culture was similar to that observed after $24 \mathrm{~h}$ (not shown). These data show that, below a concentration of $50 \mu \mathrm{M}$ ambient arginine, GH secretion is reduced, with a half-maximal effect at $\sim 20 \mu \mathrm{m}$ arginine.

As early as 3 days after birth (ND3), F/A2 mice can be distinguished from their wild-type littermates by a lower body weight (14). To assess whether the typically hypomorphic tissues of F/A2 mice (muscle, hair, and B-cells (15)) respond to GH supplementation, mice were subcutaneously injected twice daily with $3 \mathrm{mg} / \mathrm{kg}$ recombinant human (rh)GH from ND3 onwards. This dose of rhGH mediates growth in liver IGF-1-deficient mice (40). Fig. $1 C$ shows that the growth rate of homozygous F/A2 mice was $\sim 50 \%$ of that of wild-type mice and that treatment with rhGH had no effect on the growth rate of either wild-type or F/A2 mice.

$\mathrm{GH}$ action is mediated by $\mathrm{GH}$ receptors (GHR) and results in the synthesis and secretion of IGF1 in target tissues. Ghr mRNA concentrations in the livers of ND1, ND10, and ND21 mice increased with age, but were not different in wild-type and F/A2 mice (supplemental Fig. S2). To assess the functionality of these GHRs and their downstream signaling pathway, Igf 1 mRNA concentrations were quantified in liver and muscle of GHtreated and control mice (Fig. 1D). In both tissues, Igf1 mRNA concentrations in F/A2 mice were only $10-15 \%$ of those in wild-type mice. Although the rhGH injections increased IgfI mRNA concentration in liver and muscle of both F/A2 and wild-type mice considerably ( $\sim 8$ - and $\sim 2.5$-fold, respectively; $p<0.01)$, Igf1 mRNA levels in the liver and muscle of treated F/A2 mice increased to only $\sim 65$ and $\sim 25 \%$, respectively, of that in untreated wild-type mice. We then measured plasma and tissue IGF1 concentrations to assess whether F/A2 mice suffer from a low production of IGF1 (Fig. 2). In wild-type and

\section{As}


The Arginine Deficiency Syndrome

F/A2 ND1 mice, no differences in plasma, muscle, or liver IGF1 protein were detected (Fig. $2 A$ ). However, plasma IGF1 levels increased $\sim 7$-fold faster in wild-type than F/A2 mice during the first 5 postnatal weeks (Fig. $2 B$, left panel; $p<0.001$ )) Plasma IGF1 levels reflect hepatic IGF1 production, but liver IGF1 does not affect growth until 6 weeks postnatally $(48,49)$. We, therefore, measured IGF1 levels in an affected tissue (calf muscle) of the same mice (Fig. 2B, right panel). Muscular IGF1 concentration decreased gradually between 1 and 3 weeks after birth, without difference between F/A2 and wild-type mice. After weaning, the IGF1 concentration in muscle increased again, with a $\sim 1$ week delay in F/A2 relative to wild-type mice. Although the age-dependent changes in muscle IGF1 content were significant $(p<0.01)$, they did not differ between F/A2 and wild-type mice. Because IGF1 in skeletal muscle affects growth only after the 3 rd postnatal week (32), that is, coincident with the resumption of growth in F/A2 mice (14), we further concluded that, although the GH-IGF-1 axis did not function properly in F/A2 mice, its disturbed function could not account for the marked hypotrophy seen in these animals.

Arginine Is Essential for Muscle Development-F/A2 skeletal muscles have an immature appearance (14). We, therefore, investigated if arginine directly affects muscle development in differentiating $\mathrm{C} 2 \mathrm{C} 12$ myoblasts that were cultured in the presence of different concentrations of arginine. Supplemental Fig. S3A shows representative pictures after 4 days of myogenic differentiation in the presence $(200 \mu \mathrm{M})$ or absence of arginine. Both the myogenic index (the fraction of nuclei residing in cells with three or more nuclei and considered an early differentiation parameter; supplemental Fig. S3B) and the cellular concentration of the late differentiation marker creatine kinase-M (supplemental Fig. S3C) increased with increasing arginine concentration to plateau at 25-50 $\mu \mathrm{M}$ arginine. Myogenic differentiation is, therefore, clearly dependent on arginine availability, with a half-maximal effect at $10-20 \mu \mathrm{m}$ arginine in the medium.

Arginine Deficiency Induces the Integrated Stress Response in Vitro-Amino acid deficiency can activate the GCN2 stress kinase pathway (50). An early step is the phosphorylation of translation factor eIF2 $\alpha$ (51). As anticipated, arginine deprivation of $\mathrm{C} 2 \mathrm{C} 12$ cells at $80 \%$ confluence induced phosphorylation of eIF $2 \alpha$ on serine 51 within $30 \mathrm{~min}$. The protein remained phosphorylated for at least $2 \mathrm{~h}$ (supplemental Fig. S4A). Furthermore, arginine depletion induced the accumulation of the transcription factors ATF4 and CHOP, which are well-established downstream mRNA targets of the GCN2 stress-kinase pathway $(23,52)$, in a concentration-dependent way in both $\mathrm{C} 2 \mathrm{C} 12$ and GH3 cells (supplemental Fig. S4B). In both cell types, Chop mRNA concentration increased more gradually with declining arginine concentration in the medium than Atf4 mRNA, indicating that Chop mRNA accumulation was more sensitive to arginine removal than that of Atf4 mRNA. The adaptive response of Atf4 and Chop mRNA expression in primary cultures of mouse B-lymphocytes, another hypomorphic tissue in F/A2 mice, to arginine deprivation was similar to that of $\mathrm{C} 2 \mathrm{C} 12$ and GH3 cells (not shown). Supplemental Fig. S4C, finally, shows that ATF4 protein accumulates at arginine concentrations below $25 \mu \mathrm{M}$ (see Ref. 52). These findings reveal that the integrated stress response becomes induced at arginine concentrations in the medium below $50 \mu \mathrm{M}$, with an $\mathrm{EC}_{50}$ of $\sim 12.5 \mu \mathrm{M}$.

Arginine Deficiency Does Not Affect Signaling through the mTORC1 Pathway-Amino acid deficiency can regulate protein synthesis by up-regulating signaling via the GCN2 pathway and by down-regulating signaling via the mTORC1 pathway. We, therefore, compared the effects of $0,12.5$, and $200 \mu \mathrm{M}$ arginine in the culture medium on the degree of phosphorylation of the translation factors eIF $2 \alpha$ as target of GCN2 kinase and 4EBP1, and S6K1 as targets of mTORC1 kinase in the same cell extracts (supplemental Fig. S5, column "Ctrl"). As expected, arginine deficiency caused a significant $>2$-fold increase in eIF2 $\alpha$ phosphorylation, but did not significantly affect either S6K1- or 4EBP1 phosphorylation $(p=0.13$ and 1.0, respectively). Furthermore, arginine deficiency increased the mRNA concentrations of Atf4, ATF4 target Chop, and CHOP target Gadd34, which dephosphorylates eIF4 $\alpha$-P. In addition, the expression of the ATF4 target Cat-1 was induced. Collectively, these data show that the ambient arginine concentration affects the activity or expression of all investigated parameters except the mTORC1 targets S6K1 and 4EBP1.

The eIF $2 \alpha$ P-specific phosphatase inhibitor salubrinal was used to assess to what extent arginine deficiency induced maximal eIF $2 \alpha$ phosphorylation and whether the degree of eIF $2 \alpha$ phosphorylation affected the stress-kinase esponse only quantitatively or also qualitatively (supplemental Fig. S5, column "Sal"). At the concentration used (50 $\mu \mathrm{M})$, salubrinal increased eIF2 $\alpha$ phosphorylation $\sim 3$-fold over basal levels $(p<0.001)$ and abolished the dependence of eIF $2 \alpha$ phosphorylation and its downstream targets on arginine concentration. Furthermore, salubrinal decreased overall S6K1 phosphorylation levels $\sim 3$-fold ( $p<0$.001) and increased the mRNAs of Atf4 ( $\sim 3$-fold; $p<0.001)$, Chop ( $\sim 20$-fold; $p<0.001)$, Gadd34 ( $\sim 6$-fold; $p<$ 0.001 ), and Cat-1 ( $\sim 3$-fold; $p<0.001)$, that is, the $\sim 3$-fold increase in eIF $2 \alpha$ phosphorylation had quantitatively a disproportional effect on its downstream targets. These data reveal that the effects of a graded phosphorylation of eIF $2 \alpha$ due to arginine deficiency differ both qualitatively and quantitatively from the effects of a maximal phosphorylation due to salubrinal treatment.

Constitutive Gcn 2 knockdown in $\mathrm{C} 2 \mathrm{C} 12$ muscle cells by integration of a viral vector carrying Gcn2-specific shRNA reduced Gcn 2 mRNA expression to $\sim 25 \%$ of control values (not shown). It strongly inhibited myotube formation, suggesting that GCN2 activation is involved in myocyte differentiation. This level of knockdown did, however, not affect the argininedependent stress-kinase response (supplemental Fig. S5, column "Gcn2-kd"). Similarly, treatment with the muscle growth factor IGF1 did not mediate, at the concentration used $(0.13$ $\mathrm{nM})$, a change in effects on the arginine-dependent phosphorylation of eIF2 $\alpha$, S6K1, or 4EBP1 $(p<0.05, p=0.18$, and $p=$ 0.66 , respectively) or their downstream targets.

Collectively, these data show that arginine deficiency induced a graded and comparatively mild increase in eIF $2 \alpha$ phosphorylation and ATF4-dependent gene expression, but did not affect phosphorylation of S6K1 or 4EBP1. However, when eIF $2 \alpha$ became hyperphosphorylated after treatment with 


\section{The Arginine Deficiency Syndrome}
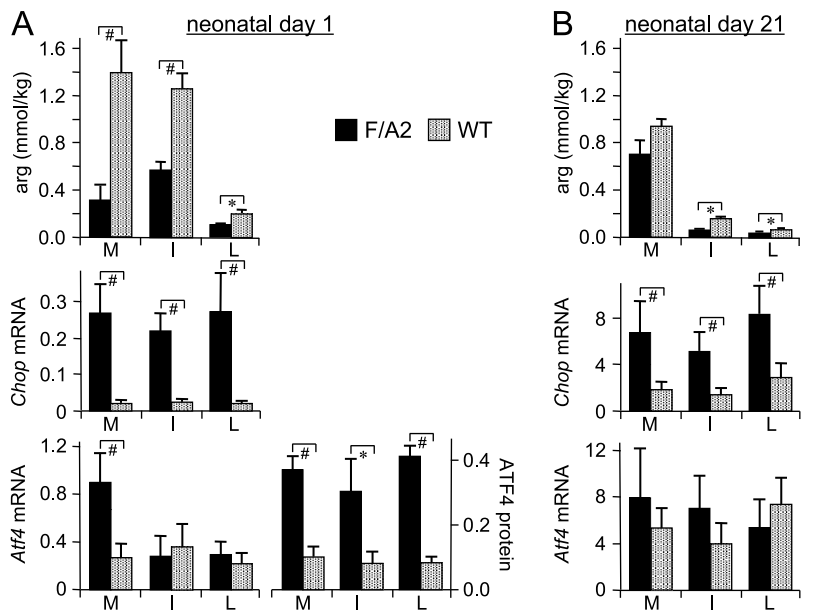

FIGURE 3. The stress-kinase pathway is activated in neonatal F/A2 mice. Panel A, concentration of arginine, Chop mRNA, and Atf4 mRNA and ATF4 protein in skeletal muscle $(M)$, small intestine $(I)$, and liver $(L)$ of ND1 F/A2 and wild-type mice. mRNA concentrations were corrected for $18 \mathrm{~S}$ rRNA content, while equal protein loading was checked by pre-staining Western blots with Ponceau-S. $n=8-12$ mice per genotype for arginine and mRNA concentration, and $n=3$ for ATF4 protein. Panel B, concentration of arginine, and Chop and Atf4 mRNA concentration in muscle, small intestine, and liver of ND2 F/A2 and wild-type mice. $n=8-12$ mice per genotype. ${ }^{*}, p<0.05 ; \#, p<0.01$.

the phosphatase inhibitor salubrinal, this specificity was lost Gcn 2 knockdown blocked myotube differentiation, without totally eliminating the dependence of eIF $2 \alpha$ phosphorylation on ambient arginine concentrations. The muscle growth factor IGF1, finally, increased the effect of arginine deficiency.

The Stress Kinase Pathway Is Activated in F/A2 Mice-On neonatal day 1 , the tissue concentration of arginine in skeletal muscle was only $20 \%(p<0.01)$ and that in intestine and liver $\sim 50 \%$ ( $p<0.01$ and $<0.05$, respectively) in F/A2 compared with wild-type mice (Fig. $3 A$, top subpanel). The low concentration of arginine in liver can be ascribed to the high concentration of the urea cycle enzyme arginase- 1 in the liver. The low tissue arginine concentration induced Chop mRNA expression $>8$-fold in all tissues investigated $(p<0.001$; Fig. $3 A$, middle subpanel), but Atf4 mRNA expression in skeletal muscle only ( $~ 3$-fold; $p<0.05$; Fig. 3A, bottom subpanel). These findings in vivo reveal that the tissue arginine concentration had decreased most in muscle and that Chop mRNA concentration was a more sensitive parameter to monitor the stress-kinase response to amino acid deprivation than Atf4 mRNA.

Because phosphorylation of eIF $2 \alpha$ facilitates translation of Atf4 mRNA (53), we also determined ATF4 protein concentration in ND1 mice (Fig. 3A, bottom subpanel). Western blot analysis of muscles of F/A2 mice showed the expected 38-kDa band (bold arrow in supplemental Fig. S6) and a much weaker band at $\sim 50 \mathrm{kDa}$ (small arrow), whereas these bands were absent in muscle of wild-type mice. The $\sim 50 \mathrm{kDa}$ band may correspond to an ubiquitinated form of ATF4 (54). ATF4 protein was 3-4-fold higher in muscle, small intestine, and liver of F/A2 than of wild-type animals (Fig. $3 A$, bottom subpanel; $p<$ $0.01,<0.02$, and $<0.01$, respectively). The data in Fig. $3 A$ demonstrate that Chop mRNA and ATF4 protein are equally sensitive parameters to assess the response to arginine deficiency in muscle, intestine, and liver.
TABLE 1

Distribution of genotypes and plasma glucose concentrations in the offspring of crosses of hemizygous F/A2 (F/A2 $\left.{ }^{\text {tg/- }}\right)$ mice and heterozygous $\mathrm{Gcn} 2\left(\mathrm{Gcn2}^{+/-}\right)$mice

Panel A: six different genotypes could be identified by PCR $\left(F / A 2^{t g /-}\right.$ and $F / A 2^{t g / t g}$ mice could not be distinguished; $F / A 2^{-1-}$ mice denote wild-type animals). A total of 60 could not bedistinguished, $F / A 2-1$ mice denote wild-type animals) A total of nests in the first two days and could not be analyzed. Panel B: blood was collected nests in the first two
from mice at ND1.

\begin{tabular}{|c|c|c|c|c|}
\hline \multirow[b]{2}{*}{ Genotype (A) } & \multirow[b]{2}{*}{ Expected } & \multirow{2}{*}{$\frac{\text { Day } 0}{\text { Alive }}$} & \multicolumn{2}{|c|}{ Day 2} \\
\hline & & & Alive & Dead \\
\hline$F / A 2^{-/-} / G c n 2^{+/+}$ & 4 & 0 & & \\
\hline$F / A 2^{-1-} / G c n 2^{+/-}$ & 8 & 10 & 10 & \\
\hline$F / A 2^{-/-} / G c n 2^{-1-}$ & 4 & 6 & 5 & 1 \\
\hline$F / A 2^{\operatorname{tg} / !} / G i n 2^{+/+}$ & 11 & 10 & 10 & \\
\hline$F / A 2^{\operatorname{tg} / ?} / G i n 2^{+/-}$ & 22 & 23 & 23 & \\
\hline$F / A 2^{\operatorname{tg} / ?} / G \operatorname{Gn} 2^{-/-}$ & 11 & 7 & 0 & 7 \\
\hline$F / A 2^{? / ?} / G i c n 2^{? / ?}$ & & 4 & & 4 \\
\hline \multirow[t]{2}{*}{ Total } & & 60 & 48 & 12 \\
\hline & & \multicolumn{3}{|c|}{ Plasma glucose } \\
\hline Genotype (B) & & $\mathbf{m M}$ & & $\mathbf{N}$ \\
\hline$F / A 2^{-/-} / G c n 2^{+/+}$ & & $3.3 \pm 0.2$ & & 23 \\
\hline$F / A 2^{-/-} / G c n 2^{-/-}$ & & $2.8 \pm 0.3$ & & 7 \\
\hline$F / A 2^{\operatorname{tg} / ?} / \mathrm{Gcn} 2^{+/+}$ & & $3.2 \pm 0.2$ & & 25 \\
\hline$F / A 2^{t g / ?} / G c n 2^{-1-}$ & & $2.7 \pm 0.2$ & & 15 \\
\hline
\end{tabular}

On neonatal day 21, the concentration of arginine in wildtype muscle was similar to that on ND1, but in the intestine and liver, it had decreased to $\sim 15$ and $\sim 30 \%$ of that on ND1 ( $p<$ 0.01 ). This pronounced decline can be ascribed to the cessation of intestinal arginine biosynthesis just prior to weaning (10) and the continued maturation of the function of the urea cycle in the liver (55). The arginine concentration in F/A2 muscle had increased 2-fold relative to that on ND1 $(p<0.05)$ and was no longer different from that in controls (Fig. 3B, top subpanel). However, the concentration of arginine in F/A2 intestine and liver remained depressed $(p<0.05)$. Tissue Chop and Atf4 mRNA concentration had increased $\sim 20$-fold and $\sim 10$-fold, respectively, relative to ND1 (Fig. $3 B$, middle and bottom subpanels). Chop mRNA concentrations were still significantly elevated in F/A2 tissues $(p<0.01$; Fig. $3 B$, middle subpanel, but Atf4 mRNA concentrations in F/A2 mice were no longer different from those in control mice (Fig. 3B, bottom subpanel). Together, these in vivo data show that the stress-kinase response pathway is strongly activated in neonatal F/A2 mice. This activation persists throughout the suckling period, although its severity appears to decline, in agreement with the disappearance of the phenotype after weaning.

GCN2 Mediates the Activation of the Stress Response in Arginine-deficient Neonatal Mice-In addition to GCN2, three other stress kinases can phosphorylate eIF $2 \alpha$. To demonstrate that GCN2 is the only stress kinase that becomes activated in neonatal F/A2 mice, we crossed $F / A 2^{t g /-}$ mice with Gcn2 $2^{-1-}$ mice. Table $1 A$ lists the genotypes of the offspring and shows that the respective genotypes were born at the expected Mendelian frequency. This Table also shows that all F/A2 mice that were deficient for Gcn2 $\left(F / A 2^{\operatorname{tg} / ?} / G c n 2^{-1-}\right)$ died within $48 \mathrm{~h}$ after birth $(p<0.001)$. The plasma arginine concentration in F/A2 neonates was only $25-40 \%$ of that in control neonates, irrespective of whether Gcn2 was or was not expressed ( $p<$ 0.01; Fig. 4A). Gcn2-deficient F/A2 neonates did drink, but their plasma glucose concentration on ND1 was significantly lower 
The Arginine Deficiency Syndrome

A

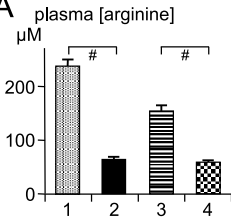

B

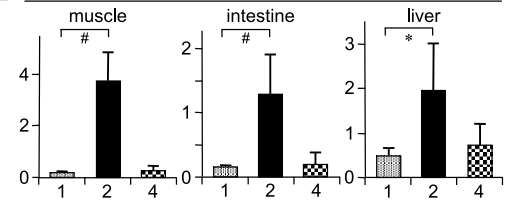

C elF2a-P/elF2 $\alpha$

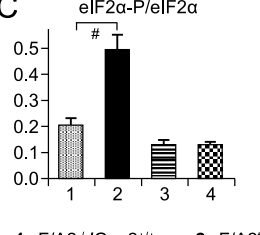

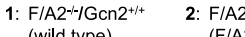

4EBP1-P/4EBP1

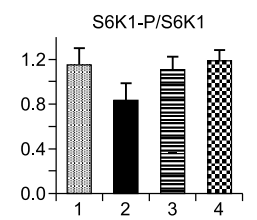

(wild type)

(F/A2)

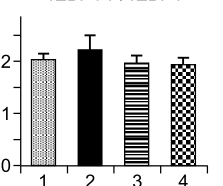

3: $\mathrm{F} / \mathrm{A} 2^{-1}-\mathrm{G} \mathrm{Gn} 2^{-1-}$

(Gcn2-KO)

4: $\mathrm{F} / \mathrm{A} 2^{\mathrm{tg} /}-\mathrm{GG \textrm {cn }} 2^{-1}$

(F/A2/Gcn2-KO)

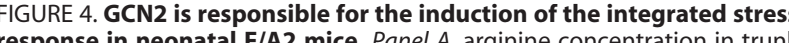
in neonatal F/A2 mice. Panel $A$, arginine concentration in trunk blood of ND1 mice. Panel $B$, Chop mRNA expression in muscle, small intestine, and liver of the same mice as shown in panel A. Panel C, Ser51-elF2 $\alpha$, Ser654EBP1, and Thr389-S6K1 phosphorylation in skeletal muscle of ND1 mice. $n=$ $8-12$ mice per genotype. ${ }^{*}, p<0.05 ; \#, p<0.01$.

than that in wild-type controls $(p<0.01)$, with Gcn2-deficient and F/A2 neonates taking intermediate positions (Table $1 B$ ).

To establish whether Gcn2 deficiency prevented the activation of the stress response, we determined Chop mRNA concentrations in muscle, small intestine and liver of neonatal wildtype mice $\left(F / A 2^{-/-} / G c n 2^{+/+}\right)$, F/A2 mice $\left(F / A 2^{t g / ?} / G c n 2^{+/+}\right)$ and F/A2 mice that were also Gcn2-deficient $\left(F / A 2^{t g / ?}\right.$ Gcn2 $2^{-\prime}$ ) (Fig. 4B). As expected, Chop mRNA concentrations were low in muscle, liver and gut of wild-type $\left(F / A 2^{-/-}\right.$, $\mathrm{Gcn}^{+/+}$) mice and elevated in the same organs of F/A2 $\left(F / A 2^{t g / ?} / G c n 2^{+/+}\right)$mice $(p<0.01,<0.01$, and $<0.05$, respectively). However, the elevation of Chop mRNA concentration was not found in muscle, liver, and gut of the F/A2 neonates that were, in addition, deficient for Gcn2 $\left(F / A 2^{t g / ?} / G c n 2^{-/-}\right)$ Similarly, the degree of phosphorylation of eIF $2 \alpha$ in muscle was increased in F/A2 mice $(p<0.01)$, but not in F/A2 mice that were also deficient in Gcn2 (Fig. 4C, left subpanel, and supplemental Fig. S6). These findings demonstrate that GCN2 activation is necessary for postnatal survival in F/A2 mice and that the phosphorylation of eIF $2 \alpha$ and the induction of Chop expression in these mice are solely dependent on GCN2 activation. Gcn2deficient neonates further had a significantly higher plasma IGF1 level than wild-type or F/A2 mice (Fig. 2A, left subpanel) F/A2 neonates had a lower plasma IGF1 level than wild-type or Gcn2-deficient neonates, but the difference was significant for only the latter.

mTORC1-mediated Translational Control Is Not Affected in Arginine-deficient Neonatal Mice-The degree of phosphorylation of S6K1 and 4EBP1 in neonatal skeletal muscle was not significantly different in any of the four genotypes (Fig. $4 C$ and supplemental Fig. S6; $p=0.36$ and 0.71 , respectively). These findings indicate that the reduction in circulating arginine concentration in F/A2 mice does not affect signaling through the mTORC1 signaling pathway. $C k m, M y h c 1$, and $M y h c 2 B$ mRNA concentrations were not affected either by arginine or Gcn2 deficiency in neonates (supplemental Fig. S7).

\section{DISCUSSION}

Suckling F/A2 mice, which express arginase I from the Fabp1-promoter exclusively in the enterocytes of the small intestine (14), suffer from a severe reduction in plasma arginine levels $(\sim 70 \mu \mathrm{M}$ versus $\sim 230 \mu \mathrm{M})$, reduced hair and muscle growth, and a specific block in B-cell development (14-17). In this study, we show that the deficiency of arginine causes an impaired function of the endocrine GH/IGF1 axis of these mice, but that the compromised function of the somatotropic axis does not account for the observed growth deficiency. Instead, activation of the GCN2-dependent stress response was found to be responsible for the hampered growth and even to be necessary for postnatal survival. Arginine deficiency does not suppress growth factor (mTORC1)-dependent signaling.

The Somatotropic Axis Is Not Responsible for the Runting Phenotype of F/A2 Mice-The gradual accumulation of GH in the pituitary gland from wild-type mice via hemizygous to homozygous F/A2 mice suggests that decreasing circulating concentrations of arginine progressively suppresses GH synthesis or secretion. Using GH3 cells, we could demonstrate that arginine deficiency blocks GH secretion rather than synthesis. Our findings, therefore, complement the recent finding that chronic arginine supplementation stimulates $\mathrm{GH}$ secretion (56) and imply that a broad dose-response relation exists between circulating arginine and $\mathrm{GH}$ secretion. The severely reduced plasma IGF1 concentration in suckling and weanling F/A2 mice also underscores the presence of a GH deficiency in F/A2 suckling mice, as IGF1 production is dependent upon GH stimulation $(38,57)$ and $>75 \%$ of plasma IGF1 is produced by the liver $(48$, 49). In vivo, the effects of arginine deficiency on growth in suckling mice become apparent when the circulating arginine concentration falls below $\sim 80 \mu \mathrm{M}$ (14), which compares well with our present finding in vitro that arginine concentrations below $50 \mu \mathrm{M}$ inhibit GH secretion (neonatal plasma arginine concentrations are $\sim 1.6$-fold higher than those after weaning $(14,16)$ ). However, neonatal F/A2 mice are not growth-retarded, even though their plasma arginine concentration is low, whereas Igf1-deficient mice are $(58,59)$. Furthermore, GH supplementation could not restore growth in suckling F/A2 mice. In addition, IGF1 concentration in skeletal muscle, one of the most severely affected tissues, was similar in F/A2 and wild-type mice. These findings demonstrate that the activity of the somatotropic axis is impaired in arginine-deficient suckling mice, but not directly responsible for the runted phenotype observed in these mice.

Arginine Deficiency Selectively Induces the Integrated Stress Response in Vitro-Because skeletal muscle is a severely affected tissue in F/A2 mice (14), we used the C2C12 muscle cell line to investigate the mechanism underlying the observed effects of arginine deficiency. Whereas arginine withdrawal increased, as expected, eIF $2 \alpha$ phosphorylation and the expression of its established downstream targets Atf4, Chop, Gadd34, and Cat-1 $(39,60,61)$, it did not significantly affect the degree of phosphorylation of S6K1 or 4EBP1, demonstrating that, in vitro, a deficiency of arginine activates the stress kinase GCN2, but does not block mTORC1 signaling. The pronounced effect of arginine deficiency on GCN2 activation contrasts with an 


\section{The Arginine Deficiency Syndrome}

earlier report that the depletion of all essential amino acids for $6 \mathrm{~h}$ does not activate the GCN2 pathway in $\mathrm{C} 2 \mathrm{C} 12$ myotubes (62). It is well possible that, as the authors themselves suggest (62), the complete removal of all essential amino acids strongly induces intracellular proteolysis in myotubes, whereas the selective depletion of arginine does not, or to a much lesser extent, as shown by the absence of an effect of arginine withdrawal on the expression of the ubiquitin ligases Atrogin 1 and Murf- 1.5 These discrepant findings underscore, nevertheless, that results obtained after complete removal of amino acids (e.g. Ref. 62), sometimes followed by adding back a single amino acid (30), often differ from results obtained after selectively removing a single amino acid from a complete mixture $(29,63)$ and present study). We opted to selectively remove arginine, because that intervention best mimicked the difference in plasma amino acid concentration between wild-type and F/A2 mice $(14,16)$.

The restriction of the effects of arginine deficiency to activation of the GCN2 stress-kinase pathway appears to reflect a limited increase in eIF $2 \alpha$ phosphorylation, because maximizing the degree of phosphorylation of eIF $2 \alpha$ with salubrinal caused a severe suppression of S6K1 phosphorylation and a disproportionate up-regulation of Atf4, Chop, Gadd34, and Cat-1 expression. These data suggest that crosstalk of the stress-kinase and the mTORC1 pathways only occurs when eIF $2 \alpha$ phosphorylation reaches an unphysiologically high level. Gcn2 knockdown in $\mathrm{C} 2 \mathrm{C} 12$ myoblasts almost completely prevented myotube formation, but did not affect the degree of phosphorylation of eIF2 $\alpha$, S6K1, or 4EBP1. Treatment with the growth factor IGF1 also did not affect eIF $2 \alpha$, S6K1, or 4EBP1 phosphorylation in response to arginine withdrawal. Our findings in $\mathrm{C} 2 \mathrm{C} 12$ cells, therefore, support the hypothesis that arginine deficiency selectively affects the GCN2 stress-kinase pathway.

Arginine Deficiency Selectively Induces the Integrated Stress Response in Vivo-Based on the degree of phosphorylation of eIF $2 \alpha$ and the expression of Chop mRNA, the GCN2 signaling pathway was activated in all F/A2 tissues tested on postnatal day 1. Atf4 mRNA was only up-regulated in skeletal muscle of 1-day-old F/A2 mice, but ATF4 protein concentration was elevated in all tissues. These findings underline the severity of the muscle phenotype in F/A2 mice and the primarily translational regulation of ATF4 expression (52, 53). The concentration gradient of arginine between plasma and muscle was similar in control and F/A2 mice (4-5-fold), but the absolute concentrations were 3-4-fold lower in F/A2 than in wild-type mice, in agreement with an arginine supply rather than transport problem. F/A2 homozygotes resume growth around weaning (14), in all likelihood due to the increasing cellular arginine, IGF1, and IGF1R1 (64) concentrations in target tissues. In combination, these data, therefore, indicate that the GCN2 signaling pathway in muscle in vivo becomes activated when intracellular arginine concentrations in muscle decrease below $\sim 400 \mu \mathrm{mol} / \mathrm{kg}$. GCN2 activation in the neonatal intestine appears to have a similar

${ }^{5}$ S. E. Kohler, unpublished observations.

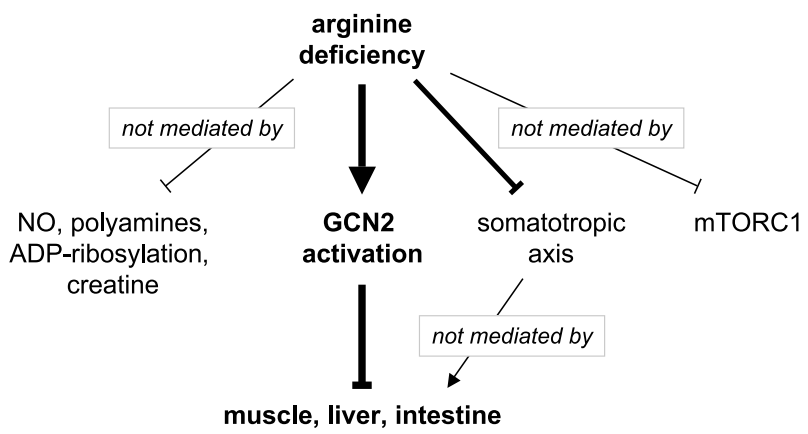

FIGURE 5. Proposed mechanism underlying the arginine-deficient phenotype in mice. Arginine is the precursor for NO, polyamines, and creatine synthesis, and regulates ADP-ribosylation, but these molecules do not mediate the developmental impairment of F/A2 mice. The somatotropic (GH/IGF1) axis does not function properly in arginine-deficient mice, but although $\mathrm{GH}$ supplementation increases Igf1 mRNA concentration to wild-type values, it cannot restore growth. Arginine deficiency, finally, does not block mTORC1 phosphorylation-dependent signaling, but does activate the stress kinase GCN2 in neonatal and suckling F/A2 mice. The sole activation of the GCN2mediated integrated stress response is apparently necessary and sufficient to block growth in a highly distinctive way.

sensitivity to arginine, but despite much lower tissue arginine concentrations, Chop mRNA and ATF4 protein concentrations in liver are similar to those in muscle and intestine.

Neonatal F/A2 mice did not show a reduced degree of S6K1 or 4EBP1 phosphorylation, which demonstrates that the effects of arginine deficiency are restricted to GCN2 activation both in vitro and in vivo. In this respect, arginine deficiency differs from leucine deficiency, which, at least in adult mice, causes both a GCN2-dependent phosphorrylation of eIF $2 \alpha$ and a hypophosphorylation of S6K1 and 4EBP1 (65).

GCN2 Is Necessary to Cope with and Survive Neonatal Arginine Deficiency - The absence of an increase in eIF $2 \alpha$ phosphorylation and Chop mRNA expression in neonates of crosses of F/A2 and Gcn2-deficient mice confirmed our in vitro data that GCN2 was necessary to mediate the response to arginine deficiency. These data also highlighted the vital role of GCN2 activation for postnatal survival of arginine-deficient pups. When a leucine-deficient diet was fed to pregnant $G c n 2^{+/-}$dams, neonatal survival of their Gcn2-deficient offspring was only $40 \%$ (22), but F/A2 neonates show a complete loss of vitality when the concentration of arginine falls to $\sim 30 \%$ of normal. We have not yet identified the dysfunction that kills Gcn2-deficient F/A2 pups, but, in all likelihood, the decline in plasma glucose concentration, possibly in conjunction with an increase in plasma IGF1 concentration, is a contributing factor to their untimely death. A similar correlation between stress-kinase signaling and lethal hypoglycemia was also noted in pups carrying the phosphorylation-resistant Ser51Ala mutation of eIF2 $\alpha$ (66), but these latter pups died earlier $(<18 \mathrm{~h})$ and with lower blood glucose concentrations $(\leq 1 \mathrm{~mm})$ than Gcn2-deficient F/A2 neonates ( $<48 \mathrm{~h}$ and $<3 \mathrm{~mm}$, respectively). Apparently, GCN2independent phosphorylation of eIF $2 \alpha$ is also necessary to survive neonatally.

Arginine Is a Signaling Molecule in Its Own Right-The discussion of arginine-dependent signaling in tissues often focuses on arginine metabolites, such as NO, agmatine, polyamines,

\section{ASBM}

VOLUME 286•NUMBER 11·MARCH 18, 2011 


\section{The Arginine Deficiency Syndrome}

creatine, or on arginine-mediated modifications such as ADPribosylation. This and earlier studies of the F/A2 mouse (1417) demonstrate that the arginine-deficient phenotype is not mediated by a metabolite of arginine (Fig. 5). Instead, it is the low circulating concentration of arginine itself, which suppresses the somatotropic axis and activates the GCN2-signaling pathway without affecting mTORC1-mediated signaling. We would, therefore, like to propose that the striking phenotype of suckling F/A2 mice is a paradigm for selective GCN2 activation (Fig. 5).

Acknowledgments-We thank Dr. W. Gerver (Pediatrics, azM, Maastricht) for providing us with recombinant human growth hormone, Dr. T. B. M. Hakvoort (Tytgat Institute for Liver and Gastrointestinal Diseases) for determining plasma arginine concentrations and Dr. H.A.M. Geerts (Dept. Human Genetics, AMC) and Ms. W. T. Labruyere (Tytgat Institute) for providing and growing the GCN2antisense lentivirus, respectively.

\section{REFERENCES}

1. Wu, G., and Morris, S. M., Jr. (1998) Biochem. J. 336, 1-17

2. Alba-Roth, J., Müller, O. A., Schopohl, J., and von Werder, K. (1988) J. Clin. Endocrinol. Metab. 67, 1186-1189

3. Rosati, B., Marchetti, P., Crociani, O., Lecchi, M., Lupi, R., Arcangeli, A., Olivotto, M., and Wanke, E. (2000) Faseb. J. 14, 2601-2610

4. Van Haeften, T. W., Van Faassen, I., and Van der Veen, E. A. (1988) Diabetes Res. 9, 187-191

5. Visek, W. J. (1986) J. Nutr. 116, 36-46

6. Wu, G., Jaeger, L. A., Bazer, F. W., and Rhoads, J. M. (2004) J. Nutr Biochem. 15, 442-451

7. Davis, T. A., Fiorotto, M. L., and Reeds, P. J. (1993) J. Nutr. 123, 947-956

8. Wu, G. (1997) Am. J. Physiol. 272, G1382-G1390

9. Bertolo, R. F., Brunton, J. A., Pencharz, P. B., and Ball, R. O. (2003) Am. J. Physiol. Endocrinol. Metab. 284, E915-922

10. De Jonge., W. J., Dingemanse, M. A., de Boer, P. A., Lamers, W. H., and Moorman, A. F. (1998) Pediatr. Res. 43, 442-451

11. Hurwitz, R., and Kretchmer, N. (1986) Am. J. Physiol. 251, G103-G110

12. Riby, J. E., Hurwitz, R. E., and Kretchmer, N. (1990) Pediatr. Res. 28, 261-265

13. Windmueller, H. G. (1982) Adv. Enzymol. Relat. Areas Mol. Biol. 53, 201-237

14. de Jonge, W. J., Hallemeesch, M. M., Kwikkers, K. L., Ruijter, J. M., de Gier-de Vries, C., van Roon, M. A., Meijer, A. J., Marescau, B., de Deyn, P. P., Deutz, N. E., and Lamers, W. H. (2002) Am. J. Clin Nutr. 76, 128-140

15. de Jonge, W. J., Kwikkers, K. L., te Velde, A. A., van Deventer, S. J., Nolte M. A., Mebius, R. E., Ruijter, J. M., Lamers, M. C., and Lamers, W. H. (2002) J. Clin. Invest. 110, 1539-1548

16. de Jonge, W. J., Marescau, B., D'Hooge, R., De Deyn, P. P., Hallemeesch, M. M., Deutz, N. E., Ruijter, J. M., and Lamers, W. H. (2001) J. Nutr. 131, $2732-2740$

17. Kwikkers, K. L., Ruijter, J. M., Labruyère, W. T., McMahon, K. K., and Lamers, W. H. (2005) Br. J. Nutr. 93, 183-189

18. Tsutsui, M., Shimokawa, H., Morishita, T., Nakashima, Y., and Yanagihara, N. (2006) J. Pharmacol. Sci. 102, 147-154

19. Vellekamp, G., Sihag, R. K., and Deutscher, M. P. (1985) J. Biol. Chem. 260, 9843-9847

20. Ron, D. (2002) J. Clin. Invest. 110, 1383-1388

21. Wek, R. C., Jiang, H. Y., and Anthony, T. G. (2006) Biochem. Soc Trans 34, $7-11$

22. Zhang, P., McGrath, B. C., Reinert, J., Olsen, D. S., Lei, L., Gill, S., Wek, S. A., Vattem, K. M., Wek, R. C., Kimball, S. R., Jefferson, L. S., and Cavener, D. R. (2002) Mol. Cell Biol. 22, 6681-6688

23. Averous, J., Bruhat, A., Jousse, C., Carraro, V., Thiel, G., and Fafournoux, P. (2004) J. Biol. Chem. 279, 5288-5297
24. Shaw, R. J. (2008) Trends Biochem. Sci. 33, 565-568

25. Avruch, J., Long, X., Ortiz-Vega, S., Rapley, J., Papageorgiou, A., and Dai, N. (2009) Am. J. Physiol. Endocrinol. Metab. 296, E592-E602

26. Ma, X. M., and Blenis, J. (2009) Nat. Rev. Mol. Cell Biol. 10, 307-318

27. Drummond, M. J., and Rasmussen, B. B. (2008) Curr. Opin. Clin. Nutr Metab. Care 11, 222-226

28. Yao, K., Yin, Y. L., Chu, W., Liu, Z., Deng, D., Li, T., Huang, R., Zhang, J. Tan, B., Wang, W., and Wu, G. (2008) J. Nutr. 138, 867-872

29. Hara, K., Yonezawa, K., Weng, Q. P., Kozlowski, M. T., Belham, C., and Avruch, J. (1998) J. Biol. Chem. 273, 14484-14494

30. Nakajo, T., Yamatsuji, T., Ban, H., Shigemitsu, K., Haisa, M., Motoki, T., Noma, K., Nobuhisa, T., Matsuoka, J., Gunduz, M., Yonezawa, K., Tanaka, N., and Naomoto, Y. (2005) Biochem. Biophys. Res. Commun. 326, $174-180$

31. Foulstone, E. J., Huser, C., Crown, A. L., Holly, J. M., and Stewart, C. E. (2004) Exp. Cell Res. 294, 223-235

32. Kim, H., Barton, E., Muja, N., Yakar, S., Pennisi, P., and Leroith, D. (2005) Endocrinology 146, 1772-1779

33. Landreth, K. S., Narayanan, R., and Dorshkind, K. (1992) Blood 80, $1207-1212$

34. Sumita, K., Hattori, N., and Inagaki, C. (2005) J Pharmacol. Sci. 97, $408-416$

35. Weger, N., and Schlake, T. (2005) J. Invest. Dermatol. 125, 873-882

36. Soulard, A., and Hall, M. N. (2007) Cell 129, 434

37. Rodriguez, S., Gaunt, T. R., and Day, I. N. (2007) Hum. Genet. 122, 1-21

38. Laron, Z. (1995) Drugs 50, 595-601

39. Harding, H. P., Novoa, I., Zhang, Y., Zeng, H., Wek, R., Schapira, M., and Ron, D. (2000) Mol. Cell 6, 1099-1108

40. Liu, J. L., Yakar, S., and LeRoith, D. (2000) Endocrinology 141, 4436-4441

41. van Eijk, H. M., Rooyakkers, D. R., and Deutz, N. E. (1993) J. Chromatogr. 620, $143-148$

42. Ruijter, J. M., Ramakers, C., Hoogaars, W. M., Karlen, Y., Bakker, O., van den Hoff, M. J., and Moorman, A. F. (2009) Nucleic Acids Res. 37, e45

43. Ruijter, J. M., Thygesen, H. H., Schoneveld, O. J., Das, A. T., Berkhout, B. and Lamers, W. H. (2006) Retrovirology 3, 2

44. van Straaten, H. W., He, Y., van Duist, M. M., Labruyère, W. T., Vermeulen, J. L., van Dijk, P. J., Ruijter, J. M., Lamers, W. H., and Hakvoort, T. B. (2006) Biochem. Cell Biol. 84, 215-231

45. Akaike, H. (1973) Second International Symposium on Information The ory, Akademia Kiado

46. Adrião, M., Chrisman, C. J., Bielavsky, M., Olinto, S. C., Shiraishi, E. M., and Nunes, M. T. (2004) Neuroendocrinology 79, 26-33

47. Liu, Y. L., Zhong, Y. Q., Chi, S. M., and Zhu, Y. L. (2005) Sheng. Li Xue Bao. 57, 254-258

48. Sjögren, K., Liu, J. L., Blad, K., Skrtic, S., Vidal, O., Wallenius, V., LeRoith, D., Törnell, J., Isaksson, O. G., Jansson, J. O., and Ohlsson, C. (1999) Proc. Natl. Acad. Sci. U.S.A. 96, $7088-7092$

49. Yakar, S., Liu, J. L., Stannard, B., Butler, A., Accili, D., Sauer, B., and LeRoith, D. (1999) Proc. Natl. Acad. Sci. U.S.A. 96, 7324-7329

50. Gebauer, F., and Hentze, M. W. (2004) Nat. Rev. Mol. Cell Biol. 5, 827-835

51. Harding, H. P., Zhang, Y., Zeng, H., Novoa, I., Lu, P. D., Calfon, M., Sadri, N., Yun, C., Popko, B., Paules, R., Stojdl, D. F., Bell, J. C., Hettmann, T. Leiden, J. M., and Ron, D. (2003) Mol. Cell 11, 619-633

52. Ameri, K., and Harris, A. L. (2008) Int. J. Biochem. Cell Biol. 40, 14-21

53. Holcik, M., and Sonenberg, N. (2005) Nat. Rev. Mol. Cell Biol. 6, 318-327

54. Lassot, I., Ségéral, E., Berlioz-Torrent, C., Durand, H., Groussin, L., Hai, T., Benarous, R., and Margottin-Goguet, F. (2001) Mol. Cell Biol. 21, 2192-2202

55. Illnerová, H. (1965) Biol. Neonat. 9, 197-202

56. de Castro Barbosa, T., de Carvalho, J. E., Poyares, L. L., Bordin, S. Machado, U. F., and Nunes, M. T. (2009) Endocrinology 150, 2080-2086

57. Le Roith, D., Bondy, C., Yakar, S., Liu, J. L., and Butler, A. (2001) Endocr. Rev. 22, 53-74

58. Liu, J. P., Baker, J., Perkins, A. S., Robertson, E. J., and Efstratiadis, A. (1993) Cell 75, 59-72

59. Powell-Braxton, L., Hollingshead, P., Warburton, C., Dowd, M., PittsMeek, S., Dalton, D., Gillett, N., and Stewart, T. A. (1993) Genes Dev. 7 , $2609-2617$ 


\section{The Arginine Deficiency Syndrome}

60. Fernandez, J., Yaman, I., Sarnow, P., Snider, M. D., and Hatzoglou, M. (2002) J. Biol. Chem. 277, 19198-19205

61. Kilberg, M. S., Shan, J., and Su, N. (2009) Trends Endocrinol. Metab. 20, $436-443$

62. Deval, C., Talvas, J., Chaveroux, C., Maurin, A. C., Mordier, S., Cherasse, Y., Parry, L., Carraro, V., Jousse, C., Bruhat, A., and Fafournoux, P. (2008) Biochimie 90, 1716-1721

63. Deldicque, L., Sanchez Canedo, C., Horman, S., De Potter, I., Bertrand, L.,
Hue, L., and Francaux, M. (2008) Amino Acids 35, 147-155

64. Sakuma, K., Watanabe, K., Sano, M., Uramoto, I., and Totsuka, T. (2000) Acta Neuropathol. 99, 169-176

65. Anthony, T. G., McDaniel, B. J., Byerley, R. L., McGrath, B. C., Cavener, D. R., McNurlan, M. A., and Wek, R. C. (2004) J. Biol. Chem. 279, 36553-36561

66. Scheuner, D., Song, B., McEwen, E., Liu, C., Laybutt, R., Gillespie, P., Saunders, T., Bonner-Weir, S., and Kaufman, R. J. (2001) Mol. Cell 7, 1165-1176 
CHAPTER VII

GENERAL DISCUSSION 


\section{CHAPTER VII}

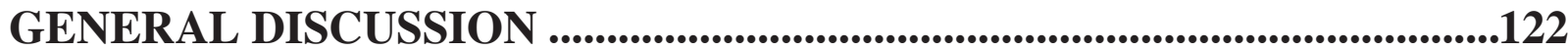

ARGININE DEFICIENCY ..............................................................................123

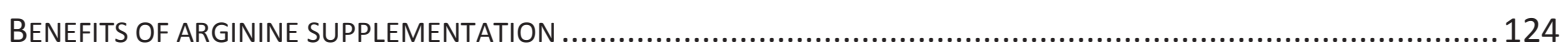

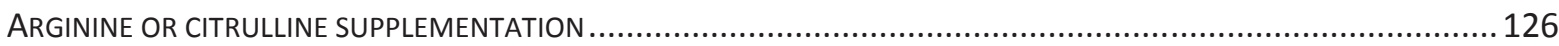

CONCLUSION....................................................................................................................126

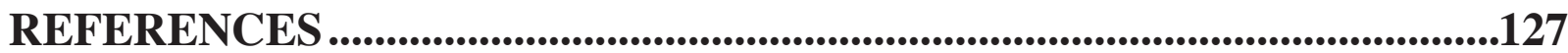

\section{GENERAL DISCUSSION}

In this thesis, I have described several genetically modified mouse models that allowed us to investigate arginine metabolism or to manipulate arginine availability. The models that were used affect arginine synthesis (conditional KO of argininosuccinate synthetase, Ass) or arginine degradation (conditional $\mathrm{KO}$ of arginase1, Arg1, and transgenic overexpression of rat arginase1 in mouse enterocytes, F/A2). Arginine metabolism in macrophages was reviewed (Chapter I) and an experimental analysis of mice with arginase 1 ablation in macrophages was described (Chapter III). The capacity of suckling mice to synthesize arginine in the enterocytes of the small intestine was confirmed for human infants (Chapter IV). Overexpression of arginase 1 in small intestinal enterocytes caused the surprisingly specific "neonatal arginine deficiency syndrome" (hypoargininemia, deficient muscle and hair growth and underdevelopment of Peyer's patches) in the suckling period (Chapter VI), whereas elimination of Ass in the same tissue did not (Chapter V). With the experience of generating several knockout models a troubleshooting guide was written (Chapter II).

Arginine is a substrate for the synthesis of proteins, ornithine, creatine, agmatine and nitric oxide (NO) (1). Arginine is also a secretagogue for growth hormone, insulin, glucagon and prolactin (2-4). Under normal conditions, endogenous arginine synthesis in adult mammals suffices to sustain daily requirements (5). A dietary source of arginine may, however, become necessary when demand increases under anabolic or catabolic conditions (5). For this reason, arginine is considered a conditionally essential amino acid.

Once inside cells, there are multiple pathways for arginine degradation to produce NO, ornithine, urea, polyamines, proline, glutamate, creatine and/or agmatine (1). These pathways are initiated by arginase, nitric oxide synthase, arginine:glycine amidinotransferase, and arginine decarboxylase. In mammals, the arginase pathway is quantitatively most important for arginine catabolism. Arginase 1 and 2 are encoded by two different genes, but hardly differ in their kinetic properties (6). 
All arginine-metabolizing enzymes except arginase 2 are cytosolic and do potentially compete for their common substrate arginine $(7,8)$. The functionally most important competition is probably between arginase 1 and nitric oxide synthase (NOS). Therefore, relative changes in their enzymatic activities serve as major determinants of NO production in e.g. endothelial cells and macrophages (9). Both arginase and arginine decarboxylase activity can mediate the increased production of the polyamine precursors ornithine and agmatine, respectively. Agmatine is also an inhibitor of NOS activity. Though it is often claimed that arginasedependent polyamine production is very important, Argl-deficient macrophages (10) produced all polyamines more efficiently than wild-type macrophages (11). In line with our observations, Arg1 and Arg2 single and double KO mice did not differ from controls with respect to polyamine concentrations.

\section{Arginine Deficiency}

There are a number of arginine-deficiency syndromes, involving immune and endothelial dysfunction, depending on the disease context in which arginine deficiency occurs. For some disorders, elevated plasma arginase concentrations may be more important as a marker of organ damage than as a mechanistic component of the disease process. The liver contains the largest amount of arginase 1 in the body. Any disease or damage to the liver that results in elevated plasma levels of transaminases or other liver enzymes also will result in elevated plasma levels of arginase 1 (12-14). Enzymatically active arginase 1 is also present in red blood cells of humans (there is much less arginase in rodent red blood cells (15)), is released upon hemolysis, and remains active for some time following release into the plasma. For this reason, hemolytic blood samples contain low plasma arginine values (16). For the same reason, high concentrations of arginase and low concentrations of arginine are found in plasma samples of individuals with chronic hemolytic anemias, such as sickle cell disease (17-20) and paroxysmal nocturnal hemoglobinuria (20). Conflicting reports exist regarding plasma arginine concentrations in sepsis. Several studies suggest that plasma L-arginine concentrations are not decreased in sepsis $(21,22)$ or that they are more markedly decreased in trauma than in sepsis $(23-26)$, but a recent meta-analysis concluded that plasma arginine concentrations are indeed reduced in sepsis in the absence of trauma or surgery (27).

Low values of the plasma [arginine]/([ornithine]+[citrulline]) ratio, the so-called "global arginine bioavailability ratio" (GABR), represent an independent risk factor for morbidity and mortality in sickle-cell and thalassemic patients $(17,28)$ and are also correlated with pulmonary hypertension in this patient population $(17,29)$. GABR values in asthma patients were, nevertheless, greater than in healthy controls, despite higher plasma arginase concentrations in the asthma group (30). Since plasma arginase activity was not determined, it is also possible that the arginase 1 protein in plasma may not have been active.

It has also been suggested, that cells expressing the cationic amino-acid transporter CAT1 can be depleted of their intracellular arginine if, there is a high ambient concentration of arginase (e.g. 


\section{Chapter VII}

due to cell lysis) or if ambient arginine is high in combination with a high intracellular arginase content in a neighboring cell (31), such as myeloid-derived suppressor cells (see Chapter I). This depletion results from concentration-dependent trans-stimulation of CAT1-mediated arginine transport by other cationic amino acids, such as ornithine or lysine. As a result, sensitive neighboring cells, such as T-cells, are rapidly depleted of arginine and become anergic $(32,33)$. The CAT1 transporter exhibits the highest trans-stimulation, but CAT2B and CAT3 also exhibit this property (34-36). As far as we know, however, none of these CAT isoforms is expressed.

Studies with cultured cells have demonstrated that arginine deficiency in the culture medium can result in T-cell dysfunction via reduced expression of the $\mathrm{CD} 3 \zeta$ chain of the T-cell receptor complex (37) and cell cycle arrest (38), suggesting that similar effects might be observed in patients with arginine deficiency. Arginine deficiency would then result in an impaired immune response (39). Arginine deficiency also inhibits the maturation of B cells (40). Available evidence suggests that arginine is also required for defense against viruses, bacteria, fungi, malignant cells, and intracellular parasites (39). Although these findings suggest that arginine plays an important role in the immunity of (young) mice, our findings in a mouse model of severe arginine deficiency generated by arginase 1 overexpression in enterocytes demonstrates that arginine deficiency activates the general control non-derepressible 2 (GCN2) stress kinase pathway in vivo (41). Activation of the GCN2 kinase was recently also shown to underlie cell cycle arrest in T-cells (38). Indeed, the activation of the GCN2 kinase stress response pathway as a consequence of arginine deficiency has now been demonstrated in several cell types $(38,42)$. The T-cell dysfunction that is observed fin chronic inflammatory disease and after physical injury (e.g. trauma or surgery) is associated with increased arginase activity in human granulocytes (43-46) and may, therefore, also result from activation of the stress kinase pathway. The non-specific immune response in the presence of abundant arginine, therefore, appears to depend on NO production and that during arginine deficiency on the integrated stress response.

\section{Benefits of arginine supplementation}

Arginine is stable under sterilization conditions (e.g. high temperature and high pressure) and is not toxic to cells (47). Thus, its administration appears safe for animals and humans, although a recent study (48) reported a higher mortality of subjects receiving L-arginine. Many claims were raised to supplement arginine as a strategy to support arginine homeostasis and, thus, improve health and productivity under many physiological and pathological conditions. We cite a few examples with an emphasis on polyamines (reproduction), intestinal arginine synthesis (neonatal hyperammonemia), and NOS stabilization (endothelial dysfunction).

Polyamines, the polycationic products of arginine degradation, are thought to be important for cell growth and differentiation (see Chapter I for a more extensive discussion). Seminal fluid is abundant in polyamines (49). The oral administration of arginine- $\mathrm{HCl}(0.5 \mathrm{~g}$ or $2.4 \mathrm{mmol} / \mathrm{day})$ to infertile men for 6-8 weeks reportedly increased sperm counts and motility markedly in most patients and resulted in successful pregnancies (50). As usual, the underlying mechanism was not 
studied, but was, in spite of the homeopathically low dose, suggested to be enhanced synthesis of polyamines and histones in sperm cells, and increased availability of NO for better sperm motility and capacitation (51). Similarly, arginine is claimed to extend the temporal window of oocytes for optimal fertilization (52) and to enhance embryonic and fetal survival and growth (53-58). As explanation, the stimulatory effects of polyamines and NO on angiogenesis and placental growth were mentioned (59). The beneficial effect of intravenous arginine supplementation on the reduction of spontaneous uterine contractility in women with the preterm onset of uterine contractions is explained by the relaxing effect of $\mathrm{NO}$ on smooth muscles (60).

Arginine deficiency in preterm infants $(<30 \mu \mathrm{mol} / \mathrm{L}$ in plasma) is associated with severe hyperammonemia (61). This type of hyperammonemia often develops if the preterm infants are maintained on parenteral nutrition (62-64) and appears to predispose them to the respiratory distress syndrome (65) and necrotizing enterocolitis $(66,67)$. The reason for the observed arginine deficiency may well be that parenteral nutrition bypasses the gut. In newborn piglets, parenteral nutrition induces hypoargininemia, whereas infusion of the same solution into the gut prevents it, showing that (small-intestinal) enterocytes are a crucial source of de novo arginine synthesis $(68,69)$. Our data show the human small intestine acquires the potential to produce arginine well before fetuses become viable outside the uterus (70). The perinatal human intestine therefore resembles that of rodents and pigs in this respect. Supplementing arginine appears to prevent the hyperammonemia (61) and to counteract pulmonary hypertension (71) and necrotizing enterocolitis (72) in preterm infants.

NO deficiency is a major factor contributing to endothelial dysfunction, which occurs in a variety of metabolic disorders, including diabetes, hypercholesterolemia, hypertension, smoking and malaria (73). Dietary supplementation with arginine or watermelon (rich in citrulline) increased circulating levels of arginine, endothelial BH4 (co-factor of NOS) availability and NO synthesis, and enhanced endothelium-dependent relaxation in Zucker diabetic fatty rats (74). Hypertension in adult rats with intestinal resection (taking away the animal's capacity to produce citrulline (75) or patients with lysinuric protein intolerance (deficiency of the $\mathrm{y}^{+} \mathrm{L}$ amino acid transporter ( $S l c 7 a 7$ gene) which causes a rare autosomal recessive defect of dibasic amino acid transport resulting in a L-arginine deficiency (76)) could be prevented by parenteral administration of arginine. Either arginine or BH4 becomes deficient, NOS "uncouples" and releases free superoxide $\left(\mathrm{O}_{2}^{-}\right)$radicals (77), which enhance oxidative stress and BH4 oxidation (78). This mechanism is responsible for many of the observed features and may explain why arginine supplementation may not only cause recovery of endothelial NO synthesis and reduction of superoxide production but also reduction of vascular oxidative damage and inhibition of platelet adherence and aggregation, leukocyte adherence to the endothelium, and inhibition of the proliferation of vascular smooth muscle cells $(73,79)$. The beneficial effects of arginine supplementation on renal diseases that cause systemic hypertension $(80,81)$, gastric ulcer healing (82), (hepatic) ischemia/reperfusion injury (83-85) and pulmonary function in patients with cystic fibrosis (86) probably all have a similar mechanistic basis. 


\section{Chapter VII}

In some cases, arginine supplementation appears to exert its beneficial effects via more than one mode of action. The beneficial effect of subcutaneous administration of arginine at the site of foot ulcers in diabetic patients (87) may involve both enhanced proline and polyamine synthesis, and NO-dependent increases in blood flow and nutrient supply. The basal arginine and ornithine fluxes are distinctly higher in burn patients than in healthy controls, conforming an accelerated turnover of arginine after burn injury (88). The function of arginine may also change with the progress of the condition it affects. The majority of in vivo studies showed that arginine supplementation from the time of tumor induction or inoculation was protective (89), whereas arginine supplementation during the promotion stage stimulated (colorectal) tumor growth (90).

\section{Arginine or citrulline supplementation}

If a dysfunction or disease is caused by deficiency of arginine, it should be ameliorated or reversed by supplementation with arginine or its precursor citrulline. As a practical consideration, the efficacy of enteral arginine supplementation is limited by gastrointestinal discomfort following ingestion of large amounts of arginine and by catabolism of a significant fraction of ingested arginine due to the huge arginase content of the body (91). The transstimulatory property of CAT transporters can also cause intracellular arginine deficiency if the extracellular concentration of ornithine or lysine is high (see earlier and Chapter I). Although dietary L-arginine supplementation enhanced the blood flow response to acetylcholine in some studies (92), it did not lead to significant improvements of endothelium-dependent vasodilation and blood flow in others (93). In most studies arginine supplementation increased plasma arginine concentrations, but functionally had no beneficial effects $(94,95)$. These disperse findings with respect to the functional benefits made arginine supplementation highly controversial (96-99).

For these reasons, citrulline has been advanced as an indirect source of arginine. Supplementation with citrulline efficiently increases the circulating and tissue arginine concentration, and mediates functional effects, such as NO production, without (thus far) side effects $(95,100$, 101).

Arginase enzyme inhibitors or siRNAs that inhibit expression arginase or its transcription factors (102) represent a potential alternative for treatment of arginine deficiency, but side effects, such as inhibition of arginase function, require selective uptake in target cells and for that reason clearly limit its applicability.

\section{Conclusion}

Arginine deficiency is detrimental to many cell functions and tends to activate the powerful integrated stress-response pathway. The high sensitivity to catabolism by arginase and the peculiar characteristics of arginine transport across the cell membrane limit the applicability of arginine supplementation. Presently, citrulline supplementation appears to be a more promising 
strategy. These findings show that intensive-care and pediatric physicians should have a basic, but up-to-date knowledge of arginine metabolism and transport.

\section{References}

1. Wu G, Morris SM, Jr. Arginine metabolism: nitric oxide and beyond. Biochem J 1998;336 ( Pt 1):1-17.

2. Alba-Roth J, Muller OA, Schopohl J, von Werder K. Arginine stimulates growth hormone secretion by suppressing endogenous somatostatin secretion. J Clin Endocrinol Metab 1988;67:1186-9.

3. Rosati B, Marchetti P, Crociani O, Lecchi M, Lupi R, Arcangeli A, Olivotto M, Wanke E. Glucose- and arginine-induced insulin secretion by human pancreatic beta-cells: the role of HERG $\mathrm{K}(+)$ channels in firing and release. FASEB J 2000;14:2601-10.

4. Van Haeften TW, Van Faassen I, Van der Veen EA. Repetitive stimulation of insulin secretion with arginine and glucose. Diabetes Res 1988;9:187-91.

5. Visek WJ. Arginine needs, physiological state and usual diets. A reevaluation. J Nutr 1986;116:36-46.

6. Morris SM, Jr. Arginine metabolism: boundaries of our knowledge. J Nutr 2007;137:1602S-9S.

7. Li H, Meininger CJ, Hawker JR, Jr., Haynes TE, Kepka-Lenhart D, Mistry SK, Morris SM, Jr., Wu G. Regulatory role of arginase I and II in nitric oxide, polyamine, and proline syntheses in endothelial cells. Am J Physiol Endocrinol Metab 2001;280:E75-82.

8. Wei LH, Wu G, Morris SM, Jr., Ignarro LJ. Elevated arginase I expression in rat aortic smooth muscle cells increases cell proliferation. Proc Natl Acad Sci U S A 2001;98:9260-4.

9. Durante W, Johnson FK, Johnson RA. Arginase: a critical regulator of nitric oxide synthesis and vascular function. Clin Exp Pharmacol Physiol 2007;34:906-11.

10. Cloots RH, Sankaranarayanan S, de Theije CC, Poynter ME, Terwindt E, van Dijk P, Hakvoort TB, Lamers WH, Kohler SE. Ablation of Arg1 in hematopoietic cells improves respiratory function of lung parenchyma, but not that of larger airways or inflammation in asthmatic mice. Am J Physiol Lung Cell Mol Physiol 2013;305:L364-76.

11. Van den Bossche J, Lamers WH, Koehler ES, Geuns JM, Alhonen L, Uimari A, Pirnes-Karhu S, Van Overmeire E, Morias Y, et al. Pivotal Advance: Arginase-1-independent polyamine production stimulates the expression of IL-4-induced alternatively activated macrophage markers while inhibiting LPS-induced expression of inflammatory genes. J Leukoc Biol 2012;91:685-99.

12. Ashamiss F, Wierzbicki Z, Chrzanowska A, Scibior D, Pacholczyk M, Kosieradzki M, Lagiewska B, Porembska Z, Rowinski W. Clinical significance of arginase after liver transplantation. Ann Transplant 2004;9:58-60.

13. van de Poll MC, Hanssen SJ, Berbee M, Deutz NE, Monbaliu D, Buurman WA, Dejong CH. Elevated plasma arginase-1 does not affect plasma arginine in patients undergoing liver resection. Clin Sci (Lond) 2008;114:231-41.

14. Ikemoto M, Tsunekawa S, Awane M, Fukuda Y, Murayama H, Igarashi M, Nagata A, Kasai Y, Totani M. A useful ELISA system for human liver-type arginase, and its utility in diagnosis of liver diseases. Clin Biochem 2001;34:455-61.

15. Yang J, Gonon AT, Sjoquist PO, Lundberg JO, Pernow J. Arginase regulates red blood cell nitric oxide synthase and export of cardioprotective nitric oxide bioactivity. Proceedings of the National Academy of Sciences of the United States of America 2013;110:15049-54. 


\section{Chapter VII}

16. Davis JS, Darcy CJ, Piera K, McNeil YR, Woodberry T, Anstey NM. Ex-vivo changes in amino acid concentrations from blood stored at room temperature or on ice: implications for arginine and taurine measurements. BMC Clin Pathol 2009;9:10.

17. Morris CR, Kato GJ, Poljakovic M, Wang X, Blackwelder WC, Sachdev V, Hazen SL, Vichinsky EP, Morris SM, Jr., et al. Dysregulated arginine metabolism, hemolysis-associated pulmonary hypertension, and mortality in sickle cell disease. JAMA 2005;294:81-90.

18. Vilas-Boas W, Cerqueira BA, Zanette AM, Reis MG, Barral-Netto M, Goncalves MS. Arginase levels and their association with Th17-related cytokines, soluble adhesion molecules (sICAM-1 and sVCAM-1) and hemolysis markers among steady-state sickle cell anemia patients. Ann Hematol 2010;89:877-82.

19. Scavella A, Leiva L, Monjure H, Zea AH, Gardner RV. Effect of L-arginine supplementation on immune responsiveness in patients with sickle cell disease. Pediatr Blood Cancer 2010;55:318-23.

20. Sullivan KJ, Kissoon N, Sandler E, Gauger C, Froyen M, Duckworth L, Brown M, Murphy S. Effect of oral arginine supplementation on exhaled nitric oxide concentration in sickle cell anemia and acute chest syndrome. J Pediatr Hematol Oncol 2010;32:e249-58.

21. Askanazi J, Carpentier YA, Michelsen CB, Elwyn DH, Furst P, Kantrowitz LR, Gump FE, Kinney JM. Muscle and plasma amino acids following injury. Influence of intercurrent infection. Ann Surg 1980;192:78-85.

22. Ochoa JB, Udekwu AO, Billiar TR, Curran RD, Cerra FB, Simmons RL, Peitzman AB. Nitrogen oxide levels in patients after trauma and during sepsis. Ann Surg 1991;214:621-6.

23. Kalil AC, Danner RL. L-Arginine supplementation in sepsis: beneficial or harmful? Curr Opin Crit Care 2006;12:303-8.

24. Ochoa JB, Makarenkova V, Bansal V. A rational use of immune enhancing diets: when should we use dietary arginine supplementation? Nutr Clin Pract 2004;19:216-25.

25. Weitzel LR, Mayles WJ, Sandoval PA, Wischmeyer PE. Effects of pharmaconutrients on cellular dysfunction and the microcirculation in critical illness. Curr Opin Anaesthesiol 2009;22:177-83.

26. Chiarla C, Giovannini I, Siegel JH. Plasma arginine correlations in trauma and sepsis. Amino Acids 2006;30:81-6.

27. Davis JS, Anstey NM. Is plasma arginine concentration decreased in patients with sepsis? A systematic review and meta-analysis. Crit Care Med 2011;39:380-5.

28. Cox SE, Makani J, Komba AN, Soka D, Newton CR, Kirkham FJ, Prentice AM. Global arginine bioavailability in Tanzanian sickle cell anaemia patients at steady-state: a nested case control study of deaths versus survivors. Br J Haematol 2011;155:522-4.

29. Morris CR, Vichinsky EP. Pulmonary hypertension in thalassemia. Ann N Y Acad Sci 2010;1202:205-13.

30. Lara A, Khatri SB, Wang Z, Comhair SA, Xu W, Dweik RA, Bodine M, Levison BS, Hammel J, et al. Alterations of the arginine metabolome in asthma. Am J Respir Crit Care Med 2008;178:673-81.

31. Closs EI, Simon A, Vekony N, Rotmann A. Plasma membrane transporters for arginine. J Nutr 2004;134:2752S-9S; discussion 65S-67S.

32. Rodriguez PC, Ernstoff MS, Hernandez C, Atkins M, Zabaleta J, Sierra R, Ochoa AC. Arginase Iproducing myeloid-derived suppressor cells in renal cell carcinoma are a subpopulation of activated granulocytes. Cancer Res 2009;69:1553-60.

33. Rodriguez PC, Quiceno DG, Ochoa AC. L-arginine availability regulates T-lymphocyte cell-cycle progression. Blood 2007;109:1568-73.

34. Closs EI, Lyons CR, Kelly C, Cunningham JM. Characterization of the third member of the MCAT family of cationic amino acid transporters. Identification of a domain that determines the transport properties of the MCAT proteins. J Biol Chem 1993;268:20796-800.

35. Kavanaugh MP, Wang H, Zhang Z, Zhang W, Wu YN, Dechant E, North RA, Kabat D. Control of cationic amino acid transport and retroviral receptor functions in a membrane protein family. J Biol Chem 1994;269:15445-50. 
36. Ito K, Groudine M. A new member of the cationic amino acid transporter family is preferentially expressed in adult mouse brain. J Biol Chem 1997;272:26780-6.

37. Zea AH, Rodriguez PC, Culotta KS, Hernandez CP, DeSalvo J, Ochoa JB, Park HJ, Zabaleta J, Ochoa AC. L-Arginine modulates CD3zeta expression and $\mathrm{T}$ cell function in activated human $\mathrm{T}$ lymphocytes. Cell Immunol 2004;232:21-31.

38. Rodriguez PC, Hernandez CP, Morrow K, Sierra R, Zabaleta J, Wyczechowska DD, Ochoa AC. L-arginine deprivation regulates cyclin D3 mRNA stability in human T cells by controlling HuR expression. J Immunol 2010;185:5198-204.

39. Li P, Yin YL, Li D, Kim SW, Wu G. Amino acids and immune function. Br J Nutr 2007;98:237-52.

40. de Jonge WJ, Kwikkers KL, te Velde AA, van Deventer SJ, Nolte MA, Mebius RE, Ruijter JM, Lamers MC, Lamers WH. Arginine deficiency affects early B cell maturation and lymphoid organ development in transgenic mice. J Clin Invest 2002;110:1539-48.

41. Marion V, Sankaranarayanan S, de Theije C, van Dijk P, Lindsey P, Lamers MC, Harding HP, Ron D, Lamers WH, Köhler SE. Arginine deficiency causes runting in the suckling period by selectively activating the stress kinase GCN2. J Biol Chem 2011;286:8866-74.

42. Lee J, Ryu H, Ferrante RJ, Morris SM, Jr., Ratan RR. Translational control of inducible nitric oxide synthase expression by arginine can explain the arginine paradox. Proc Natl Acad Sci U S A 2003;100:4843-8.

43. Munder M, Schneider H, Luckner C, Giese T, Langhans CD, Fuentes JM, Kropf P, Mueller I, Kolb A, et al. Suppression of T-cell functions by human granulocyte arginase. Blood 2006;108:1627-34.

44. Bryk JA, Popovic PJ, Zenati MS, Munera V, Pribis JP, Ochoa JB. Nature of myeloid cells expressing arginase 1 in peripheral blood after trauma. J Trauma 2010;68:843-52.

45. Zhu X, Herrera G, Ochoa JB. Immunosupression and infection after major surgery: a nutritional deficiency. Crit Care Clin 2010;26:491-500, ix.

46. Munder M. Arginase: an emerging key player in the mammalian immune system. Br J Pharmacol 2009;158:638-51.

47. Flynn NE, Meininger CJ, Haynes TE, Wu G. The metabolic basis of arginine nutrition and pharmacotherapy. Biomed Pharmacother 2002;56:427-38.

48. Schulman SP, Becker LC, Kass DA, Champion HC, Terrin ML, Forman S, Ernst KV, Kelemen MD, Townsend SN, et al. L-arginine therapy in acute myocardial infarction: the Vascular Interaction With Age in Myocardial Infarction (VINTAGE MI) randomized clinical trial. JAMA 2006;295:58-64.

49. Janne J, Holtta E, Haaranen P, Elfving K. Polyamines and polyamine-metabolizing enzyme activities in human semen. Clin Chim Acta 1973;48:393-401.

50. Tanimura J. Studies on arginine in human semen. II. The effects of medication with L-arginine-HCL on male infertility. Bull Osaka Med Sch 1967;13:84-9.

51. Balercia G, Moretti S, Vignini A, Magagnini M, Mantero F, Boscaro M, Ricciardo-Lamonica G, Mazzanti L. Role of nitric oxide concentrations on human sperm motility. J Androl 2004;25:245-9.

52. Goud PT, Goud AP, Diamond MP, Gonik B, Abu-Soud HM. Nitric oxide extends the oocyte temporal window for optimal fertilization. Free Radic Biol Med 2008;45:453-9.

53. Wu G, Bazer FW, Tuo W, Flynn SP. Unusual abundance of arginine and ornithine in porcine allantoic fluid. Biol Reprod 1996;54:1261-5.

54. Wu G, Bazer FW, Cudd TA, Meininger CJ, Spencer TE. Maternal nutrition and fetal development. J Nutr 2004; 134:2169-72.

55. Wu G, Jaeger LA, Bazer FW, Rhoads JM. Arginine deficiency in preterm infants: biochemical mechanisms and nutritional implications. J Nutr Biochem 2004;15:442-51.

56. Mateo RD, Wu G, Bazer FW, Park JC, Shinzato I, Kim SW. Dietary L-arginine supplementation enhances the reproductive performance of gilts. J Nutr 2007;137:652-6.

57. Zeng X, Wang F, Fan X, Yang W, Zhou B, Li P, Yin Y, Wu G, Wang J. Dietary arginine supplementation during early pregnancy enhances embryonic survival in rats. J Nutr 2008;138:1421-5. 


\section{Chapter VII}

58. Lassala A. Arginine and fetal growth in ovine models of intrauterine growth restriction. Tamu: Texas A\& M University; 2008.

59. Wu G, Bazer FW, Datta S, Gao H, Johnson GA, Lassala A, Li P. Intrauterine growth retardation in livestock: implications, mechanisms and solutions. Arch. Tierz. Dummerstorf 2008;51:4-10.

60. Facchinetti F, Neri I, Genazzani AR. L-arginine infusion reduces preterm uterine contractions. J Perinat Med 1996;24:283-5.

61. Heird WC, Nicholson JF, Driscoll JM, Jr., Schullinger JN, Winters RW. Hyperammonemia resulting from intravenous alimentation using a mixture of synthetic 1-amino acids: a preliminary report. J Pediatr 1972;81:162-5.

62. Hurwitz R, Kretchmer N. Development of arginine-synthesizing enzymes in mouse intestine. Am J Physiol 1986;251:G103-10.

63. De Jonge WJ, Dingemanse MA, de Boer PA, Lamers WH, Moorman AF. Arginine-metabolizing enzymes in the developing rat small intestine. Pediatr Res 1998;43:442-51.

64. de Jonge WJ, Hallemeesch MM, Kwikkers KL, Ruijter JM, de Gier-de Vries C, van Roon MA, Meijer AJ, Marescau B, de Deyn PP, et al. Overexpression of arginase I in enterocytes of transgenic mice elicits a selective arginine deficiency and affects skin, muscle, and lymphoid development. Am J Clin Nutr 2002;76:128-40.

65. Castillo L, DeRojas-Walker T, Yu YM, Sanchez M, Chapman TE, Shannon D, Tannenbaum S, Burke JF, Young VR. Whole body arginine metabolism and nitric oxide synthesis in newborns with persistent pulmonary hypertension. Pediatr Res 1995;38:17-24.

66. Zamora SA, Amin HJ, McMillan DD, Kubes P, Fick GH, Butzner JD, Parsons HG, Scott RB. Plasma Larginine concentrations in premature infants with necrotizing enterocolitis. J Pediatr 1997;131:226-32.

67. Becker RM, Wu G, Galanko JA, Chen W, Maynor AR, Bose CL, Rhoads JM. Reduced serum amino acid concentrations in infants with necrotizing enterocolitis. J Pediatr 2000;137:785-93.

68. Brunton JA, Bertolo RF, Pencharz PB, Ball RO. Proline ameliorates arginine deficiency during enteral but not parenteral feeding in neonatal piglets. Am J Physiol 1999;277:E223-31.

69. Wu G. Synthesis of citrulline and arginine from proline in enterocytes of postnatal pigs. Am J Physiol 1997;272:G1382-90.

70. Kohler ES, Sankaranarayanan S, van Ginneken CJ, van Dijk P, Vermeulen JL, Ruijter JM, Lamers WH, Bruder E. The human neonatal small intestine has the potential for arginine synthesis; developmental changes in the expression of arginine-synthesizing and -catabolizing enzymes. BMC Dev Biol 2008;8:107.

71. McCaffrey MJ, Bose CL, Reiter PD, Stiles AD. Effect of L-arginine infusion on infants with persistent pulmonary hypertension of the newborn. Biol Neonate 1995;67:240-3.

72. Amin HJ, Zamora SA, McMillan DD, Fick GH, Butzner JD, Parsons HG, Scott RB. Arginine supplementation prevents necrotizing enterocolitis in the premature infant. J Pediatr 2002;140:425-31.

73. Wu G, Meininger CJ. Arginine nutrition and cardiovascular function. J Nutr 2000;130:2626-9.

74. Wu G, Collins JK, Perkins-Veazie P, Siddiq M, Dolan KD, Kelly KA, Heaps CL, Meininger CJ. Dietary supplementation with watermelon pomace juice enhances arginine availability and ameliorates the metabolic syndrome in Zucker diabetic fatty rats. J Nutr 2007;137:2680-5.

75. Wakabayashi Y, Yamada E, Yoshida T, Takahashi H. Deficiency of endogenous arginine synthesis provokes hypertension by exhausting substrate arginine for nitric oxide synthesis. Biochem Biophys Res Commun 1994;205:1391-8.

76. Kamada Y, Nagaretani H, Tamura S, Ohama T, Maruyama T, Hiraoka H, Yamashita S, Yamada A, Kiso S, et al. Vascular endothelial dysfunction resulting from L-arginine deficiency in a patient with lysinuric protein intolerance. The Journal of clinical investigation 2001;108:717-24.

77. Rabelink TJ, van Zonneveld AJ. Coupling eNOS uncoupling to the innate immune response. Arteriosclerosis, thrombosis, and vascular biology 2006;26:2585-7.

78. Forstermann U, Munzel T. Endothelial nitric oxide synthase in vascular disease: from marvel to menace. Circulation 2006;113:1708-14. 
79. Wu G, Meininger CJ. Nitric oxide and vascular insulin resistance. Biofactors 2009;35:21-7.

80. Bellinghieri G, Santoro D, Mallamace A, Di Giorgio RM, De Luca G, Savica V. L-arginine: a new opportunity in the management of clinical derangements in dialysis patients. J Ren Nutr 2006;16:245-7.

81. Ito K, Chen J, Seshan SV, Khodadadian JJ, Gallagher R, El Chaar M, Vaughan ED, Jr., Poppas DP, Felsen D. Dietary arginine supplementation attenuates renal damage after relief of unilateral ureteral obstruction in rats. Kidney Int 2005;68:515-28.

82. Wang WW, Qiao SY, Li DF. Amino acids and gut function. Amino Acids 2009;37:105-10.

83. Jeyabalan G, Klune JR, Nakao A, Martik N, Wu G, Tsung A, Geller DA. Arginase blockade protects against hepatic damage in warm ischemia-reperfusion. Nitric Oxide 2008;19:29-35.

84. Nikolic J, Stojanovic I, Pavlovic R, Sokolovic D, Bjelakovic G, Beninati S. The role of L-arginine in toxic liver failure: interrelation of arginase, polyamine catabolic enzymes and nitric oxide synthase. Amino Acids 2007;32:127-31.

85. Reid KM, Tsung A, Kaizu T, Jeyabalan G, Ikeda A, Shao L, Wu G, Murase N, Geller DA. Liver I/R injury is improved by the arginase inhibitor, N(omega)-hydroxy-nor-L-arginine (nor-NOHA). Am J Physiol Gastrointest Liver Physiol 2007;292:G512-7.

86. Grasemann H, Kurtz F, Ratjen F. Inhaled L-arginine improves exhaled nitric oxide and pulmonary function in patients with cystic fibrosis. Am J Respir Crit Care Med 2006;174:208-12.

87. Arana V, Paz Y, Gonzalez A, Mendez V, Mendez JD. Healing of diabetic foot ulcers in L-arginine-treated patients. Biomed Pharmacother 2004;58:588-97.

88. Yu YM, Ryan CM, Castillo L, Lu XM, Beaumier L, Tompkins RG, Young VR. Arginine and ornithine kinetics in severely burned patients: increased rate of arginine disposal. Am J Physiol Endocrinol Metab 2001;280:E509-17.

89. Eremin O. L-Arginine: biological aspects and clinical applications Chapman \& Hall, 1997: 161.

90. Ma Q, Williamson KE, O'Rourke D, Rowlands BJ. The effects of 1-arginine on crypt cell hyperproliferation in colorectal cancer. J Surg Res 1999;81:181-8.

91. de Jonge WJ, Marescau B, D'Hooge R, De Deyn PP, Hallemeesch MM, Deutz NE, Ruijter JM, Lamers WH. Overexpression of arginase alters circulating and tissue amino acids and guanidino compounds and affects neuromotor behavior in mice. J Nutr 2001;131:2732-40.

92. Drexler H, Zeiher AM, Meinzer K, Just H. Correction of endothelial dysfunction in coronary microcirculation of hypercholesterolaemic patients by L-arginine. Lancet 1991;338:1546-50.

93. Blum A, Cannon RO, 3rd, Costello R, Schenke WH, Csako G. Endocrine and lipid effects of oral Larginine treatment in healthy postmenopausal women. J Lab Clin Med 2000;135:231-7.

94. Little JA, Hauser KP, Martyr SE, Harris A, Maric I, Morris CR, Suh JH, Taylor J, Castro O, et al. Hematologic, biochemical, and cardiopulmonary effects of L-arginine supplementation or phosphodiesterase 5 inhibition in patients with sickle cell disease who are on hydroxyurea therapy. Eur J Haematol 2009;82:315-21.

95. Wijnands KA, Vink H, Briede JJ, van Faassen EE, Lamers WH, Buurman WA, Poeze M. Citrulline a more suitable substrate than arginine to restore NO production and the microcirculation during endotoxemia. PloS one 2012; 7:e37439.

96. Boger RH. L-Arginine therapy in cardiovascular pathologies: beneficial or dangerous? Curr Opin Clin Nutr Metab Care 2008;11:55-61.

97. Coeffier M, Dechelotte P. Combined infusion of glutamine and arginine: does it make sense? Curr Opin Clin Nutr Metab Care 2010;13:70-4.

98. Loehe F, Bruns CJ, Nitsch SM, Angele MK. The role of L-arginine following trauma and blood loss. Curr Opin Clin Nutr Metab Care 2007;10:80-7.

99. Drover JW, Dhaliwal R, Weitzel L, Wischmeyer PE, Ochoa JB, Heyland DK. Perioperative use of arginine-supplemented diets: a systematic review of the evidence. J Am Coll Surg 2011;212:385-99, 99 e1. 


\section{Chapter VII}

100. Moinard C, Nicolis I, Neveux N, Darquy S, Benazeth S, Cynober L. Dose-ranging effects of citrulline administration on plasma amino acids and hormonal patterns in healthy subjects: the Citrudose pharmacokinetic study. Br J Nutr 2008;99:855-62.

101. van Wijck K, Wijnands KA, Meesters DM, Boonen B, van Loon LJ, Buurman WA, Dejong CH, Lenaerts K, Poeze M. L-citrulline Improves Splanchnic Perfusion and Reduces Gut Injury during Exercise. Med Sci Sports Exerc 2014.

102. Steppan J, Nyhan D, Berkowitz DE. Development of novel arginase inhibitors for therapy of endothelial dysfunction. Front Immunol 2013;4:278. 


\section{NEDERLANDSTALIGE SAMENVATTING}

In dit proefschrift komen verschillende aspecten van het arginine metabolisme aan de orde. De rol van arginine en arginase in de synthese van ureum mag als bekend worden verondersteld. Echter, arginine en arginase spelen ook een zeer belangrijke rol in de fysiologie van macrofagen (hoofdstuk 1). Macrofagen zijn een heterogene groep cellen die ingedeeld worden op basis van hun weefselverdeling, activiteit, en oppervlaktemarkers. In navolging van de $T_{H} 1 / T_{H} 2$ naamgeving worden ze vaak ingedeeld als klassiek (M1) of alternatief (M2) geactiveerde macrofagen. M1 macrofagen zouden vooral verantwoordelijk zijn voor het opruimen van tumorcellen en micro-organismen, terwijl M2 macrofagen betrokken zijn bij wondgenezing, doden van parasieten en immuun regulering. Omdat de weefseldistributie en het fenotype snel kunnen veranderen in reactie op omgevingsfactoren en vergelijkbare functies teweeggebracht kunnen worden door verschillende factoren, past een classificering op grond van functies beter.

De verschillende typen macrofagen verschillen in hun gebruik van arginine voor stikstofoxide (NO via NO synthases) en ornithine synthese (via arginase). NOS2 is de belangrijkste NOS isoform in macrofagen die tumorcellen en micro-organismen opruimen, terwijl arginase $1 \mathrm{~m} . \mathrm{n}$. in macrofagen wordt aangetroffen die betrokken zijn bij wondgenezing, het opruimen van parasieten en de immuun regulering. In muizenmacrofagen wordt de expressie van arginase sterk gestimuleerd door de $\mathrm{T}_{\mathrm{H}}$ 2-type cytokines IL4, IL10, IL13 en TGF $\beta$, terwijl arginase in humane macrofagen alleen door eencellige parasieten wordt geïnduceerd. Om de betekenis van arginine voor het functioneren van macrofagen beter te begrijpen hebben wij genetisch gemodificeerde muismodellen gemaakt waarin arginase tot overexpressie komt of waarin arginase of argininosuccinaat synthetase weefselspecifiek kan worden geïnactiveerd (hoofdstukken 2,3,5, en 6).

De ontwikkeling van technieken om de nucleotidenvolgorde van een gen in embryonale stamcellen te modificeren stelt ons in staat om de expressie van deze genen in levende organismen, meestal muizen, te veranderen. Vooral uitschakeling (knock-out) of vervanging (knock-in) van genen is een krachtig instrument gebleken. In hoofdstuk $\mathbf{2}$ bespreken we daarom onze ervaringen met het maken van 3 zogenaamde conditionele knock-out muizen. Uitschakeling van de expressie van een gen in slechts één weefsel is nodig als deletie in alle cellen niet met het leven verenigbaar is. Daarnaast is een dergelijke muis beter geschikt om de functie van het betreffende gen in één type weefsel of op een bepaald moment in het leven te onderzoeken. Het maken van een conditionele knock-out muis vergt ten minste 2 jaar en bestaat uit een relatief groot aantal opeenvolgende stappen die elk voor zich "haken en ogen" hebben. Dit hoofdstuk beschrijft onze ervaring met de constructie van de vectoren welke nodig zijn voor het wijzigen van de nucleotidenvolgorde van een gen en de protocollen om het relatief geringe aantal embryonale stamcellen dat per "targeting" op de juiste wijze gewijzigd is op te sporen en te vermeerderen. Door de komst van de "CRISPR" (clustered regularly interspaced short palindromic repeats, een gen editerend systeem) en "TALENs" (transcription activator-like 
effector nucleases, een soort restrictie-enzymen) is de opzet van targeting vectoren sterk veranderd. De daarop volgende selectie en vermeerdering van de juiste stamcel is nog grotendeels hetzelfde als toen dit overzicht werd samengesteld.

In hoofdstuk 3 wordt de eerste toepassing van de door mij vervaardigde conditionele arginase 1 knock-out muis beschreven. Astma is een chronische ontsteking van de kleine luchtwegen, vaak als gevolg van overgevoeligheid voor een bepaald allergeen. De expressie van arginase1 in macrofagen is vrijwel afwezig in de long van controle muizen en zeer sterk verhoogd in de longmacrofagen van muizen waarin door sensibilisering tegen het kippeneiwit ovalbumine astma is opgewekt. Met behulp van een stabiele variant van acetylcholine kan de reactiviteit van de luchtwegen getest worden. In deze studie hebben we de expressie van arginase 1 in macrofagen uitgeschakeld met zogenaamde Tie2Cre (uitschakeling in alle hematopoietische cellen) en LysMCre (uitschakeling in allen de macrofagen) transgenen. Helaas bleek LysMCre slechts in $\sim 60 \%$ van de macrofagen voldoende actief om arginasel te elimineren, terwijl dat $96-98 \%$ was voor Tie2Cre. De studie rapporteert alleen de effecten in mannelijke muizen waarvan het arginase 1 gen met Tie2Cre is uitgeschakeld. Longfunctie werd met de "Flexivent" gemeten. Uitschakeling van arginasel in macrofagen veranderde de allergische reactie op ovalbumine sensibilisering en de weerstand in de grotere luchtwegen niet, maar verbeterde wel de functie van de kleinere luchtwegen. Voorts was de expressie van andere arginine-verbruikende enzymen en van arginine transporters, van de chemokines $C c l 2$ en $C$ cl11, van de pro-inflammatoire cytokines Tnfa en Ifng, en van de epitheliale markers Ccla3 en Muc5ac verminderd. De expressie van de voor astma typische genen Il4, Il5, en Ill3 was echter niet veranderd. Analyse van de correlaties tussen de verschillende parameters liet duidelijk zien dat arginase deficiëntie in macrofagen de coördinatie van de reactie op ovalbumine sensibilisering verminderde. De verwachte vermindering van de ontstekingsreactie werd dus niet waargenomen.

Moedermelk bevat relatief weinig arginine, maar aminozuren waaruit arginine gemaakt kan worden, zoals proline en glutamine, zijn rijkelijk aanwezig. De dunne darm van knaagdieren en varkens produceert arginine uit proline in de zoogperiode. Voorts lijden parenteraal gevoede zuigelingen vaak aan een te lage concentratie arginine (en daardoor een te hoge concentratie ammoniak) in hun bloed. Dit deed ons de vraag stellen of de dunne darm van de mens ook arginine zou kunnen maken. Om dit aannemelijk te maken beschrijven we in hoofdstuk 4 metingen aan darmdoorsneden van 89 kinderen en volwassenen die semi-kwantitatief aangekleurd zijn op de aanwezigheid van de cruciale enzymen carbamoylfosfaat synthetase (CPS), ornithine aminotransferase (OAT), argininosuccinaat synthetase (ASS), arginase-1 en -2 (ARG1 en ARG2), en NO synthases (NOS1, -2, en -3). De CPS en ASS concentraties waren hoog tussen 23 weken zwangerschap en 3 jaar na de geboorte en daalden in de volgende 2 jaar tot het volwassen niveau. De OAT concentratie daalde ook, maar meer geleidelijk, terwijl ARG1 niet aantoonbaar was en ARG2 in de neonatale periode tot het volwassen niveau steeg. De 
neuronen van de enterische plexus brachten ASS, OAT, NOS1 en ARG2 tot expressie, terwijl de zenuwen in de muscularis propria alleen ASS en NOS1 tot expressie brachten. Het endotheel van de arteriolen bracht ASS en NOS3 tot expressie en de gladde spierlaag eromheen OAT en ARG2. Op grond van deze bevindingen hebben we geconcludeerd dat de dunne darm van de mens ook de capaciteit heeft om arginine te maken. De expressie van ASS verdwijnt, net als die van lactase, geheel tussen 3 en 5 jaar na de geboorte, wat suggereert dat dat de normale speentijd van de mens als soort is.

Omdat alle tot nu toe bestudeerde zoogdieren, zoals in het vorige hoofdstuk is beschreven, in hun zuigelingenperiode alle enzymen die nodig zijn om arginine te maken in de enterocyten van de dunne darm tot expressie brengen, hebben we het enzym argininosuccinaat synthetase met behulp van het VillinCre transgen specifiek in deze enterocyten uitgeschakeld (hoofdstuk 5). De volledigheid van de uitschakeling in de enterocyten is vervolgens immunohistochemisch aangetoond (er wordt ook argininosuccinaat synthetase in de zenuwen van de darm tot expressie gebracht; zie vorige hoofdstuk). Onverwacht bleken deze muizen echter geen tekort aan arginine in hun bloed te hebben. We hebben daarom de flux van aminozuren in de darm en de lever bepaald. Hiervoor werd ook de arteriële bloedstroom naar de darm, de lever, en de nieren gemeten in 14-dagen oude muizen (respectievelijk $86 \%$, 14\% en 33\% van de totale bloedstroom door de lever). Door de deletie van Ass in de enterocyten verdween de netto arginine synthese in de darm, terwijl de citrulline synthese verdubbelde. Voorts nam de arginine productie in de lever af of veranderde zelfs in een opname. Deze veranderingen in de lever vinden normaliter pas na het spenen plaats, als de darm niet langer arginine produceert. In overeenstemming met deze waarnemingen nam de expressie van enzymen die betrokken zijn bij de stofwisseling of het transport over de levercelmembraan toe, terwijl (behalve uitschakeling van Ass) geen veranderingen in gen expressie in de enterocyten werden gevonden. Deze waarnemingen wijzen er dus op dat de voortijdige (genetische) verwijdering van arginine biosynthese uit de enterocyten leidt tot een premature inductie van het patroon van aminozuurstofwisseling in de lever dat normaliter pas na het spenen wordt gezien.

In hoofdstuk 6 is gezocht naar een mechanisme dat het fenotype van "F/A2" muizen verklaart. Deze transgene muizen brengen arginase 1 tot overexpressie in de enterocyten van de dunne darm en hebben een fenotype dat lijkt enigermate lijkt op een deficiëntie van het groeihormoon IGF1 (insulin-like growth factor-1; te laag plasma arginine gehalte, verminderde haargroei, en onvolledige rijping van B-cellen). Lage arginine concentraties bleken de secretie van groeihormoon (GH) in hypofysecellen te remmen en de concentratie van Igf1 mRNA in de lever en het plasma IGF1 gehalte te verlagen, maar niet dat in de atrofische spieren. GH suppletie van de muizen deed weliswaar het Igf1 mRNA gehalte in de lever toenemen, maar niet de groei van de F/A2 muizen. Arginine depletie in het kweekmedium van de C2C12 spiercellijn activeerde voorts GCN2 signalering, maar liet dat van mTORC1 ongemoeid. GCN2 signalering, een 
endoplasmatisch reticulum stress response, wordt geactiveerd door deficiëntie van belangrijke aminozuren. In homozygote F/A2 neonaten bedragen de plasma en weefsel concentraties van arginine slechts $\sim 25 \%$ van de wild-type waarden. Gcn2-deficiente F/A2 muizen sterven kort na de geboorte door hypoglycemie, zodat activering van GCN2 kennelijk essentieel is voor het overleven van F/A2 neonaten. Omdat "downstream" effecten van andere stress kinases (eIF2 $\alpha$ fosforylering, Chop expressie) niet verhoogd waren in Gcn2-deficiente F/A2 muizen, konden de effecten van arginine deficiëntie aan GCN2 signalering worden toegeschreven.

In hoofdstuk 7 ten slotte worden pro's en con's van arginine en citrulline suppletie om een arginine deficiëntie te bestrijden besproken. 


\section{ACKNOWLEDGEMENTS}

Behind every exhaustive thesis are a million things that help shape it. Apart from all the mice and bacteria that have helped me, I would like to thank those people who have been an amazing support in achieving this significant milestone.

I would like to acknowledge Wout and Leo for being present from Day 1. Thank you Wout for encouraging me into authorship and for all the support you've given over the years. Leo has been my rock during the storms of my journey in Maastricht with clear and crisp advice. Thank you Leo, I've learnt a lot about composure from you.

In a high octane world of research and hectic schedules, I found friends that made the intensity fun. Vincent, thank you for all the laughs and making Netherlands so memorable for me. Thank you Rinus for being such a great person to be around. Chiel, for all the technics up your sleeve, and your kindness in sharing those invaluable technics. My gratitude to everybody in the lab for helping me give life to this thesis.

7000 miles away from home, my friends were as supportive and special as when they had been closer. Thank you Gowthamee for being you and having courage enough for the two of us. Sandeep Rajan Nair and Sejal Naik for introducing me to some of the best times of my life. Jerlin, for being present and patient with me throughout my journey.

Thank you Mr. M.R.Anantha Padmanaban for the timely help and motivation during the last stages of my thesis. Until recently I was unaware of how operative his motivations were. Prof. Chellam Balasundram for all the recommendations/guidance. He has been a critical resource without which the struggle would have been real. Prof. Emmanuvel Rajan, my thesis guide during the last stages, for making a great impact in my outlook about work. I would also like to extend my gratitude to Dr. Palani, Chairman of Alpha group of schools. Ms. Raji Ramakrishnan and Ms. Manju Varrier, also of Alpha group, for helping me cement my communication with the authority. I also thank Ms. Brinda and Ms.Sundaravalli whose support enabled me to spare time for finishing my thesis.

Although the deep gratitude and love I feel for my family cannot be bound by words, I need to make a note of how very imperative they have been in my journey. My parents, for bringing me to this world and making this world beautiful with their kindness and lessons. Dr. V. Arunachalam, for being the effervescent guiding light. Rajendran athaan and Meena akka for being the most dependable humans I have been lucky enough to know. Athaan has been one of my primary motivations to go beyond my comfort zone and achieve larger than life goals. Kanna annan and Koki for being there in my heart. My love and thanks to all the Shrees of the house for making me understand the vastness of motherhood and the bundle of happiness which comes along. My little girls add the spice, which fuels my life. A special thanks to my little niece Mahashree for loving me and understanding me and helping at all times of need. 
I am grateful to all those who have wished and blessed me with all the good things in my world because in the words of John Whittier- "No longer forward nor behind I look in hope or fear; but, grateful, take the good I find, the best of now and here."

-SelvakumariSankaranarayanan 


\section{CURRICULUM VITAE}

\section{SELVAKUMARI SANKARANARAYANAN}

Born $20^{\text {th }}$ of November, 1976 in Tirunelveli, Tamil Nadu, India

E: selvima@yahoo.com•M: +91-9962223110

A: Sanjeevie Nagar Ext, Airport, Tiruchirappalli - 620007, Tamil Nadu, India.

\section{EDUCATION}

- Ph.D. Thesis

2015

Maastricht University, the Netherlands

- M.Sc.in Life Sciences, Specialization in Biotechnology

1996-2001

Bharathidasan Universtity, Tamil Nadu, India

\section{WORK EXPERIENCE}

- Science coordinator at an International School, Trichy, Tamil Nadu since Jan 2014.

- Business Process Lead, Tata Consultancy Services, Chennai, Tamil Nadu, India. Nov 2012Jan 2014

- Customer Care Executive, Teknicon Enterprises, Mumbai. Oct 2011-Nov-2012.

- Guest Lecturer, Department of Biotechnology, Bharathidasan University, Tiruchirappalli, Tamil Nadu, India. Sept 2009 - Dec 2009.

- Lecturer, Department of Biotechnology, St. Joseph's College, Tiruchirappalli, Tamil Nadu, India. June 2007 - April 2008.

- PhD student, Department of Anatomy and Embryology, Maastricht University, The Netherlands. Feb 2003 - Dec 2007. "Role of arginine in chronic inflammatory diseases"

- Scientific assistant, Department of Gastroenterology, Universitätsklinikum Essen, Essen, Germany. Aug 2002 - Feb 2003.

- Research Assistant, School of Life Sciences, Jawaharlal Nehru University, New Delhi, India. May 2001- August 2002. Project: "Establishment of a transformation method on Vigna mungo for stress tolerance".

- Graduate Student, School of Life Sciences, Bharathidasan University, Tiruchirappalli, Tamil Nadu, India. Jan 2001 - May 2001. Project: "Regeneration and somatic embryogenesis in Cajanus cajan". 


\section{PUBLICATIONS}

1. Cloots, R. H., Sankaranarayanan, S., de Theije, C. C., Poynter, M. E., Terwindt, E., van Dijk, P., Hakvoort, T. B., Lamers, W. H., and Kohler, S. E. (2013) Ablation of Arg1 in hematopoietic cells improves respiratory function of lung parenchyma, but not that of larger airways or inflammation in asthmatic mice. American journal of physiology. Lung cellular and molecular physiology 305, L364-376

2. Marion, V., Sankaranarayanan, S., de Theije, C., van Dijk, P., Hakvoort, T. B., Lamers, W. H., and Kohler, E. S. (2013) Hepatic adaptation compensates inactivation of intestinal arginine biosynthesis in suckling mice. PloS one $\mathbf{8}$, e67021

3. Marion, V., Sankaranarayanan, S., de Theije, C., van Dijk, P., Lindsey, P., Lamers, M. C., Harding, H. P., Ron, D., Lamers, W. H., and Kohler, S. E. (2011) Arginine deficiency causes runting in the suckling period by selectively activating the stress kinase GCN2. The Journal of biological chemistry 286, 8866-8874

4. Kohler, E. S., Sankaranarayanan, S., van Ginneken, C. J., van Dijk, P., Vermeulen, J. L., Ruijter, J. M., Lamers, W. H., and Bruder, E. (2008) The human neonatal small intestine has the potential for arginine synthesis; developmental changes in the expression of arginine-synthesizing and -catabolizing enzymes. BMC developmental biology 8, 107

5. Elke Cario, Meenakshi Rani, S. Sankaranarayanan, Carsten J. Kirschning, Guido Gerken, Daniel K. Podolsky. (2003). Characterization of a novel toll-like receptor 2-dependent pathway regulating intestinal epithelial barrier function via protein kinase $C$. Gastroenterology 124(4): A26

6. Cloots, R. H., Sankaranarayanan, S., Poynter, M. E., Terwindt, E., van Dijk, P., Hakvoort, T. B., Lamers, W. H., and Kohler, S. E. Effect of Argl deletion in myeloid cells on allergic asthma in female mice. Manuscript in preparation

\section{PROFESSIONAL ACTIVITIES}

- Course on Laboratory Animal Science, Department of Laboratory Animal Science, Utrecht University, The Netherlands, 2003

- Course on Radiological protection, Maastricht University, The Netherlands, 2005

- Capita Selecta, parts I and II, Graduate Program Metabolism and Nutrition, 2004-2005

- Metabolomics course, VLAG, Wageningen University, The Netherlands ,2005

- Advanced Microscopy and Vital Imaging, Department of Molecular Cell Biology, CARIM Maastricht University, The Netherlands, 2005 